\title{
Through the Cowgate: life in 15th-century Edinburgh as revealed by excavations at St Patrick's Church
}

\author{
Elizabeth Jones
}

Headland Archaeology Ltd, 13 Jane Street, Edinburgh EH6 5HE

with contributions by Anne Crone, Morag Cross, Julie Franklin, Sarah-Jane Haston, N M McQ Holmes, Stephen Lancaster, T M Mighall, Eileen Reilly, Clare Thomas, Scott Timpany \& Auli Tourunen 
Published by the Society of Antiquaries of Scotland, www.socantscot.org.uk with Historic Scotland, www.historic-scotland.gov.uk

and the Council for British Archaeology, www.britarch.ac.uk

Editor Helen Bleck

Produced by Archétype Informatique SARL, www.archetype-it.com

ISBN: 9780903903578

ISSN: $1773-3803$

Requests for permission to reproduce material from a $S A I R$ report should be sent to the Director of the Society of Antiquaries of Scotland, as well as to the author, illustrator, photographer or other copyright holder.

Copyright in any of the Scottish Archaeological Internet Reports series rests with the SAIR Consortium and the individual authors.

The maps are reproduced from Ordnance Survey material with the permission of Ordnance Survey on behalf of The Controller of Her Majesty's Stationery Office. (C) Crown copyright 2001. Any unauthorised reproduction infringes Crown copyright and may lead to prosecution or civil proceedings. Historic Scotland Licence No. GD 03032G, 2002.

The consent does not extend to copying for general distribution, advertising or promotional purposes, the creation of new collective works or resale. 


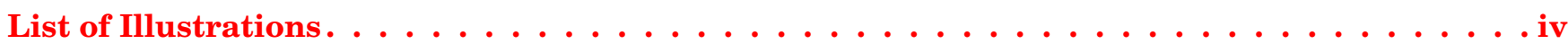

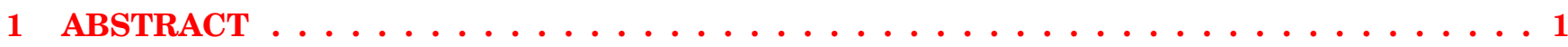

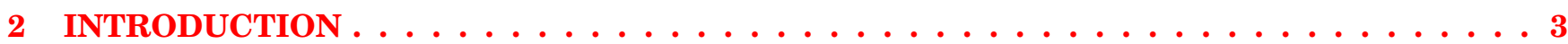

3 ARCHAEOLOGICAL AND HISTORICAL BACKGROUND $\ldots \ldots \ldots \ldots \ldots$

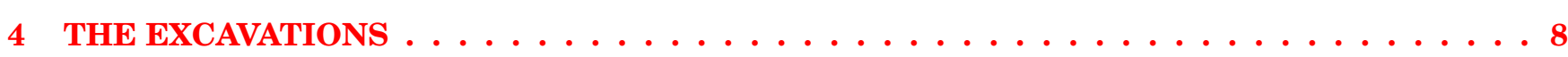

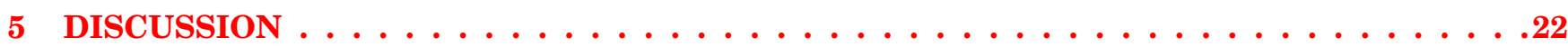

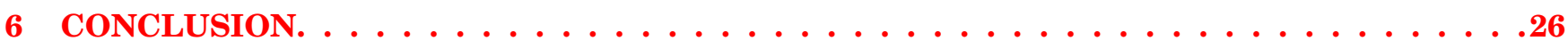

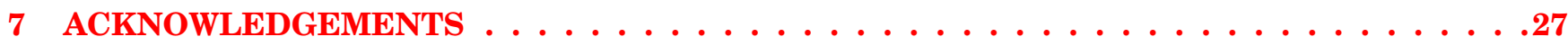

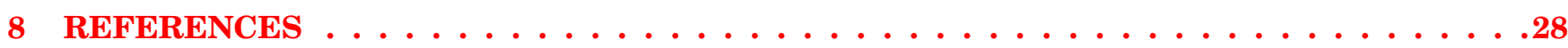

Appendix 1 FINDS, by Julie Franklin with contributions by Anne Crone,

N M McQ Holmes \& Clare Thomas . . . . . . . . . . . . . . . . . . . . . 37

Appendix 2 FAUNAL REMAINS, by Auli Tourunen $\ldots \ldots \ldots \ldots \ldots \ldots$

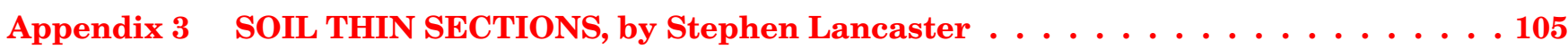

Appendix 4 PLANT MACROFOSSILS, by Scott Timpany \& Sarah-Jane Haston . . . . . . . 117

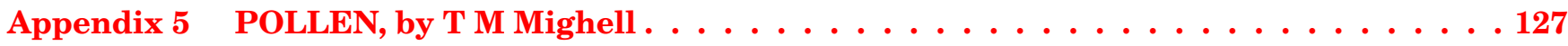

Appendix $6 \quad$ INSECT REMAINS, by Eileen Reilly $\ldots \ldots \ldots \ldots \ldots \ldots$ 


\section{LIST OF ILLUSTRATIONS}

Site location plan. . . . . . . . . . . . . . . . . . . . . . . . . 2

Location of recent excavations along the Cowgate, superimposed on Edgar's plan of 1742 . . . .5

Indicative south-west-facing section across site . . . . . . . . . . . . . . . . 10

Phase 2: Medieval town ditch with modern streetscape . . . . . . . . . . . . . . . . . 11

Ditch under excavation looking south-east . . . . . . . . . . . . . . . . . . . . . 12

Ditch fully excavated looking north-east . . . . . . . . . . . . . . . . . . . . . 12

Finds illustrations $1-3,19 \ldots \ldots \ldots \ldots \ldots \ldots$

Finds illustrations $6-17 \ldots \ldots \ldots \ldots \ldots \ldots$

Pre-excavation view of site looking south. . . . . . . . . . . . . . . . . . . . . . 15

Phase $4: 16$ th-17th-century features . . . . . . . . . . . . . . . . . . . 17

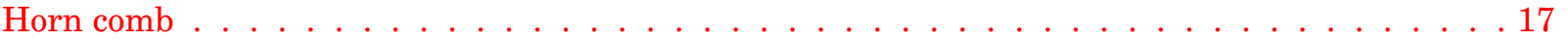

Pre-excavation view of barrel . . . . . . . . . . . . . . . . . . . . 17

Part-excavated view of barrel . . . . . . . . . . . . . . . . . . . . . . . 17

Close-up of barrel staves. . . . . . . . . . . . . . . . . . . . . . . . . . . 17

Withy-wrapped hoops . . . . . . . . . . . . . . . . . . . . 18

Culvert looking south-west . . . . . . . . . . . . . . . . . . . . 18

Location of post-medieval tenement walls and supporting stakes. . . . . . . . . . . . . . . . 19

View of timber piles and Trench 2 , looking south. . . . . . . . . . . . . . . . . . . . 20

The 17th-century Earl of Selkirk's House as imagined in the 1880s

(source: Grant 1880, Vol. II, p35) . . . . . . . . . . . . . . . . . . . . . . . . . . 20

Elphinstone Court $c 1880$ (source: Grant 1880, Vol. II, p272) . . . . . . . . . . . . . . . . . . 20 


\section{$1 \quad$ ABSTRACT}

Excavations in the grounds of St Patrick's Church, Edinburgh were undertaken by Headland Archaeology from November 2006 to February 2007 on behalf of the Archdiocese of St Andrews and Edinburgh in advance of the construction of a hotel on the site. Soil analyses suggested that flash floods had swept through this part of Cowgate up until the early development of the medieval town upslope in the 11 th-12th centuries. This early pattern was followed by the gradual build-up of material washed downslope from the High Street; this contained midden material and dung beetles, illustrating the nearby presence of the town. The site lay outwith the bounds of the burgh until the 14 th century, when a substantial ditch was cut across the site, believed to be the medieval town boundary. The ditch was backfilled in the 15th century and finds and samples have revealed a vivid picture of life in the medieval town. The ditch was a stinking rubbish dump for many kinds of human and animal detritus, which illustrates that the Cowgate was a busy thoroughfare to the town's markets and contained a variety of industries, including horn working. After the ditch was filled in deep midden deposits, characteristic of this area of Edinburgh, built up on the site. 


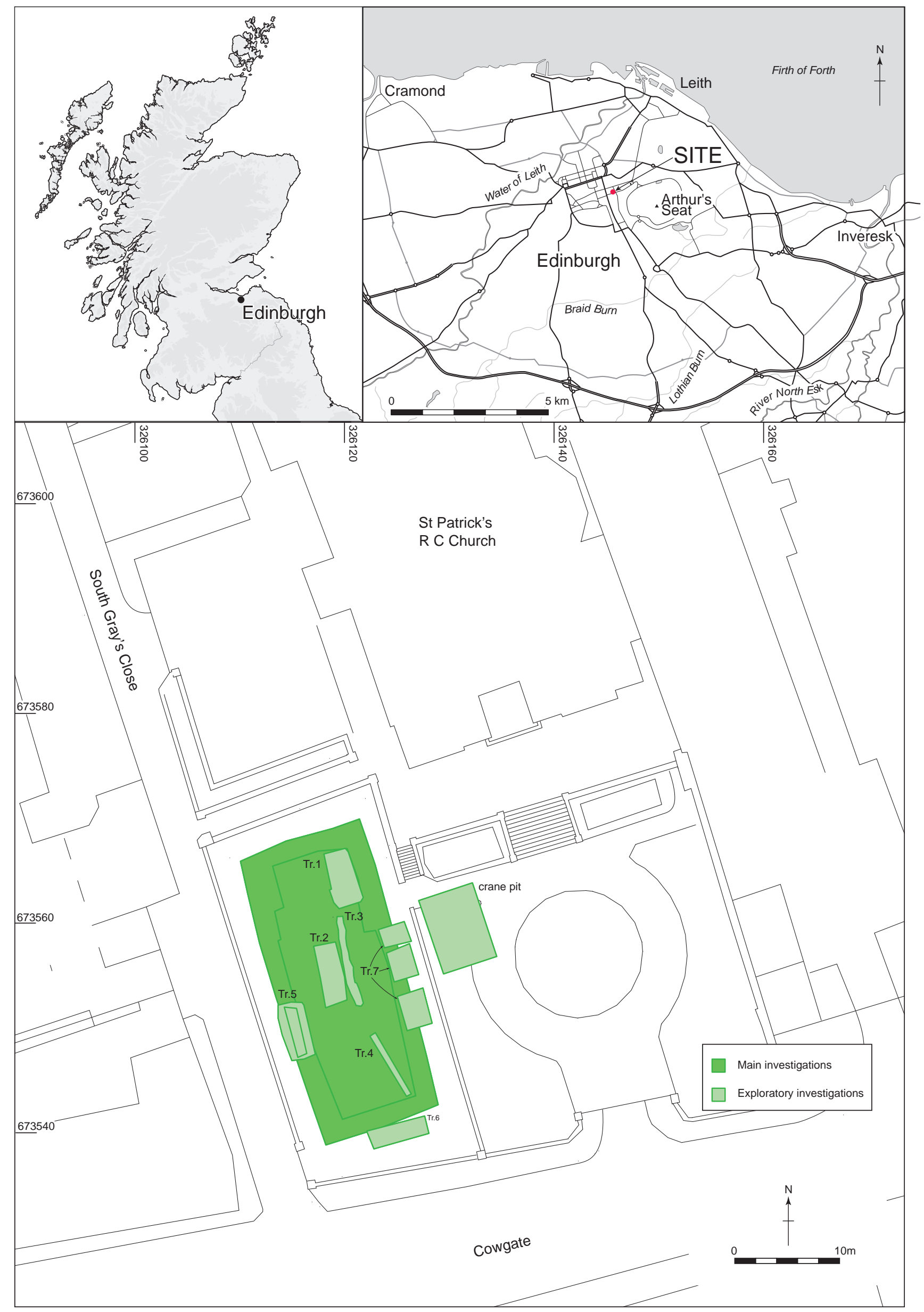

Illus 1 Site location plan 


\section{INTRODUCTION}

The excavations took place in advance of a hotel development adjacent to St Patrick's Church. The site is located on the north side of the Cowgate and is bounded to the west by South Gray's Close (illus 1, illus 9). The development extended $17 \mathrm{~m}$ eastwards from South Gray's Close and 36m back from the Cowgate. The site was formerly occupied by a bowling green, which had been built over a WWII concrete water tank. Previous evaluation of the site established that medieval archaeological deposits survived up to a depth of $2.5 \mathrm{~m}$ below the modern ground surface (CECAS 1990; Rees \& Martin 2000). The main research objective of the excavation was to further our understanding of the development of the Cowgate during the medieval period, especially through the study of soil formation processes and archaeobotanical evidence. To this end a multidisciplinary palaeoenvironmental study including pollen, beetles and plant macrofossils accompanied the excavation. 


\section{ARCHAEOLOGICAL AND HISTORICAL BACKGROUND by Morag Cross \& Elizabeth Jones}

\subsection{Medieval development}

The Cowgate lies in a valley to the south of the ridge on which the High Street stands. The valleys on either side of the High Street (Princes Street Gardens and Cowgate) were formed through glacial erosion and earlier writers have postulated the existence of two small streams running down both valleys, converging in the area of Holyrood Abbey (Makey 1988, 200). Previous work at the Scottish Parliament site suggested that there might be an infilled stream channel under Holyrood Road, possibly taking drainage from the Cowgate. The channel may have turned to the north-east and joined water flowing down the valley from what is now Calton Road (Carter et al 2008).

The site lay within the core of medieval Edinburgh from the 14th century onwards and would appear to form part of the rear backlands of a High Street plot or plots. The origins and early development of the High Street are poorly understood. Edinburgh is mentioned as a King's Burgh in a charter of David I in the 12th century and the High Street is thought to have existed in some form by then (Stevenson et al 1981, 2). One model for the development of Edinburgh suggests that the first settlement was around Lawnmarket with St Giles' and the frontage line to the east a later development (Duncan 1975, 466). This model suggests that the Netherbow Port, which marked the eastern edge of the burgh, was in existence by the mid-12th century but that it lay further west at this time (ibid). The separate burgh of Canongate was to the east, with development here concentrated on the street frontage. The site would therefore appear to lie on the very outskirts of medieval Edinburgh, away from development on the Canongate, and possibly outwith Duncan's early postulated east gate.

The Cowgate developed about 1330 and perhaps represented Edinburgh's first municipal extension (Stevenson et al 1981). Writing in 1937 Malcolm states that the original settlement on the Cowgate was concentrated on the south side because of a burn on the north (Malcolm 1937). He goes on to state that this burn was filled in around 1490 and that buildings were laid out with piles of oak and willows on levelled ground (ibid). Cowgate Port was erected in 1516 and stood at the junction with St Mary's Wynd.

\subsection{Town boundary}

Very few Scottish burghs were defended and the back of the rigs, defined by a back or heid dyke, often formed the burgh boundary. Access to the fields was through gates or gaps in the dyke, which led to a lane. As this gave access to grazing for livestock it was often called a 'cowgate' (Coleman 2004, 292). The back dyke was usually represented by a ditch and bank or a fence. Although each plot holder was responsible for the maintenance of the dyke, it was often in a state of disrepair (Torrie 1990, 56). The back dyke marked the limit of the burgh jurisdiction and privileges and also functioned as a first line of defence in times of war and pestilence (Coleman 2004, 292). Back dykes have rarely been identified in the archaeological record, although ditches marking the backs of plots have been identified recently on the Canongate (Gooder 2001; Stronach et al 2008).

Documentary references to west and east gates in the late 12 th and early 13 th centuries suggest that Edinburgh may have had some sort of defensive enclosure as early as the 12 th century; other documentary evidence states that the gates of the town existed in 1369 (Duncan 1975). The wars of the 14th century had a marked effect on the town. Accounts describe the burgh as 'totally waste' and 'burned to the ground' in 1342 and 1385 (Stevenson et al 1981, 3). In a charter of 1450 James II gave licence to the burgesses to 'fosse, bulwark, wall, toure, turate and uther wais to strengthen our forsaid burgh'; a later James III charter of 1472 gave orders for the refurbishment of the town wall and the demolition of houses built adjoining it. ${ }^{1}$ The exact course of this so-called 'King's Wall' is unclear, and earlier estimates placed it halfway down the slope between the south side of the High Street and the Cowgate (Miller 1887, 251-5). Masonry fragments, presumed to derive from the King's Wall, were recovered in the 19 th century at Parliament House, south of the Advocates' Library and on the east side of the Old Parliament stairs, which have been taken as confirmation of the wall on this line (Stevenson et al 1981). The charter of 1450 ordered the inhabitants to join together the 'hede roumys', the ends of the burgage plots, which on the south side would imply that the wall ran along the Cowgate.

\subsection{Other investigations in the area}

Excavations on Blackfriars Street, to the west of the site, revealed substantial 15th-century midden deposits and backlands activity within late medieval burgage plots that included a well lined with a wooden barrel (Collard 1992; Will \& Radley 2005, 2006). Excavations between Blackfriars Street and 


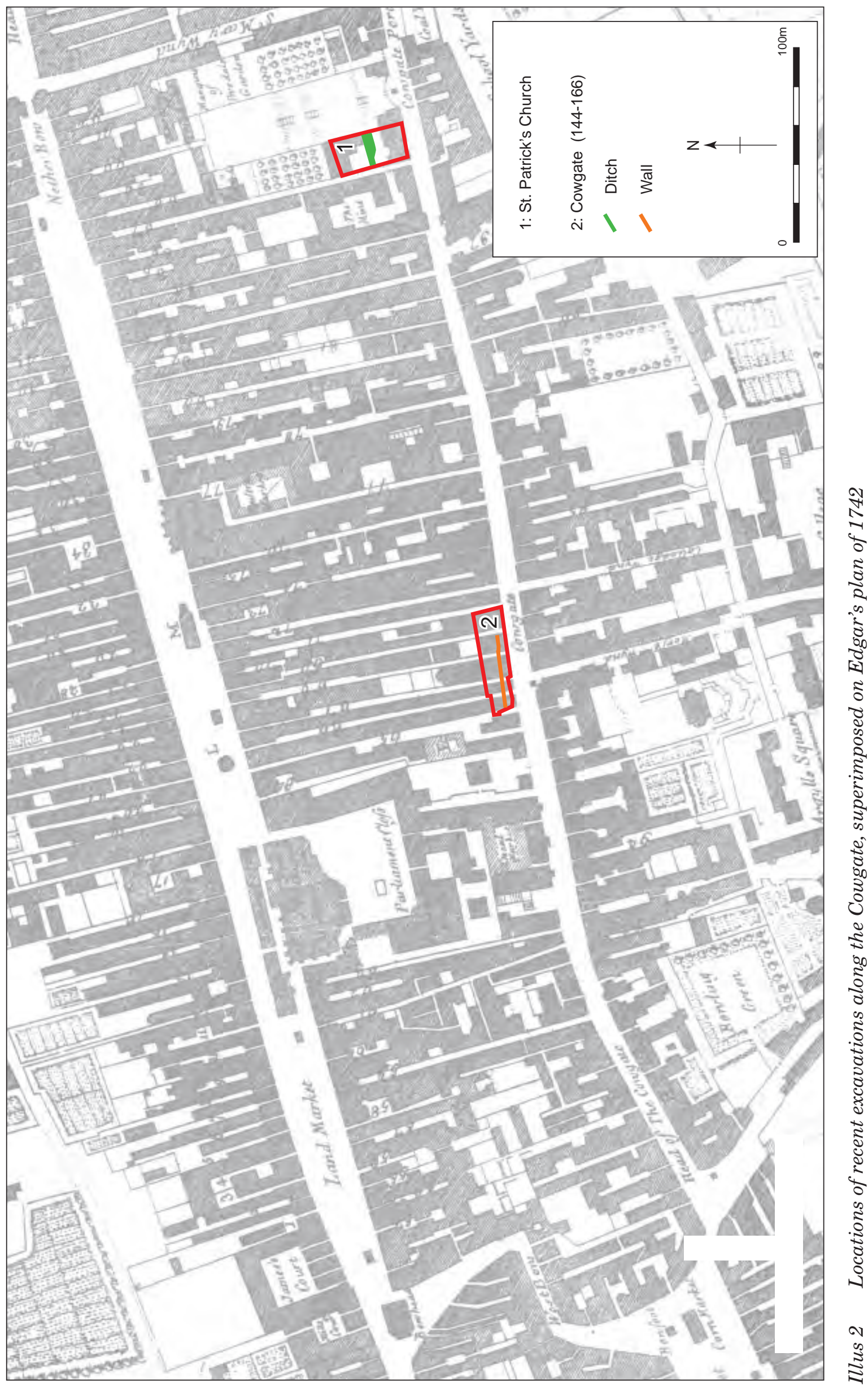


Niddry Street in 1975 also revealed a substantial midden, $3 \mathrm{~m}$ in depth and $40 \mathrm{~m}$ north of the Cowgate frontage (Schofield 1976).

Schofield's excavations also revealed a ditch approximately halfway up the slope, interpreted as an early version of the town defences, while the clay-bonded stone walls of a building to the north were interpreted as representing the King's Wall (Schofield 1976). This was partly based on an interpretation of a 1635 house maills description of 'a long rouynous waste, old wall southwards' (ibid, 164). On re-examination, the book says 'a long rouynous waiste old walls southwards', demoting the special status Schofield assigned to the singular 'old wall'. 'Southwards' describes the circuit taken by a moving tax collector and implies the walls were south of the adjacent wasteland. More recently, excavations at 144-166 Cowgate (illus 2) revealed a 40m stretch of uninterrupted wall running $4 \mathrm{~m}$ north of the present building line on the Cowgate, and this has been interpreted as the remains of the King's Wall (Dalland 2004 and forthcoming). The wall had been built up against the north side of a substantial ditch, also running parallel to the Cowgate (Magnar Dalland pers comm).

\subsection{Properties and owners, by Morag Cross}

Property deeds from 1503-31 indicate a linear strip of wasteground lying on the north side of the Cowgate and extending from St Giles' Cemetery eastwards. ${ }^{3}$ This waste strip probably contained some feature, such as waterlogged ground, that made it unattractive to build on. When Archbishop James Beaton built his palace a short distance west of the site $c 1509,{ }^{4}$ he also purchased much of this waste, including the site, possibly for some function in connection with his palace. ${ }^{5}$

Another linear division running east to west was the King's Wall, which is first mentioned in $1427 .{ }^{6}$ The wall is recorded as running to the east of the site in 1456 (Wilson 1891, II, 65) and two plots west of the site in $1502 .^{7}$ The sasines suggest that the wall was about one or two properties north of the Cowgate, although the properties were not of a uniform length from north to south. This suggests that any wall may lie around the northern timber yard boundary on the first edition Ordnance Survey map (1849, illus 17). This line is continued in property boundaries and closes in tenements running westwards (eg south walls of closes in Beaton's palace and Dickson's Wynd).

The site covered a double-width burgage plot or tenement. ${ }^{8}$ It is first mentioned in 1503 as a yard forming part of a single economic unit combined with a kiln and cellar on the western side of Gray's Close. ${ }^{9}$ At least until the $1530 \mathrm{~s}$, the area was mostly open yards and outdoor workspaces, with three properties. ${ }^{110}$

The southern end of the site was a yard owned by Archbishop Beaton in 1526, and later by Mary,
Queen of Scots' Italian servant Francisco de Busso, ${ }^{11}$ (imprisoned for Darnley's murder in 1567; Fraser 1969, 236, 338). This became a wood yard in the mid-19th century. ${ }^{12}$

The northern end of the site was a mason's yard in 1526, belonging to Thomas Johnson, a 'paviour', or 'calsaymaker'. ${ }^{13}$ In the late 16 th to early 17 th centuries it belonged to Dr John Naysmith, surgeon to James VI, and to his son-in-law, gentleman of the bedchamber to Charles I (Dingwall 2004). ${ }^{14}$ The judge Sir James Elphinstone of Logie built 'Elphinstone Court' or Land here in the 1670s (MacRae 1929, 15).

The yard to the north of the site was owned by fleshers ${ }^{15}$ and later by the Incorporation of Skinners, who owned several properties nearby in the late 16th and 17th centuries (including Skinners Close). ${ }^{16}$ The 1635 house maills book mentions 'St Michael's Well', since 'lost'. ${ }^{17}$ It appears in 19th-century church deeds as lying immediately east of St Patrick's grounds. ${ }^{18}$ The skinners' deeds from 1638 include 'the bake hous... wall and wast yard lyand in foote of grays close', ${ }^{19}$ 'wall' here being Scots for 'well'. ${ }^{20}$ Before 1512, the skinners' yard had belonged to the baker John Grey, after whom the close may have been named. ${ }^{21}$ Successive bakers owned the well until the $1630 \mathrm{~s}^{22}$ Andrew Ainslie, a wealthy wine importer, bought the yard from the Incorporation in the $1630 \mathrm{~s}$. He joined it on to the garden of his house (which later belonged to the earls of Selkirk and Hyndford).$^{23}$ The Episcopal Congregation of the Cowgate Chapel bought the land to the east of the site in $1775 .^{24}$

\section{Notes}

1 Prot Bk Foular I (contd), No. 26; III, Nos 56, 674.

2 ECA, HTB 1635, 393.

3 Eg Prot Bk Foular I, No. 279; I (contd), Nos 237, 895; IV, Nos 55, 126, 448.

4 NMRS No NT27SE 65.

5 Prot Bk Foular III, Nos 293, 296, 317, 754; IV, No. 453.

6 St Giles' Reg No. 34.

7 Prot Bk Foular I, No. 158

8 Prot Bk Foular I (contd), No. 26; III, Nos 56, 674.

9 Prot Bk Foular I, Nos 88, 208.

10 Prot Bk Foular I (contd) No. 838; III, Nos 476 [for William Fauside, substitute Luke Young], 481.

11 NAS, CC8/8/4/285.

12 AA, M49/16, M49/17.

13 Prot Bk Foular III, 476, 481, 754.

14 AA, M46/1, M46/10.

15 Prot Bk Foular I (contd), No. 349, 666; III, No. 481, 476.

16 ECA, Acc 617, No. 13, Barclay's alias Skinner's Close Writs.

17 ECA, HTB 1635, 435; NMRS No. NT27SE 539.

18 AA, M49/6, pp 4, 5.

19 ECA, Acc 617, No. 3, f383r. 
20 ECA, Acc 617, No. 3, f383r; Acc 617, No. 13, Bakehouse Writs.

21 Prot Bk Foular I (contd), No. 838; III, Nos 118, 754.
22 ECA, HTB 1635, 434.

23 AA, M46/1.

24 AA, M49/6, pp 3, 9-11; M49/10. 


\section{THE EXCAVATIONS}

\subsection{Introduction}

\subsubsection{Previous excavations on the site}

The City of Edinburgh Council Archaeology Service undertook initial evaluation of the site in 1990 (CECAS 1990). This revealed midden deposits up to $1 \mathrm{~m}$ in depth beneath the concrete tank. Finds recovered from the upper deposits were dated to the 15 th and 16th centuries and the lower deposits were waterlogged.

Monitoring by AOC Archaeology Group in 2000 revealed a similar sequence of deposits, with subsoil taken to be stiff clay beneath the midden deposits. The infilling of the burn on the north side of the Cowgate and subsequent levelling of the ground was proposed as an explanation for the moist nature of the deposit (Rees \& Martin 2000).

\subsubsection{Main excavation}

The excavation was undertaken in a number of stages due to the nature and depth of the deposits and the limited area within which we were working. In addition, the winter of 2006 was very wet and this, combined with the site's location at the base of the slope, rendered it subject to daily flooding. The water level was usually knee-high every morning and two pumps were in constant use to keep the site dry enough to work in (illus $5 \& 18$ ).

The initial excavation was stepped in $2 \mathrm{~m}$ from the existing boundary walls and modern overburden was removed by machine. Two trenches were machine-excavated through the deposits down to natural subsoil to establish the sediment history of the site and to guide the subsequent excavation strategy (Trenches 1 and 2). Kubiena tins were taken for sediment analysis and bulk samples were taken for environmental assessment. A third trench running east to west along the street frontage quickly became waterlogged and was abandoned.

The excavation then proceeded by excavating the layers encountered in the profile trenches by context and spit. Each context/spit was initially hand-cleaned and swept by a metal detector and any features excavated. A series of test pits $(1 \mathrm{~m} \times 1 \mathrm{~m})$ were excavated through each context/spit and the material wet sieved for finds retrieval. Ten per cent of the midden was excavated by hand. Excavations were stepped in by $1 \mathrm{~m}$ for every $1 \mathrm{~m}$ depth of deposit excavated. The northern two-thirds of the site were excavated first, with the southern area nearest the street frontage excavated afterwards. Trenches 3 and 4 were excavated through perceived natural deposits to clarify the sequence across the site.

\subsubsection{Watching brief}

After the insertion of sheet piling the Cowgate frontage and areas on the east and west side of the site were subject to further archaeological excavation. Three trenches were excavated (illus 1; Trenches 5-7). A crane pit was also excavated by contractors to the east of the site within the church grounds. Due to its depth it was not possible to record the sections of the trench in detail, but sketch sections were made and photographs taken.

\subsection{Phases 1-5}

The phasing scheme is based on stratigraphy and from dating of specific artefacts, primarily pottery.

\subsection{Phase 1: on the edge of urban development, 11th-14th centuries}

\subsubsection{1th-12th centuries}

Till [004] was noted at the base of the sequence, which would be the expected glacial sub-soil in this area of Edinburgh. In Trench 2 a light brown silt deposit [105] was identified overlying the surface of the till. This was interpreted in the field as a possible buried soil, however, it appeared to correspond with the upper part of [142] (see below). Directly overlying the till in the northern part of the site was stony silty clay [126] with occasional larger angular stones. This was thought to be a result of weathering of the till, however, it contained fragments of medieval pottery, although these may be intrusive given the excavation conditions.

Above the weathered surface of the underlying glacial till were irregular patches and bands of a rich organic deposit [142] (illus 3). This deposit was seen in Trenches 3 and 4 on the eastern side of the site. On the basis of the thin-section analysis this context was divided into two distinct deposits (Lancaster, Appendix 3). The lower deposit was fine, organic-rich sediment, which accumulated relatively rapidly through slope wash. A seed from this deposit has been radiocarbon dated to AD 1020-1210 at 2 -sigma (Appendix 3).

The upper deposit was characterised by unsorted sand and rock fragments, with fragments of soil and sediment, suggesting that the deposit was formed 
in high-energy conditions. The process of deposition of the upper sandy layer had caused the scouring and partial truncation of the lower organic rich silty layer. Given the apparent absence of a buried soil of prehistoric date and the medieval date of the lower deposit, a layer of this kind in the overall profile suggests an extreme event, which may have been rapid and local, such as a flash flood that had removed any earlier material (Lancaster, Appendix 3 ). The lack of an earlier ground surface suggests this was happening regularly prior to the 11 th -12 th centuries, with the final episode of flooding recorded here.

Cereal grain recovered from the earliest accumulation was preserved through charring and is thus likely to indicate anthropogenic, ie domestic/commercial, activities (Timpany \& Haston, Appendix 4). The assemblage is likely to represent waste ground with some evidence of periodic pooling of water.

Overlying the lowest deposits was mid-grey to brown silty clay [070] (illus 3). The deposit deepened towards the centre of the site $(0.4 \mathrm{~m})$ and became shallower to the south and north $(0.1 \mathrm{~m})$. It was absent in the north-eastern part of the site. The deposit was initially taken as indicative of a natural water channel, based on the presence of a postulated former stream along the Cowgate (Makey 1988; Carter et al 2008). This now appears to be incorrect because thinsection analysis demonstrated that it accumulated through slope wash (Lancaster, Appendix 3). Pottery datable to the 12 th-14th centuries was recovered from the overlying deposit. This gives the relatively short period from under 100 years to 300 years for the accumulation. From the deposit itself only one sherd of pottery was recovered, White Gritty Ware dating to the 12 th-14th centuries.

The insect remains from the deposit represented damp, foul ground conditions with occasional representations from nearby agricultural (both pasture and arable) land (Reilly, Appendix 6). Fly pupae suggested the presence of dung, human excrement and carrion (Smith 1989). There were no indicators of moving water, which would be expected in the case of a former stream, or specific indicators of wetland plant communities.

Although the pottery may be intrusive, the environmental remains indicate that the deposit contains material associated with human activity. This probably represents the beginnings of accumulated rubbish associated with the growth of the medieval town. In addition, disturbed waste ground and/or arable land is also visible in the assemblage.

\subsubsection{3th-mid-14th centuries}

Overlying the above deposit was blackish-brown sandy silt [140] and above this was greenishbrown silty sand [125]. Both contained pottery and animal and bird bone. Cut through these deposits were a small posthole [130] and an irregular linear feature [127] (illus 3). These features may represent sporadic use of the site at this time. However, given the evidence for biological mixing in the overlying midden layer (see section 4.5 below) it is possible that they represent the bases of later cut features, the upper parts of which were not identifiable. No evidence for plot boundaries along the central part of the site was found.

Grey-brown clayey silt [007], 0.40m in depth, sealed these features and deposits. This was a buried soil formed through the accumulation of midden material from the surrounding area and indicates an increase in activity.

The small collection of pottery from the early features included a sherd of probable Saintonge Ware, which was imported in the 13th and 14th centuries. Finds from the midden soil provided the first significant collection of finds from the site, however, the size and condition of the sherds implies redeposition from deposits upslope on the High Street. Three imported sherds suggest a date of 13 th or early 14 th century, while the presence of local Greywares demonstrates continued deposition into the 14th century. However, the lack of Rhenish stonewares suggests this did not continue into the late 14th century and certainly not into the 15th century. A bone bead (illus 8.17) from this layer is likely to be from a set of rosary beads (Egan \& Pritchard 1991, 305).

The pottery assemblage increases in quantity over time as activity in the medieval town gradually encroaches on the site. By the mid-14th century the site may be part of a plot on the very edge of the burgh.

\subsection{Phase 2: medieval ditch 14th-15th centuries}

\subsubsection{Initial ditch cut}

A substantial ditch [075/076], first exposed during the excavation of Trench 2, was found running east to west across the site, approximately $13 \mathrm{~m}$ from the street frontage (illus 2, 3-6). The ditch terminated around $5 \mathrm{~m}$ before the western edge of the site. The ditch was $5.5 \mathrm{~m}$ wide and $1.3 \mathrm{~m}$ deep. The primary fills were waterlogged organic-rich silty sediments [081/090/093, 089/094]. In the southern half of the ditch was a thick deposit of silty clay [104], which had been tipped in from the side. Above these fills was re-deposited subsoil [99], probably slumped from a bank on the northern side of the ditch. Above this were an organic deposit [98] and a layer of silting [103]. Bank material [078] had then been used to deliberately backfill the ditch. Above this was a layer of light brown silty clay [077].

The finds from the ditch were more varied, better preserved and less abraded than the finds from the earlier soils. There were, however, no large pottery profiles nor similar evidence of domestic rubbish being dumped straight into the ditch, and the pottery appears to derive from redeposited midden material. The stratigraphy suggests that the ditch 

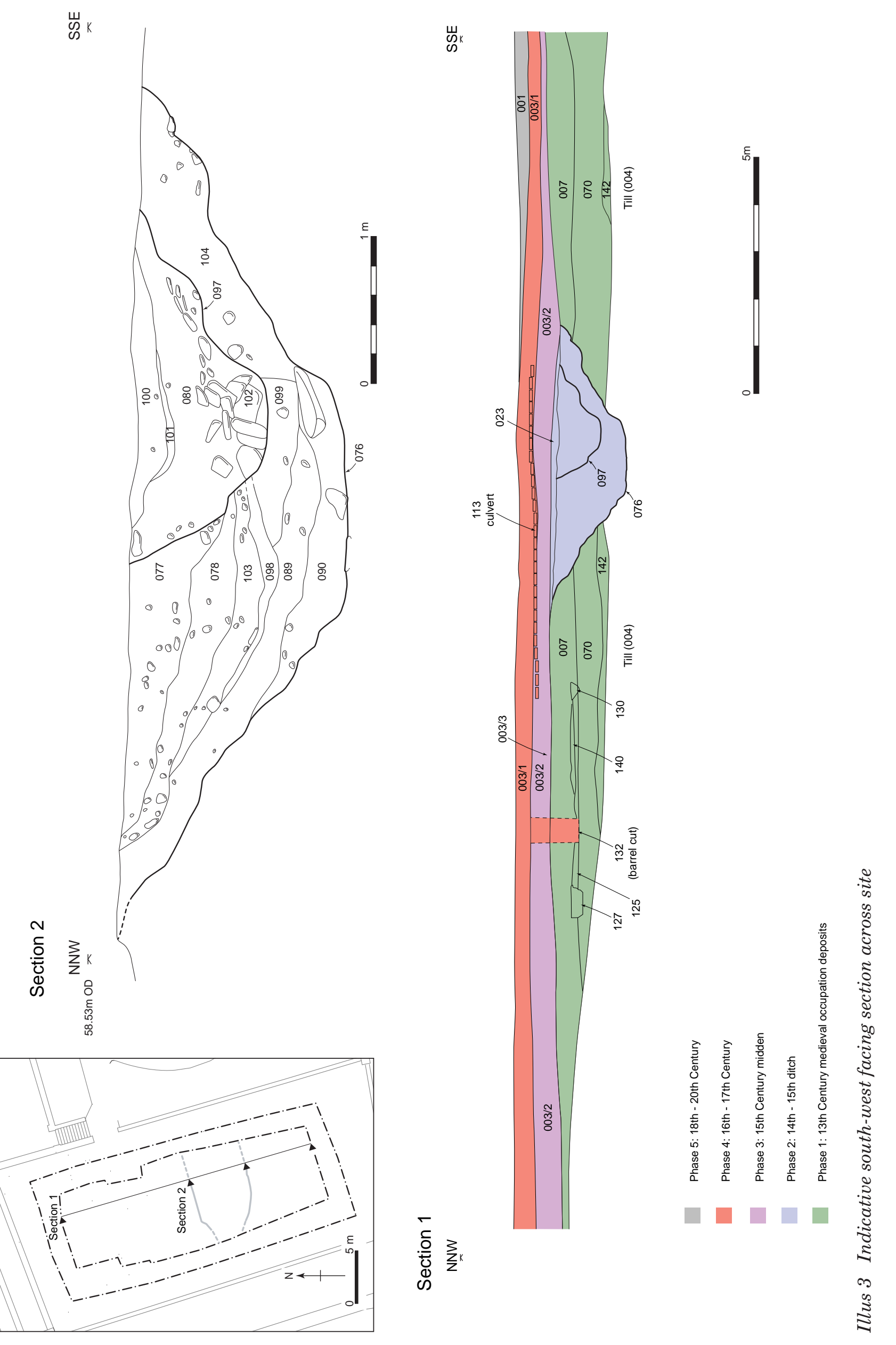




Illus 4 Phase 2: Medieval town ditch with modern streetscape 


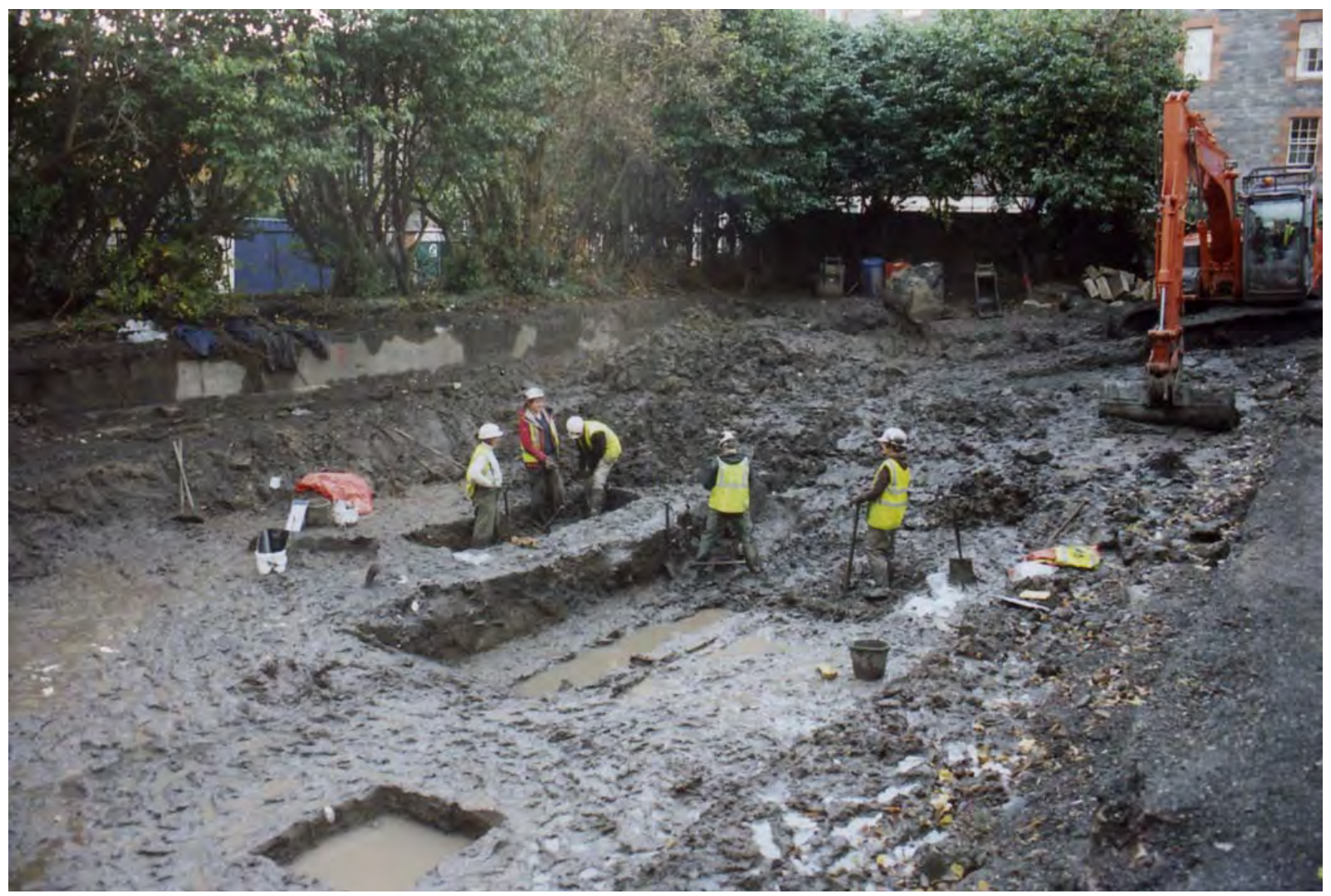

Illus 5 Ditch under excavation looking south-east

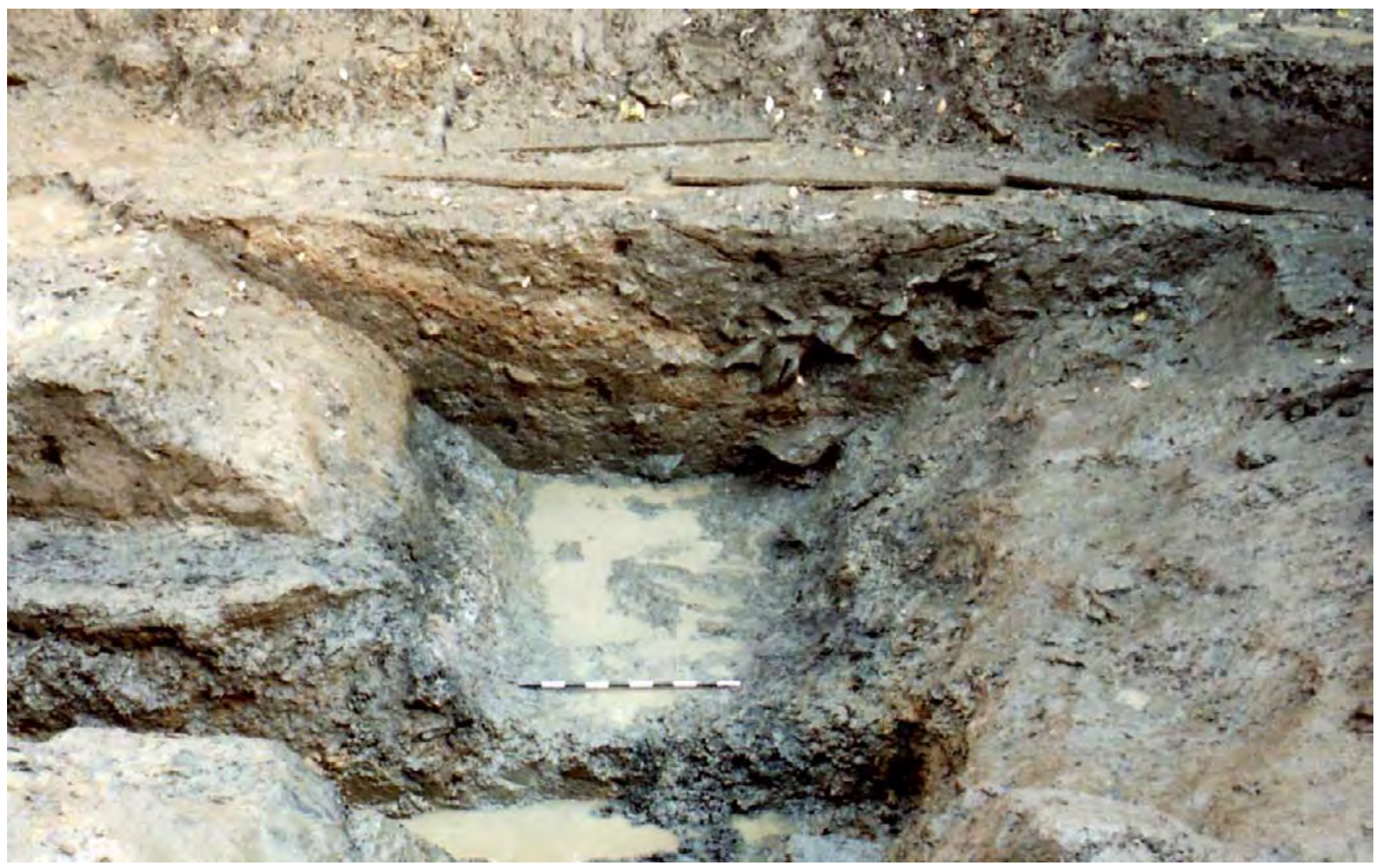

Illus 6 Ditch fully excavated looking north-east 


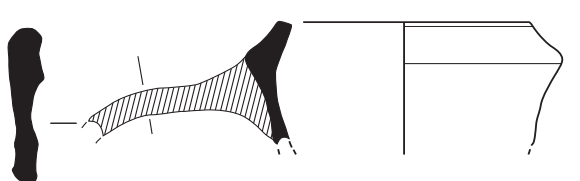

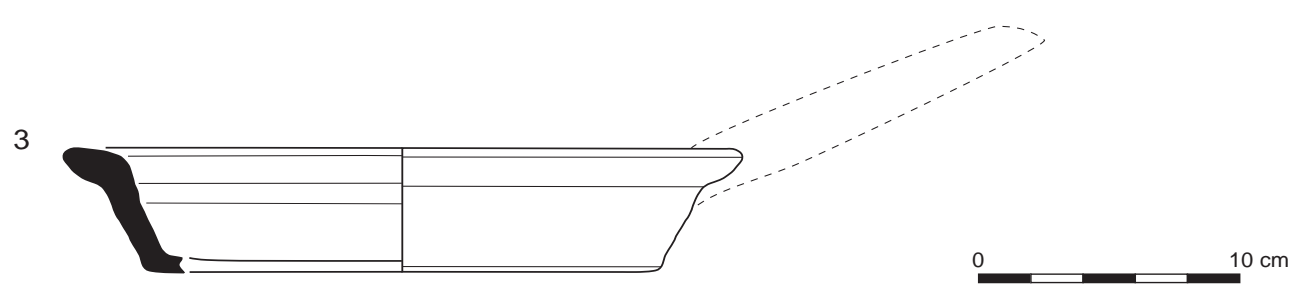

2

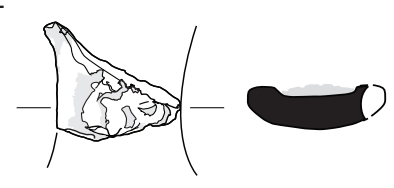

19

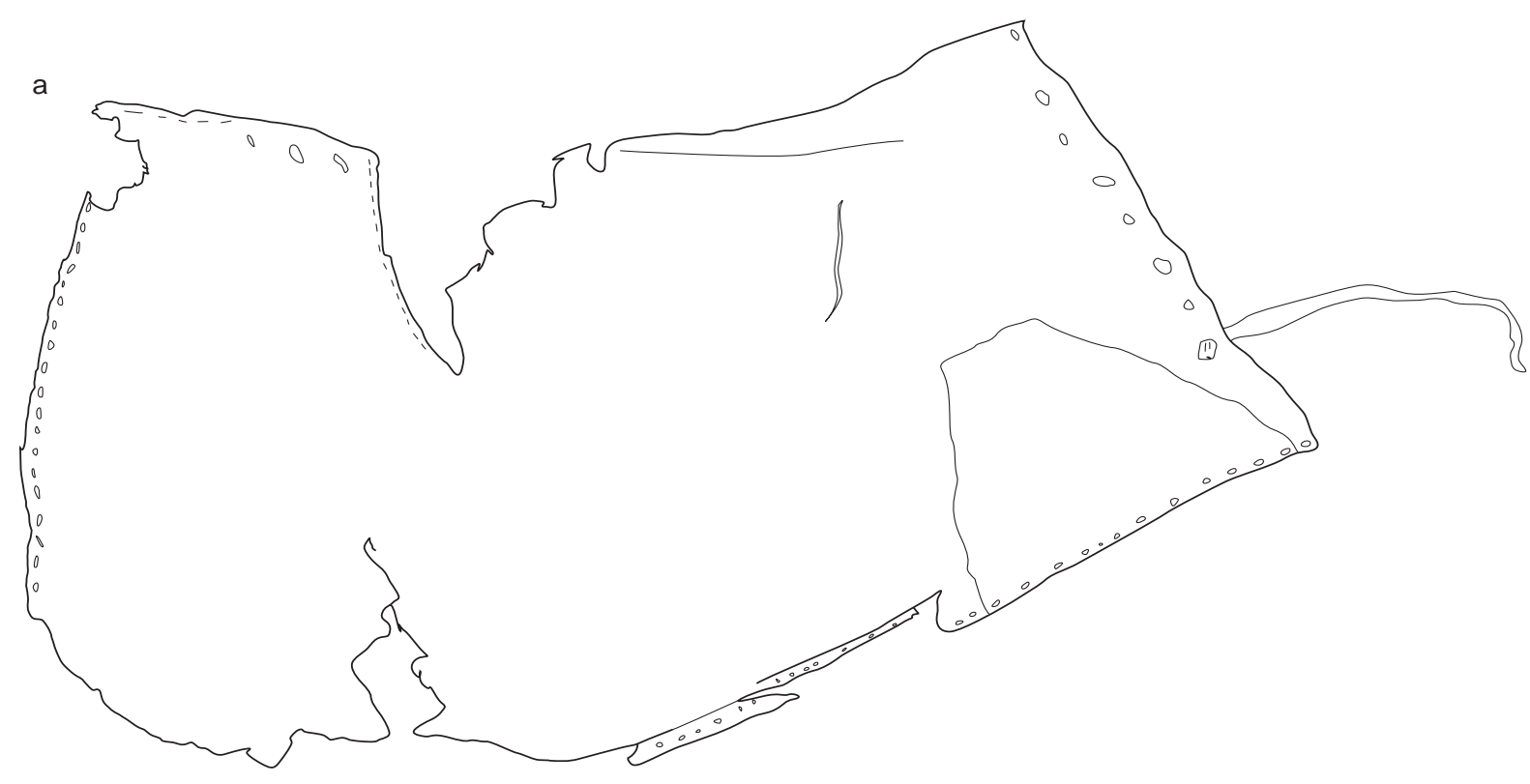

b

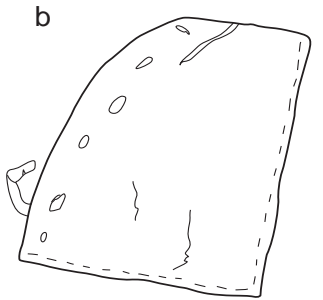

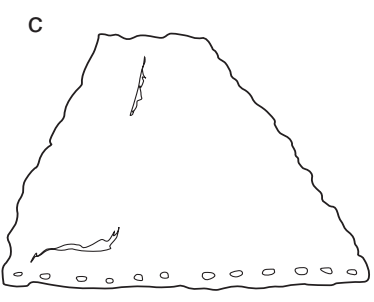

$0--^{5 \mathrm{sm}}$

Illus 7 Finds illustrations 1-3, 19 

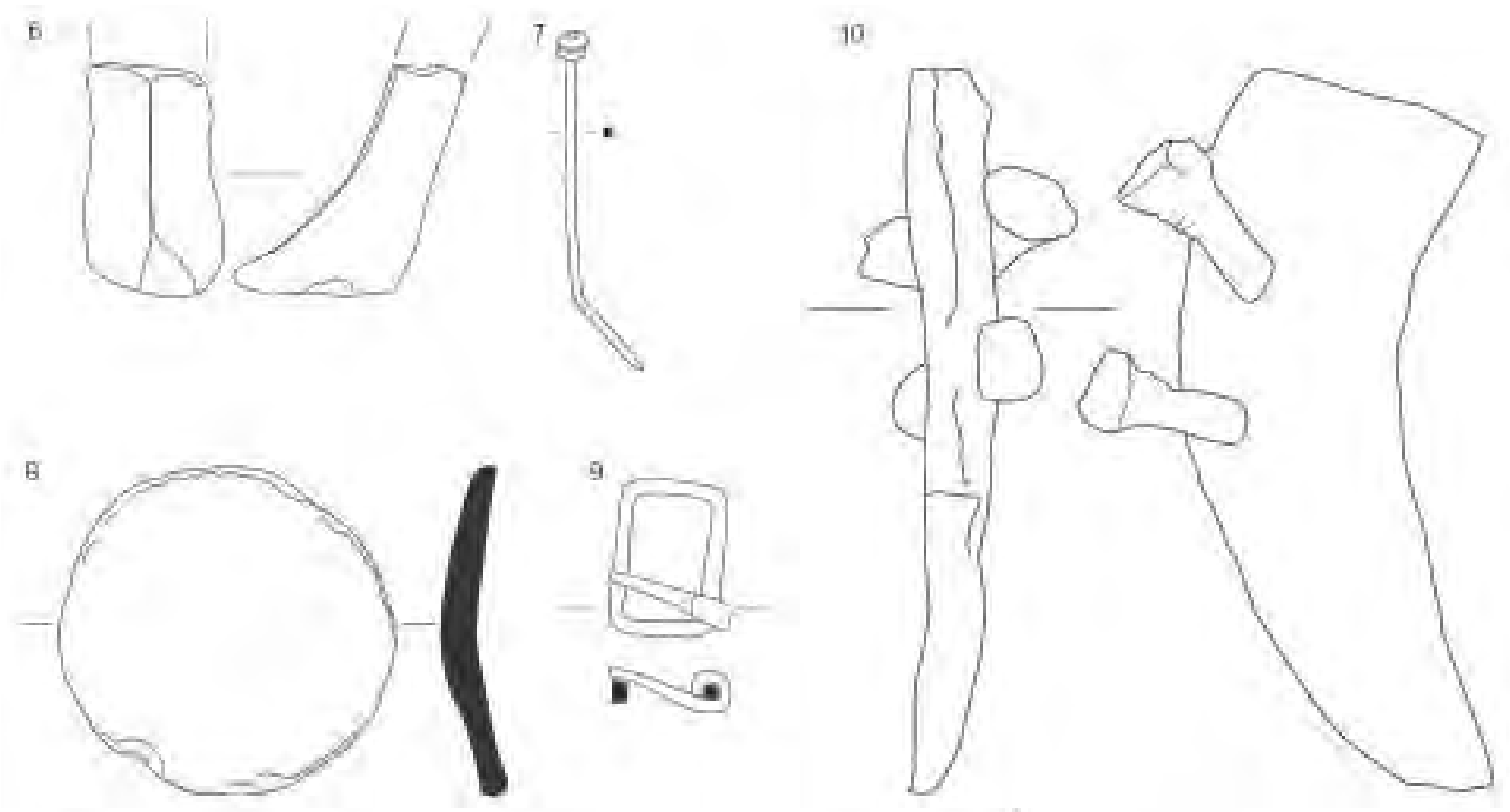

12
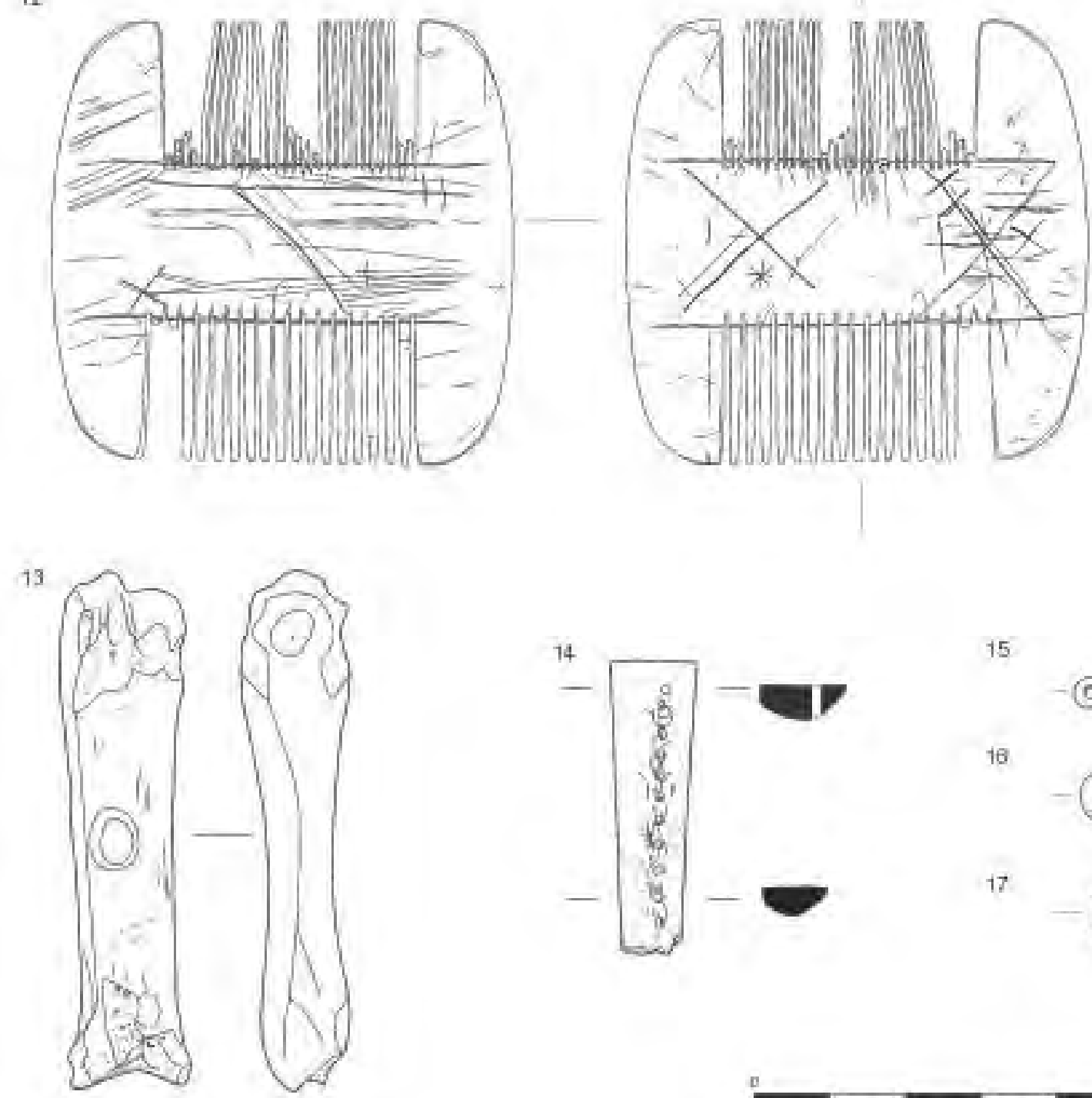

15

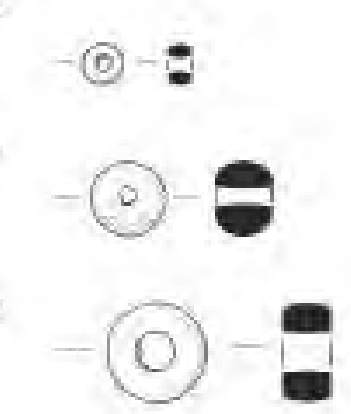

Illus 8 Finds illustrations $6-17$ 


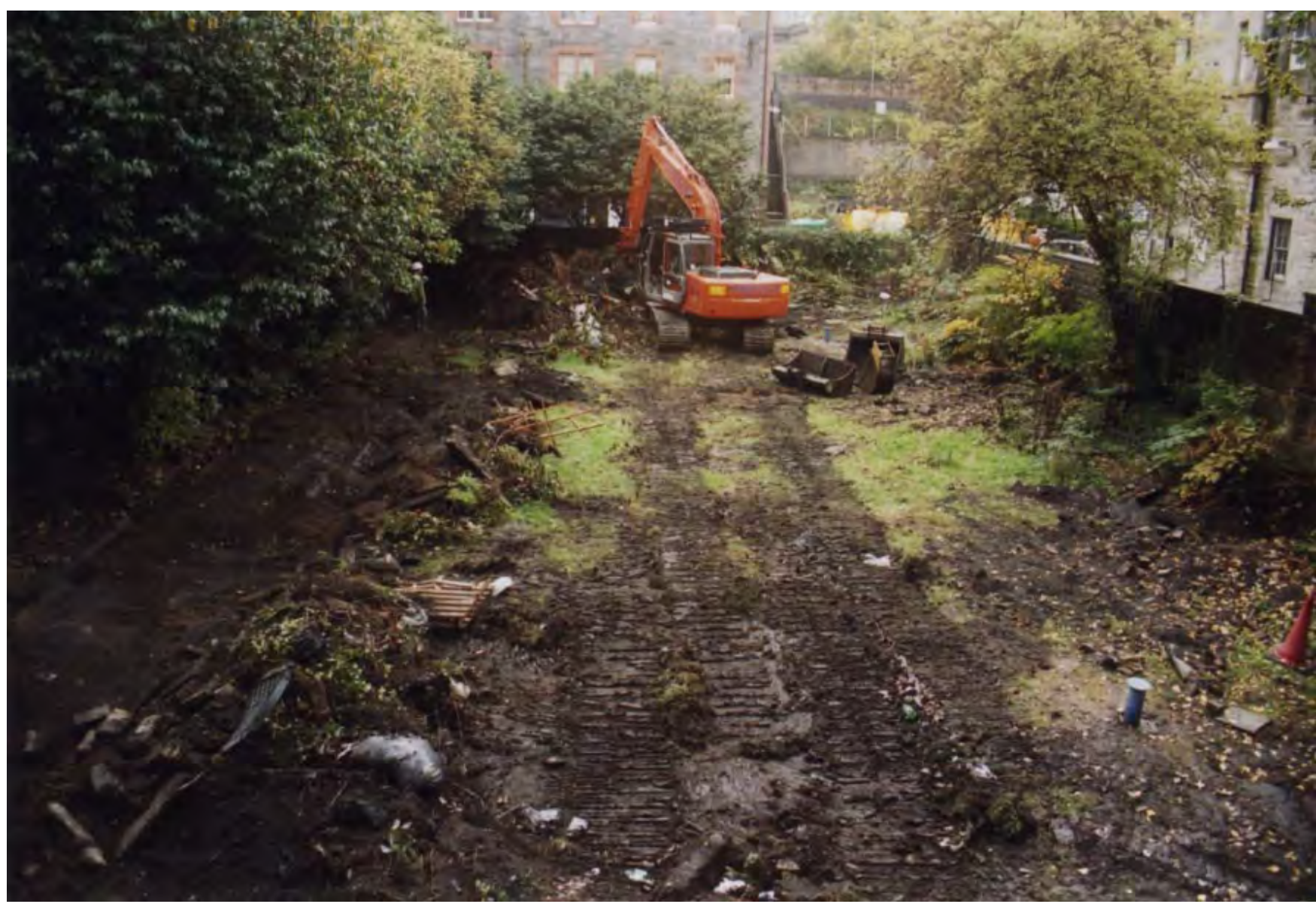

Illus 9 Pre-excavation view of site looking south

7.19). Other finds included a small iron buckle (illus 8.9), a copper alloy pin fragment and the length of a knife blade. An opaque glass bead (illus 8.15) was recovered from a sample.

Animal remains from the ditch included horn core fragments and fragments of cow and horse bones as well as sheep, smaller mammals, fish and amphibians (Tourunen, Appendix 2). The majority of the animal bone derives from domestic species and is representative of domestic waste. These mainly derive from the primary fills; smaller quantities and fragments of bones were recovered from the upper. The dominance of older and male sheep in the sample suggested that sheep were being kept for wool, with the cattle-culling pattern indicating that stock was kept mainly for hides (Hodgson 1983, 111; Smith 1997, 769). This follows patterns seen in other Scottish burghs (Smith 1997, 769; Henderson 2001; Smith 2007; Hodgson 1983, 111).

The palaeoenvironmental assemblages indicate a mixture of waste and cultivated ground, with possible scattered trees or small patches of woodland; a number of taxa associated with damp meadows are also present (Timpany \& Haston, Appendix 4; Mighall, Appendix 5; Reilly, Appendix 6). Insect species suggest that wood/leaf litter may have formed part of the fill, possibly as fuel or fodder waste (Reilly, Appendix 6). The insects all suggest locally open/disturbed ground, with a number of species associated with heath/moorland (Reilly, Appendix 6). These include the ground beetle, which only occurs in the secondary fill of the ditch. Dumped peat or turf used for roofing or fuel may possibly be the source for such beetles in the ditch fill.

Some unidentifiable fragments of 'woodworm' beetles were present, but in very small numbers. This is somewhat surprising for the fill of a medieval ditch, where species associated with wooden buildings might be expected to become incorporated into ditch fills (Reilly, Appendix 6). 'House fauna' often make up a significant proportion of deposits in cut features, like pits and wells, in medieval sites due to their location within the settlement (Kenward \& Hall 1995; Reilly 2003). Along with the lack of structural wood pests, this lack of house fauna supports the suggestion that domestic waste was not deposited in the ditch.

Charred grains are likely to have washed into the ditch and represent domestic/commercial activities taking place upslope in the town (Timpany \& Haston, Appendix 4). There is an increase in the representation of cultivated ground species within the upper layers, suggesting some cultivation was taking place near the ditch. The presence of seaweed is suggested by the finding of Cafius sp. (Reilly, Appendix 6), which may have been brought 
into Edinburgh from the coast for sheep feed or manuring.

The rise in seed numbers of R. sceleratus and Urtica dioica in the later fills of the ditch may indicate an increase in the amount of faecal matter being washed in from humans and animals (Timpany \& Haston, Appendix 4). These taxa are associated with habitats of extremely nitrogen-rich, periodically wetted and disturbed ground, such as the manured surrounds of streams where cattle water (Rodwell 2000). Rodwell notes that $R$. sceleratus is one of the few plants that will readily grow on the sludge beds of sewage farms. The ditch may also have been used to discard human waste. Parasitic eggs of the whipworm (Trichuris trichuria L.), the most common human intestinal parasite, were recorded from most of the samples (Mighall, Appendix 5). The insect remains also contain species indicative of dung, including human excrement/urine as well as common 'cess-pit' species (Reilly, Appendix 6; Smith 1989). Thus the palaeoenvironmental evidence not only provides an ecological picture of the site but also an impression of the conditions on the Cowgate during this period.

\subsubsection{Re-cut of the ditch}

The ditch had been re-cut on its southern side [097] (illus 3). The re-cut ditch had been rapidly backfilled with a layer of large stones [102] within dark greyish-brown silty clay [080]. Above this were a wood-rich organic layer [101] and a layer of silting [100]. The re-cut was $2.5 \mathrm{~m}$ wide and $0.9 \mathrm{~m}$ deep but was not clearly visible in other sections further west and at the terminal. However, the stony backfill continued into both these sections and completely filled the terminal. This suggests that the re-cut widened towards the west and encompassed the whole of the terminal.

Ten horn cores and numerous fragments of cow, horse, sheep/goat and pig bones were recovered from the fill of this ditch. Smaller mammal bones and fish remains were also retrieved from sample processing. Evidence of bone-working comes from a near-complete horn comb (illus 8.12; illus 11) and a bone buzzbone or toggle (illus 8.13). This was made from a drilled pig metatarsal with a hole drilled through the centre. These are common finds on medieval and post-medieval sites (eg Cox 1996, 787; Murray \& Murray 1993, 197) and they are now generally thought of as a kind of child's toy or musical instrument. Threaded onto a string, they can be spun to produce a humming noise (Franklin, Appendix 1). A lead weight (illus 8.8) was also recovered.

A second, shallower, ditch [095] had been cut into the top of the ditch at the west end. There was little to distinguish the backfill of the ditches, suggesting they had filled up at the same time. This ditch would appear to have been cut while the main ditch was still fairly open, presumably for drainage. At $4 \mathrm{~m}$ it was wider than the main ditch at this point and was $0.55 \mathrm{~m}$ in depth. Horn cores, cow, sheep and other large mammal bones were recovered from the upper fill [079] of this ditch.

The finds assemblages from the re-cut and the initial ditch are quite similar, although there must have been some time between the two ditches. The pottery is largely made up of similar large Late Whiteware and Greyware jugs. There is, however, no 14th-century leather. Other finds such as the horn comb could be late medieval or early post-medieval. This phase is likely to date to the second half of the 15th century (Franklin, Appendix 1).

\subsection{Phase 3: 15th-century midden deposits}

Sealing the ditch was a thick deposit of grey-brown gritty silt [003] (illus 3) up to $0.8 \mathrm{~m}$ in depth, which was fairly consistent across the site. It was broadly divided into three spits for excavation, based on the diminishing frequency of shell fragments. This was a re-worked buried soil comprising refuse dumping and accumulated deposits washed down from properties further upslope on the High Street.

The finds assemblage is the largest from any phase but is largely made up of redeposited material. This is demonstrated by the proportion of White Gritty Ware, which is almost as high as in Phase 1. Finds from the midden deposits included a copper alloy vessel foot (illus 8.6; CECAS 1990), a bone handle scale (illus 8.14) and a gaming counter made from a medieval Greyware potsherd of 14th- or 15thcentury date. There is nothing that unequivocally postdates the 15 th century. It seems unlikely this deposit was laid down any later than the late 15th or possibly early 16 th century, and could in fact be earlier (Franklin, Appendix 1).

\subsection{Phase 4: 16th-17th-century occupation}

\subsubsection{Coopered barrel and culvert}

A stone-lined culvert [013/014] (illus 3, 5 and 16) was cut into the Phase 3 midden deposit. It measured $0.5 \mathrm{~m}$ wide and $0.2 \mathrm{~m}$ in depth and ran for $12 \mathrm{~m}$ northwestwards from the eastern section. At its north end the culvert appeared to have been partly truncated by the excavation of Trench 2 , however, it did not continue beyond this point.

Three courses of large sub-rectangular stones were laid on either side of the flat base of the cut. Large, flat sandstone slabs capped the culvert with several small stones packed into the gaps. The finds from the culvert were largely redeposited but included crystalline fragments of window glass (Franklin, Appendix 1).

The upright lower half of a barrel (illus 10, 12 $13,14,15)$ was found to the north of the culvert, located approximately in the centre of the site. Although the term 'barrel' is used throughout, the 


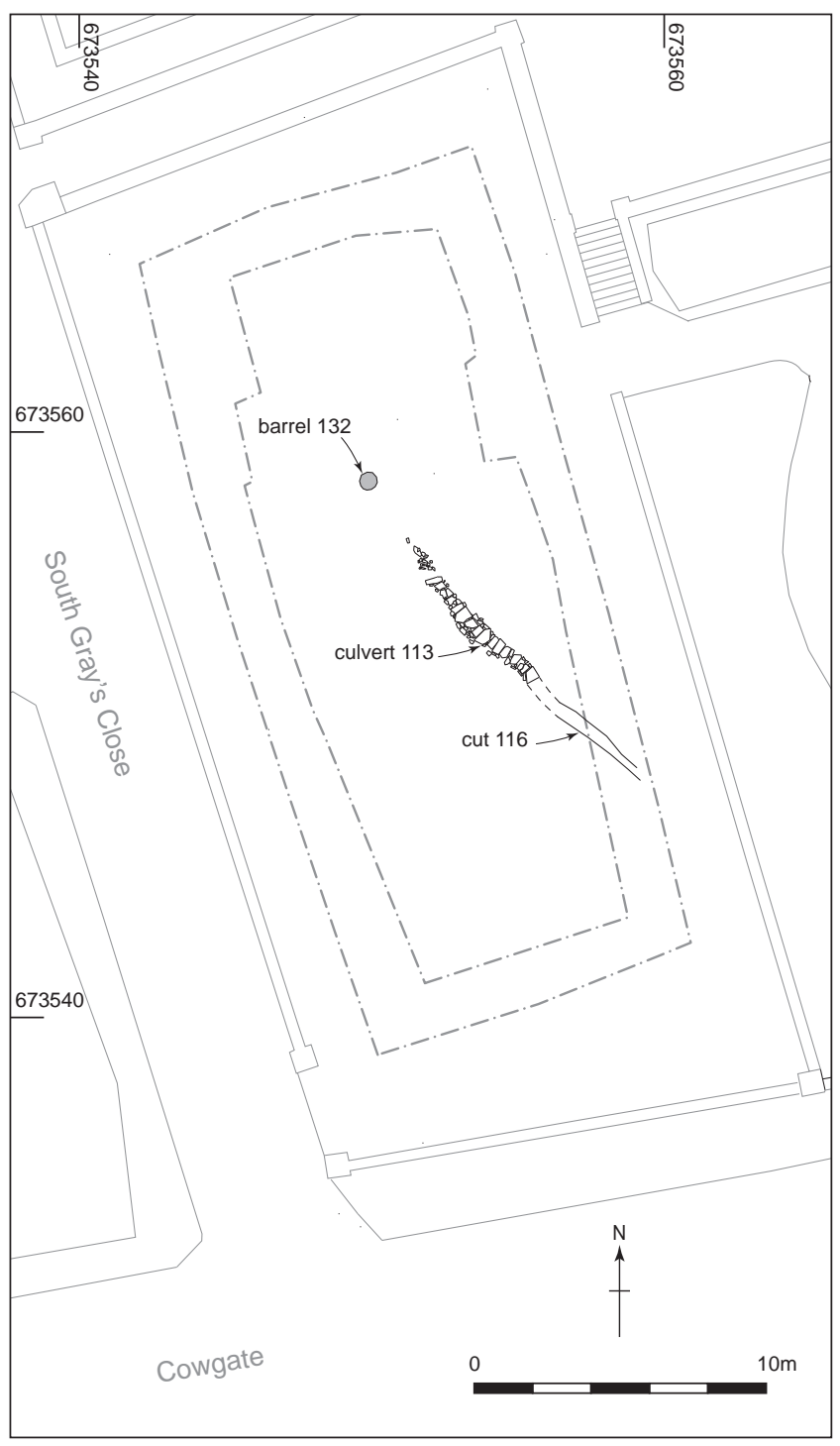

Illus 10 Phase 4: 16th-17th century features

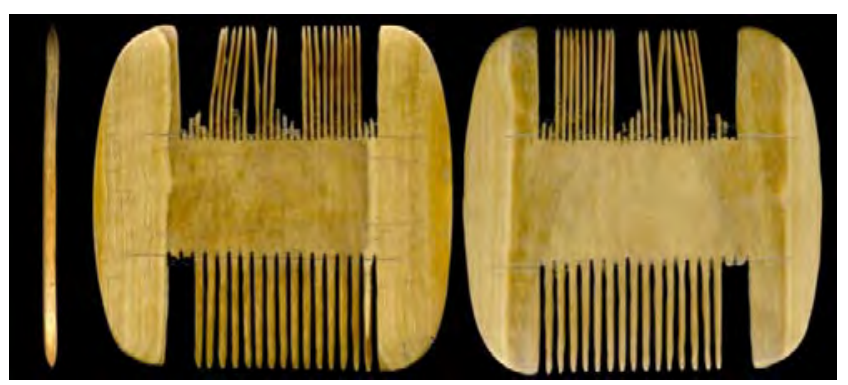

Illus 11 Horn comb

vessel may have been a tub, the widest part did not survive and it is not possible to determine this (Crone, Appendix 1). The staves, hoops and withies were all generally well preserved. An iron object, possibly a handle, was found on the outside of the barrel during the removal of the upper group of hoops. The barrel was initially identified after the removal of Phase 3 midden deposits, however it has

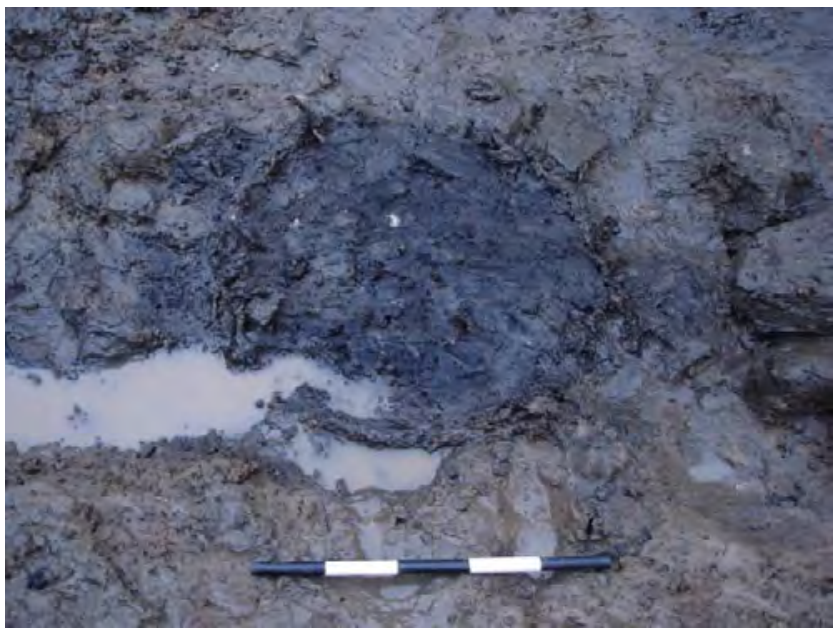

Illus 12 Pre-excavation view of barrel

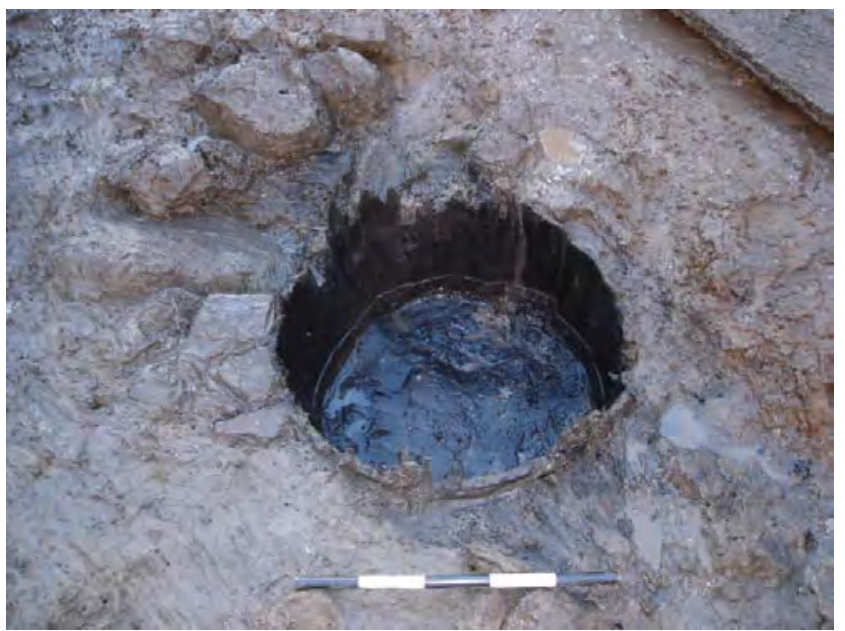

Illus 13 Part-excavated view of barrel

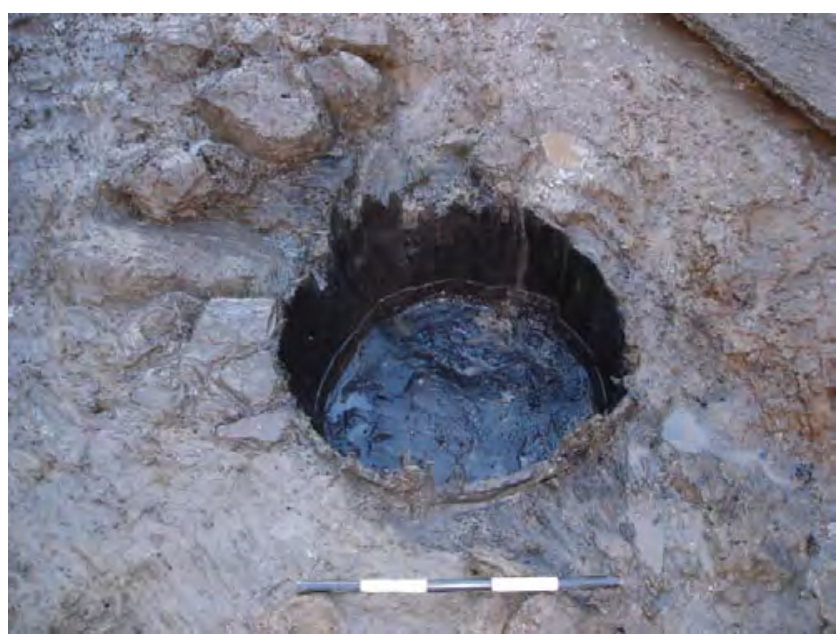

Illus 14 Close-up of barrel staves

been dendrochronologically dated to the early 17 th century (Crone, Appendix 1). The midden deposits had clearly undergone a considerable amount of mixing that had removed any distinction between 


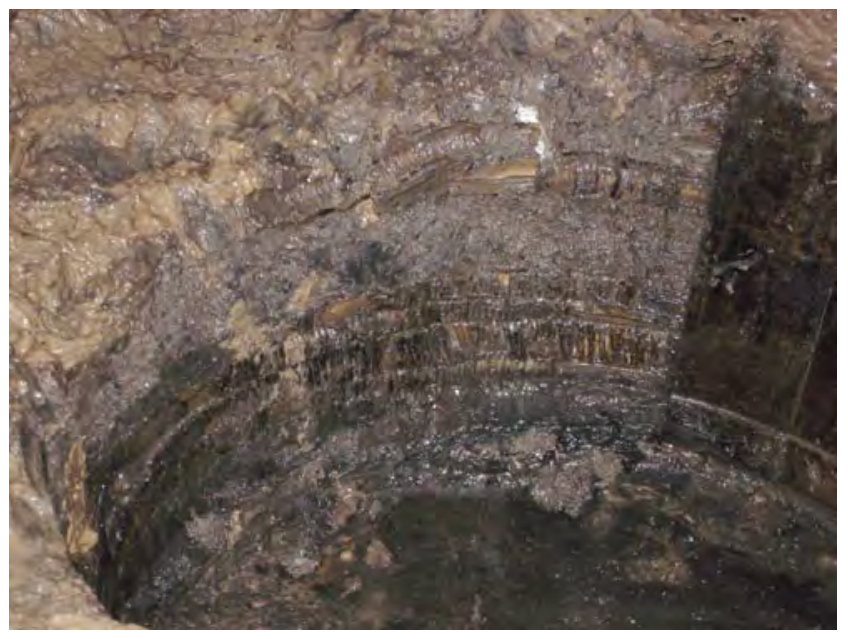

Illus 15 Withy-wrapped hoops

it and the fill of the well and hence any evidence for the cut further up the sequence.

The barrel was placed in a sub-circular pit $0.45 \mathrm{~m}$ in depth, with a flat shelf $0.1 \mathrm{~m}$ from the base. The barrel rested on this shelf and the space between the barrel and the cut was filled with sandy silt. Large boulders were placed around the edge of the cut, apparently to shore up the sides of the cut following collapse. There was a large stone at the base of the pit and a series of organic black silt deposits filled the barrel; two staves were found within the fills. There was no base.

A wooden bead (illus 8.16) from the fill of the barrel is unlikely to be earlier than the 17th century. It is likely to come from a set of rosary beads (Egan \& Pritchard 1991,305) and the post-Reformation dating of it is interesting (Franklin, Appendix 1). Crystalline fragments of window glass were also found in the fill of the barrel. Finds of similar fragments from the culvert indicate that these features are of the same date and it is thought the culvert may have drained into the barrel.

\subsubsection{Later midden development}

Overlying the culvert was a further accumulation of midden material (illus 3). This contained a greater number of marine shells, particularly oyster, than the lower midden deposits. The layer contained a large amount of finds but these were almost entirely redeposited from upslope. There are only a handful of pottery sherds dating to the 16 th and 17th centuries, nothing later, and no clay pipes. The latter are so ubiquitous in 17 thcentury deposits that their absence here is striking (Franklin, Appendix 1).

Two coins were recovered, a silver James II billon penny (1437-51) and a copper James III farthing (c 1470-82). The James II penny is unlikely to have been in circulation past the 1460 s, as early James III pennies were much smaller and more debased

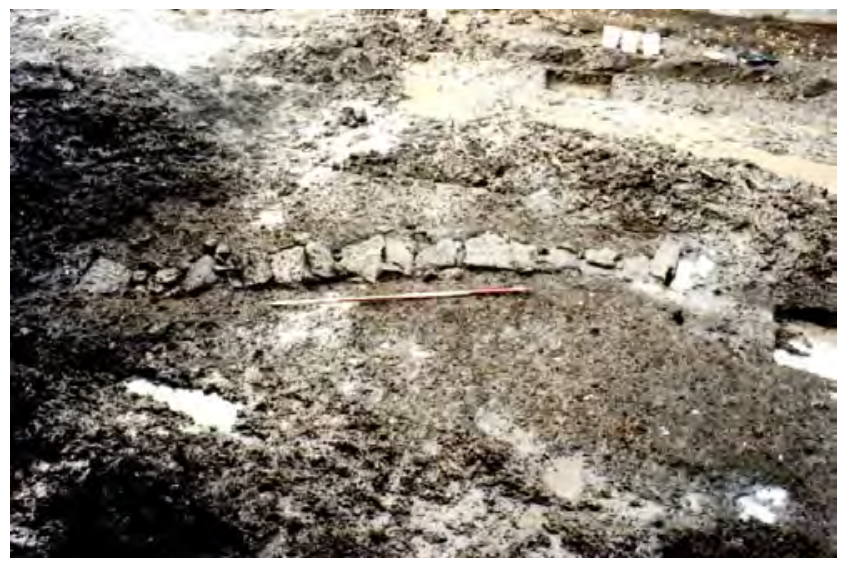

Illus 16 Culvert looking south-west

and probably drove earlier issues out of circulation. The relative lack of wear on the James III farthing suggests deposition in the 1470 s or ' 80 s (Holmes, Appendix 1).

A complete example of a copper alloy wire pin (illus 8.7) was recovered. There were other fragments recovered from the site, including from the ditch, but, as a relatively early type, this is probably redeposited (Franklin, Appendix 1). The head is soldered on, a method of fixing only common up to the 15th century (Caple 1983, 274). A horseshoe (illus 8.10) was also found in this layer. It is of a form commonly found in later medieval contexts (Clark 1995, 88, Type 4), though examples can be found as late as the 17th century (Goodall 1983, 251). Two of the nails were still in position, suggesting this shoe was deliberately removed, but was lost before it could be scrapped.

A large sherd of window glass $(25 \times 25 \mathrm{~mm})$ was found in this midden layer and its size suggests it originates from on or near the site. The fragments found in the barrel and culvert indicate they have been redeposited, as would be expected. All are most likely to derive from a high-status building, as even in the 17th century glazing was still rare in private residences in Scotland (Turnbull 2001, 52). The Earl of Selkirk's House, immediately to the north of the site, would seem the most likely candidate for the origin of the glass (illus 19). Elphinstone's Land was built above this later midden on the northern half of the site in the 17th century (illus 20).

\subsection{Phase 5: 18th-20th-century buildings}

\subsubsection{Timber piles}

A number of shaped timber stakes were found driven through the Phase 3 midden deposits (illus 17, 18). The first stakes were visible following the removal of the upper spit of the midden layer, and more stakes were recorded following the removal of each 


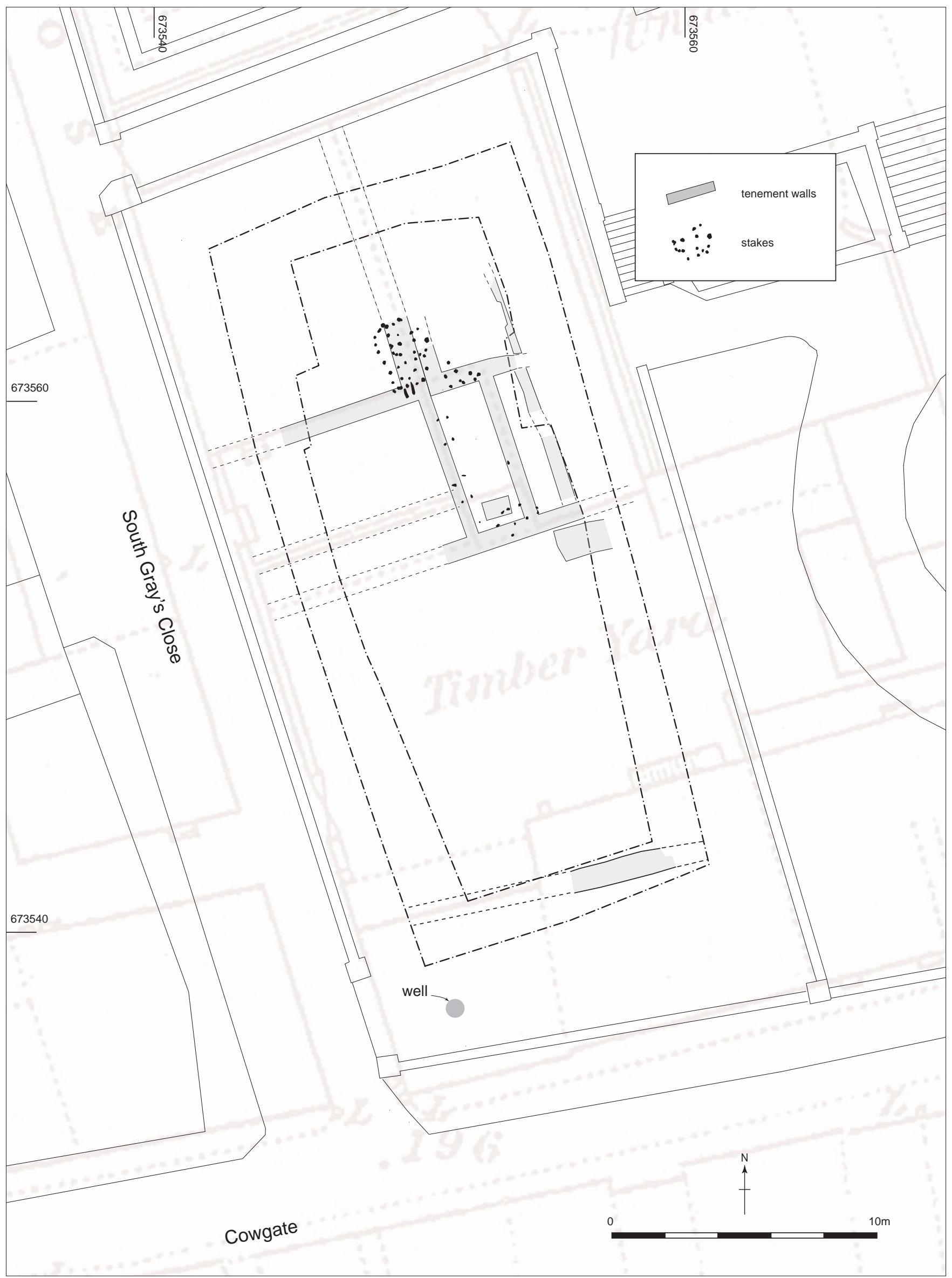

Illus 17 Location of post-medieval tenement walls and supporting stakes, overlaid on first edition Ordnance Survey map (1849) 


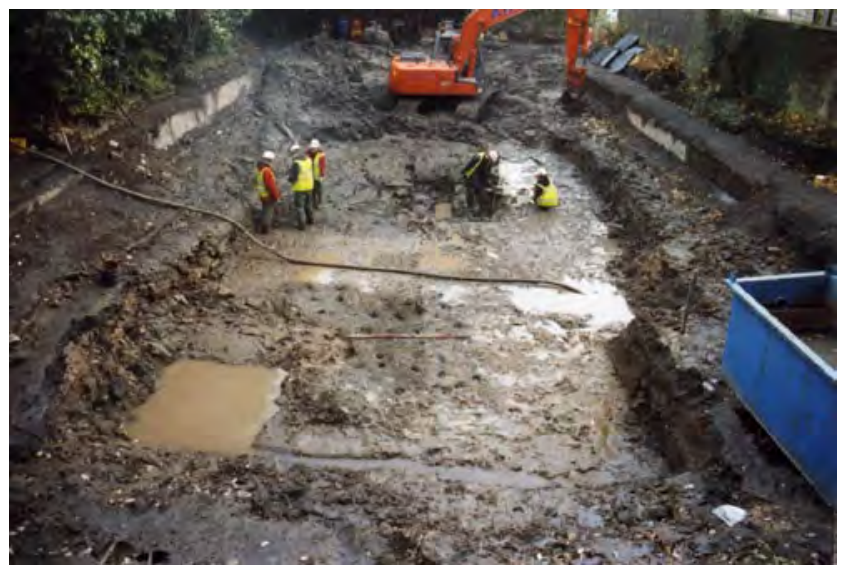

Illus 18 View of timber piles and Trench 2, looking south

of the subsequent layers. This is likely to reflect the differential survival of the timbers rather than successive building phases; only when all the midden deposits had been removed did the stakes begin to form a coherent pattern.

The stakes were all well-preserved fast-grown oak roundwood. The majority of the stakes had been roughly squared with a pointed base. A number of them contained square-shaped notches in the sides. This may reflect re-use or a means of carrying the stakes.

A number of 17th-century and later walls at 144-166 Cowgate were found to be resting on wooden piles driven into soft midden deposits (Dalland 2004). Although a number of the stakes excavated at St Patrick's Church corresponded with buildings seen on early OS maps, those that did not may have supported earlier 18th-century buildings which were later demolished. A number of 18th-century buildings are also likely to have survived into the 19th century, as maps of the site show the same building outline on the site from the mid 18th century onwards (Edgar 1742; OS 1854, 1881, 1895).

\subsubsection{9th-century walls}

The southern part of the site became a timber yard in the 19th century, seen on an illustration from the 1880 s (illus 20). A number of 19th-century walls were recorded across the site (illus 17). During the main excavation a number of sandstone and mortar walls [002] were surveyed. Following the insertion of the sheet piling a number of brick walls were revealed along the eastern, southern and western edges of the site. These were recorded on a measured sketch plan as the ongoing construction prevented any more detailed recording. The walls relate to buildings shown on the 1st edition Ordnance Survey map (1849; illus 17).

This phase includes 19th-century structures, unstratified finds and finds from the evaluation

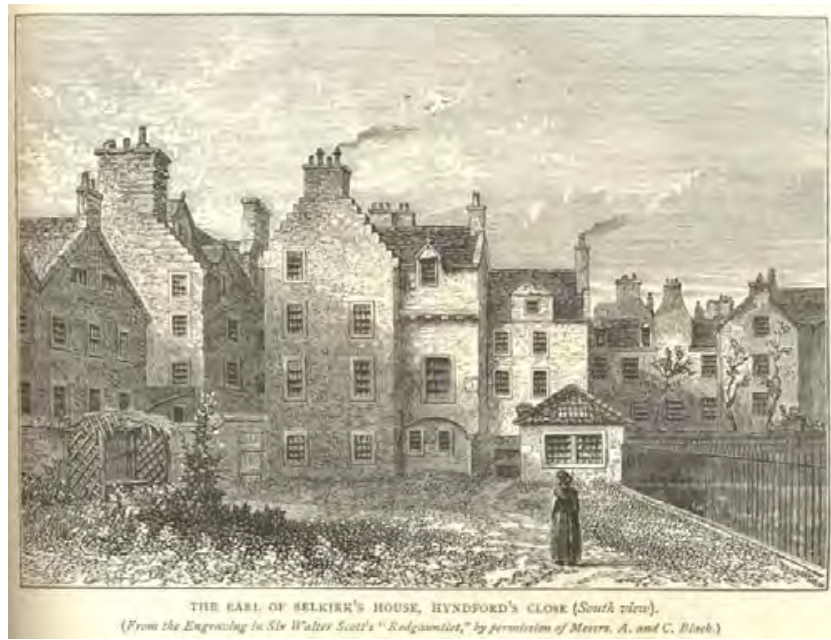

Illus 19 The 17th-century Earl of Selkirk's House as imagined in the $1880 \mathrm{~s}$

trenches. There are few finds from modern contexts, and again these are mixed modern and medieval.

Site construction workers found a brick-lined well on the southern edge of the site during the insertion of the sheet piling. The approximate location of the well is shown in illus 17. No trace of the structure was seen by monitoring archaeologists, as the void was subsequently backfilled with gravel.

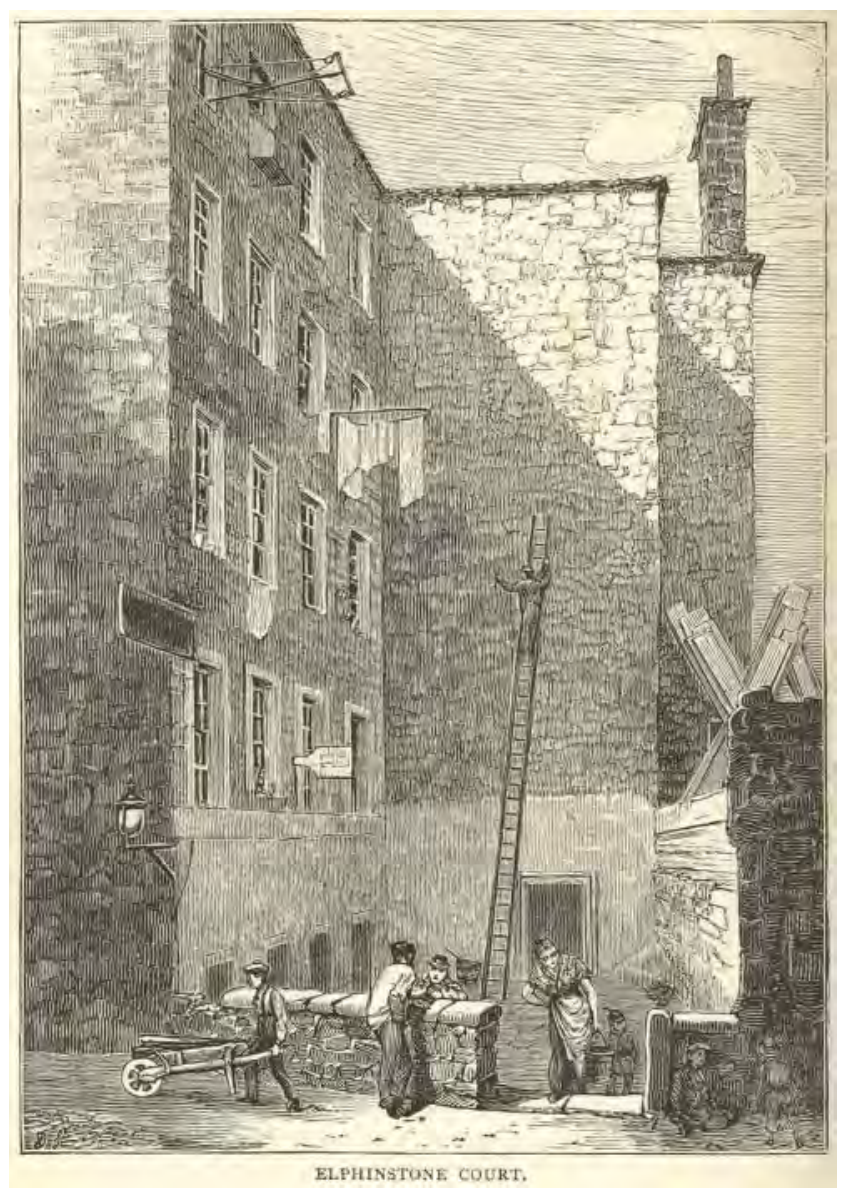

Illus 20 Elphinstone Court c 1880 


\subsubsection{0th century}

The 20th century saw the demolition of Elphinstone's Land on the northern part of the site, which became part of the lands of the church. The site was in use during World War II as an emergency water tank and later became a bowling green. 


\section{DISCUSSION}

\subsection{1th-14th centuries: development and expansion of the medieval burgh}

Prior to the 12th century the site was subject to localised flash flooding. Probably this ran eastwards along the valley occupied by the Cowgate, and we may speculate it was caused by clearance of the slopes in the early medieval or prehistoric periods. There was no evidence for a former stream. The earliest deposits on site capture the last of these periodic floods and have been radiocarbon dated to the 11th-13th centuries. Artefactual evidence dating to the 13th century from the overlying deposits suggests that they are probably of 12 th-century date. The subsequent control of water may reflect the development of the town further west; Edinburgh had obtained burgh status by the 12th century and the site appears to be on the periphery of settlement at this time.

The final flash flood was followed by a rapid accumulation of sediment. This material is likely to derive from activity upslope during the 13 th century. The deposition probably reflects disturbance occasioned by trampling and disruption of soil profiles without the laying down of hard surfaces or the efficient control of wastewater. This may be evidence for the expansion of the burgh eastwards towards the Netherbow from St Giles' Church, proposed by Duncan as a later part of the medieval development of the town (Duncan 1975, 466). At this time the site was still outwith the settlement and the local environment was a damp waste ground subject to periodic pooling of water.

By the early 14th century small-scale activity on the site is probably indicative of the development of plots in this part of the burgh as the medieval town expanded further eastwards and along the Cowgate. There may have been increased use of the Cowgate as a thoroughfare, perhaps with temporary use of the site for such activities as tethering animals or storage of materials.

\subsection{Mid 14th century - town ditch}

A ditch was cut in the mid-14th century east to west across the site. There are no historical records directly referring to the site at this time but the size of the ditch is too large for it to be a property division. The ditch is substantial, over $5 \mathrm{~m}$ in width and $1.3 \mathrm{~m}$ in depth, and lay $13 \mathrm{~m}$ to the north of the present Cowgate frontage. The ditch is also far larger than the ditch excavated further upslope between Blackfriars Street and Niddry Street that Schofield suggested was the late 14th-century burgh boundary $(1976,172)$.
The size of the ditch excavated at St Patrick's suggests it is a more likely candidate for the burgh boundary. Finds from the deposit cut by the ditch and its fills suggest it was cut in the mid 14th century, pre-dating the King's Wall by $80-100$ years. There was a bank on the northern side of the ditch, as evidenced by its fills. No evidence for a palisade was found, although presumably this would have been on top of the bank, although the lack of insect fauna associated with wood in the ditch would appear to confirm its absence (Reilly, Appendix 6). The ditch terminated just east of South Gray's Close and a smaller ditch was dug into it, also running east to west. This shallow ditch was interpreted as intended to aid drainage, and it may have served to continue to mark the line of the ditch while making it shallow enough to cross more easily.

Town ditches of similar size and scale have been excavated in other medieval burghs. In Perth, excavations of the town ditch have produced a probable 12 th-century date, which, along with the location, suggested the early settlement was smaller than the fully developed burgh (Bowler \& Perry 2004, 25). Similarly to the Cowgate example, it was also suggested that the line of the ditch was influenced by a 'rather wide area of wet and low-lying ground, progressively infilled and improved northwards' (ibid). The burgh boundary of the Canongate was identified on plots on the northern side of Holyrood Road (Gooder 2001). In Dunbar a large ditch predating the 14th century was also associated with a possible later town wall (Suddaby 2002, cited in Dennison et al 2006).

As well as the Wars of Independence, the 14th century also saw the arrival of the bubonic plague, and both events may have provided an impetus behind defining the town boundary by means of a deep ditch. Numerous waves of pestilence or plague swept through Scotland in the 14 th and 15th centuries, and when the pest was in a town the ports were closed and guarded, and it was illegal to enter the town by the backyards (Murray 1924, 258-9; Marwick 1882, 29-30). Although there are no known records detailing the regulation of people's movement prior to the mid 15th century, later recorded precautions against the plague are likely to have originated in the 14th century.

Presumably the cutting of the ditch here reflects the expansion of the burgh eastwards in the late 14th century, possibly coinciding with the movement of the Netherbow Port eastwards to its later location at the top of the Canongate, where it stood until the late 18th century. The interruption of the town ditch just east of South Gray's Close 
shows that this thoroughfare was in existence at this time and it is possible it marked an earlier edge of the town, an occurrence not uncommon in medieval burghs. This would support Duncan's assertion that the location of the Nether Bow was originally further west and it may be that it lay somewhere near the top of South Gray's Close on the High Street. This later development may be the reason why the plots are of double width on the eastern side of South Gray's Close. The plots to the west are all of the same (single) width and may be an earlier creation. Historic documents show the plot to have been double width dating back to at least the 16th century (Cross, 3.4 above), rather than two plots that were later amalgamated, as seen elsewhere in Edinburgh (Stronach et al 2008). Comparison with historic maps showing the north side of the High Street also shows a similar pattern (Gordon 1647). Recent analysis of burgage plot widths in Edinburgh also supports the idea that the burgh developed from a settlement located between the castle and St Giles' Cathedral, which extended eastwards as the burgh expanded (Tait 2006, 308).

The line of the ditch probably reflected existing restrictions like a very wet or boggy area at the base of the slope (Cross, 3.4 above). Malcolm (1937, cited in Stevenson et al 1981) stated that development along the Cowgate was originally restricted on the north side due to the presence of a stream. While the base of the slope represents the former course of an immediately post-glacial stream (Makey 1988 , 200), no evidence for a later or prehistoric stream was revealed by excavation. Malcolm (1937) goes on to say that the 'stream' was infilled in the $1490 \mathrm{~s}$, which corresponds well with the archaeological evidence for infilling of the re-cut ditch (see below). It is possible this refers to infilling a waterlogged ditch rather than a natural stream.

During excavations at 144-166 Cowgate, a ditch was tentatively identified on the south side of a wall (illus 2). This was seen only in section due to the nature of the excavations, however the nature of deposits suggested that the wall had been built on the north side of the partially infilled ditch (Dalland 2004). The size of the ditch was estimated to be $4 \mathrm{~m}$ in width, similar in size to the ditch excavated at St Patrick's Church. Here the ditch appeared to be a precursor or early defence prior to the building of the King's Wall. It appears probable that this is the same burgh boundary excavated at St Patrick's Church. Again, this may not have been a continuous boundary, as the break in the ditch at South Gray's Close demonstrates, but it served to mark the edge of the town in the mid to late 14 th century. The ditch lies $13 \mathrm{~m}$ north of the present street front, just south of a timber-yard boundary on the first edition Ordnance Survey map (1849). This line can be traced further west in property boundaries on the same map, for example the south walls of closes in Beaton's palace and Dickson's Wynd (Cross, 3.4 above).

\subsection{Early 15th century: life in the Cowgate}

The finds within the ditch suggest it was infilled fairly rapidly around the early 15 th century. This was initially through silting and sporadic rubbish disposal and later by pushing in the bank, possibly to provide access across the ditch to the Cowgate. Much of the evidence for medieval industry comes from the backlands of plots (Coleman 2004, 305). People lived and worked on the same plot of land with houses, byres, yards and workshops intermingling. Often unpleasant-smelling industries such as tanning were confined to the backlands. The pathways between plots developed into well-established vennels and closes.

The finds from the ditch give an indication of the local industries and activity in the surrounding area during the first half of the 15th century. Although there is no evidence for dwellings on the site, the ditch is on the edge of the hustle and bustle of Edinburgh's markets further along the Cowgate and up on the High Street. Descriptions of the markets show goods being bought and sold in various areas from the High Street to the Cowgate, although small stallholders may have set up elsewhere (Robertson \& Wood 1928, 268-9). It is reasonable to speculate that the diverse finds from the ditch result from casual losses from passing traffic. Traders will have passed by the ditch on their way to market and the underweight lead weight may have been deliberately thrown into the ditch (Franklin, Appendix 1). The goatskin leather shoe found in the ditch is worn and may have been discarded on the way out of town once the owner had bought him- or herself a new pair of boots. The condition of the horn comb suggests it was accidentally dropped rather than discarded, the owner perhaps being unwilling to retrieve it from a very smelly ditch. Small pins and beads are also likely to have been accidental losses.

Dung from animals being taken along the Cowgate to market was washed into the ditch. Sheep were kept for wool or woolfells, one of the main exports from Edinburgh (Stevenson et al 1981, 4), and were taken through the Cowgate to a market at West Bow for sale (Robertson \& Wood 1928, 268-9). Cattle were kept for hides, another main export, or may have been used by local shoemakers (ibid, 268-9). Pigs or cattle were reared in backlands away from dwellings further upslope, maybe for domestic consumption or for the cattle market at West Port (ibid, 268-9). There were fish markets from Netherbow to Blackfriars, selling unprocessed fish and cured herring, which were bought and processed at home, with the remains ending up in the ditch. The increase in cattle manure in the upper fills perhaps represents a busier Cowgate as the 14 th century progressed.

The ditch was also used for the disposing of unpleasant industrial waste. Skinned horse carcasses were dumped in the ditch while the hides, manes and tails were used for the production of goods for sale in the markets. A horn-worker worked in the area and dumped waste cattle-horn cores into the 
ditch. Horn workers were often found in proximity to butchering trades, and fleshers and skinners occupied the yard to the north of the site in the early 16th century (Cross, 3.4 above). At South Methven Street, Perth, there were ditch deposits containing cattle-horn cores suggesting horn working was concentrated in a specific area of town (Coleman 2004, 312). Recent mapping of occupations in Edinburgh in the 17th century also suggests that similar occupations tended to cluster together, with a number of animal-based occupations found on the Cowgate (Allen 2006, 276). It is likely that this pattern had precedents in the medieval period.

Pollen and insect remains suggest that butchery waste, animal dung and rotting vegetables and fruit were in the ditch. Similar assemblages indicative of very foul conditions were noted from midden and floor deposits in the heart of the medieval town of Novgorod at the site of a possible leather workshop (Reilly 2008a). There are also indications that the fill of the ditch included human waste. The fungal spores and whipworm eggs indicate that this material had been deposited locally (Scott Timpany pers comm) rather than being washed in from fields outside the town. There are numerous references to human waste being dumped on the streets in the town. Extracts from early 16thcentury records state that the inhabitants were responsible for the dung in the vennels and at the front of their houses and that it should be removed through the closest gate (Marwick 1871, 141, 148). In other records people are forbidden to empty their closets on the High Street and are to be given permits to put 'muck' on the town streets (Marwick 1882, 187, 391-2). The presence of turf, either for fuel or for building, is attested to by the presence of beetles associated with heather or moorland (Reilly, Appendix 6).

This area was waste ground up until the 16th century (Cross, 3.4 above), with no houses in the near vicinity. The drainage of the area was poor, with plants growing in pools of standing water in the ditch, while thistles and sedges may have grown among the cereals in surrounding fields. A number of maltman's barns to the south of the Cowgate were in existence by the 17th century (Allen 2006, 270) and charred grain from the ditch may be evidence of the earlier existence of such trades, with associated drying kilns.

\subsection{Late 15th century - recut of the ditch}

The re-cut ditch was far less substantial than the original and appears to have been in use for only a short period of time. The finds from the re-cut ditch and the overlying midden deposits all date to the 15th century. This suggests that the re-cut was made relatively soon after the initial ditch was filled, possibly around the mid 15th century. The ditch was subsequently fairly quickly backfilled and sealed by midden deposits in the latter half of the 15th century. This suggests a short-lived attempt at re-establishing the ditch before it was deliberately infilled. It is tempting to connect the filling-in of the re-cut ditch to the refurbishment of the King's Wall in 1472 (3.2 above). There was no evidence for the King's Wall on the site, although it is mentioned in relation to the tenement to the east in the mid 15th century, suggesting the wall lay one yard north of the Cowgate on the line of the former ditch (Cross, 3.4 above). The ditch at 144-166 Cowgate to the west appears to have been directly replaced by the King's Wall (Dalland forthcoming), with the wall being built up against the side of the partially infilled ditch.

\subsection{5th-century midden dumps}

A midden accumulated rapidly over a relatively short period of time after the ditch went out of use, and finds demonstrate the increased amount of material coming downslope. Once the ditch had filled up this area may have been used for a variety of purposes. Yards were common features in backlands and may have been used as stock pens, midden heaps and working spaces for crafts (Coleman 2004, 298).

Malcolm suggests that once the ditch was filled in, piles were driven through the ground to enable building in this area (1937). If this was the case, no trace of any early building or piles survived. The midden deposit may have contained the remains of rotted turf and timber buildings and the fills of cut features rendered invisible by biological mixing (Carter 2001). This process was demonstrated by the case of the coopered barrel. This was thought to be of early date due to its apparent stratigraphic position cut into the Phase 1 deposit below the midden. The dating of the barrel to the 17th century, however, makes it clear that it was cut from far higher up in the stratigraphic sequence, but that the cut and fills were made indistinguishable from the surrounding soil. The apparent hiatus between the infilling of the ditch and the later 17th-century culvert and barrel is therefore likely to be only an artefact of preservation. The relative depth preserved the barrel and its contents, while the stone structure of the culvert protected it. Many other features have presumably disappeared.

\subsection{6th-17th-century development}

The archaeological evidence supports the documentary references to a wasteland running along the north side of the Cowgate from St Giles' kirkyard in the early 16th century. Archbishop Beaton owned the southern end of the site and the northern end was a mason's yard (Cross, 3.4 above). The area was still open ground in the early 17 th century and the culvert and well may have acted as a drainage system in the lands of Dr John Naysmith or his son-in-law John Livingston (Cross, 3.4 above). The 
barrel was fashioned from Scandinavian oak (Crone, Appendix 1). From the late 15th century, Scotland was importing timber for its building requirements and throughout the 16th and 17th centuries the main source of that timber was Scandinavia (Crone $\&$ Watson 2002). As well as various types of building timber, Norway also exported barrel staves and hoops to Scotland (Lythe 1960 148; Lillehammer 1990). Scotland was not importing produce such as salted herring from these countries, which would have been packed in barrels, although ironwork was imported from Scandinavia in barrels (Cross 2008). A will from 1585 shows the sale of Scandinavian iron ingots for sale in one of the merchants' booths on the High Street (NAS, CC8/8/27, p200-1). However, it is most likely that the vessel was made in Scotland using either pre-prepared staves or boards. The barrel was probably in use for a number of years, perhaps storing goods from one of Edinburgh's markets or belonging to Andrew Ainslie, who was a merchant and owned the land immediately to the north from 1630 (Cross, 3.4 above). A barrel-lined well was also found on the site at Blackfriars Street (Will \& Radley 2005).

The drain and well were no longer in use when Sir James Elphinstone built Elphinstone's Court on the northern half of the site in the late 17th century (illus 20; Cross, 3.4 above). Permission to bring water into the town from the country was granted to Edinburgh inhabitants in 1674 , with cisterns constructed at Netherbow Port and the head of the Canongate (Maitland 1753, 317, cited in Stevenson et al 1981, 29). This would have removed the need for local wells on burgage plots.

Gordon's map of 1647 shows the Cowgate frontage to have been built up and a building is shown on the site on Edgar's map of 1742. This continues through to the Ordnance Survey first and later editions (1849, $1854,1881,1895)$. The street frontage was widened in the early 20th century, meaning the remains of these buildings lie beneath the present road (Cross 2008). Little evidence was found pertaining to frontage properties during the excavation, with the exception of one 19th-century wall. 


\section{CONCLUSION}

Previous excavations in Edinburgh further upslope and closer to the High Street frontage have revealed that a number of sites between the High Street and the Cowgate had been scarped by later building works (eg Fishmarket Close, Stronach 2000; St Mary's Street, Holmes 1980), and often produce only 17th-century and later finds. Preservation of organic materials is also relatively rare in Edinburgh. This has led to the assumption that the potential for the survival of medieval deposits is poorer in Edinburgh than in other towns. However, more recent excavations at Blackfriars Street (Will \& Radley 2005), 144-166 Cowgate (Dalland 2004; forthcoming) and the present excavations have concentrated on areas further downslope and uncovered extensive middens similar to those recorded in other Scottish burghs such as Perth, St Andrews and Aberdeen.

No evidence for a stream was found at the base of the slope and clay deposits, initially taken to be natural in origin, had washed downslope from the High Street. These contained environmental evidence for the development of the medieval town. Similar apparently archaeologically sterile clay deposits have been observed on other excavations along the slope from the High Street to the Cowgate. Given the glacial origins of these slopes, such deposits are unlikely to represent undisturbed natural deposits (Stephen Lancaster, pers comm). The results of the St Patrick's Church excavations should encourage closer examination of such deposits. Here flooding is likely to have removed prehistoric surfaces but elsewhere, as recently seen in the Grassmarket, these have survived along with cut features (Simon Stronach, pers comm).

The use of extensive environmental and finds sampling techniques has produced a broad picture of occupation in this part of Edinburgh during the later medieval period. Although there were no surviving structures, the finds from the ditch show how a collection of finds and ecofacts can produce a rich portrait when taken as a whole. The lack of medieval deposits on the top of the High Street ridge may have previously caused Edinburgh to be written off in terms of medieval research. However, the potential of the Cowgate and deposits at the base of the slope are just beginning to be tapped. 


\section{ACKNOWLEDGEMENTS}

The Archdiocese of St Andrews and Edinburgh funded the project and this publication. The fieldwork was undertaken by Roz Gillis, Sarah Jane Haston, Colin Hewat, Elizabeth Jones, Alison McCondichie, Sophie Nicol, Malgorzata Puklicz, Ben Savine, Tom Small and Dean Williams. Simon Stronach managed the project for Headland Archaeology and provided comments and suggestions on the text. John Lawson monitored the work for CECAS. Thanks to Steve Duffy and staff of Bowmer Kirkland for their assistance during fieldwork. Morag Cross would like to thank the staff of Edinburgh City Archives; Dr Rosalind K Marshall, Edinburgh; Magnar Dalland, Headland Archaeology; Anna Kulwicka, Archdiocese of St Andrews and Edinburgh and the staff of the Scottish Catholic Archives, Edinburgh. Eileen Reilly would like to sincerely thank Dr Scott Timpany, Headland Archaeology Ltd; Dr Emma Tetlow, Edinburgh University and Lorna O'Donnell, Margaret Gowen \& Co Ltd. 


\section{REFERENCES}

Allan, J \& Morris, C A 1984 'The wood' in Medieval and post-medieval finds from Exeter 1971-1980, 305-15. Exeter [= Exeter Archaeology Report $3]$.

Allen, A M 2006 'Occupational mapping of 1635 Edinburgh: an introduction', Proc Soc Antiq Scot 136 (2006), 259-96.

Allen, S J Medieval Coopered Vessels. Finds Research Group 700-1700, Datasheet 19.

Anderson, R 1989 'Haughey's Fort: Analysis of an insect death assemblage', Emania 6,37-42.

Armitage, P 1982 'A system for ageing and sexing the horn cores of cattle from British post-medieval sites (17th to early 18th century) with special reference to unimproved British Longhorn cattle' in B Wilson; C Grigson \& S Payne (eds) Ageing and Sexing Animal Bones from Archaeological Sites, 37-54. Oxford [= British Archaeological Reports 109].

Armitage, P L 1990 'Post-Medieval cattle horn cores from the Greyfriars site, Chichester, West Sussex, England', Circaea 7 (2), 81-90.

Armitage, P L \& Clutton-Brock, J 1976 'A system for classification and description of the horn cores of cattle from archaeological sites', Journal of Archaeological Science Vol. 3, 329-48.

Barber, K E 1976 'History of vegetation', in S B Chapman (ed) Methods in plant ecology, Oxford, 5-83.

Barrott, H N 2000 An Atlas of Old Edinburgh. Edinburgh.

Behre, K-E 1981 'The interpretation of anthropogenic indicators in pollen diagrams', Pollen et Spores 23, 225-45.

Benecke, N 1988 Archäozoologische Untersuchungen an Tierknochen aus der frühmittelalterlichen Siedlung von Menzlin. Berlin [= Materialhefte zur Ur- und Frühgeschichte Meklenburgs Band $3]$.

Bennett, K D; Whittington, G \& Edwards, K J 1994 'Recent plant nomenclatural changes and pollen morphology in the British Isles', Quat Newsl 73, $1-6$.

Boessneck, J 1969 'Osteological differences between sheep (Ovis aries Linne) and goat (Capra hircus Linne)', in D Brothwell \& E Higgs (eds) Science in Archaeology 2nd edition, London, 331-58.

Bowler, D \& Perry, D 2004 'The medieval and early modern town', in D P Bowler (ed), Perth: The Archaeology and Development of a Scottish Burgh. Perth, 21-34.

Brown, D H 2002 Pottery in Medieval Southampton c. 1066-1510. Southampton [= Southampton Archaeology Monographs 8, CBA Research Report 133].
Buckland, P C 1980 'Insect remains from the well' in I M Stead Rudston Villa. Leeds, 162-7.

Buckland, P C 1996 'Insects', in J May Dragonby, Report on Excavations at an Iron Age and Romano-British Settlement in North Lincolnshire, 165-70. Oxford [= Oxbow Monograph 61].

Buckland, P I \& Buckland, P C 2006 Bugs Coleopteran Ecology Package Website (Versions: BugsCEP v7.61; Bugsdata v7.09; BugsMCR v2.0; BugStats v1.2) [= www.bugscep.com. Download/ CDRom accessed 06/2007].

Buczacki, S 2002 Fauna Britannica. London.

Bullock, J A 1993 'Host plants of British beetles: A list of recorded associations', Amateur Entomologist 11a, 1-24.

Bullock, P; Federoff, N; Jongerius, A; Stoops, G \& Tursina, T 1985 Handbook for Soil Thin Section Description. Wolverhampton.

Caldwell, D H 1991 'Tantallon Castle, East Lothian: a catalogue of the finds', Proc Soc Antiq Scot 121 (1991), 335-57.

Caldwell, D 1996a 'Other Small Finds', in J H Lewis 'Dunstaffnage Castle, Argyll \& Bute: excavations in the north tower and east range, 1987-94', Proc Soc Antiq Scot 126 (1996), 579-87.

Caldwell, D 1996b 'Small Finds' in J H Lewis 'Excavations at St Andrews, Castlecliffe 1988-90', Proc Soc Antiq Scot 126 (1996), 635-45.

Caldwell, D H \& Dean, V E 1992 'The pottery industry at Throsk, Stirlingshire, in the 17th and early 18th century', Post Medi Archaeol 26 (1992), 1-46.

Caple, C 1983 'Pins and wires' in P Mayes \& L A S Butler Sandal Castle Excavations 1964-1973. Leeds, 269-78.

Cappers, R T J;Bekker, R M \& Jans, J E A2006 Digital seed atlas of the Netherlands. Groningen.

Carter, S 2001 'A reassessment of the origin of the St Andrews "garden soil", Tayside Fife Archaeol J, 7 (2001), 87-92.

Carter, S; Dennison, E P \& Tipping, R 2008 'Edinburgh before the Burgh: the pre-medieval evolution of the Parliament Site to $c$ 1128' in Holyrood Archaeology Project Team Scotland's Parliament Site and the Canongate: Archaeology and History. Edinburgh, 9-16.

CECAS 1990 Edinburgh, St Patrick's Church, Cowgate: Trial Excavation: Summary of Results. CECAS unpublished report.

Cerón-Carrasco, R 2010 'Fish remains', in Holyrood Archaeology Project Team Artefactual, Environmental and Archaeological Evidence from the Holyrood Parliament Site Excavations, 2.4, Edinburgh [=Scottish Archaeological Internet Report 40, http://www.sair.org.uk/sair40/]. 
Clapham A R; Tutin, T G \& Warburg, E F 1962 Flora of the British Isles. Cambridge.

Clark, John 1995 'Horseshoes', in J Clark (ed) Medieval finds from excavations in London, 5: The Medieval Horse and its Equipment. London, 75-123.

Clark, J 2004 (ed) Medieval finds from excavations in London, 5: The Medieval Horse and its Equipment. London.

Clarke, P V \& Hurst J G 1976 'German stoneware' \& 'Dating' in J Schofield 'Excavations south of Edinburgh High Street, 1973-4', Proc Soc Antiq Scot 107 (1975-6), 206-11.

Clutton-Brock, J 1976 'The animal resources', in D M Wilson The Archaeology of Anglo-Saxon England. Cambridge, 373-92.

Coleman, R 2004 'The archaeology of burgage plots in Scottish medieval towns: a review', Proc Soc Antiq Scot 134 (2004), 281-323.

Collard, M 1992 '50-56 Blackfriars Street, Edinburgh (City parish of Edinburgh): evaluation: medieval midden, structures, artefacts?', Discovery and Excavation Scotland, 1992, 53.

Collard, M; Lawson, J A \& Holmes, N 2006 Archaeological excavations in St Giles' Cathedral, Edinburgh, 1981-93. Edinburgh [= Scottish Archaeological Internet Report 22 http://www. sair.org.uk accessed 05/2008].

Connor, R D \& Simpson, A D C 2004, Weights and Measures in Scotland: A European Perspective. East Lothian.

Coope, G R \& Osborne, P J 1968 Report on the Coleopterous Fauna of the Roman Well at Barnsley Park, Gloucestershire, Transactions of the Bristol and Gloucestershire Archaeological Society 86, 84-87.

Coull, J R 1996 The Sea Fisheries of Scotland. A Historical Geography. Edinburgh.

Courty, MA; Goldberg, P \& Macphail, R 1989 Soils and micromorphology in archaeology. Cambridge.

Cowgill, J; de Neergaard, M \& Griffiths, N 1987 Medieval finds from excavations in London, 1: Knives and Scabbards. London.

Cox, A 1996 'Backland activities in Medieval Perth: excavations at Meal Vennel and Scott Street', Proc Soc Antiq Scot 126 (1996), 733-821.

Crone, B A \& Watson, F 2002 Chapter 3, Sufficiency to scarcity: medieval Scotland, 500-1600', in T C Smout (ed) People and woods in Scotland. A History. Edinburgh, 60-81.

Cross, M 2008 Historical Report on St Patrick's Church, Cowgate. Archive report for Headland Archaeology.

Dalland, M 2004 'Archaeological Excavation at 144-166 Cowgate, Edinburgh: Data Structure Report'. Headland Archaeology unpublished report.

Dalland, M 2005 Bishop's Residence, Lochwood, Glasgow: Evaluation Data Structure Report. Headland Archaeology unpublished report.

Dalland, M forthcoming Excavations at 144-166 Cowgate. Edinburgh [= Scottish Archaeological Internet Report http://www.sair.org.uk/].
Dark, P 2004 'New evidence for the antiquity of the intestinal parasite Trichuris (whipworm) in Europe', Antiquity 78, 676-81.

Davidson, J \& Gray, A 1909 The Scottish Staple at Veere. London.

Davis, S J M 1987 The Archaeology of Animals. New Haven, Yale.

Dennison, E P; Stronach, S \& Coleman, R 2006 Historic Dunbar: Archaeology and Development. Edinburgh [= Scottish Burgh Survey].

Dingwall, H 1995 Physicians, Surgeons and Apothecaries: Medical Practice in Seventeenth-Century Edinburgh. East Linton.

Dingwall, H M 2004 'Nasmyth, John (1556/7-1613)', Oxford Dictionary of National Biography. Oxford [http://www.oxforddnb.com/view/article/19796, accessed 26 Aug 2009].

Dobney, K M; Jaques S D \& Irwing B G 1996 Of Butchers and Breeds. Report on Vertebrate Remains from Various Sites in the City of Lincoln. Lincoln [= Lincoln Archaeological Studies: 5].

Driesch, A von den 1976 A Guide to the Measurement of Animal Bones from Archaeological Sites. Cambridge, Massachusetts.

Driscoll, S \& Yeoman, P A 1997 Excavations within Edinburgh Castle in 1988-91. Edinburgh [= Society of Antiquaries of Scotland Monograph $12]$.

Dumbrell, R 1983 Understanding Antique Wine Bottles. Woodbridge, Suffolk.

Duncan, A A M 1975 The Making of the Kingdom of Scotland. Edinburgh.

Eames, E 1976 'The plain-glazed floor tiles' in J Schofield 'Excavations south of Edinburgh High Street, 1973-4', Proc Soc Antiq Scot 107 (19756), 211-13.

Edin Chrs I = Charters and Other Documents relating to the City of Edinburgh AD1143-1540, 1871, J D Marwick (ed), Edinburgh.

Edgar, W 1742 'The plan of the city and castle of Edinburgh', in H N Barrott 2000 An Atlas of Old Edinburgh, Edinburgh.

Edwards, K J 1981 'The separation of Corylus and Myrica pollen in modern and fossils samples', Pollen et Spores 23, 205-18.

Egan, G 1997 'Medieval Vessels of Other Materials - A Non-Ceramic View from London', Medieval Ceramics 21, 109-14.

Egan, G 1998 Medieval Finds from Excavations in London, 6: The Medieval Household, Daily Living c. 1150-c. 1450. London.

Egan, G \& Pritchard, F 1991 Medieval Finds from Excavations in London 3: Dress Accessories c.1150-c.1450. London.

Egardt, B 1962 Hästslakt och rackarskam: En etnologisk undersökning av folkliga fördomar. Stockholm [= Brumme Nordiska Museets Handlingar 57].

Ellison, M 1981 'The Pottery', in B Harbottle \& M Ellison 'An Excavation in the Castle Ditch, Newcastle upon Tyne, 1974-6', Archaeologia Aeliana 5th Series, Vol IX, 95-164. 
Fægri, K; Kaland,PE \& Krzywinski, K 1989 Textbook of pollen analysis, 4 th edition. Chichester.

Farmer, P G \& Farmer, N C 1982 'The dating of the Scarborough-ware pottery industry', Medieval Ceramics 6, 66-86.

Fisher, R A; Corbet, A S; \& Williams, C B 1943 'The relation between number of species and the number of individuals in a random sample of an animal population', Journal of Animal Ecology $12,42-58$.

Ford, B 1987 'Bone Objects', in P Holdsworth (ed) Excavations in the Medieval Burgh of Perth 1979-1981, 150-51. Edinburgh [= Society of Antiquaries of Scotland Monograph 5].

Franklin, J 2001 'Glass Beads from Stoneypath Tower', Headland Archaeology unpublished report.

Franklin, J 2002a 'Finds', in S Stronach 'The medieval development of South Leith and the creation of Rotten Row', Proc Soc Antiq Scot 132 (2002), 400-08.

Franklin, J 2002b 'Small Finds of Metal, Stone and Bone', in J Lewis \& D Pringle Spynie Palace and the Bishops of Moray: History, Architecture and Archaeology, 113-24. Edinburgh [= Society of Antiquaries of Scotland Monograph 21].

Franklin, J 2010 'Ceramic and Stone Building Material', in Holyrood Archaeology Project Team Artefactual, Environmental and Archaeological Evidence from the Holyrood Parliament Site Excavations, 1.7, Edinburgh [=Scottish Archaeological Internet Report 40, http://www.sair.org. $\mathrm{uk} / \mathrm{sair} 40 /]$.

Franklin, $J$ forthcoming a 'Pottery and Finds Reports', in M Dalland Excavations at 144-166 Cowgate, Edinburgh.

Franklin, J forthcoming b 'Finds Report', Stirling Castle (Excavations 1992-97), Kirkdale Archaeology.

Franklin, J forthcoming c 'Pottery Report', Hamilton Kiln site, SUAT.

Fraser, A 1969 Mary Queen of Scots. London.

Gaimster D 1997 German Stoneware 1200-1900: Archaeology and Cultural History. London.

Geel, B van 1978 'A palaeoecological study of Holocene peat bog sections in Germany and the Netherlands', Rev Palaeobot Palynol 25, 1-120.

Geel, B van 1986 'Application of fungal and algal remains and other microfossils in palynological analyses', in B Berglund (ed) Handbook of Holocene palaeoecology and palaeohydrology. Chichester, 497-505.

Geel, B van 2001 'Non-pollen palynomorphs', in J P Smol; H J B Birks \& W M Last (eds) Tracking environmental change using lake sediments. Volume 3, terrestrial, algal and siliceous indicators. Dordrecht, 99-119.

Geel, B van; Bohncke, S J P \& Dee, H 1981 'A palaeoecological study of an upper late glacial and Holocene sequence from De Borchert, The Netherlands', Rev Palaeobot Palynol 31, 367-448.

Geel, B van; Buurman, J; Brinkkemper, O; Schelvis,
J; Aptroot, A; van Reenen, G \& Hakbijl, T 2003 'Environmental reconstruction of a Roman period settlement site in Uitgeest (The Netherlands), with special reference to coprophilous fungi', J Archaeol Sci 30, 873-84.

Geel, B van; Hallewas, D P \& Pals, J P 1983 'A late Holocene deposit under the Westfriese Zeedijk near Enkuhizen (Prov. of Noord-Holland, the Netherlands)', Rev Palaeobot Palynol 38, 269-335.

Girling, M A 1989 'The insect fauna from the roman well at the Cattlemarket' in A Down Chichester Excavations 6, Chichester, 234-41.

Goodall, I H 1983 'Iron Objects' in P Mayes \& L A S Butler Sandal Castle Excavations 1964-1973. Leeds, 240-52.

Gooder, J 2001 'Holyrood Road, Development Plot $\mathrm{N}$ : medieval/post-medieval cultivation soils', Discovery and Excavation Scotland 2, 2001, 4.

Grant, A 1979 'Bone report' in J Hassal 'St Johns Street', Bedfordshire Arc. Journal 13, 103-7.

Grant, A 1982 'The use of tooth wear as a guide to the age of domestic ungulates', in B Wilson, C Grigson \& S Payne (eds) Ageing and Sexing Animal Bones from Archaeological Sites, 55-71. Oxford [= British Archaeological Reports Series 109].

Grant, J 1880-83 Old and New Edinburgh. Edinburgh (6 vols) [= www.oldandnewedinburgh.co.uk accessed 06/12/2007].

Greig, J R A; Pelling, R; Robinson, M \& Stevens, C 2004 'Environmental evidence', in G Hey Yarnton: Saxon and Medieval Settlement and Landscape. Results of Excavations 1995-96, 351-410. Oxford [=Thames Valley Landscapes $20]$.

Grew, F \& de Neergaard, M 1988 Medieval Finds from Excavations in London 2: Shoes and Pattens. London.

Grimm, E C 2004 TGView Version 2.0.2. Springfield, Illinois.

Haggarty, G 2006 A Gazetteer and Summary of French Pottery in Scotland c. 1150-c. 1650. Edinburgh.

Hall, A R \& Kenward, H K 1998 'Disentangling dung: pathways to stable manure', Environmental Archaeology 1, 123-6.

Hall, A R; Kenward, H K \& Carrott, J 2004 Technical Report: Plant and Invertebrate Remains from Medieval Deposits at Various Sites in Aberdeen Part 1 and 2. York [= Report for the Centre for Human Palaeoecology 2004/06].

Hall, D 2006 'The ceramic building material', in Collard et al Archaeological excavations in St Giles' Cathedral, Edinburgh, 1981-93, 51. Edinburgh [= Scottish Archaeological Internet Report 22, http://www.sair.org.uk accessed 01/05/2008].

Hall, D W 2010 'Pottery', in Holyrood Archaeology Project Team Artefactual, Environmental and Archaeological Evidence from the Holyrood Parliament Site Excavations, 1.7, Edinburgh 
[=Scottish Archaeological Internet Report 40, http://www.sair.org.uk/sair40/].

Hall, D W \& Haggarty, G 2006 'The Pottery', in Collard et al Archaeological excavations in St Giles' Cathedral, Edinburgh, 1981-93, 46-51. Edinburgh [= Scottish Archaeological Internet Report 22 http://www.sair.org.uk accessed 01/05/2008].

Hall, D W \& Hunter, D 2001 'The Rescue Excavations of some Medieval Redware Pottery Kilns at Stenhousemuir, Falkirk in 1954, 1959, 1960, 1961 and 1978' Medi Archaeol 45, 97-168.

Hallen, Y 2001 'Worked Bone', in K L Mitchell; K R Murdoch \& J R Ward Fast Castle: Excavations 1971-86. Edinburgh, 147-52.

Harbottle, B \& Ellison, M 1981 'An Excavation in the Castle Ditch, Newcastle upon Tyne, 19746', Archaeologia Aeliana 5th Series Vol IX, $75-250$.

Harland, J F; Barrett, J H; Carrott, J; Dobney, K \& Jaques, D 2003 The York System: An integrated zooarchaeological database for research and teaching. York [= Internet Archaeology 13 http:// intarch.ac.uk/journal/issue13/harland_index. html (accessed 02/2011)].

Havinga, A J 1985 'A 20-year experimental investigation into the differential corrosion susceptibility of pollen and spores in various soil types', Pollen et Spores 26, 541-58.

Heim, J 1962 'Recherches sur les relations entre la vegetation actuelle et le spectre pollinique recent dans les Ardennes Belges', Bulletin de la Societe Royal de Botanique de Belgique 96, 5-92.

Henderson, D 1986 'The faunal remains' in P J Dixon Excavations in the Fishing Town of Eyemouth 1982-84, 57-63. Edinburgh [= Border Burghs Archaeology Project Monograph Ser 1].

Henderson, D 2001 Final report on the Faunal and Fish Remains from 40-43 Water Street. Headland Archaeology unpublished report.

Henderson, D 2006. 'The faunal remains' in M Collard, J A Lawson \& N Holmes 'Archaeological excavations in St Giles' Cathedral Edinburgh, 1981-93'. SAIR 22, 63-65.

Hill, P 1997 Whithorn and St Ninian: the Excavation of a Monastic Town, 1984-91. Stroud.

Hodgson, G W I 1983 'The animal remains from medieval sites within three burghs on the eastern Scottish seaboard' in B Proudfoot (ed), Site, environment and economy, 3-32. Oxford [= BAR International Series 173].

Holdsworth, P (ed) 1987 Excavations in the Medieval Burgh of Perth 1979-1981. Edinburgh [= Society of Antiquaries of Scotland Monograph 5].

Holmes, N M McQ 1980 'Excavations at St Mary's Street, Edinburgh, 1974', Post-Medi Archaeol 14, 157-84.

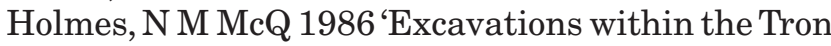
Kirk, Edinburgh: A post-script', Post-Medieval Archaeology 20, 297-302.

Holmes, N \& Schofield, J 1976 'Small finds', in J Schofield 'Excavations south of Edinburgh High
Street, 1973-4', Proc Soc Antiq Scot 107 (19756), 216-17.

Hurst, J G; Neal, D S \& van Beuningen, H J E 1986 Pottery Produced and Traded in North-west Europe 1350-1650. Rotterdam [= Rotterdam Papers V].

Innes, J B; Blackford, J J 2003 'The ecology of Late Mesolithic woodland disturbances: model testing with fungal spore assemblage data', J Archaeol Sci 30, 185-94.

Janssen, H L 1983 'Later medieval pottery production in the Netherlands', in P Davey \& R Hodges (eds) Ceramics and Trade. Sheffield, 121-86.

Jessop, L 1986 'Coleoptera: Scarabaeidae', Handbooks for the Identification of British Insects. London, 5, 11.

Jones, A K G 1985 'Trichurid ova in archaeological deposits: their values as indicators of ancient faeces', in N R J Fieller; D D Gilbertson \& N G A Ralph (eds) Palaeobiological Investigations: Research Design, Methods and Interpretation, 105-119. Oxford [= BAR International Series $266]$.

Jones, E 2007 'St Patrick's Church, Cowgate, Edinburgh: Results of Archaeological Excavation'. Headland Archaeology unpublished report.

Jones, R; Will, R; Haggarty, G \& Hall, D 2002/3 'Sourcing Scottish White Gritty Ware', Medieval Ceramics 26/7 (2002/3), 45-84.

Kenward, H K 1978 'The analysis of archaeological insect assemblages: a new approach' in $\mathrm{P} \mathrm{V}$ Addyman The Archaeology of York, Volume 19: Principles and Methods. London, 1-61.

Kenward, H K 1980 'A tested set of techniques for the extraction of plant and animal macrofossils from waterlogged archaeological deposits', Science and Archaeology 22, 3-15.

Kenward, H K 2001 Insect remains from the Romano-British ditch terminal at the Flodden Hill Rectilinear Enclosure. York [= Reports from the Environmental Archaeology Unit, 2001/49].

Kenward, H K; Engleman, C; Robertson, A \& Large, F 1986 'Rapid scanning of urban archaeological deposits for insect remains', Circaea 3, 163-72.

Kenward, H K \& Hall, A R 1995 Biological Evidence from Anglo-Scandinavian Deposits at 16-22 Coppergate. London [= The Archaeology of York 14/7].

Kenward, H K \& Hall, A R 2001 'Plants, intestinal parasites and insects', in A S Cameron \& J A Stones (eds) Aberdeen: an in-depth view of the city's past, 280-97. Edinburgh [= Society of Antiquaries of Scotland Monograph Series 19].

Kiesewalter, L 1888 Skelettmessungen am Pferde. Inaugural.dissertation, Leipzig.

Kilby, K 1971 The cooper and his trade. London.

Kilmurry, K 1980 The Pottery Industry of Stamford, Lincolnshire, c. $A D$ 850-1250. Oxford [= British Archaeological Reports Series 84].

Koch, K1989-1992 Die Käfer Mitteleuropas. Ökologie 1-3. Krefeld. 
Lawson, G 1995 Pig Metapodial 'Toggles' and Buzzdiscs - Traditional Musical Instruments. Finds Research Group 700-1700, Datasheet 18.

Lillehammer, A 1990 'Boards, beams and barrelhoops: contacts between Scotland and the Stavanger area in the 17th century', in G G Simpson (ed) Scotland and Scandinavia 800 1800. Aberdeen, 100-6.

Lindroth, C H 1974 'Coleoptera: Carabidae', Handbook for the Identification of British Insects IV, 2. London.

Lindroth, C H 1985 'The Carabidae (Coleoptera) of Fennoscandia and Denmark', Fauna Entomologica Scandinavica 15, 1, 1-232.

Lindroth, C H 1986 The Carabidae Coleoptera of Fennoscandia and Denmark. Fauna Entomol. Scand. 15, 2, 233-497.

Lucht, W H 1987 Die Käfer Mitteleuropas, Katalog. Krefeld

Luff, M L 1998 Provisional atlas of the ground beetles (Coleoptera, Carabidae) of Britain. Abbots Rippon.

Lythe, S G E 1960 The economy of Scotland in its European setting 1550-1625. Edinburgh.

MacAskill, N L 1985 'Pottery' in N M McQ Holmes 1985 'Excavations south of Bernard Street, Leith, 1980', Proc Soc Antiq Scot 115 (1985), 413-18.

MacAskill, N L 1987 'Pottery' in P Holdsworth (ed) Excavations in the Medieval Burgh of Perth 1979-1981. Edinburgh [= Society of Antiquaries of Scotland Monograph 5], 89-120.

Macdonald, A D S \& Laing, L R 1975 'Excavations at Lochmaben Castle, Dumfriesshire', Proc Soc Antiq Scot 106 (1975), 124-57.

MacGregor, A 1985 Bone Antler Ivory \& Horn: the technology of skeletal materials since the Roman period. London.

Macguire, D 1983 'The identification of agricultural activity using pollen analysis', in M Jones (ed) Integrating the subsistence economy, 5-18. Oxford [= BAR International Series 181].

MacRae, E J 1929 'Details from Old Edinburgh 1, Elphinstone House', Roy Incorp Architects Scotl Quarterly Illus 29 (Spring 1929), 12-15.

Makey, W 1988 Edinburgh in Mid-Seventeenth Century. Edinburgh.

Malcolm, D C A 1937 Medieval Edinburgh, Rhind Lectures in Archaeology 1937. Edinburgh Library.

Margeson, S 1993 Norwich Households: The Medieval and Post-medieval Finds from Norwich Survey Excavations 1971-1978. Norwich [= East Anglian Archaeology Report 58].

Marwick, J D (ed) 1871 Extracts from the records of the burgh of Edinburgh, Vol II, 1528-1557. Edinburgh.

Marwick, J D (ed) 1882 Extracts from the Records of the Burgh of Edinburgh, Vol IV, 1573-89. Edinburgh.

Mayes, P \& Butler, L A S 1983 Sandal Castle Excavations 1964-1973. Leeds.
McCune, B \& Grace, J B 2002 Analysis of Ecological Communities. Oregon.

Miller, P 1887 'Was the town of Edinburgh an open and defenceless one previous to 1450 ?' Proc Soc Antiq Scot 21 (1886-87), 251-60.

Moore, P D, Webb, J A \& Collinson, M E 1991 Pollen analysis 2nd edition. London.

Morris, C A 2000 Craft, Industry and Everyday Life. Wood and Woodworking in Anglo-Scandinavian and Medieval York. York [= The Archaeology of York Vol 17].

Morris, M G 1997 'Broad-nosed weevils (Coleoptera): Curculionidae (Entiminae)', Handbooks for the Identification of British Insects, 5, 17a, London.

Murphy, C P 1986 Thin Section Preparation of Soils and Sediments. Berkhamsted.

Murray, D 1924 Early Burgh Organisation in Scotland as illustrated in the History of Glasgow, Vol. I. Glasgow.

Murray, H J R 1951 A History of Board Games Other Than Chess. Oxford.

Murray, H K \& Murray, J C 1993 'Excavations at Rattray, Aberdeenshire - A Scottish Deserted Burgh', Medi Archaeol 37, 175-88.

Nakagawa, T; Brugiapaglia, E; Digerfeldt, G; Reille, M; de Beaulieu, J-L \& Yasuda, Y 1998 'Dense-media separation as a more efficient pollen extraction method for use with organic sediment/deposit samples: comparison with the conventional method', Boreas 27, 15-24.

Nicholson, A 1997a 'The Lead' in P Hill Whithorn and St Ninian: the Excavation of a Monastic Town, 1984-91. Stroud, 389-97.

Nicholson, A 1997b 'The Bone and Horn Artefacts' in P Hill Whithorn and St Ninian: the Excavation of a Monastic Town, 1984-91. Stroud, 495-9.

Norton, C 1994 'Medieval floor tiles in Scotland', in J Higgit (ed) 'Medieval Art and Architecture in the Diocese of St Andrews', Brit Archaeol Assoc Conf Trans 1986, $137-73$.

O'Connor, T P 2003 The analysis of urban animal bone assemblages: a handbook for archaeologists. York [= The Archaeology of York 19/2].

Osborne, P J 1979 'The insect remains', in C Smith (ed) Fisherwick: The Reconstruction of an Iron Age Landscape, 85-7 \& 189-93. Oxford [= British Archaeological Reports Series 61].

Payne, B 1965 History of Costume: from the Ancient Egyptians to the Twentieth Century. New York.

Pearson, E \& Robinson, M 1995 'Environmental evidence from the villa', in $\mathrm{R} \mathrm{J}$ Williams \& $\mathrm{R} \mathrm{J}$ Zeepvat Bancroft: The Late Bronze Age and Iron Age Settlements and Roman Temple-Mausoleum. The Roman Villa 2: Finds and Environmental Evidence, 565-84. Buckingham [= Buckingham Archaeological Society Monograph 7].

Pike, A W \& Biddle, M 1966 'Parasite eggs in medieval Winchester', Antiquity 40, 293-6.

Ponel, P 1995 'Rissian, Eemian and Wurmian Coleoptera assemblages from La Grande Pile (Vosges, France)', Palaeogeography, Palaeoclimatology, Palaeoecology 114, 1-41. 
Prilloff, R-J 2000 Tierknochen aus dem mittelalterlichen Konstanz. Eine archäeozoologische Studie zur Ernährungswirtschaft und zum Hantwerk in Hoch- und Spätmittelalter. Stuttgart [= Materialhefte zur Archäeologie in Baden-Württemberg Heft 50].

Prot Bk Foular I = Protocol Book of John Foular 1500-03, Wood, M (ed) 1930, Edinburgh.

Prot Bk Foular I (contd) = Protocol Book of John Foular 1503-13, Wood, M (ed) 1941, Edinburgh.

Prot Bk Foular III = Protocol Book of John Foular 1513-28, Wood, M (ed) 1953, Edinburgh.

Prot Bk Foular IV = Protocol Book of John Foular 1528-34, Durkan, J (ed) 1985, Edinburgh.

Rackham, D J 2004 'Physical remains of medieval horses' in J Clark (ed) 'The medieval horse and its equipment c. 1150-c. 1450', Medieval finds from excavations in London: 5, London, 19-22.

RCAHMS 1951 Edinburgh Inventory. Edinburgh [RCAHMS XI].

Rees, T \& Martin, J 2000 St Patrick's Church, Cowgate: Archaeological Monitoring. AOC Archaeology Group unpublished report.

Reilly, E 2003 'The contribution of insect remains to an understanding of the environment of Vikingage and medieval Dublin', in S Duffy, Medieval Dublin IV, Dublin, 40-63.

Reilly, E 2008a "Fair and Foul": Analysis of sub-fossil insect remains from Troitsky XI-XIII, Medieval Novgorod', in M Brisbane et al, The Archaeology of Medieval Novgorod in its Wider Context: A Study of Centre / Periphery Relations. Oxford.

Reilly E 2008b 'A study of the Bronze Age insect fauna' in $\mathrm{M}$ Doody The Ballyhoura Hills Project, 443-456. Dublin [Discovery Programme Monograph Volume 7].

Reitz, E J \& Wing, E S 1999 Zooarchaeology. Cambridge $[=$ Cambridge manuals in archaeology].

RMS II = Register of the Great Seal Vol II, 1424-1513.

RMS V = Register of the Great Seal Vol V, 1580-93.

Robertson, D \& Wood, M 1928 Chapters in the History of the Royal Burgh of Edinburgh. Edinburgh.

Robinson, M A 1975 'The environment of the Roman defences at Alchester and its implications', Oxoniensia 40, 161-70.

Robinson, M A1981 'Roman waterlogged plant and invertebrate evidence', in J Hinchcliffe $\& \mathrm{R}$ Thomas 'Archaeological investigations at Appleford', Oxoniensia, 45,90-106.

Robinson, M A 1993 'The scientific evidence', in T G Allen \& M A Robinson (eds) The prehistoric landscape and Iron Age enclosed settlement at Mingies Ditch, Hardwich-with-Yelford, Oxon. London, 101-41.

Robinson, M A 2001 'Insects as palaeoenvironmental indicators', in D R Brothwell \& A M Pollard (eds) Handbook of the Archaeological Sciences. Chichester, 121-33.

Robinson, M A 2003 'Palaeoenvironmental studies', in ABarclay; G Lambrick; J Moore \& M Robinson
Lines in the Landscape. Cursus Monuments in the Upper Thames Valley, 163-78. Oxford [= Thames Valley landscapes Monograph 15].

Rodwell, J S 2000 British Plant Communities Volume 5: Maritime communities and vegetation of open habitats. Cambridge.

Roper, T \& Whitehouse, N 1997 'Beetle remains', in M Parker Pearson \& $\mathrm{R}$ E Sydes 'Iron Age enclosures and prehistoric landscape of Sutton Common, South Yorkshire', Proceedings of the Prehistoric Society 63, 238-45.

Rouffignac, C de 1991 'Parasite remains', in A Vince (ed) Aspects of Anglo Saxon-Norman London: 2. Finds and Environmental Evidence, 386-8. London [= London and Middlesex Archaeological Society Special Paper 12].

Ryder, M L 1983 Sheep \& Man. London.

Schibler, J 1989 'Tierknochen als Informationsquelle zu Handwerk, Ernährung und Wirtschaftsweise im Mittelalter der Nordwest-schweiz' in J Tauber (ed.) Methoden und Perspektiven der Archäologie des Mittelalters, 145-56. Liestal (Schweiz) [Tagungsberichte zum interdisziplinären Kolloquium vom 27-30. September 1989].

Schofield, J 1976 'Excavations south of Edinburgh High Street 1973-4', Proc Soc Antiq Scot 107 (1975-76), 155-241.

Silver, I 1969 'The ageing of domestic animals', in D Brothwell \& E Higgs (eds) Science in Archaeology 2nd edition. London, 331-58.

Simpson, T 2001 'The roman well at Piddington, Northamptonshire, England: an Investigation of the Coleopterous Fauna', Environmental Archaeology 6, 91-6.

Smith, C 1997 'Animal bone' in C Moloney \& R Coleman 'The development of a medieval street frontage: the evidence from excavations at 80 86 High Street, Perth', Proc Soc Antiq Scot 127 (1997), 767-73

Smith, C 1998 'Dogs, cats and horses in the Scottish medieval town', Proc Soc Antiq Scot 128, 859-85.

Smith, C 2006 The Animal Bone from 144-166 Cowgate, Edinburgh. Headland Archaeology unpublished report.

Smith, C 2007 The Mammalian, Bird and Molluscan Remains. Headland Archaeology unpublished report (Excavations in advance of the New Scottish Parliament).

Smith, C \& Henderson D 2002 'The animal bone' in P J Dixon; J R Mackenzie; D R Perry \& P Sharman The origins of the settlements at Kelso and Peebles, Scottish Borders, 126-30. Edinburgh [= Scottish Archaeological Internet Report 2, http:// www.sair.org.uk accessed 09/2007].

Smith, C \& McCormick, F 2001 'The mammal bone' in A S Cameron \& J A Stones (eds) Aberdeen: an in-depth view of the city's past, 271-5. Edinburgh [= Society of Antiquaries of Scotland Monograph Series 19].

Smith, K G V 1989 'An introduction to the immature stages of British flies: Diptera larvae, with notes on eggs, puparia and pupae', Handbook for the 
Identification of British Insects, Vol. 10, Part 14. London.

Stace, C 1997 New flora of the British Isles, 2nd edition. Cambridge.

Stevenson, S; Simpson, A \& Holmes, N 1981 Historic Edinburgh, Canongate \& Leith the archaeological implications of development. Edinburgh [= Scottish Burgh Survey].

St Giles' Reg = Registrum Cartarum Ecclesie Sancti Egidii de Edinburgh (Laing, D, ed), 1859, Edinburgh.

Stockmarr, J 1971 'Tablets with spores used in absolute pollen analysis', Pollen et Spores 13, 615-21.

Stronach S 2000 Results of an archaeological evaluation at Old Fishmarket Close, Edinburgh. Headland Archaeology unpublished report.

Stronach, S; Cox, A; Hall, D \& Carter, S 2008 'The Archaeological Evidence from the Parliament Site', in Holyrood Archaeology Project Team Scotland's Parliament Site and the Canongate: Archaeology and History, Edinburgh, 17-58.

Suddaby, I 2002 Lawson Place (138-140 High Street) Dunbar, East Lothian Archaeological Evaluation, unpublished CFA client report no. 694.

Sudell, T L 1990 'The insects from the well', in S Wrathmell \& A Nicholson (eds) Dalton Parlours: Iron Age settlement and Roman villa site, 267271. Wakefield [= Yorkshire Archaeology 3].

Tait, R 2006 'Configuration and dimensions of burgage plots in the burgh of Edinburgh', Proc Soc Antiq Scot 136 (2006), 297-310.

Teichert, M 1975 'Osteometrische Untersuchungen zur Berechnung der Widerristhöhe bei Schafen’, in A T Clason (ed) Archaeolozoological studies, Amsterdam, 51-69.

Tetlow, E A 2006a The insect remains from a Romano-British Well, Wheatpieces, Tewkesbury. Birmingham Archaeo-Environmental Report No. OA-02-06.

Tetlow, E A 2006b The insect remains from Heathrow Terminal 5. Birmingham Archaeo-environmental Report No. OA-14-06.

Thomas, C 1981'Leatherwork' in G L Good \& C $J$ Tabraham 'Excavations at Threave Castle, Galloway 1974-78', Medieval Archaeol 25, 123-6.

Thomas, C, 2001 'The Leather' in A S Cameron \& J A Stones Aberdeen: an in-depth view of the city's past, 241-58. Edinburgh [= Society of Antiquaries of Scotland Monograph 19].

Thomas, C, forthcoming 'The Leather from Perth High Street 1975-77'.

Thoms, L M 1982 'Trial Excavations at St Ann's Lane, Perth, Proc Soc Antiq Scot 112 (1982), 437-54.

Timpany, S 2007 St Patrick's Church, Cowgate, Edinburgh: Environmental samples report. Headland Archaeology unpublished report.

Torrie, E P D 1990 Medieval Dundee: A Town and its People. Dundee.

Turnbull, J 2001 The Scottish Glass Industry 1610 1750 'To serve the whole nation with glass'.
Edinburgh [= Society of Antiquaries of Scotland Monograph Series 18].

Tyers, I 1999 Dendro for Windows Program Guide, $2^{\text {nd }}$ edition, ARCUS Rep, 500.

Vretemark, M 1997 Från ben till boskap. Kosthåll och djurhållning med utgångspunkt $i$ medeltida benmaterial från Skara. Del 1. Skara, Sweden [= Skrifter från Länsmuseet Skara 25].

Watkins, J G 1987 'The Pottery', in P Armstrong \& B Ayers Excavations in High Street and Blackfriargate, Hull [=East Riding Archaeologist Vol.8, Hull Old Town Report Series No.5] 53-181.

Whitehouse, N J 2007 'The study of fossil insect remains in environmental and archaeological investigations: an Irish perspective', in $\mathrm{E}$ Murphy \& N J Whitehouse Environmental Archaeology in Ireland. Oxford, 136-63.

Wigh, B 2001 Animal Husbandry in the Viking Age Town of Birka and its Hinterland. Excavations in the Black Earth 1990-95. Stockholm [= Birka Studies 7].

Will, R S 1997 'The Medieval Pottery', in Driscoll \& Yeoman, Excavations within Edinburgh Castle in 1988-91, Edinburgh [= Society of Antiquaries of Scotland Monograph 12], 140-6.

Will, R \& Radley, A 2005 'Blackfriars Street (City parish of Edinburgh), medieval urban', Discovery and Excavation Scotland, 6, 2005, 62.

Will, R \& Radley, A 2006 Excavations at Blackfriars Street, Edinburgh: Data Structure Report. GUARD unpublished client report, Project 1942.

Wilson, B \& Edwards, P 1993 'Butchery of horse and dog at Witney Palace, Oxfordshire and the knackering and feeding of meat to hounds during the post-medieval period' Post-Medieval Archaeology 27, 43-56.

Wilson, D 1891 Memorials of Edinburgh in the Olden Time. Edinburgh (2 vols).

\subsection{Maps}

1647. Gordon, J (Rothiemay). Viro Amplissimo . . . Edinodunensis.

1742. Edgar, W. City and Castle of Edinburgh.

1849. Ordnance Survey. Edinburgh and its Environs, Sheet 36, 1:1056 ( $1^{\text {st }}$ edition).

1854. Ordnance Survey. Edinburgh and its Environs Sheet 36, 1:1056 (surveyed 1853).

1881. Ordnance Survey. Edinburgh and its Environs Sheet 36, 1:1056 (surveyed 1876).

1895. Ordnance Survey. Edinburgh (New Series) Sheet III.8.16, 1:500 (surveyed 1894).

\subsection{Archives}

8.2.1 $\mathrm{AA}=$ Archdiocesan Archives, Archdiocese of St Andrews and Edinburgh.

M46/1 Extract of sasine in favour of Barbara, 
Isobella and Mariota Ainslie, daughters of Andrew Ainslie, 10 May 1643.

M46/10 Disposition and assignation of house by $\mathrm{Mr}$ Andrew Wilkie to the Earl of Hyndford, 1720.

M46/16 Disposition by Earl of March to Dr John Rutherford, of a house in Hyndford's Close, 20 June 1758 (sale by public roup, 26 Nov 1757).

M46/22 Inventory of the title deeds of house sold by Dr Daniel Rutherford to George Borthwick, 19 Dec 1803.

M49/6 Disposition by United Presbyterian Congregation to Rt Rev J Gillis, of Cowgate Church, 1856 , with inventory.

M49/10 Obligation and Inventory by Scottish Union Insurance Co to Bishop Strain, of deeds against which United Presbyterian Congregation borrowed money, 16 May 1856.

M49/16 Sketch of Cowgate Church Property, Oct 1856.

M49/17 Memorandum on ground to west of church, nd (c1860).

\subsubsection{NMRS = National Monuments Record of Scotland}

NT27SE 539, St Michael's Well, Cowgate, Edinburgh.

NT27SE 65 Edinburgh, Cowgate, Cardinal Beaton's House.

\subsection{3 $\mathrm{NAS}=$ National Archives of Scotland}

CC8/8/27/200-203 Testament and Inventory of John Adamson, younger, 28 Nov 1594.
CC8/8/4/284-6 Testament testamentary and Inventory of Johne Francisco de Busso, 15 May 1576.

CC8/8/64/49-53 Testament testamentary and Inventory of Andrew Ainslie, 25 July 1648.

8.2.4 ECA = Edinburgh City Archives.

HTB 1635 = Housemaills Taxation Book, 1634-6.

Acc 617, No. 3 = Incorporation of Skinners, Catalogue Pt 4, No. 3, Book of Elections of Deacons . . . 1603-1819.

Acc 617 , No. 13 = Incorporation of Skinners and Furriers, Inventory of Writs and Evidents, 1704-14 (unpaginated).

PBK = Protocol Book of Alexander King Vol 5, 155563, transcription bym Wood, 1954.

PBS = Protocol Book of Vincent Strathauchin Vol 1, 1507-1524/5, transcription by M Wood, 1954 .

\subsection{5 $\mathrm{SCA}=$ Scottish Catholic Archives}

DE58/225/11 Letter from Rev W Glancy to Ministry of Works re demolition of water tank, 8 July 1950.

DE58/225/20 Ministry of Works Building Licence to demolish water tank and re-erect railing to Cowgate, 1950.

GD10/47 Business Account Rt Rev Mgr P Morris to Charles George, Cowgate Improvement Scheme and purchase of area included therein, correspondence, 1924-28. 



\title{
Appendix 1 - Finds
}

\author{
by Julie Franklin \\ Headland Archaeology, 13 Jane Street, Edinburgh EH8 9JA \\ with contributions by \\ Anne Crone, ${ }^{2} \mathrm{~N}$ M McQ Holmes ${ }^{3}$ \& Clare Thomas ${ }^{4}$
}

${ }^{2}$ AOC Archaeology Group, Edgefield Road

Industrial Estate, Loanhead, Midlothian, Scotland, EH20 9SY

${ }^{3}$ National Museums of Scotland, Chambers Street, Edinburgh

${ }^{4}$ Perth College, Crieff Road, Perth PH1 2NX 

LIST OF ILLUSTRATIONS $\ldots \ldots \ldots \ldots \ldots \ldots \ldots \ldots \ldots$

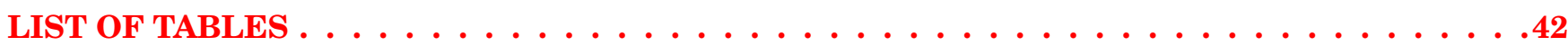

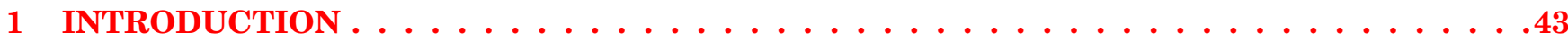

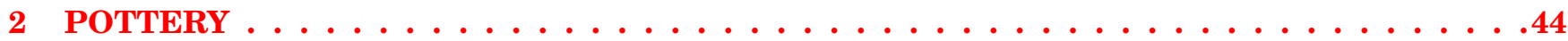

2.1 Scottish White Gritty Ware . . . . . . . . . . . . . . . . . . . . . . . . . . . . . 44

2.2 Scottish Medieval Redwares . . . . . . . . . . . . . . . . . . . . . . . . 44

2.3 Scottish Late Medieval Whiteware . . . . . . . . . . . . . . . . . . . . . . . . . . . . 44

2.4 Scottish Late Medieval-Early Post-Medieval Greywares and Redwares . . . . . . . . . . . . . . 44

2.5 French wares . . . . . . . . . . . . . . . . . . . . . . . . . . . . . . . .44

2.6 Scarborough-Type Ware. . . . . . . . . . . . . . . . . . . . . . . . 45

2.7 Low Countries Grey and Redwares. . . . . . . . . . . . . . . . . . . . . . . . . . . 45

2.8 Rhenish Stoneware . . . . . . . . . . . . . . . . . . . . . . . . 46

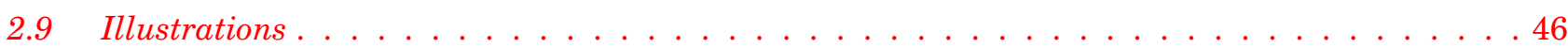

3 COINS, by $N M M c Q$ Holmes $\ldots \ldots \ldots \ldots \ldots \ldots \ldots \ldots \ldots \ldots \ldots$

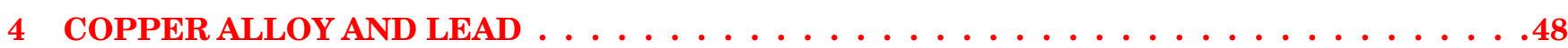

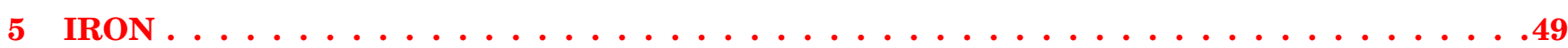

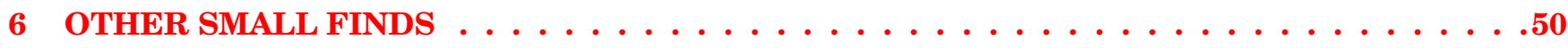

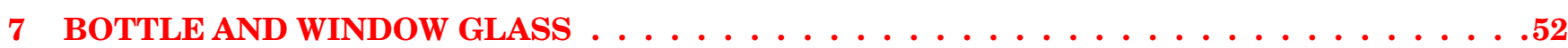

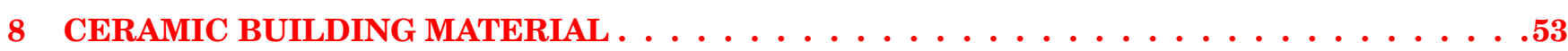

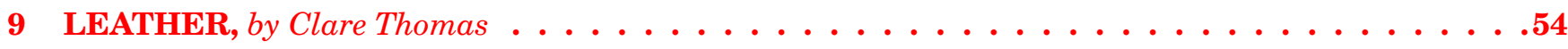

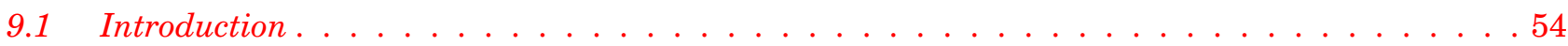

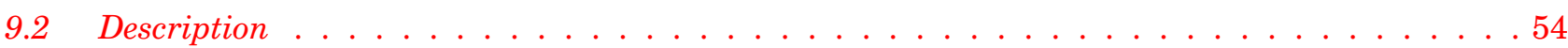

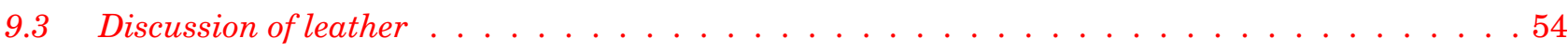

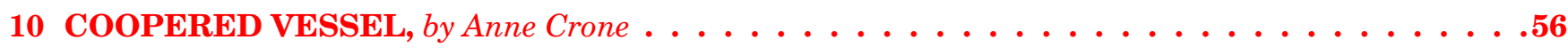

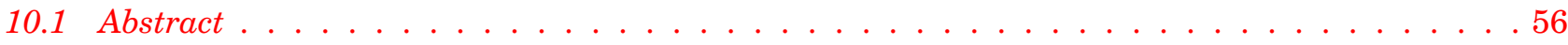

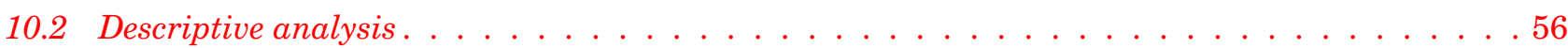

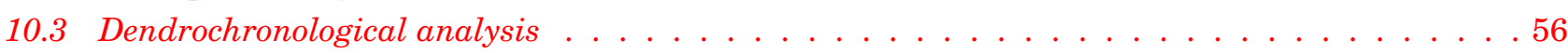

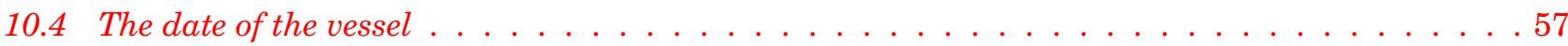




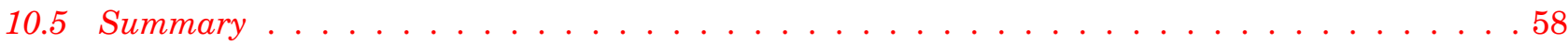

11 DISCUSSION OF FINDS AND POTTERY $\ldots \ldots \ldots \ldots \ldots \ldots \ldots \ldots \ldots$

11.1 Phase 1A: 11th/12th centuries . . . . . . . . . . . . . . . . . . . . . . . 59

11.2 Phase 1B: 13th century . . . . . . . . . . . . . . . . . . . . . . 59

11.3 Phase 1C: 13 th to mid 14th centuries. . . . . . . . . . . . . . . . . . . . . . . . 59

11.4 Phase 2A: first half of 15 th century. . . . . . . . . . . . . . . . . . . . . 59

11.5 Phase $2 B: 15$ th century . . . . . . . . . . . . . . . . . . . . . 59

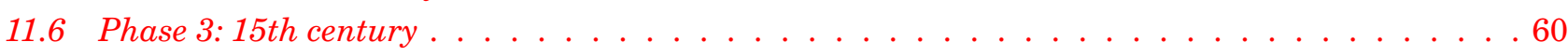

11.7 Phase 4A: 16th to 17 th centuries . . . . . . . . . . . . . . . . . . . . 60

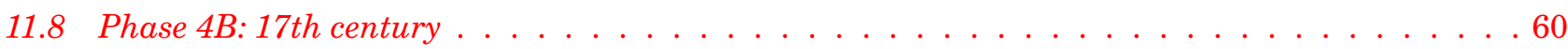

11.9 Phase $5: 18$ th to 20 th centuries . . . . . . . . . . . . . . . . . . . . . . . 60 


\section{LIST OF ILLUSTRATIONS}

1.1 Bar diagram showing the chronological relationships between the dated staves. . . . . . . 57 


\section{LIST OF TABLES}

1.1

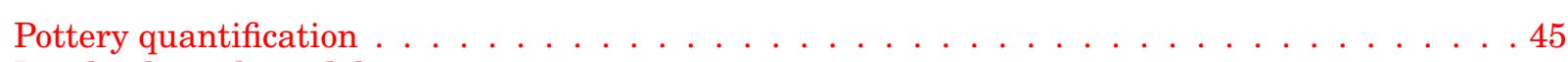

1.2

Dendrochronological data . . . . . . . . . . . . . . . . . . . . . . . . . . . . . . . .

1.3

Statistical comparisons with Scottish import chronologies and regional chronologies.. . . . . . . 57 


\section{INTRODUCTION}

The finds assemblage was almost entirely of medieval date, but for a handful of post-medieval and modern finds. The ditch provided the best of the assemblage. Other finds were from garden soils and were considerably more abraded. Waterlogging led to some good preservation of organic materials and metals, unusual in Edinburgh, including leather footwear, a wooden barrel and a horn comb. The finds from the 1990 CECAS excavations are also included here. Reference is made throughout the report to assemblages from other nearby sites along the Royal Mile, in order, west to east: Edinburgh Castle (Driscoll \& Yeoman 1997); St Giles Cathedral (Collard et al 2006); Cowgate/Old Fishmarket Close, directly East of the Close (Dalland forthcoming); 'Edinburgh High St', between Niddry St \& Blackfriars St (Schofield 1976); Scottish Parliament Site (Stronach et al 2008). The nearest neighbouring site, St Mary's St (Holmes 1980), has no comparable finds, as the assemblage dates almost entirely to the 17 th century and later, with only small quantities of re-deposited medieval pottery. 


\section{POTTERY (ILLUS 7)}

The small sherd size of finds from the soil and midden deposits means there is little evidence of form, and identification of some sherds is hampered. The ditch provides the best evidence, with several large and joining sherds, though there are no nearcomplete pots or profiles.

\subsection{Scottish White Gritty Ware (Illus 7.1)}

This is the typical pottery of SE Scotland from the 12 th to the 15th centuries (Jones et al 2002/3) and is always the most common type found in medieval deposits in Edinburgh. It makes up 79\% of the early deposits pre-dating the ditch. By the time the ditch came to be backfilled the industry would appear to be in sharp decline, in favour of Late Whitewares and Greywares. Though still accounting for 57\% of the assemblage, almost all of these sherds are small and residual and the true proportion of White Gritty Wares still in circulation at this time must have been a great deal lower.

Jugs are more common than cooking pots in the early (Phase 1C) soil, with decoration being most commonly executed by means of applied strip and scales, sometimes in contrasting coloured clay or coloured by addition of iron to the glaze. By the time of the ditch backfill, forms present seem to be the same as those of the Late Whitewares, large, badly formed jugs (as illus 7.1).

\subsection{Scottish Medieval Redwares (Illus 7.2)}

There are generally a small proportion of redwares found in any medieval Edinburgh assemblage. Similar pottery was produced in Perth (MacAskill 1987) and Stirling (Franklin 2010) and the wares may have been brought in from the West, or via Leith. Fabrics are gritty, and vary from pink to red, sometimes covered in a white slip. Both cooking pots and jugs are represented. One handle sherd is unusually decorated with a complex design applied in white clay (illus 7.2).

\subsection{Scottish Late Medieval Whiteware}

This is a late variant of the White Gritty industry, characterised by poorer quality clays and poorer workmanship than the earlier types. The fabric is variable though generally buff, pale grey or pink and characterised by sparse though often coarse tempering and thick walls $(c 10 \mathrm{~mm})$. Forms present are all large jugs. Decoration is rare, but an applied thumbed strip and a ring and dot impressed sherd are present.

It is found in 15th-century deposits in the Edinburgh area and continues into the 16th century, though there is little accurate dating evidence for its range (MacAskill 1985, 416: fabric groups 1 and 2; Franklin 2002a, 403, 'Late Medieval White Gritty Ware'; Franklin forthcoming a).

\subsection{Scottish Late Medieval-Early Post-Medieval Greywares and Redwares}

Greywares, typically in the form of olive-glazed, strap-handled jugs, were widely produced in Scotland from around the 14th century to the early 18th century. Kiln sites are known at Hamilton (Franklin forthcoming c) and Throsk, Stirlingshire (Caldwell \& Dean 1992), but there must have been many more. The coarser fabric and lack of later forms such as handled jars and skillets places this assemblage in the earlier part of the range.

This type already makes up a proportion of the pottery in the Phase $1 \mathrm{C}$ soil. It increases as the Whiteware industry declines and would be the dominant fabric by Phase 3, were it not for the large amounts of residual White Gritty sherds. Decoration includes grooved strap handles, applied strips, applied ring and dot stamped pads, a nose fragment from an applied face mask, and horizontal incised lines. These were typical decorative devices of the 15 th century (see Hall \& Hunter 2001).

\subsection{French wares}

These were two small body sherds, both predating the ditch. The first appears to be of Saintonge Mottled Green Glaze (Brown 2002, 26). Saintonge jugs were produced in the Bordeaux region of France in the 13th and 14th centuries and are associated with the wine trade. Sherds have been found in some numbers in Leith (Haggarty 2006, files 3 \& 42). It was found in an early (Phase 1B) occupation deposit associated with one sherd of local White Gritty from the base of a cooking pot.

The second sherd, though small, shows the distinctive decoration of Rouen-type Ware. It is a fine, sandy pale buff fabric, covered in a red slip and then with decoration applied in white clay. When glazed, this appears yellow on an orange-red ground. The sherd is too small for any details of the design to be visible. Typical forms are jugs with red-slipped 
Table 1.1 Pottery quantification

\begin{tabular}{|c|c|c|c|c|c|c|c|c|}
\hline & $\begin{array}{l}\text { Early } \\
\text { occup }\end{array}$ & Early soil & Ditch fill & $\begin{array}{l}\text { Ditch } \\
\text { re-cut }\end{array}$ & Midden & Post-med & $\begin{array}{l}\text { Unstrat \& } \\
\text { Modern }\end{array}$ & \\
\hline Phase/fabric & $\mathbf{1 A}-\mathbf{B}$ & $1 \mathrm{C}$ & $\mathbf{2 A}$ & 2B & 3 & 4 & 5 & Total \\
\hline Local wares & 20 & 203 & 65 & 118 & 320 & 255 & 105 & 1086 \\
\hline White Gritty & 16 & $\begin{array}{c}164 \\
80 \%\end{array}$ & $\begin{array}{l}41 \\
57 \%\end{array}$ & $\begin{array}{l}71 \\
57 \%\end{array}$ & $\begin{array}{l}251 \\
77 \%\end{array}$ & $\begin{array}{l}153 \\
56 \%\end{array}$ & 56 & 752 \\
\hline Medi Redwares & 4 & 11 & 2 & & 1 & 2 & 3 & 23 \\
\hline $\begin{array}{l}\text { Late Grey \& } \\
\text { Redwares }\end{array}$ & & $\begin{array}{l}27 \\
13 \%\end{array}$ & $\begin{array}{l}15 \\
21 \%\end{array}$ & $\begin{array}{l}23 \\
18 \%\end{array}$ & $\begin{array}{l}56 \\
17 \%\end{array}$ & $\begin{array}{l}73 \\
27 \%\end{array}$ & 33 & 227 \\
\hline Late Whitewares & & 1 & $\begin{array}{c}7 \\
10 \%\end{array}$ & $\begin{array}{l}24 \\
19 \%\end{array}$ & $\begin{array}{l}12 \\
4 \%\end{array}$ & $\begin{array}{l}27 \\
10 \%\end{array}$ & 13 & 84 \\
\hline Imports & $\begin{array}{l}1 \\
5 \%\end{array}$ & $\begin{array}{l}3 \\
1 \%\end{array}$ & $\begin{array}{c}7 \\
10 \%\end{array}$ & $\begin{array}{l}7 \\
6 \%\end{array}$ & $\begin{array}{l}4 \\
1 \%\end{array}$ & $\begin{array}{l}17 \\
6 \%\end{array}$ & $\begin{array}{l}8 \\
7 \%\end{array}$ & 47 \\
\hline Saintonge & 1 & & & & & & & 1 \\
\hline Rouen & & 1 & & & & & & 1 \\
\hline Scarborough & & 1 & 2 & 1 & 1 & 3 & & 8 \\
\hline LC Grey & & 1 & & & & 1 & & 2 \\
\hline LC Red & & & 3 & 5 & 1 & 9 & 6 & 24 \\
\hline Siegburg & & & 1 & & 2 & 2 & & 5 \\
\hline Lang/Raer & & & 1 & 1 & & 1 & 1 & 4 \\
\hline Modern & & & & & & 3 & 4 & 7 \\
\hline Total & 21 & 206 & 72 & 125 & 324 & 274 & 116 & 1138 \\
\hline
\end{tabular}

Numbers $=$ sherd count after joining. Percentages are of total of sherds from that phase. Abbreviations: LC Grey = Low Countries Greyware; LC Red = Low Countries Redware; Lang/Raer = Langerwehe/Raeren Stoneware

panels and applied rouletted white strips. Rouentype Ware has been found in Leith before, though not so far in Edinburgh. All examples so far found in Scotland have been of the 'Standard' fabric, dated in London from the late 12th to first half of the 13 th century, rather than the later 'Developed' type, (Brown 2002, 23-4; Haggarty 2006, File 22 \& 42). It was found in the Phase 1C soil layer, though its size, in common with all the sherds in this context, implies it was re-deposited from earlier occupation deposits, or possibly rolled downhill from the High Street.

\subsection{Scarborough-type Ware}

This is the most commonly imported pottery in 13 th- and early 14th-century deposits in east coast Scotland (Farmer \& Farmer 1982; Ellison 1981, 122). Though some sherds were redeposited in the ditch and the later midden layers, they clearly derive from the early (Phase 1C) soil, in which the earliest sherd was stratified. Decorated sherds include a grooved rod handle, a fragment of applied incised face mask beard and an applied scale in contrasting red clay on a pale pinkish buff body.

\subsection{Low Countries Grey and Redwares (Illus 7.3)}

The earliest stratified and most distinctive of the Greyware sherds was a round-sectioned loop handle from a cooking pot or pipkin from the early (Phase 1C) soil. Though in production earlier and later, these Greywares are commonly found in 13th and 14th century deposits, along the east coast of Britain, particularly in Scotland (Hurst et al 1986, 136; Ellison 1981, 146; Watkins 1987, 146).

Low Countries redwares are the most common type of imported ware present on site, the sherds representing a minimum of six vessels. The earliest sherds are found stratified in the ditch backfill. Redwares are the oxidised version of the Greyware fabric, produced by the same potters, and are common finds along the British east coast. The redwares became increasingly common during the second half of the 14 th century, almost entirely supplanting Greywares during the 15 th century, and they continued to be imported up to the 17th century (Janssen 1983, 134-6; Ellison 1981, 146; Watkins 1987, 141). They have been found at a number of 15th-century sites in Edinburgh and Leith (MacAskill 1985, 416: fabric group 6, fig. 16:75-83; Franklin 2002a, 404, phases 5-7; Franklin forthcoming a). The only iden- 
tifiable form among this assemblage is a skillet, a large sherd forming the complete wall profile (No. $3)$. Two other fragments show traces of slip-trailed decoration.

\subsection{Rhenish Stoneware}

There were a minimum of four vessels of Siegburg stoneware, all of the distinctive pale grey fabric, unglazed but for occasional patches of orange ash glaze. Forms present all seem to be rilled jugs, including an upright rim fragment, and a neck sherd with a small sharp cordon at the shoulder (cf Hurst et al 1986, 178, fig. 88: 263; Gaimster 1997, 163-85). The earliest stratified is one large sherd from the ditch backfill.

The salt-glazed stoneware is more problematic. Very similar pottery was produced in different centres in the Rhineland at different times. The pottery of Langerwehe imported in the 15th century is largely indistinguishable from the pottery of Raeren, which dominated the British market from the 1480 s to the mid 16th century (Gaimster 1997). Often the date of the context is the only way to distinguish these types. The sherds represent a minimum of two vessels. The earliest are a large frilled base sherd and a body sherd, both relatively thick walled, of a dark grey fabric, glazed grey with brown patches. The base was found in the ditch backfill (Phase 2A), the body in the backfill of the ditch re-cut (Phase 2B). The dating of this deposit and the association with Siegburg stoneware, means these sherds are probably from Langerwehe. Other sherds from postmedieval or unstratifed contexts could be from either centre. These include a strap handle sherd from a smaller jug, with a brown speckled salt glaze.

Siegburg and Langerwehe stonewares are regular finds in 15th-century contexts in Edinburgh (Hall \& Haggarty 2006, 47; Will 1997, 140; Hall 2010), most notably at the Edinburgh High Street site, which still remains, at 313 sherds, one of the largest assemblages of Langerwehe stoneware found in Britain (Clarke \& Hurst 1976).

\subsection{Illustrations (Illus 7)}

1. White Gritty jug rim and handle. Greyish white gritty fabric, with buff surfaces. Poorly formed, unusually wide handle. Unglazed. Context [081], ditch fill, Phase $2 \mathrm{~A}$.

2. Redware strap handle. Pink Gritty fabric with pale grey core. Applied decoration in contrasting white clay in curvilinear relief design. Top surface largely abraded away. Appears pale green on orange ground. Context [125], occupation deposit, Phase 1B.

3. Low Countries redware skillet rim profile. Internal glossy red-brown glaze, becoming thinner on upper wall and rim, external sooting. Context [072], ditch fill, Phase 2A. 


\section{COINS by NM McQ Holmes}

Both coins were from the midden overlying the ditch and the post-medieval structures, but were found some distance apart and were not deposited together. The James II penny belongs to a rare type, referred to as James I Group D, although now accepted as belonging to the early part of James II's reign. It is unlikely to have been in circulation past the 1460 s as the early James III pennies were so much smaller and more debased that they probably drove earlier issues out of circulation. The relative lack of wear on the James III farthing suggests deposition in the 1470 s or ' 80 s.
4. Silver Coin

JAMES II billon penny, first coinage (James I Group D), uncertain mint (Edinburgh or Stirling); (1437-51) $16.5 \times 17.5 \mathrm{~mm} ; 0.46 \mathrm{~g}$; die axis uncertain. Chipped; some flattening; fairly worn. SF101, context [003], Spit 1, Test Pit 2, midden layer, Phase 4B (not illus).

5. Copper Coin

JAMES III copper farthing, 'ecclesiastical' type III (c 1470-82). Oxidised, slightly worn. SF102, context [003], Spit 1, Test Pit 13, midden layer, Phase 4B (not illus). 


\section{COPPER ALLOY AND LEAD (ILLUS 8)}

The vessel foot (illus 8.6) is unfortunately from an evaluation trench, and cannot be related to the excavation stratigraphy. Cast vessel sherds are occasionally found in later medieval and early post-medieval excavation contexts in Scotland. They are no doubt under-represented in the archaeological record, compared to pottery vessels, due to their value as scrap metal. Cast vessel sherds are more commonly found at castles than on urban sites (eg MacDonald \& Laing 1975, 145; Caldwell 1996a, 582; Franklin 2002b, 117; Caldwell 1991, 339), and do indicate a certain degree of wealth. A metal-detector survey at the Bishop's Loch, Easterhouse, Glasgow (Dalland 2005), for example, found no fewer than four feet from different vessels. A survey of recent finds from London found a sharp increase in cast copper alloy vessels from the second half of the 14th century (Egan 1997). The most common forms found are ewers, skillets and cauldrons, all of which have tripod feet of various forms. Some are ornate, shaped like animal feet, some, like this example, are plainer (Egan 1998, 161-6).

There are also the remains of two copper alloy lace tags and three wire pins (illus 8.7). These are both common types of find in the late medieval period. The former was to bind the ends of laces to prevent fraying and ease threading and the latter used in sewing and to fix items of costume. Only one is from a good context, a pin fragment from the ditch fill (context [094], Phase 2A). The only complete example is from the buried soil overlying the site, but, as a relatively early type, is probably redeposited. The head is soldered on, a method of fixing only common up to the 15 th century (Caple 1983, 274).

The lead disc (illus 8.8) is featureless, with no clue to its function but for its weight, which approximates an ounce. The lack of suspension holes implies it is a pan weight, for use as part of a set in a balance scale pan. Similar round weights have been found in London (Egan 1998, 311-17). Relatively few have been found on Scottish sites, though there may be examples of such plain discs unrecognised and unpublished. A thick disc from St Andrews was interpreted as a possible weight (Caldwell 1996b, 638, no.30) and the function is suggested for a variety of discoid lead objects from Whithorn (Nicholson 1997a, 392-3).
The weights of these items are not as standardised as might be expected. Medieval systems of weights and measures were extremely complex and could vary from place to place. The Scottish system, though based on the English, evolved separately, influenced by Scotland's major trading partners, the Low Countries and France. The standard merchant ounce in earlier medieval Scotland was 29.14g (Connor \& Simpson 2004, 752). The 'trois' system, identical to the English troy system, appearing in the 1426 Assize, defines an ounce of 31.08g. Each burgh held physical standards of weight units so that weights used in the market place could be checked by officials, and destroyed if found inaccurate (Connor \& Simpson 2004, 750-1).

It is interesting to note therefore that this disc appears to be a little underweight. Though a little dented and bent, there does not appear to be any significant metal missing and no deposits adhering to it, and hence its current weight is probably very close to its original weight. It is $6 \%$ under a merchant ounce, which may have been an acceptable variation, but a full $12 \%$ under a troy ounce. It is tempting to picture an unscrupulous market trader casting it into the ditch when he saw a burgh official approaching.

However, in practice, there is a wide variation in medieval weights, and it would not do to overinterpret this one. Examples of ounce weights from excavations in London (England had similar standards of $28.4 \mathrm{~g}, 29.2 \mathrm{~g}$ and $31.1 \mathrm{~g}$ ounces) weigh in at $26.0 \mathrm{~g}, 26.5 \mathrm{~g}, 27.0 \mathrm{~g}, 28.5 \mathrm{~g}, 29.5 \mathrm{~g}$ and $30.0 \mathrm{~g}$ (Egan $1998,302-4)$.

6. Copper alloy vessel foot

Triangular sectioned rod, flattening out to a small plain flat foot. Heavy leaded bronze? Height $27 \mathrm{~mm}$ ESP90 evaluation find, SF1, context [106], equivalent to Phase 3?

7. Copper alloy wire pin

Head formed from wire, coiled twice around top of shaft and soldered in place. Length 41 , wire thickness $1.0 \mathrm{~mm}$. SF104, context [003], Spit 1, Test Pit 3, midden layer, Phase 4B.

8. Lead weight

Disc, a little bent. Diameter 38, thickness $2 \mathrm{~mm}$, weight $27.4 \mathrm{~g}$ (0.97 imperial oz). SF011, context [080], ditch fill, Phase 2B. 


\section{$5 \quad$ IRON (ILLUS 8)}

As with most medieval iron assemblages, nails made up the majority of the ironwork, 80 nails from a total of 93 iron objects. The largest concentrations come from the two midden layers [003 and 007]. The earliest is from the primary occupation layers [140], with relatively few found in the ditch. In terms of form, they all appear to be large- to medium-sized wood-working nails.

The small iron buckle (illus 8.9) survived due to waterlogging. Too small for a waist belt, it would have fitted a strap of about $12 \mathrm{~mm}$. It is the right size for a spur buckle, though, as these were generally considerably more decorative and robust (Clark 1995, 150-1), it probably had a more humble function.

The horseshoe (illus 8.10) was found in the midden layer overlying the site. It is of a form commonly found in later medieval contexts (Clark 1995, 88,
Type 4), though examples can be found as late as the 17th century (Goodall 1983, 251). The position of the nails suggests this shoe was deliberately removed, but was lost before it could be scrapped.

9. Buckle

Small, simple rectangular buckle frame. Strip pin. Length $12 \mathrm{~mm}$, width $17 \mathrm{~mm}$, to fit strap no wider than $13 \mathrm{~mm}$. SF114, context [086], ditch fill, Phase 2A.

10. Horseshoe

Heel sherd, narrowing to tip. Two square-headed nails partly clawed out but still in place in possibly countersunk holes. No calkin. Length 87, max width 26mm. SF13, context [003], Spit 3, midden layer, Phase 3.

11. Knife blade

Length of blade, missing tip and tang. Length 77, width $18 \mathrm{~mm}$. Context [072], ditch fill, Phase 2A (not illus). 


\section{OTHER SMALL FINDS (ILLUS 8)}

The comb (illus 8.12) was found in an upper ditch fill associated with 14 th and 15 th century pottery. It is of a shape typical of the late medieval and postmedieval periods (MacGregor 1985, 81). The fact that it is made of horn is more unusual. The majority of excavated examples in Scotland are of bone or antler (eg Holmes \& Schofield 1976, 216; Franklin forthcoming a; Hallen 2001, 149) but this is not representational. The majority of late medieval combs were almost certainly of boxwood, as excavations in waterlogged conditions in London have shown (Egan \& Pritchard 1991, 366).

Horn, from cows and sheep, which, unlike bone and antler, can be softened and flattened out into large sheets is ideal for making combs (MacGregor 1985, 95) and, having certain advantages over plastic, is still used for the purpose today. However, like wood, horn is unlikely to survive in most burial conditions compared to the more sturdy bone and antler. The extremely poorly drained conditions in the Cowgate must be thanked for the survival of this horn comb in near perfect condition. Only a handful of horn combs are known from Scotland (Nicholson 1997b, 495, no.1; Ford 1987, 151, no.154, single-sided) and the Cowgate example is by far the earliest stratified and best preserved, though a similarly dated fragment was found in Newcastle (Harbottle \& Ellison 1981, 183, fig.41: 499, early 16th-century context).

The scratched lines in the central area of the comb are rather shallow and irregular and are not particularly effective as decoration. The comb itself is well made in comparison and it could be that the marks were added at a later date, possibly by the owner.

Drilled pig metapodials (illus 8.13) are common finds on medieval and post-medieval sites (eg Cox 1996, 787; Murray \& Murray 1993, 197). Previously interpreted as toggle fastenings or thread bobbins, they are now generally thought of as a kind of child's toy or musical instrument. Threaded onto a string, they can be spun to produce a humming noise. There are recent ethnographic parallels from Scandinavia of these bones being given to children to play with after the eating of pigs' trotters (Lawson 1995; MacGregor 1985, 102). The polish on the sides but not the ends of this example suggests a buzzbone is more likely. The handle scale (illus 8.14) is most likely from a knife. Decoration by means of a row of copper alloy pins is not uncommon on medieval knife handles (Cowgill et al 1987, 95, no.125-6).

Making gaming pieces out of potsherds (18, not illus) was a common practice. It was a readily available and easily worked raw material. They would have been used for games such as merels (eg nine men's morris), tables (early backgammon) or draughts, all of which involve 'men' of two different colours (Murray 1951). This sherd may have been selected for its colour. One side is dark green, the other is off-white, and it could therefore have been used as either a 'black' or a 'white' piece.

The glass bead (illus 8.15) is from the ditch fill associated with medieval pottery. Small glass beads are becoming increasingly common finds since on-site sampling became common practice. Small beads, especially dull-coloured examples, are exceptionally hard to spot during excavation. Medieval glass is also prone to decay in most depositional conditions and thus they are probably much under-represented in the archaeological record. Occasional finds of large numbers of beads hint at how common they might once have been. At St Ann's Lane, Perth, 158 small amber-coloured glass beads were found in a 13th- and 14th-century midden (Thoms 1982, 449), while 171 beads of indeterminate colour came from a probably 16thcentury deposit at Stoneypath Tower, East Lothian (Franklin 2001). The latter were found in close association and were assumed to have adorned a piece of dress fabric. This was a popular way of embellishing fabric in the late medieval period. Though relatively expensive, glass beads were a cheaper alternative to pearls or gemstones (Egan \& Pritchard 1991, 305; Payne 1965, 291). Small glass beads were also used to decorate wirework jewellery (Margeson 1993, 5).

The larger wooden and bone beads (illus 8.16 and 8.17) are more likely from sets of rosary beads (Egan \& Pritchard 1991, 305). The bone bead is from a layer containing finds ranging from the 14th to the 16 th centuries. The wooden bead is from the fill of the barrel and is thus unlikely to be earlier than the 17 th century. The post-Reformation dating of the wooden bead is interesting.

12. Horn comb

Comb, one piece, double-sided, rounded ends, profile uniform thickness, slightly curving. Material gives stripy wood-grain effect with ends buff coloured, central area darker brown. Scored along both sides to mark limit for tooth cutting. Roughly scratched marks: two large crosses with smaller crosses, cross bars and asterisk; on reverse rough lines and crosses. Decoration or to mark ownership? In very good condition, but for few broken teeth. Length 62 , width 58 , thickness $2.5 \mathrm{~mm}$, teeth $5 / 9$ per $10 \mathrm{~mm}$. SF008, context [080], ditch fill, Phase 2B.

13. Bone buzzbone or toggle

Pig metatarsal with hole drilled through centre. Some polish on concave sides of bone. Centre of gravity towards one end, though affected by damage 
at end. Length $66 \mathrm{~mm}$. SF117, context [080], ditch fill, Phase 2B.

14. Bone handle scale

Length of bone, plano-convex in section, broken at one end, widening to a square-cut end at other. Empty rivet hole at intact end. Row of 11 decorative copper alloy pins, which do not penetrate back of scale, inlaid along central axis. Some polish on convex side, suggests it may have been used, rather than broken during manufacture, though lack of rivet or ironstaining on back suggests it was detached before deposition. Length $39+$, max width $11 \mathrm{~mm}$. SF109, context [003], Spit 3, Test Pit 8, midden layer, Phase 3.

15. Glass bead

Ring bead, rounded. Glass appears opaque and dark, original colour indeterminable. Diameter 4, hole diam1, length 2mm. SF115, context [093], ditch fill, Phase 2A.

16. Wooden bead

Rounded bead. Diameter 12 , hole diameter 1, length $6 \mathrm{~mm}$. SF116, context [124, barrel fill], Phase 4A.

17. Bone bead

Ring bead, flat-ended. Some polish on all surfaces. Diameter 10, hole diameter 3, length 4mm. SF111, context [007], Test Pit 16, soil layer, Phase 1C.

18. Ceramic gaming counter

Made from a medieval Greyware pot sherd of 14thor 15th-century date. Olive-glazed on one side, white surface on reverse. Clipped into rounded shape, edges sanded. Diameter 20, thickness $6 \mathrm{~mm}$. SF110, context [003], Spit 3, Test Pit 7, midden layer, Phase 3 (not illus). 


\section{BOTTLE AND WINDOW GLASS}

There are a few small sherds and fragments of window glass. Crystalline fragments were found in the fill of a culvert (context [015], Phase 4A) and the fill of the barrel (context [124], Phase 4A), while a larger sherd $(25 \times 25 \mathrm{~mm})$ was found in the overlying midden layer ([003], Spit 1, TP13, Phase 4B). The sherds are most likely to derive from a church, of which there are several to choose from, as even in the 17 th century glazing was still rare in private residences in Scotland (Turnbull 2001, 52). The sherd has a greenish hue, is badly laminated and features one grozed edge.

There is no early bottle or vessel glass. However, from surface deposits (context [001], Phase 5), there was a fragment of wine bottle neck, datable by its string rim to the later 17th century (Dumbrell 1983). Wine bottles of this early date are relatively unusual finds and it probably derives from an inn or wealthy household. 


\section{CERAMIC BUILDING MATERIAL}

The ceramic building materials amounted to a few fragments of brick, tile, drainpipe and daub. Most are modern and were found in upper layers. A fragment of Netherlandish-type floor tile is of some interest though is essentially unstratified, being from an evaluation context (context [101], equivalent to Phase 5?). It has no top surface, but has a characteristic sandy bottom with a patch of green glaze on its base. These types of tile were imported into east coast Scotland in large quantities between the late 14th and early 16 th centuries (Norton 1994 , 150-153). They are known to have been used in the nearby Trinity College Collegiate Church (founded $c 1460$ on the north side of the Canongate) and similar tiles have been found in 15th-century and later layers at a number of other nearby sites (eg Eames 1976; Franklin 2010, forthcoming a; Hall 2006). 


\section{$9 \quad$ LEATHER by Clare Thomas (ILLUS 7)}

\subsection{Introduction}

The leather consists of the upper of a side-laced boot and three sole fragments, all of turnshoe construction.

\subsection{Description}

19. Sole, upper and stitching channel fragments of sidelaced boot. SF9, context [081], ditch fill, Phase 2A. (a) Large fragment of upper comprises vamp, with vamp throat and vamp wing, and quarters (illus 7.19a). Lace holes on vamp wing (3) and on vertical edge of quarters (7) for side-lacing. Two fragments of thong survive, one in vamp wing, the other in the quarters. Holes are $3 \mathrm{~mm} \times 5 \mathrm{~mm}$, and $12-14 \mathrm{~mm}$ apart. Edge adjacent to lace-holes has possibly been oversewn. There is no indication of stitching for lacehole facings or strengtheners. On inside of quarters, faint traces of tunnel stitching show where a trapezoidal heel-stiffener, which survives separately, was attached.

Lasting margin with grain to flesh-stitching channel, stitch length $6-7 \mathrm{~mm}$; stitch holes are round, not elongated. Lasting margin is missing at front and outer edges of vamp. Edge-flesh stitching channel, stitch length $4-5 \mathrm{~mm}$, on vamp throat and on lower part of vamp wing and of quarters. Top edge of quarters has been cut, and bears no trace of stitching for a binding.

Fragment is worn, torn and partially delaminated.

Approximate height of quarters $160 \mathrm{~mm}$.

Probably goatskin.

(b) Trapezoidal fragment, consisting of front leg flap, fitting above vamp throat and wing, next to higher part of vertical edge of quarters (illus 7.19b). Six laceholes, with fragment of thong threaded through one; spacing and size of holes as on (a).

Edge-flesh stitching channel on bottom edge and on vertical edge without lace-holes; stitch length $4-5 \mathrm{~mm}$. Top edge cut.

Top of flesh side delaminated.

Approximate height $70 \mathrm{~mm}$; width of base $65 \mathrm{~mm}$.

(c) Trapezoidal heel-stiffener with lasting margin matching that of quarters, and with stitch holes for attachment to inside of quarters (illus 7.19c).

Approximate height $75 \mathrm{~mm}$; width of base $105 \mathrm{~mm}$.

(d) Two irregularly shaped fragments with edgeflesh stitching channel, stitch length $5-6 \mathrm{~mm}$; torn and delaminated. Most probably parts of sole of boot. (e) 6 fragments of grain-flesh-stitching channel, stitch length 6-7mm; delaminated. Possibly rand.

(f) Small fragment of upper with lasting margin with grain to flesh stitching channel, stitch length $6 \mathrm{~mm}$.

(g) Small fragment of upper with edge-flesh stitching channel, stitch length 4-5mm.

(h) Small strip, possibly thong; dimensions $45 \times 5 \times$ $1 \mathrm{~mm}$.

(i) 3 small scraps, probably broken-off upper (a).
20. Three sole fragments, one with pointed toe. SF12, context [094], Ditch fill, Phase 2A (not illus).

Three fragments of sole, one ending in sharp point, with edge-flesh stitching channel, stitch length 5$7 \mathrm{~mm}$. No obvious joins, probably parts of forepart and waist. Delaminated and cracked.

\subsection{Discussion of leather}

Both upper and sole fragments are of turnshoe construction, where the shoe is made inside out by sewing the lasting margin of the upper to the edge of a single sole. The shoe is then turned, so that the seam is on the inside. The sole fragments have typical edge-flesh stitching channels, while the upper has a corresponding lasting margin with a grain-flesh stitching channel. Fragments of stitching channel suggest that a rand, or strip of leather, was inserted between sole and upper, to strengthen the seam and make it more waterproof. The upper fragments have been joined to each other with butted edge-flesh seams.

One sole fragment ends in a sharp point. The other sole pieces are too insubstantial for any shape to be determined. The upper is of one-piece wraparound style, with an extra piece inserted above the vamp throat, and with a trapezoidal heel-stiffener sewn into the inside of the quarters. The upper was fastened, probably on the inside of the foot, with a thong threaded through lace-holes on either side of an opening between the vamp wing and leg flap and the vertical edge of the quarters.

Soles ending in points were represented at Perth High Street by Sole Types 4 and 5 . Type 4 soles ranged from mid 12th century to mid 14th century, but were predominantly of 14th-century date. Parallels from elsewhere include Threave Castle, Galloway (late 14th-early 15th centuries) and Aberdeen (12th-13th centuries) (Thomas forthcoming; Thomas 1981, 123-4; Thomas 2001, 243). Type 5 occurred in contexts dating to mid 13th-mid 14th century. Parallels from London are of similar date, early 13th to late 14th century (Thomas forthcoming; Grew \& de Neergaard 1988, 57-60, fig. 90, 98, 100).

Fourteen examples of side-laced boots were found at Perth High Street, where they ranged in date from the second half of the 12 th century to the early 14 th century, but were mainly from mid 13th- to early 14th-century contexts. Other parallels include Aberdeen (14th century) and London (early to mid 14 th century, early to mid 15 th century) (Thomas forthcoming, Type C; Thomas 2001, 248-9; Grew \& de Neergaard 1988, 27, fig. 39-40, 42-43). 
Both sole and upper fragments are worn and torn. This is normal for medieval footwear. Soles, especially turnshoe soles, became worn through quickly. They could be repaired by the addition of clump soles; however, this leather bears no signs of repair. Uppers were less easy to repair; less worn parts were often reused.

This very small assemblage consists of typical 13 th14th-century footwear. To the author's knowledge, this is the first medieval leather found in Edinburgh. 


\section{COOPERED VESSEL by Anne Crone}

\subsection{Abstract}

The coopered vessel may be either a tub or the lower half of a barrel. Dendrochronological analysis of some of the staves has determined that the barrel was fashioned from Scandinavian oak, which had been felled sometime after AD 1567. Allowing for a period of use before the vessel was reused as a well lining, this suggests a terminus post quem of the early 17 th century for the construction of the well.

\subsection{Descriptive analysis}

The vessel consisted of 20 staves of oak (Quercus sp.), bound just above the base by a group of four hoops and by a group of three hoops some $200 \mathrm{~mm}$ further up from the base. It had survived to a height of $0.20-0.30 \mathrm{~m}$, the staves having decayed above that height. The croze groove, into which the base of the vessel would have fitted, was cut some $40 \mathrm{~mm}$ above the base of the staves. It was V-shaped in profile and was $4 \mathrm{~mm}$ wide and $2-3 \mathrm{~mm}$ deep. The thickness of the staves has been reduced by adzing just above the groove to allow the insertion of the base.

The vessel was $0.54 \mathrm{~m}$ in diameter at the base, expanding to $0.62 \mathrm{~m}$ at the top. Were it a barrel, the original height and capacity of the vessel could be calculated as $0.77 \mathrm{~m}$ high and 36 gallons (Kilby 1971, 61). However, the pitch, the widest part of a barrel, has not survived, so it is not possible to determine conclusively whether the vessel was a barrel or a splay cask (ie open, without a pitch) such as a tub.

The hoops that bound the vessel were fashioned from withies, which had been split in half; they all still retained the bark. They varied in width from

Table 1.2 Dendrochronological data

\begin{tabular}{lccl}
\hline Stave & $\begin{array}{c}\text { Max width } \\
(\mathbf{m m})\end{array}$ & $\begin{array}{c}\text { No. rings } \\
\text { present }\end{array}$ & $\begin{array}{l}\text { Calendar } \\
\text { date }\end{array}$ \\
\hline $\mathrm{C} 1$ & 95 & 65 & $\mathrm{AD} \mathrm{1410-1474}$ \\
$\mathrm{D}$ & 120 & 70 & $/$ \\
$\mathrm{E}$ & 160 & 106 & $/$ \\
$\mathrm{F}$ & 120 & 67 & $/$ \\
$\mathrm{G}$ & 105 & 61 & $/$ \\
$\mathrm{I}$ & 120 & 68 & $/$ \\
$\mathrm{J}$ & 115 & 81 & $/$ \\
$\mathrm{O}$ & 90 & 75 & $\mathrm{AD} \mathrm{1478-1552}$ \\
$\mathrm{P} 2$ & 85 & 104 & $\mathrm{AD} \mathrm{1436-1530}$ \\
\hline
\end{tabular}

$20 \mathrm{~mm}$ to $34 \mathrm{~mm}$ but all had been cut from threeyear-old oak withies. The withies had been reduced in thickness and width at each end so that they were rectangular in cross-section; this would enable them to be neatly overlapped and bound together. They were bound tightly together with strips of 1-year old split willow (Salix sp.) withies, no more than 5-6mm wide and up to $2 \mathrm{~mm}$ thick.

On six of the staves there were pegholes just below the level of the croze groove. They occurred in groups of three, on Staves C2, D and E, and on Staves L, M and N. In both pairs the central stave had two holes, while the flanking staves had a single hole. The holes were mainly $10 \mathrm{~mm}$ in diameter and had been drilled at an angle downwards from the outside to the inside of the vessel. Pegs were still in situ in Staves E and L and in one hole each on both Staves D and M. These groups of staves lay diametrically opposite each other within the barrel. It has not been possible to find comparable features on other coopered vessels, nor to determine their function. They may have originally secured strengthening boards across the head of the barrel but holes drilled at right angles to the boards rather than obliquely, as these are, would have made for a stronger joint.

\subsection{Dendrochronological analysis}

The majority of the 20 staves that made up the coopered vessel were fast-grown, with only between 35 and 60 rings present. Only nine staves were considered suitable for dendrochronological analysis on the basis of their estimated ring-sequence, that is they were thought to have at least 70 rings present. In order to access the longest available ring-pattern a cross-section was cut from these staves at the widest point. The surfaces were pared with a razor blade and powdered chalk rubbed into the surface to enhance the ring-pattern. The ring-patterns were then measured and analysed using DENDRO (Tyers 1999). The dendrochronological data is presented in Table 1.2.

Many of the staves did not have as many growthrings present as estimated. Despite this, one of the shortest sequences produced very robust results (Table 1.3). The sequences were initially compared against each other but there was very little internal correlation. Three pairs compared well with each other, both visually and statistically, and mean sequences were made for each pair; these are Staves $\mathrm{I}$ and $\mathrm{G}(\mathrm{t}=5.66)$, Staves $\mathrm{C} 1$ and $\mathrm{J}(\mathrm{t}=6.17)$, and Staves D \& E $(t=7.4)$.

The mean sequences, as well as all the individual 


\begin{tabular}{|c|c|}
\hline Group & Span of ring sequences \\
\hline STPCMNX & Stave C \\
\hline 3 & Stave $O$ \\
\hline
\end{tabular}

\begin{tabular}{llll}
\hline Calendar years & $A D 1450$ & $A D 1500$ & AD1552 >
\end{tabular}

Illus 1.1 Bar diagram showing the chronological relationships between the dated staves

Table 1.3 Statistical comparisons with Scottish import chronologies and regional chronologies

\begin{tabular}{lcccc}
\hline Master chronologies/dated sequences & $\begin{array}{c}\text { Stave C1 } \\
\text { @ AD 1474 }\end{array}$ & $\begin{array}{c}\text { Stave O } \\
\text { @ AD 1552 }\end{array}$ & $\begin{array}{c}\text { Stave P2 } \\
\text { @ AD 1539 }\end{array}$ & STPCMN×3 \\
\hline Scottish import chronologies & & & & \\
TC1 Tantallon Castle, East Lothian & 6.38 & $/$ & $/$ & 5.18 \\
BRECHIN 1 High St, Brechin & 6.01 & $/$ & $/$ & 6.72 \\
FTMAS 1 Fenton Tower, East Lothian & 5.78 & 4.72 & 5.12 & 9.16 \\
FTMAS 2 Fenton Tower, East Lothian & 5.36 & $/$ & $/$ & $/$ \\
GAROOF2 Guthrie Aisle, Angus & 5.22 & $/$ & $/$ & 6.05 \\
OSU1NEW Old Students' Union, St Andrews & 6.43 & $/$ & $/$ & $/$ \\
EP21505 Episode 2, Stirling Palace & 6.46 & $/$ & $/$ & 5.60 \\
EP31538_9 Episode 3, Stirling Palace & 6.40 & 3.83 & 4.85 & 7.54 \\
EP1539 Episode 3, Stirling Palace & 7.30 & \multicolumn{1}{|c}{ / } & 4.57 & 8.60 \\
EP41592 Episode 4, Stirling Palace & 6.50 & & 5.80 & 8.35 \\
Regional master chronologies & & & & \\
SM000012 West Sweden & 7.99 & 3.63 & 7.62 & 10.48 \\
2X900001 East Denmark & 6.51 & 4.12 & 4.84 & 8.69 \\
SM00005 Skane/Blekinge, Sweden & 6.75 & 4.09 & 5.02 & 8.01 \\
NB800000 Sealand, Denmark & 6.33 & 4.27 & 4.19 & 7.53 \\
JUTLAND6 Jutland, Denmark & 5.54 & 4.11 & 4.33 & 7.34 \\
\hline
\end{tabular}

sequences were then compared against a suite of dated Scottish, English, Scandinavian and Baltic master chronologies. The results are presented above in Table 1.3.

Only three sequences, $\mathrm{C} 1, \mathrm{O}$ and $\mathrm{P} 2$ displayed the strong, consistent correlations which enabled them to be dated with confidence. Despite poor correlation between the individual sequences, the three dated sequences were averaged together to form a sub-master, STPCMN $\times 3,143$ years in length (illus 1.1). Illus 1.1 makes clear that, given their chronological relationship, Stave C and Stave O may well have been fashioned from the same radially split plank. The significant increase in statistical correlation between this sub-master and the regional chronologies, in particular (table 1.3), indicates that the climatic signal has been enhanced and that the relative positions of the sequences within the submaster are indeed correct. STPCMN $\times 3$ spans the period AD 1410-1552.

The three sequences compared strongly only against regional chronologies from Sweden and Denmark and a group of Scottish import chronologies, the components of which are also Scandinavian in origin. The statistical correlations are not sufficiently high to pinpoint a particular country but we can be certain that the oak used to make the barrel originated in Scandinavia.

\subsection{The date of the vessel}

As all the staves have been trimmed to shape, the outermost rings have been removed and so the date 
of the surviving outermost ring bears no direct relation to the date of construction of the vessel or of the well that it was ultimately used to line. It provides at most a terminus post quem for the construction of the vessel. The date of the outermost heartwood ring present is $\mathrm{AD} 1552$ and to this must be added an allowance for the sapwood that would have been trimmed off. As the timber is Scandinavian, a minimum sapwood estimate of 15 years is applied (Niels Bonde, pers comm), so the tree must have been felled, and the vessel constructed, some time after $\mathrm{AD}$ 1567. If allowance is made for a limited number of heartwood rings that will also have been trimmed off, and for a period of use for the vessel before it was reused as a well-lining, then the earliest time that the well could have been constructed is the early 17 th century.

\subsection{Summary}

The coopered vessel found at St Patrick's Church in the Cowgate may be either a tub or the lower half of a barrel. It has been fashioned from Scandinavian oak. From the late 15th century Scotland was importing timber for its building requirements and throughout the 16th and 17th centuries the main source of that timber was Scandinavia (Crone \& Watson 2002). As well as various types of building timber, Norway also exported barrel staves and hoops to Scotland (Lythe 1960, 148; Lillehammer 1990). As Scotland was not importing produce such as salted herring, which would have been packed in barrels from these countries, it is most likely that the vessel was made in Scotland using either preprepared staves or boards. 


\section{DISCUSSION OF FINDS AND POTTERY}

The finds assemblage represents a selection of the belongings and tools of the people who lived and worked along the Cowgate and upslope along the High Street during the medieval period, particularly during the 15 th century.

\subsection{Phase 1A: 11th/12th centuries}

This phase has been radiocarbon dated to AD 1020 1210 . The deposits were not fully excavated and only one potsherd was recovered. It is an olive-glazed sherd of White Gritty Ware of apparent 13th- or 14th-century date. It may be intrusive.

\subsection{Phase 1B: 13th century}

This would appear to date to the 13th century. The small collection of pottery from these early features includes a sherd of probable Saintonge Ware, which was imported in the 13th and 14th centuries. The lack of Scarborough-type Ware is odd, as it was the most common import during this period, but the assemblage is not large enough for this to be statistically significant. Occupation in the vicinity by the early 13th century is evidenced by a redeposited fragment of probable Rouen-type Ware in the overlying soil.

\subsection{Phase 1C: 13th to mid 14th century}

The soil build-up that makes up this phase provides the first significant collection of finds from the site, albeit somewhat abraded. The soil build-up might have continued for some time and the dating of the end of this build-up is significant in that it provides a terminus post quem for the cutting of the ditch. Unfortunately, few of the finds are tightly datable. Most are small potsherds, largely White Gritty Wares, which had a long lifespan. Three imported sherds suggest a date of the 13th or the first half of the 14th century, while the presence of local Greywares suggests deposition continued into the 14th century. However, the lack of Rhenish stonewares suggests it did not continue as late as the late 14 th century and certainly not into the 15 th century. In short, the most likely date for the ditch cutting would be around the middle of the 14th century.

\subsection{Phase 2A: first half of 15th century}

This is the fill of the ditch. The finds from this phase were more varied, better preserved and less abraded than the finds from the soil. There were however no large pottery profiles, nor similar evidence of rubbish being dumped straight into the ditch. Instead, these finds appear to be part of midden material redeposited into the ditch. There is a great deal of earlier material included in these deposits, most of the White Gritty assemblage, for example, but for the most part this stood out due to its much smaller sherd size, akin to that from the Phase 1C soil, from whence it must have derived. This is not gradual silting, but, from the uniformity and condition of finds throughout this part of the stratigraphy, would appear to be deliberate and rapid infilling, possibly a single event.

In terms of dating, firstly, it is fair to assume that some period of time passed between the ditch being cut and its being backfilled. The marked difference in the types of pottery found in Phases $1 \mathrm{C}$ and $2 \mathrm{~A}$ supports this supposition and suggests a hiatus of at least 30 years, and possibly over a century.

Absolute dating evidence comes from the presence of Rhenish stoneware, and from the leather footwear. Siegburg stoneware was in production from the 14th century onwards, but it is more commonly found in Scotland in 15th-century contexts. The large assemblage of Siegburg stoneware from the Edinburgh High Street site has been dated to the first half of the 15th century (Clarke \& Hurst 1976). The stoneware unfortunately lacks any diagnostic sherds in terms of form, by which it might be more accurately dated. The local pottery, particularly the profusion of Late Whiteware jugs, confirms a late medieval date, though there is little accurate dating evidence so far for this type. It is certainly present in 15th-century contexts in Edinburgh and Leith and continues into the 16th century, but it may also stretch backwards into the late 14th century. The latest parallels for the leather boot and shoe sole are both early 15 th century, though both are more common in earlier deposits, (mid 13th- to early 14th-century and 14thcentury contexts respectively).

In conclusion, the date of the backfill probably falls between the late 14th and mid 15th centuries, and is most likely to be early 15 th century.

\subsection{Phase 2B: 15 th century}

This is the fill of the ditch re-cut. Presumably then there must be some passage of time between this and the previous phase. However, the finds assemblages from both are quite similar. The pottery is largely made up of similar large Late Whiteware and Greyware jugs. There is, however, no 14th-century 
leather. Other finds such as the comb could be late medieval or early post-medieval. The best date for this phase then would be 15th century, more likely the second half.

\subsection{Phase 3: 15th century}

The midden layer, which accounts for the whole finds assemblage from this phase and the largest assemblage from any phase, is largely made up of material redeposited from lower layers. This is demonstrated by the proportion of White Gritty, which is almost as high as in the Phase 1C soil. There is nothing that unequivocally post-dates the 15 th century. It seems unlikely this deposit was laid down any later than the late 15 th or possibly early 16 th century, and could in fact be earlier.

\subsection{Phase 4A: 16th to 17th centuries}

The best dating for this phase comes from the barrel itself. The dendrochronological dating evidence suggests it was deposited around the early 17 th century. There are very few finds associated with this or the culvert. The only datable finds are redeposited fragments of medieval pottery.

\subsection{Phase 4B: 17th centuries}

This phase is defined by the midden development. The layer contained a large amount of finds but these were almost entirely redeposited from upslope or underlying soil layers. There are only a handful of pottery sherds dating to the 16 th and 17 th centuries, nothing later, and no clay pipes. The latter are so ubiquitous in 17th-century deposits that their absence here is striking.

\subsection{Phase 5: 18 th to 20 th centuries}

This phase includes 18th/19th-century structures, unstratified finds and finds from the evaluation trenches. There are few finds from modern contexts and again these are mixed modern and medieval. 


\title{
Appendix 2 - Faunal Remains
}

\author{
Auli Tourunen
}

Headland Archaeology Ltd-Ireland, Unit 1, Wallingstown Business Park, Little Island, Cork 

LIST OF ILLUSTRATIONS $\ldots \ldots \ldots \ldots \ldots \ldots \ldots$

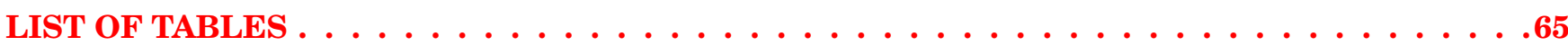

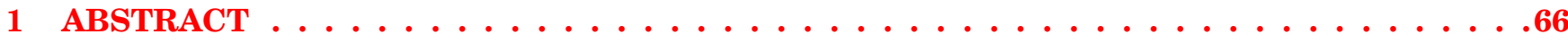

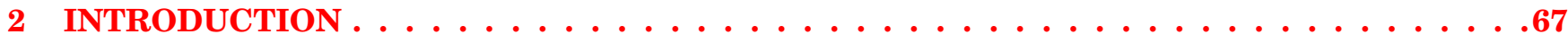

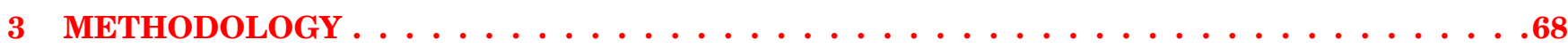

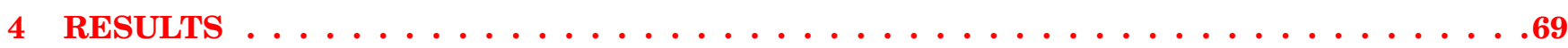

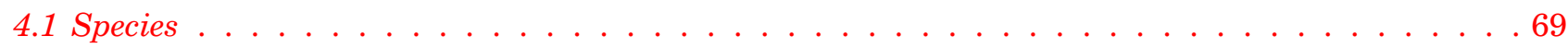

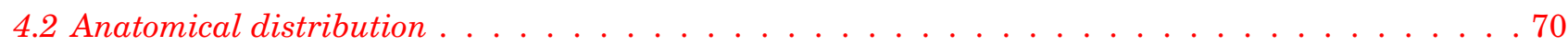

4.3 Preservation . . . . . . . . . . . . . . . . . . . . . . . 71

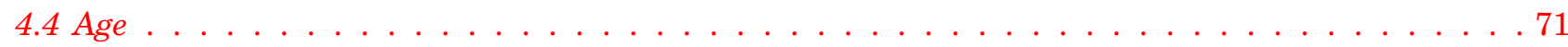

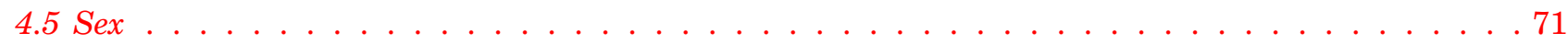

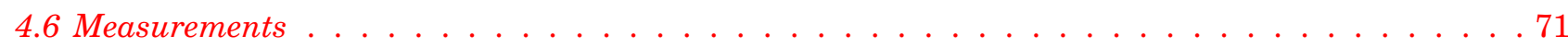

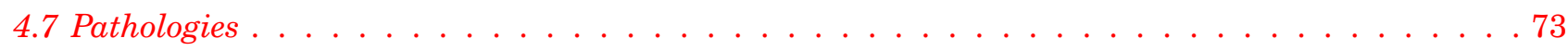

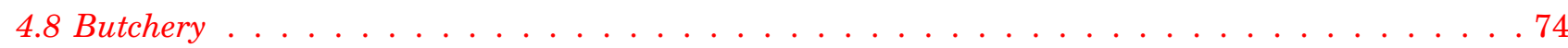

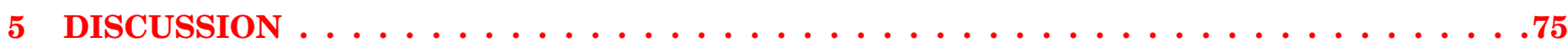

5.1 Domestic waste . . . . . . . . . . . . . . . . . . . . . . . . . . 75

5.2 Crafts in St Patrick's Church . . . . . . . . . . . . . . . . . . . . 76

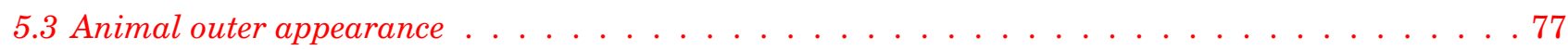

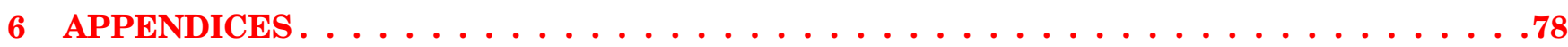

6.1 Division of epiphyses in early, intermediate and late fusing groups . . . . . . . . . . . . . . 78

6.2 Anatomical distribution of the animal bones in material . . . . . . . . . . . . . . . . . 78

6.3 Cattle, sheep or goat and pig epiphyseal data (medieval sample) . . . . . . . . . . . . . . . 81

6.4 Measurements . . . . . . . . . . . . . . . . . . . . . . . 82

6.5 Comparison of the Scottish medieval samples . . . . . . . . . . . . . . . . . . . 84

6.6 Complete list of animal bones . . . . . . . . . . . . . . . . . . . . . . . . . 85 


\section{LIST OF ILLUSTRATIONS}

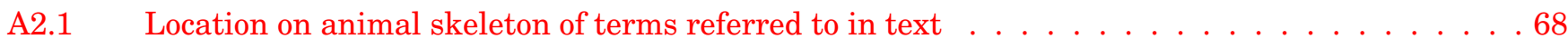

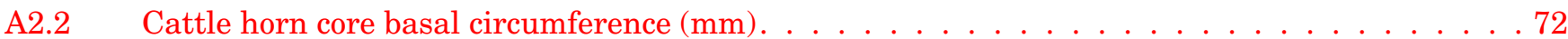

A2.3 Cattle horn core minimum/maximum diameter $\times 100$ compared to basal circumference $\ldots \ldots 73$

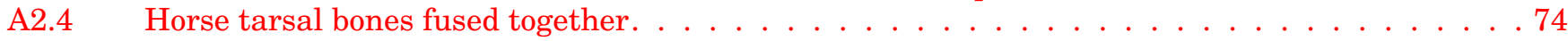

A2.5 Cattle skull showing healed fracture on frontal bone . . . . . . . . . . . . . . . . . . 74

A2.6 Cattle horn size and shape variation found in the Cowgate material . . . . . . . . . . . . . 77 


\section{LIST OF TABLES}

$2.1 \quad$ Mammal and amphibian species representation of sample (NISP) $\ldots \ldots \ldots \ldots 1$

$2.2 \quad$ MNE figures of cattle, sheep (and goat) and pig . . . . . . . . . . . . . . . . . . 61

$2.3 \quad$ Fish species representation of sample (NISP) $\ldots \ldots \ldots \ldots \ldots \ldots$

2.4 Bird species representation of sample (NISP) $\ldots \ldots \ldots \ldots \ldots \ldots \ldots$

$2.5 \quad$ Species recovery with different recovery methods . . . . . . . . . . . . . . . . . . 71

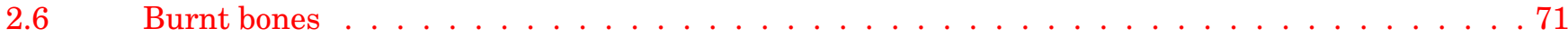

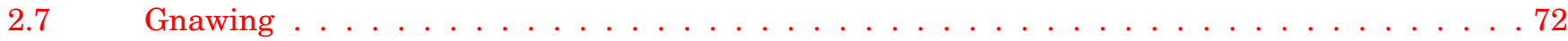

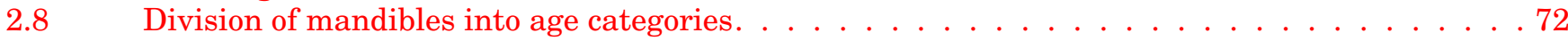

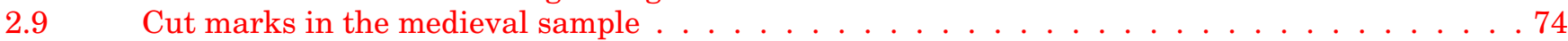




\section{ABSTRACT}

A total of 2080 specimens of animal bone were recovered from St Patrick's Church, Cowgate, Edinburgh. The site included both medieval and post-medieval features. The majority of the bones derive from domestic mammals with cattle, sheep/ goat, pig and horse being represented in the sample. A number of fish species were identified, among which herring- and cod-related species dominated.
Domestic chicken was the most abundant bird species: red grouse was the only wild bird identified. The species distribution is typical for medieval Scottish urban sites. Bone material derived from both domestic and industrial waste (signs of horn working and disposal of horse carcasses, probably after skinning) were evident. 


\section{INTRODUCTION}

This report presents the results of analysis of animal bones from St Patrick's Church, Cowgate, Edinburgh.

The animal bone specimens were recovered by both hand-picking and sieving. Most of the animal bones analysed for this report derive from medieval ditches (contexts [075/076] and [095]) but material from other medieval and post-medieval well-stratified layers was examined as well. Bone material from contexts [003] and [007] was evaluated but not analysed closely. The material from these layers was less well preserved than the rest of the material, and very fragmented. It proved to consist of domestic waste, most bones deriving from cattle, sheep and pig. 


\section{METHODOLOGY}

Each specimen was identified according to species and skeletal element, where possible using an animal bone reference collection located in Headland Archaeology Ltd, Unit 1 Wallingstown Business Park, Little Island, Co. Cork. The York System bone database program was used for the recording (Harland et al 2003). The bird bones were identified by using the bone collection in the Natural History section of the National Museum of Ireland.

The categories 'large mammal' (LM) and 'medium mammal' (MM) were used for specimens (mainly ribs and vertebrae) that could not be assigned to species. The specimens categorised as large mammal are likely to belong to cattle or horse; red deer was absent in the assemblage. Medium mammal specimens are most likely to consist of sheep and pig bones; however the presence of goat and roe deer is possible. The category 'small mammal' (SM) includes mammal bones from cat-sized animals or smaller.

The material was quantified by using the number of identified specimens (NISP) and minimum number of elements (MNE). Distinctions made between sheep and goat follow Boessneck (1969) for limb bones. Tooth eruption and wear were recorded according to Grant (1982). Mandibles were further divided into age groups presented by O'Connor $(2003,160)$. For ages of tooth eruption and epiphyseal fusion Silver's (1969) figures were followed. Division of epiphyses in early, intermediate and late fusing groups was done according to Vretemark (1997) (Appendix 6.1). Measurements were taken following von den Driesch (1976). In addition, the medial edge of pelvis was measured according to Vretemark (1997).

During the analysis pathological changes, carnivore and rodent gnawing, signs of burning and butchery marks were recorded. All data is stored in digital and written form in Headland Archaeology Ltd, Unit 1 Wallingstown Business Park, Little Island, Co. Cork.

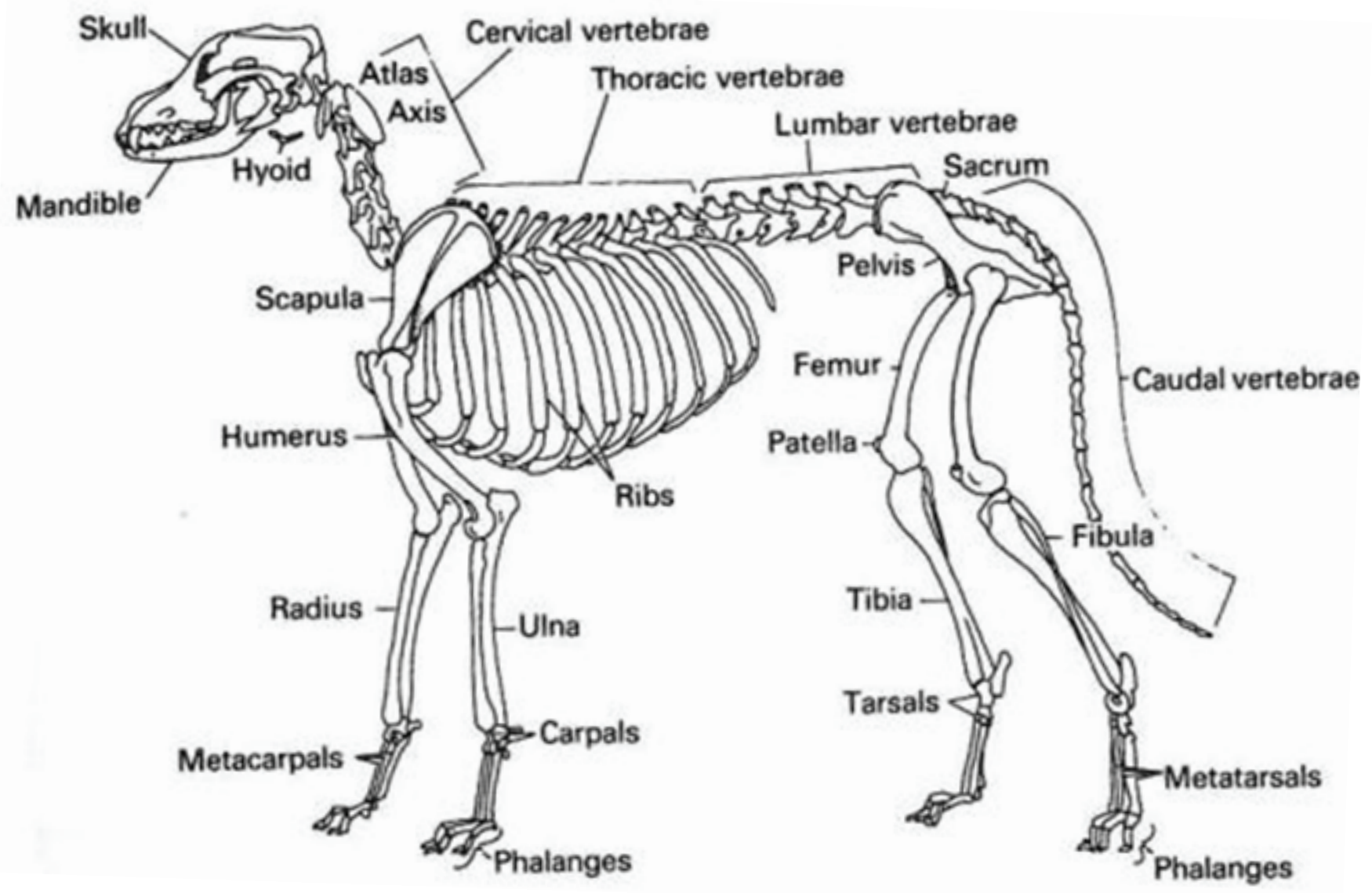

Illus A2.1 Location on animal skeleton of terms referred to in text (Davis 1987, 54) 


\section{RESULTS}

Table 2.1 Mammal and amphibian species representation of sample (NISP) * horn cores

\begin{tabular}{|c|c|c|c|c|}
\hline Species & Medieval & Medieval ditches & Post-medieval & Total \\
\hline Cattle & 4 & $118(25)^{*}$ & & 122 \\
\hline Sheep/goat & 3 & 66 & & 69 \\
\hline Sheep & 1 & 39 & & 40 \\
\hline Horse & & 23 & & 23 \\
\hline Pig & 2 & 14 & & 16 \\
\hline Shrew & & 1 & & 1 \\
\hline Rabbit & & 3 & & 3 \\
\hline Rabbit/hare & 1 & 1 & & 2 \\
\hline Vole & & 1 & & 1 \\
\hline Mouse & & & 1 & 1 \\
\hline Vole/mouse & & 2 & 2 & 4 \\
\hline Rat & & 2 & 2 & 4 \\
\hline Large mammal & 3 & 97 & 1 & 101 \\
\hline Medium mammal & 3 & 36 & 2 & 41 \\
\hline Small mammal & & 3 & 28 & 31 \\
\hline Frog/toad & 1 & 24 & & 25 \\
\hline Unidentified & 196 & 477 & 226 & 899 \\
\hline Total & 214 & 907 & 262 & 1383 \\
\hline
\end{tabular}

\subsection{Species}

A total of 2080 bone specimens were analysed from the site. $43.2 \%$ of the specimens were unidentified to any taxonomic level, which reflects rather the careful sampling strategy than the high fragmentation rate of material. Most of the bones derive from contexts dated as medieval. However, some specimens were recovered from the soil samples of post-medieval deposits.

Most of the identified mammal specimens derive from domestic animals (table 2.1). The assemblage is dominated by cattle. However, part of the cattle bones derive from horn cores not relating to normal consumption but craft activities. If horn cores are excluded from the tables, sheep or goat are the most

Table 2.2 MNE figures of cattle, sheep (and goat) and pig * = excluding horn cores in medieval sample. Large ungulate bones included in cattle numbers.

\begin{tabular}{lcr}
\hline Species & number & $\%$ \\
\hline cattle & $63^{*}$ & 41.4 \\
sheep & 76 & 50.0 \\
pig & 13 & 8.6 \\
total & 152 & 100.0 \\
\hline
\end{tabular}

abundant species. As large animal bones are often found in a higher fragmentary state than the bones of smaller mammals, NISP (number of identified specimens) figures of cattle can be overrepresented compared to sheep and pig. Therefore species abundance was quantified with MNE (minimum number of elements, Table 2.2) as this method is less sensitive to fragmentation. With MNE, sheep or goat dominate over cattle (again excluding the horn cores). However, even taking these factors into account, cattle would have produced the most meat consumed at the site due to the larger size of cattle carcass.

Specimens categorised as large ungulates are likely to derive mainly from cattle: however, some specimens may be those of horse. Sheep and goat bones are very similar and only some parts of their skeletons can be identified to species. No goat bones were identified from the sample and it can be assumed that most of the bones in category 'sheep or goat' are sheep bones. In the assemblage, horse is more abundant than pig. This is due to the high incidence of horse bones in the medieval ditch (see below). Few fragments were identified as rabbit. In addition, material included bones of small mammals and frog or toads that were living on the site. As no mandibles or skulls of mice were found, the species could not be identified. Voles are represented by one tooth (likely to belong to water vole, Arvicola terrestris). 
Table 2.3 Fish species representation of sample (NISP)

\begin{tabular}{|c|c|c|c|c|}
\hline Species & Medieval & Medieval ditches & Post-medieval & Total \\
\hline Thornback ray & & 4 & & 4 \\
\hline Ray family & & 1 & & 1 \\
\hline Herring & 1 & 1 & 10 & 12 \\
\hline Herring family & 2 & 51 & 24 & 77 \\
\hline Pike & & 3 & & 3 \\
\hline Cyprinid family & & & 1 & 1 \\
\hline Cod & & 1 & & 1 \\
\hline Haddock & 1 & 1 & 2 & 4 \\
\hline Whiting & 1 & 3 & & 4 \\
\hline Cod family & 7 & 31 & 13 & 51 \\
\hline Flatfish & & 3 & & 3 \\
\hline Unidentified fish & 26 & 179 & 291 & 496 \\
\hline Total & 38 & 278 & 341 & 657 \\
\hline
\end{tabular}

Table 2.4 Bird species representation of sample (NISP)

\begin{tabular}{lcccc}
\hline Species & Medieval & Medieval ditches & Post-medieval & Total \\
\hline Domestic chicken & 1 & 2 & 3 & 6 \\
Galliformes & & 2 & 1 & 3 \\
Goose & & 2 & 1 & 2 \\
Duck & 1 & & 1 & 1 \\
Red grouse & 5 & & 12 & 25 \\
Unidentified bird & $\mathbf{7}$ & 8 & $\mathbf{1 8}$ & $\mathbf{3 9}$ \\
Total & & $\mathbf{1 4}$ & & \\
\hline
\end{tabular}

Most of the fish bones derive from the herring family, most likely herring (Clupea harengus; Table 2.3). Cod family was well represented in the material. Identified species were cod (Gadus morhua), haddock (Melanogrammus aeglefinus) and whiting (Merlangius merlangus). In addition, a few bones of pike (Esox lucius), cyprinid (Cyprinidae), flatfish (Pleuronectiformes) and thornback ray (Raja clavata) were found. Most of the unidentified fish bones represent fin or rib bones.

Most of the bird bones derive from domestic chicken (Gallus gallus; Table 2.4). Bones categorised as Galliformes are likely to derive from domestic chicken but might belong to other related game birds like capercaillie, black grouse and (for the post-medieval period) pheasant. Few bones belonging to goose (Anser sp.) and duck (Anatidae) might belong to wild or domestic birds. Red grouse (Lagopus lagopus) was represented in both medieval and post-medieval samples.

Species representation and the anatomical distribution of the hand-picked assemblage are influenced by the method of recovery. Bones of medium-sized and small animals like sheep, fish and birds are regularly missed when sieving is not practised. As can be seen from Table 2.5, in sieved samples sheep or goat bones dominate over cattle bones. All the bone material from post-medieval layers derives from soil samples and thus is not included in the table. Moreover, bones of shrew, rodent, amphibian and fish were only recovered through sieving.

\subsection{Anatomical distribution}

Anatomical distribution was studied in order to examine the past activities on the site. Bone elements can be divided into high and low utility parts, representing the body parts relating to primary and secondary butchery. High utility elements include spinal column and ribs and upper parts of the limbs. Low utility elements include the head, tail and lower parts of the limbs.

The bone material from medieval layers excluding ditches, even if small, proved to include remains from all stages of the processing of animal carcasses and is likely to represent domestic waste (Appendix 6.2). The anatomical distribution of the material recovered from the ditches exhibited signs of professional activities. High numbers of cattle horn cores is likely to represent industrial waste from horn working. The horn comb found from context [080] might be related to horn working on the site. However, other elements and species are also present in the sample. As a result, the assemblage is likely to be a mixture of domestic and industrial waste.

Horse bones from at least three different indi- 
Table 2.5 Species recovery with different recovery methods ( $1 \mathrm{~mm}$ sieve and hand collecting), medieval material

\begin{tabular}{lrrr}
\hline Species & $\mathbf{1}$ & HC & Total \\
\hline Cattle & 10 & 112 & 122 \\
Sheep/goat & 16 & 53 & 69 \\
Sheep & 3 & 37 & 40 \\
Horse & & 23 & 23 \\
Pig & 3 & 13 & 16 \\
Shrew & 1 & & 1 \\
Rabbit & & 3 & 3 \\
Rabbit/hare & 2 & & 2 \\
Vole & 1 & & 1 \\
Vole/mouse & 2 & & 2 \\
Rat & 2 & & 2 \\
Rodent & 1 & & 1 \\
Large mammal & 15 & 85 & 100 \\
Medium mammal & 15 & 24 & 39 \\
Small mammal & 3 & & 3 \\
Bird & 15 & 6 & 21 \\
Frog/toad & 25 & & 25 \\
Fish & 316 & & 316 \\
Unidentified & 626 & 47 & 673 \\
Total & $\mathbf{1 0 5 6}$ & $\mathbf{4 0 3}$ & $\mathbf{1 4 5 9}$ \\
\hline
\end{tabular}

viduals were recovered from Ditches 075 and 076 . The anatomical distribution of the sample is of interest. Limb bones are well represented and some vertebrae and ribs were found. Skull and mandible are absent as well as scapula and pelvis. The only chop mark was found in the distal femur, probably due to dismemberment of the carcass. The sacrum from Context [093] belongs to the same individual as the lumbar vertebrae found in Context [081]. Thus, it seems likely that the two contexts were deposited at the same time.

Even if the small number of the fish bones hampers any closer analysis of the fish processing on the site, it seems likely that the fish remains represent domestic waste. A wide range of skeletal elements are represented and fish were probably brought to the site relatively unprocessed. It is, however, possible that herring bones derive from cured (salted or smoked) fish.

\subsection{Preservation}

The material proved to be well preserved, most of the fragments being extremely well or well preserved. It included 91 burnt bone fragments, distributed in various contexts (Table 2.6).

Carnivore gnawing was present in 11 specimens (Table 2.7). No evidence of rodent gnawing was present in the material.
Table 2.6 Burnt bones

\begin{tabular}{lc}
\hline Context & Total \\
\hline 015 & 23 \\
070 & 3 \\
074 & 24 \\
078 & 1 \\
079 & 1 \\
086 & 5 \\
092 & 5 \\
093 & 2 \\
094 & 1 \\
124 & 3 \\
126 & 2 \\
133 & 2 \\
141 & 5 \\
146 & 1 \\
Total & 1 \\
& 19 \\
\hline
\end{tabular}

\subsection{Age}

The best indicators for ageing mammal osteological material are usually obtained from an examination of the wear and eruption of mandibular teeth. The epiphyseal fusion evidence can also be used to age structure analysis, thus it is usually seen as a less reliable method.

Only three cattle mandibles could be divided into age categories (according to O'Connor 2003 method), all of them from adult or elderly animals (Table 2.8). However, according to epiphyseal data part of the cattle bones derive from sub-adult individuals even if mature animals dominate the assemblage (Appendix 6.3). The difference is likely be caused by the small sample size.

The majority of the sheep (or goat) mandibles derive from mature animals. Again, epiphyseal fusion indicates a higher proportion of juvenile animals in the material. One pig mandible available for age determination is from a sub-adult individual. The epiphyseal data for pig is scarce but all the bones derive from animals under the age of three and a half years.

The assemblage included few bones of infant animals. Calf bone from Context [082] might derive from veal consumed at the site, or a stillborn calf. The piglet tibia is likely to derive from a stillborn or neonatal animal, thus representing local animal, breeding and not consumption.

\subsection{Sex}

Only one cattle pelvis was available for sex determination: the animal is most likely male as indicated by the high value of the medial edge measurement (17.3mm; Vretemark 1997, 103).

Cattle horn core basal circumference exhibits a 
Table 2.7 Gnawing. LM = large mammal

\begin{tabular}{|c|c|c|c|c|c|c|c|c|}
\hline Context & Cattle & Horse & $\mathbf{L M}$ & Pig & Sheep/goat & Sheep & Unidentified & Total \\
\hline 023 & & & & & & 1 & & 1 \\
\hline 074 & & & & 1 & 1 & & & 2 \\
\hline 080 & 2 & & & & & & & 2 \\
\hline 082 & 1 & & & & 1 & & & 2 \\
\hline 086 & & & & & 1 & & & 1 \\
\hline 089 & & & 1 & & & & & 1 \\
\hline 093 & & 1 & & & & & & 1 \\
\hline 135 & & & & & & & 1 & 1 \\
\hline Total & 3 & 1 & 1 & 1 & 3 & 1 & 1 & 11 \\
\hline
\end{tabular}

Table 2.8 Division of mandibles into age categories.

$J=$ juvenile, $\mathbf{S A}=$ sub adult, $A=$ adult, $E=$ elderly (O'Connor 2003, 160)

\begin{tabular}{|c|c|c|c|c|c|c|}
\hline & $\mathbf{J}$ & SA1 & SA2 & A2 & A 3 & $\mathbf{E}$ \\
\hline Cattle & & & & & 2 & 1 \\
\hline Sheep/goat & 1 & 1 & & 1 & 4 & \\
\hline Pig & & & 1 & & & \\
\hline
\end{tabular}

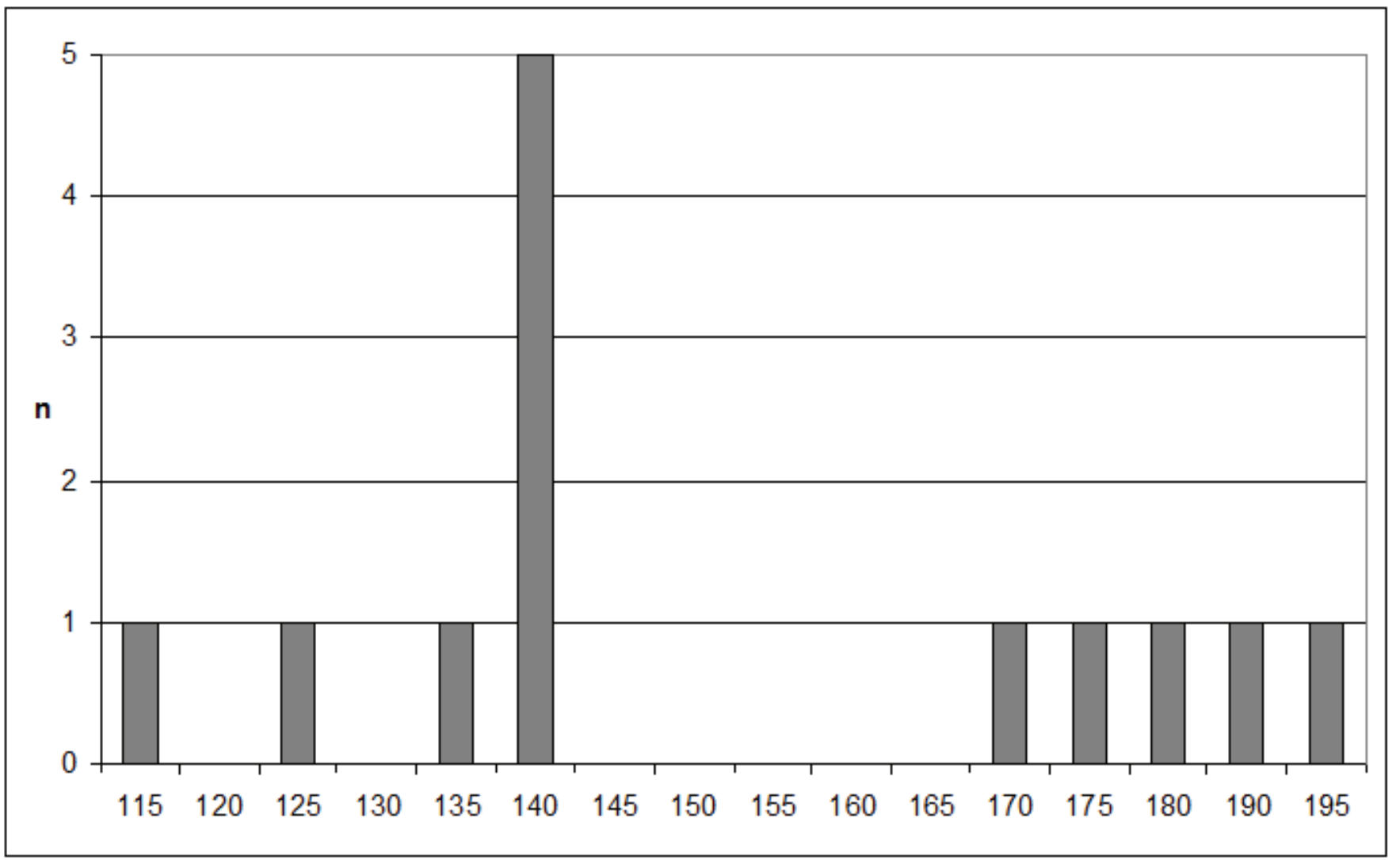

Illus A2.2 Cattle horn core basal circumference ( $\mathrm{mm}$ )

clear dual distribution of values (illus A2.2). Horn cores with smaller basal circumference are cows, the larger ones males: the threshold between females and males was set to $150 \mathrm{~mm}$ basal circumference on the basis of the distribution found in St Patrick's
Church material and with reference to other studies (Prillof 2000, 30-4; Vretemark 1997, 106; Wigh 2001, $65)$. By these criteria, $62 \%$ of horn cores derive from females.

The shape of the horn core base exhibits some 


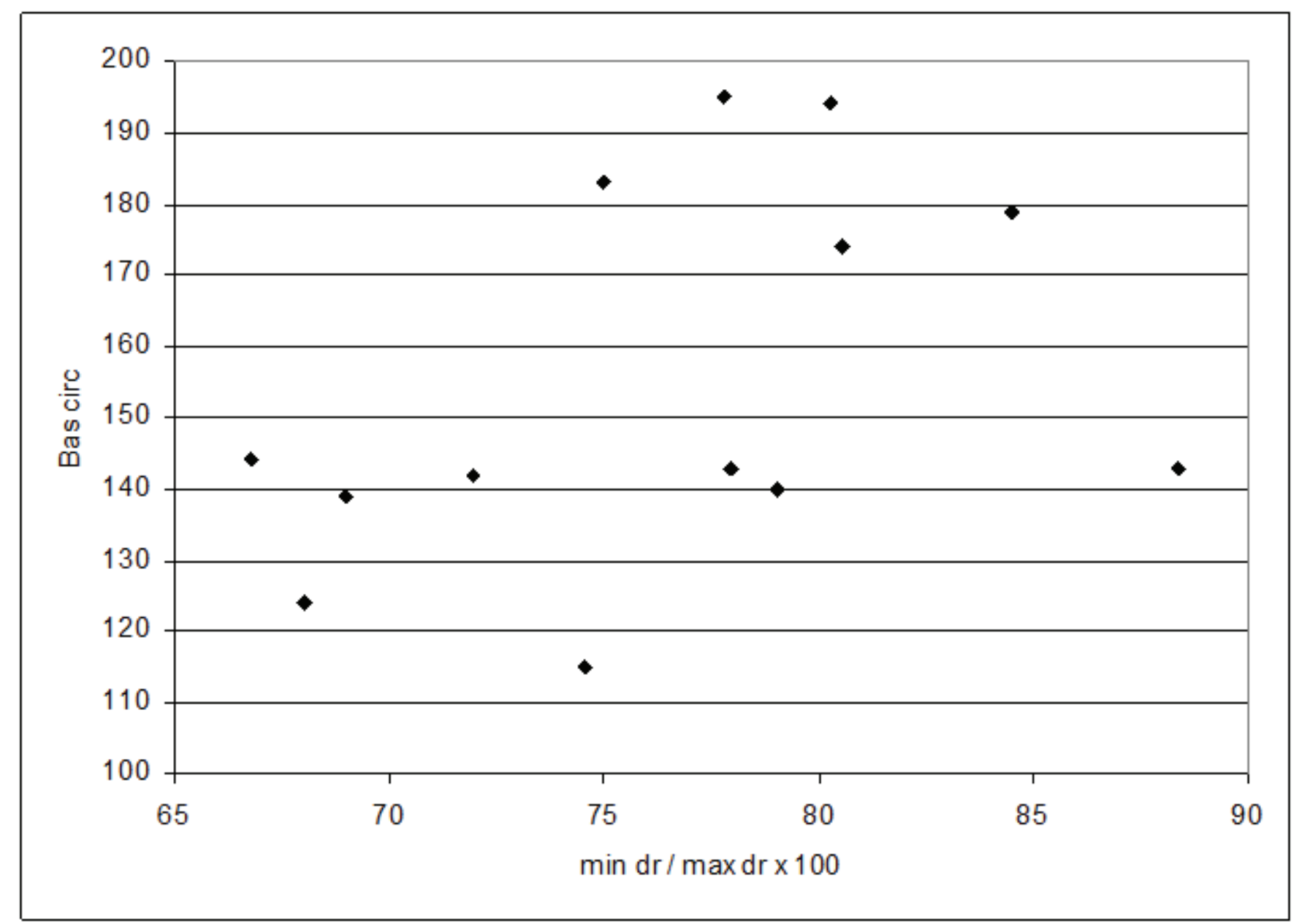

Illus A2.3 Cattle horn core minimum diameter/maximum diameter $\times 100$ compared to basal circumference

sexual variation: thus, the basal circumference was plotted against the index describing the shape of the horn core base (illus A2.3). The horn cores of bulls are rounder in cross-section than the horn cores of oxen (the index being closer to 1 than 0; Benecke 1988). The horn cores with basal circumference over $150 \mathrm{~mm}$, thus the likely males, exhibit very uniform shape. However, these horn cores represent more likely oxen than bulls. The one round horn core has a basal circumference under $150 \mathrm{~mm}$. It is possible that this specimen represents a small male or natural variation among female horn core shapes.

As these horn cores are likely to derive from craft activities males are likely to be overrepresented: their larger horn cores would have been more attractive for this purpose. Most of the horn cores derive from adult animals (age class 4 or 5 according to Armitage (1982) $\mathrm{n}=12$ and 1 respectively), but a few were those of juvenile $(n=1)$, sub-adult $(n=$ 1 ) or young adult $(n=3)$. The preference of adult males is understandable, as these animals yielded the largest horn sheets.

Four sheep pelves could be measured for sex estimation (Appendix 6.4). All values are greater than $4.7 \mathrm{~mm}$, and thus likely males. One with a medial edge value of 4.8 was identified as male by morphological criteria. However, the other pelvis (med. edge $4.9 \mathrm{~mm}$ ) was judged to be possibly female in character. It is likely that these pelves derive from wethers (castrated males; cf Vretemark 1997, 45).

\subsection{Measurements}

Several measurements were taken from the bones to examine the size of the animals (Appendix 6.4). A withers height of horse could be estimated from nine bones, giving the average height of $132.5 \mathrm{~cm}$ (range $127.2-140.0 \mathrm{~cm}$; according to Kiesewalter 1888). The average withers height of sheep was $55.9 \mathrm{~cm}$ (range 55.3-56.7cm; Teichert 1975).

\subsection{Pathologies}

A total of four bones showed pathological changes. Three of these derive from horse and are arthritic in nature. In one case tarsal bones (bones in hock joint: talus, Tc, T1+2, 3 and 4) were fused together (illus A2.4). Articular surfaces towards metatarsals and 
Table 2.9 Cut marks in the medieval sample. $L M=$ large mammal, $M M=$ medium mammal

\begin{tabular}{|c|c|c|c|c|c|c|c|c|c|}
\hline Element & Cattle & Sheep & Sheep/goat & Pig & Horse & LM & MM & Unidentifiable & Total \\
\hline Horncore & 10 & & & & & & & & 10 \\
\hline Skull & 4 & & & & & & & & 4 \\
\hline Mandible & 1 & & 1 & 1 & & & & & 3 \\
\hline Atlas & 1 & & & & & & & & 1 \\
\hline Axis & 1 & & & & & & & & 1 \\
\hline Cervical vertebrae & & & & 1 & & 2 & & & 3 \\
\hline Thoracic vertebrae & & & & & & 3 & & & 3 \\
\hline Lumbar vertebrae & & & & & & 5 & & 1 & 6 \\
\hline Sacrum & 1 & & & & & 3 & & & 4 \\
\hline Vertebra & & & & & & & 2 & & 2 \\
\hline Rib & & & & & & 3 & 8 & & 11 \\
\hline Scapula & 2 & 2 & & 1 & & & & & 5 \\
\hline Radius & 2 & & 1 & & & & & & 3 \\
\hline Pelvis & 4 & & 2 & 1 & & & & & 7 \\
\hline Femur & 1 & & 3 & & 1 & 1 & & & 6 \\
\hline Tibia & 1 & & & 1 & & & & & 2 \\
\hline Calcaneum & 1 & & & & & & & & 1 \\
\hline Astragalus & 1 & & & & & & & & 1 \\
\hline Metatarsal & & 2 & & & & & & & 2 \\
\hline Total & 30 & 4 & 7 & 5 & 1 & 17 & 10 & 1 & 75 \\
\hline
\end{tabular}

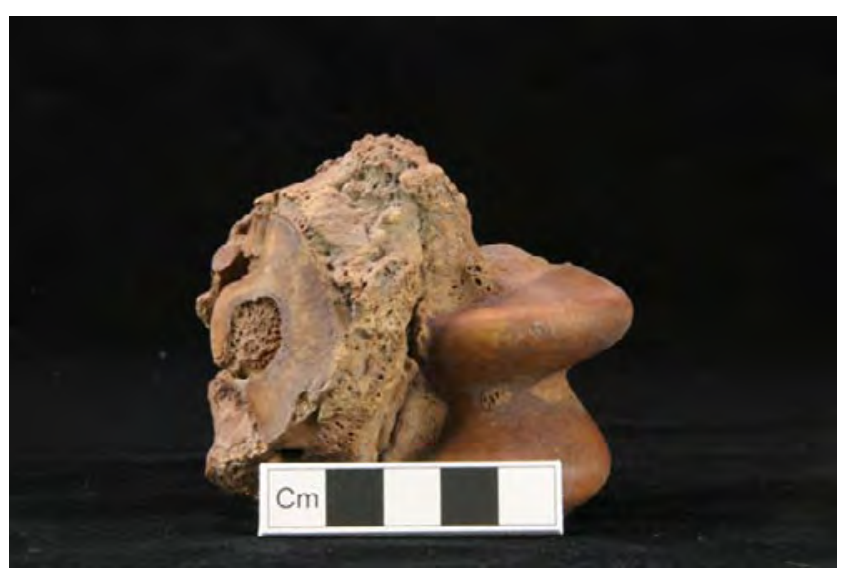

Illus A2.4 Horse tarsal bones fused together

tibia were unaltered. In addition, one horse radius and metatarsal bone exhibited exostosis (extra bone growth) at their proximal end.

One cattle skull had a depression on the frontal bone (illus A2.5). The surface was smooth except for one edge and appeared to be a healed trauma caused by some relatively sharp instrument, eg horn.

\subsection{Butchery}

A total of 75 specimens showed butchery marks. Cattle horn cores and adjacent skull pieces exhibited evidence of horn sheath utilisation. Horn cores were detached from the skull by cutting the nuchal part of the skull with the horn core. One horn core had

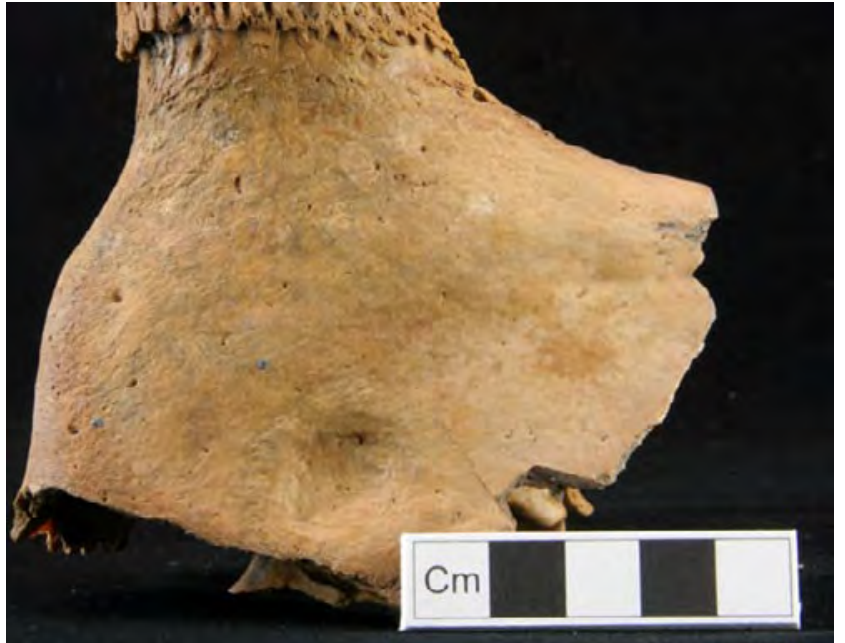

Illus A2.5 Cattle skull showing healed fracture on frontal bone

knife marks in its base, indicating horn sheath removal. The tip of the other horn core was removed by sawing, relating also to horn sheath utilisation.

Other cut marks relate to skinning, dismemberment and filleting of the carcass. Cut marks are more common in cattle bones than in sheep/goat or pig, due to the larger size of the cattle carcass. The cattle carcass has been split in two halves through the spine (sagittal plan). One vertabra of medium sized mammal (sheep, goat or pig) exhibited evidence of cutting the carcass into three sections through parasagittal planes. 


\section{DISCUSSION}

\subsection{Domestic waste}

The assemblage consists mostly of domestic animals. As already noted above, the 'abundance' of species is a complex concept requiring careful definition. Part of the bones (cattle horn cores and horse bones) deposited at St Patrick's Church are likely to derive from craft activities and are not related to human consumption. Therefore, the aim being to examine the importance of different species in diet, these bones should be excluded.

The proportion of cattle, sheep or goat, pig and horse bones (NISP) in different medieval Scottish assemblages was compared to the St Patrick's Church material (Appendix 6.5). Before making direct comparisons between the sites a few factors affecting the results should be noted. First, different recovery methods produce different rations of species. Thus, if only hand-picked assemblages are used, higher proportions of cattle (and other large mammals) are to be expected. Second, the recording of vertebrae and ribs can affect species abundances. These body parts are sometimes identified only as large mammals and medium mammals (or large and small ungulates) as the bones are difficult to identify as cattle, horse and red deer respectively. However, sometimes, especially when horse and red deer are absent in the material, these bones are included in the cattle bone counts. As the bones from the trunk (vertebrae and ribs) can be identified variably to species, the wider categories of large and small ungulates were used to include these elements equally. Cattle and large mammal bones were counted together as well as sheep or goat, pig and medium mammal bones.

Smith (2007) suggested that higher numbers of sheep are found in ecclesial contexts, probably relating to specialised sheep breeding. Thus, the abundance of sheep at the Parliament site was interpreted as being influenced by the Abbey of Holyrood (Smith 2007). Whether the bone material from St Giles' Cathedral is actually connected with an ecclesial context is unclear - however it was interpreted to derive from households with a higher than average social standing (Henderson 2006, 63-5). According to written records the house and garden of the Vicar (later the Provost) of St Giles were located on the site (Collard et al 2006, 5).

At first, the comparison of the figures exhibits clear differences between the abundance of cattle and sheep or goat in the materials. However, a closer examination reveals that in some cases the seen pattern is affected by the identification method used - that is, whether or not the trunk elements are included in the cattle counts. The two sites exhibit- ing the highest levels of cattle bones in the material are Water Street, Edinburgh and Cinemahouse, St Andrews, both of which have the trunk elements counted with the cattle bones. As can be seen in Appendix 6.5, the proportion of cattle is notably higher in St Patrick's Church, Cowgate, and Parliament material, when counting the category 'large ungulates' with the cattle bones. The same effect is seen, although it is less obvious, in Peebles Bridgegate and Perth High Street materials. Thus, in most of the materials the proportion of cattle seems to fall between $50 \%$ and $60 \%$, with only the Parliament and St Giles' Cathedral assemblages having less than $50 \%$ cattle. Thus, it seems possible that in these two sites the presence of ecclesial buildings has affected the higher abundance of sheep.

The only wild mammals utilised for their meat in the St Patrick's Church material were rabbit and possibly hare. Rabbit bones have been found earlier in medieval Edinburgh, but they are scarce and sometimes referred to as possible later intrusions by burrowing animals (Smith 2007). As the St Patrick's Church site is located in the city area, the presence of a rabbit community seems unlikely and the rabbit bones are interpreted as food refuse.

No red or roe deer bones were recovered from the site. Even if not abundant, both deer species have been recovered previously from medieval Edinburgh (Smith 2006, Smith 2007). Their absence in the St Patrick's Church material is probably caused by the small sample size.

The observed cattle-culling pattern, with most of the animals reaching a mature age, follows that seen in other Scottish burghs (Smith 1997, 769; Henderson 2001; Smith 2007; Hodgson 1983, 111). The pattern has been interpreted to represent stock kept mainly for hides (Hodgson 1993, 11; Smith 1997, 769) with milk and meat production being less important (Smith 2007, but see also Henderson 2006, 64).

According to sheep (and goat) age data from mandibles, most of the animal remains in the St Patrick's Church assemblage derive from animals over four years of age. This contrasts with the evidence found in Water Street, St Giles' Cathedral and Cowgate assemblages in Edinburgh (Henderson 2001; Henderson 2006; 64 , Smith 2006), where the majority of sheep were culled at a relatively young age, as well as in the faunal assemblages recovered from Perth (Smith 1997, 769; Hodgson 1983, 206). However, in Peebles most of the sheep were slaughtered at a more mature age (Smith \& Henderson 2002, 128). The St Patrick's Church assemblage is small $(\mathrm{n}=$ 7) so it is possible that the discrepancy is caused 
by small size of the assemblage. The epiphyseal data exhibits more young individuals than data from mandibles. Culling of young sheep emphasises the importance of meat and hide (woolfells) production (eg Smith \& Henderson 2002; Hodgson 1983, 13; Henderson 2006, 64). Keeping sheep to an older age is related to the importance of wool or milk production. As male sheep seem to dominate the sample, wool was likely to be the main product the sheep were kept for. Castration promotes wool production and the presence of castrated animals has been considered an indication of the importance of wool: castrating would also keep the flock steadier, as rams tend to fight (Clutton-Brock 1976, 382; Ryder 1983a, 452, 465).

Both marine and freshwater fish were recovered from the St Patrick's Church assemblage. The marine fish dominated the assemblage: herring family (likely herring) and cod family (cod, haddock and whiting) comprised most of the assemblage, as in the other fish-bone samples from Edinburgh (Cerón-Carrasco 2010, Henderson 2001). No cod family bones were complete enough for measuring. However, as in the case of the Water Street assemblage (Henderson 2001), most of them derive from fish small in size. The species representation found at the St Patrick's Church site reflects the abundance of marine resources in Scotland (Coull 1996, 14-15). Commercial herring fishing was already established during the medieval period in Scotland (ibid, 54-5). White fish (cod family and flatfish) was an item of trade as well but to a lesser extent; it was probably caught mostly for local consumption (ibid, 79-80).

A few freshwater fish bones, three pike and one belonging to the carp family, were recovered as well. The all-time British monster pike, weighing almost $33 \mathrm{~kg}$, was caught in Loch Ken in Dumfries and Galloway in 1774 (Buczacki 2002, 141); however, the pike bones present in the St Patrick's Church material derive from less impressive small fish.

The bird bone distribution in the St Patrick's Church material is similar to that found in Holyrood and the Cowgate (Smith 2006, Smith 2007). Domestic chicken dominates the material. Some goose and duck bones were present, possibly belonging to domestic birds as well. The only certainly wild bird in the St Patrick's Church material was the red grouse, previously identified in the Holyrood sample (Smith 2007).

\subsection{Crafts in St Patrick's Church}

The ditches included, among domestic waste, cattle horn cores likely to relate to horn working activities. Horn sheaths are used as raw material, and horn cores are deposited in the location where sheaths are separated from the useless cores. This is done at the latest by the horn-worker (Dobney et al 1996, 23). The separation of the sheaths could have been done earlier by either the tanner or the butcher, who would have sold the sheaths forward to the horn- worker (Armitage 1990, 84). However, as no other signs of tannery and butchery are present in this material (overrepresentation of other parts of the skull, lower parts of the legs, low utility skeletal elements) the horn cores are likely to derive from horn-working activities. Moreover, horn cores with cutmarks and sawn into cylindrical sections can usually be associated with horn-working (Schibler 1989, 151), both of which are present in the St Patrick's Church material. Large collections of cattle and goat horn cores interpreted as industrial waste have previously been found in Perth High Street material (Hodgson 1983, 5, 7).

A number of horse bones were recovered from the same ditch. None of them showed signs of meat removal: one exhibited chop marks consistent with dismemberment. Horseflesh consumption was forbidden by the Church during the medieval period (Egardt 1962, 109). However, butchered horse bones have been recovered in several Scottish medieval sites (eg Smith 1998; Smith 2007). The human consumption of horseflesh cannot be excluded. However, very few records are available and it is likely that horsemeat consumption was restricted to special circumstances or social groups (Wilson \& Edwards 1993, 51; Smith 1998, 876). Some evidence exists, especially from the post-medieval period, that horseflesh was fed to hounds (Wilson \& Edwards 1993, 52).

Even if horsemeat was not utilised, horse hides, bones, manes and tails were collected. A number of horse bones found in pits, ditches and waterfront dumps in London have been interpreted as disposals of (probably skinned) horse carcasses (Rackham 2004, 20-21). In medieval London dumping skinned horse carcasses was apparently illegal inside city walls, but the rule was not always obeyed (Clark 2004, 20; Rackham 2004, 20-21).

A bone assemblage recovered from Bedford analysed by Grant $(1979,105-6)$ exhibits similar features to the St Patrick's Church material from the medieval ditch. Horn cores of cattle in particular, but also from sheep and goat, were well represented. Horse remains were abundant in Bedford and they have been interpreted as a result of disposal of skinned horse carcasses. Skulls and metapodials were underrepresented in the sample, interpreted as being detached with the hides and transported elsewhere. Few butchery marks were present, but were regarded as signs of dismemberment for easier disposal and burial. The St Patrick's Church horse bone sample could represent similar activities. No skulls or mandibles were recovered and bones from the lower extremities were scarce. Bones were complete and no signs of meat utilisation were evident. The ditch could have been used for disposing of unpleasant waste of an industrial nature, for example cattle horn cores and skinned horse carcasses. A sample of horse bones interpreted as carcass dumping has previously been identified in Eyemouth, however here all the anatomical parts were presented (Henderson 1986, $62)$. 


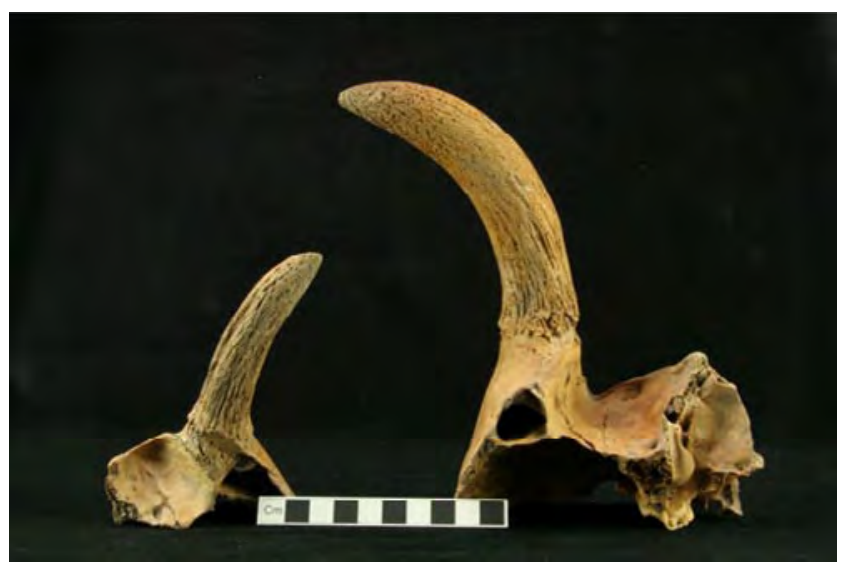

Illus A2.6 Cattle horn size and shape variation found in the Cowgate material

\subsection{Animal outer appearance}

Unfortunately, only a few cattle bone measurements were available from the St Patrick's Church material and no withers height could be reconstructed. The available measurements do, however, show that the cattle were small in size. Cattle horn cores show variable size and shape. The shortest one is only 95mm long (category 'small' according to Armitage and Clutton-Brock 1976), a curious upward-pointing horn (illus A2.6). Other horn cores were either 'short' (96-150mm, $\mathrm{n}=2$ ) or ' medium' (between 150 and $200 \mathrm{~mm}, \mathrm{n}=5$ ). The observed range and variability of horn core length seems to be in line with the previous results from Scottish medieval assemblages: the shortest horn core from Perth is just $32 \mathrm{~mm}$ and the longest $237 \mathrm{~mm}$ (Hodgson 1983, 27).

The average withers height of sheep in the St Patrick's Church material was $55.9 \mathrm{~cm}$. Sheep bones from previous studies in Edinburgh and Perth have shown a similar range, however, especially in the Cowgate, Edinburgh, a number of smaller individuals were present (Smith 2006, Hodgson 1983, 29-30). This is probably due to the small sample size of the St Patrick's Church site. No horn cores or polled skulls of sheep were recovered in the St Patrick's Church excavations, but previous studies have shown a great variability from four-horned individuals to polled sheep (Hodgson 1983, 11, Smith 2006).

The average horse withers height in the $\mathrm{St}$ Patrick's Church material was only $c 133 \mathrm{~cm}$, with a range of $126-140 \mathrm{~cm}$. Thus, these animals are better described as ponies (under $147.3 \mathrm{~cm}$ or 14.2 hands). This again is in line with previous results (Smith $1998,871-2)$. These animals were probably common work animals used as pack and carthorses and for riding (cf Smith 1998, 875). They were likely to form most of the horse population in the medieval town, the larger quality riding horses being in the minority (cf Clark 2004, 32; Smith 1998 871-3). The observed pathologies in the horse bones probably relate to the stress caused by their use. 


\section{APPENDICES}

Appendix 6.1

Division of epiphyses in early, intermediate and late fusing groups (Vretemark 1997)

\begin{tabular}{lll}
\hline Cattle, sheep, goat & \\
\hline Early & Intermediate & Late \\
Scapula tuber & Mc dist & Humerus prox \\
Humerus dist & Mt dist & Radius dist \\
Radius prox & Tibia dist & Ulna prox \\
& & Femur prox \\
& & Femur dist \\
& & Tibia prox \\
& & Calcaneus \\
& & \\
\hline Pig & Intermediate & Late \\
\hline Early & Mc dist & Humerus prox \\
Scapula tuber & Mt dist & Radius dist \\
Humerus dist & Tibia dist & Ulna prox \\
Radius prox & Calcaneus & Femur prox \\
& & Femur dist \\
& & Tibia prox \\
\hline
\end{tabular}

Appendix 6.2

Anatomical distribution of the animal bones in material (NISP): LM = large mammal, $M M=$ medium mammal, $S M=$ small mammal, $\mathrm{sh} / \mathrm{g}=$ sheep/goat

See following pages 


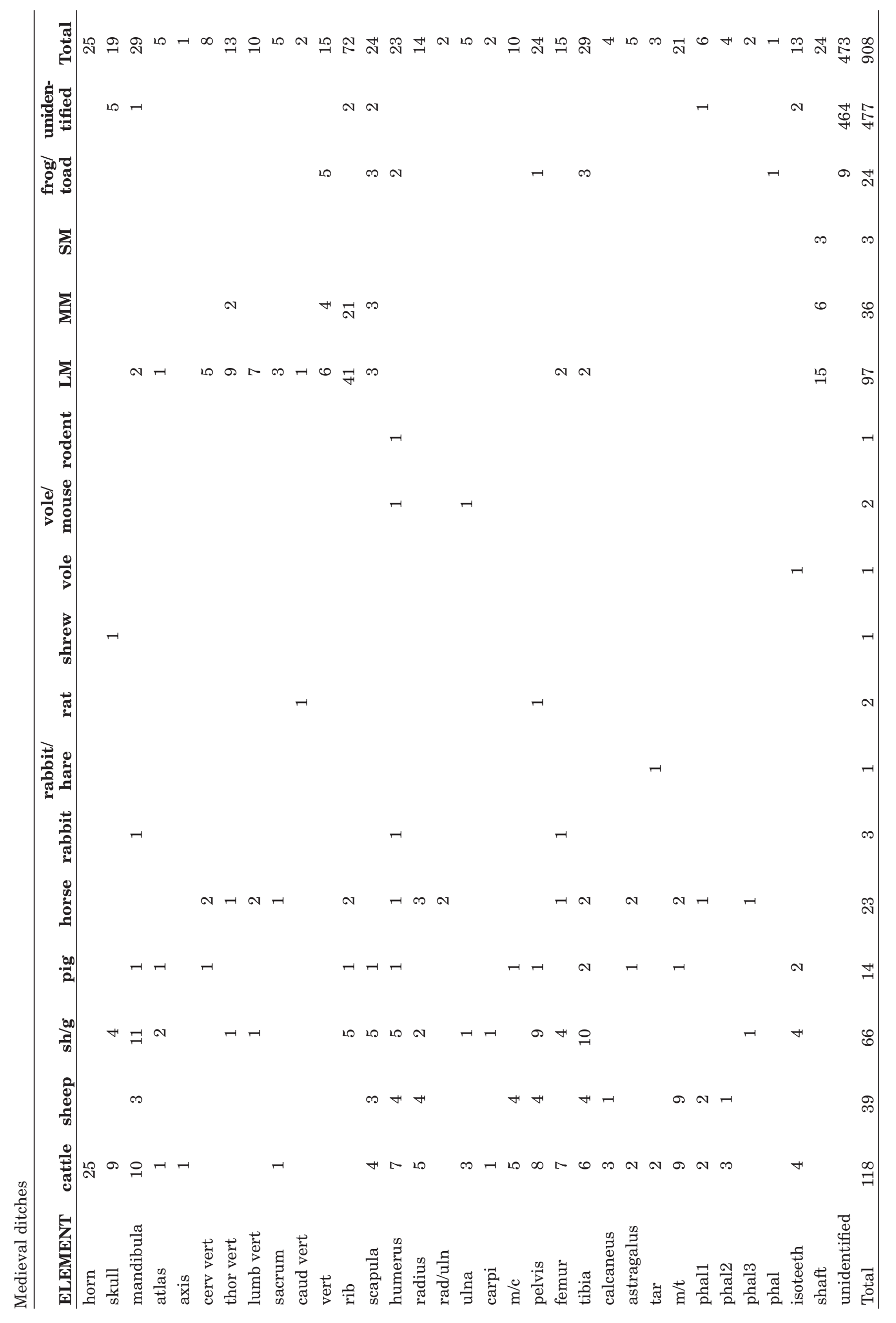




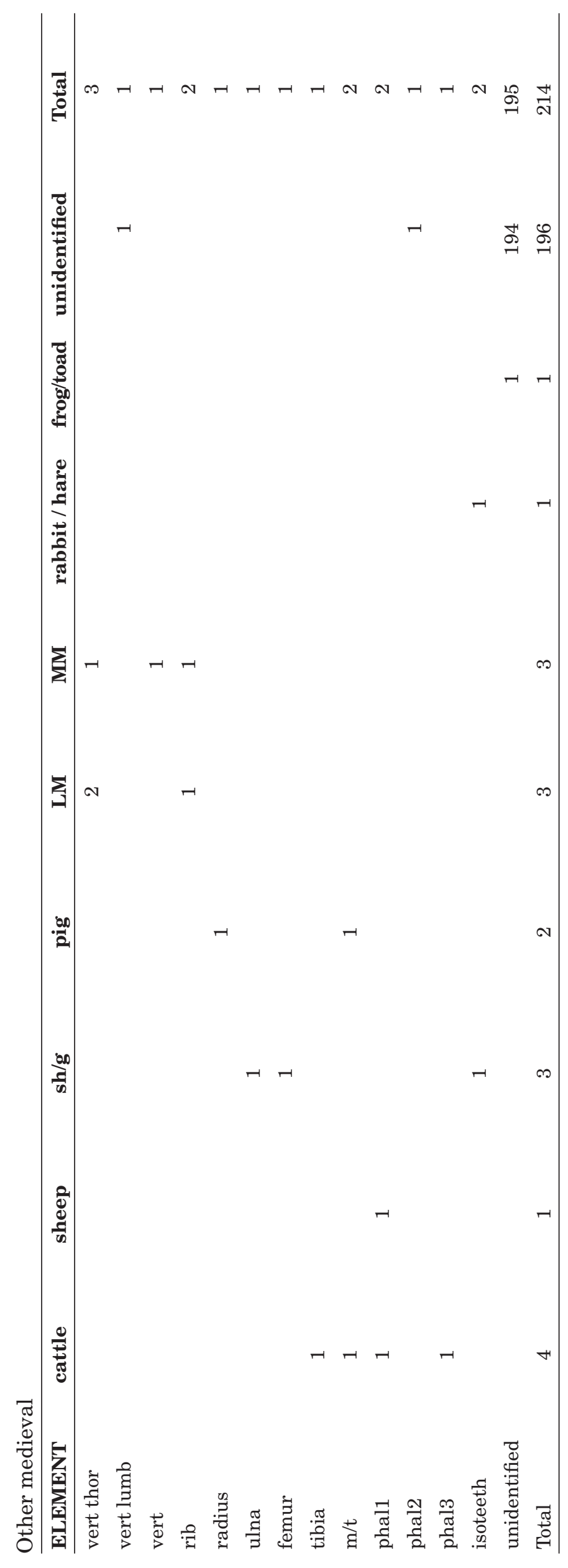




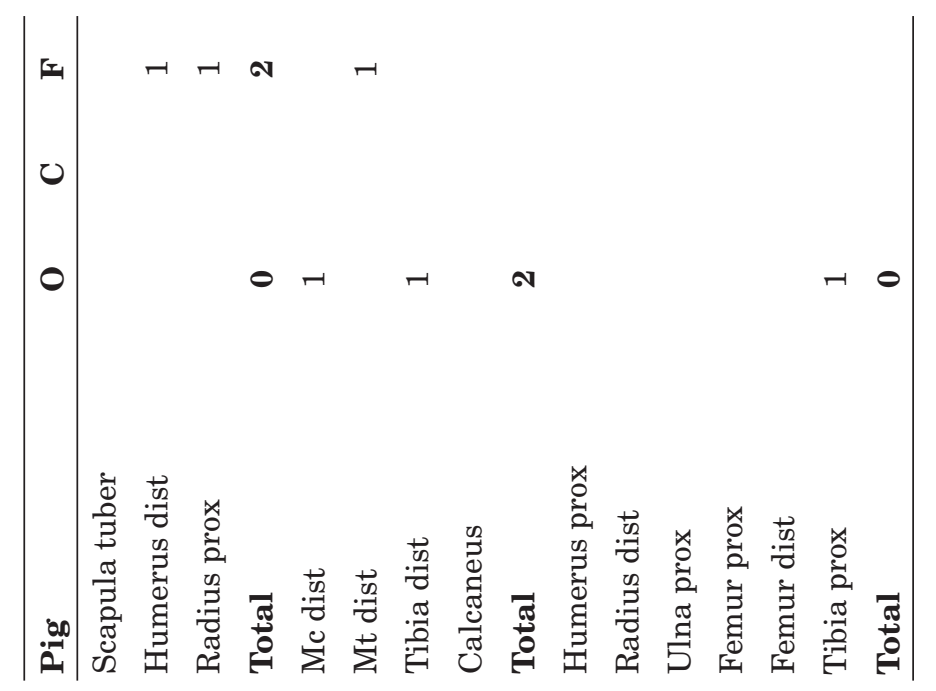

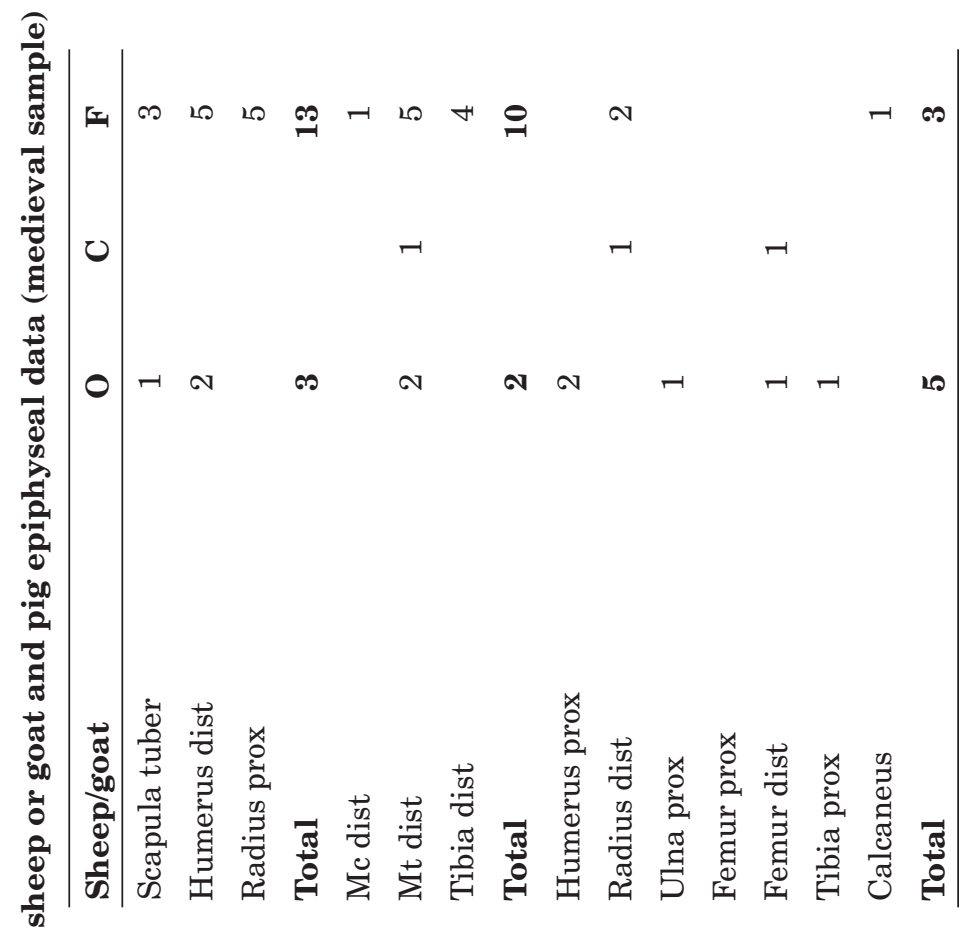

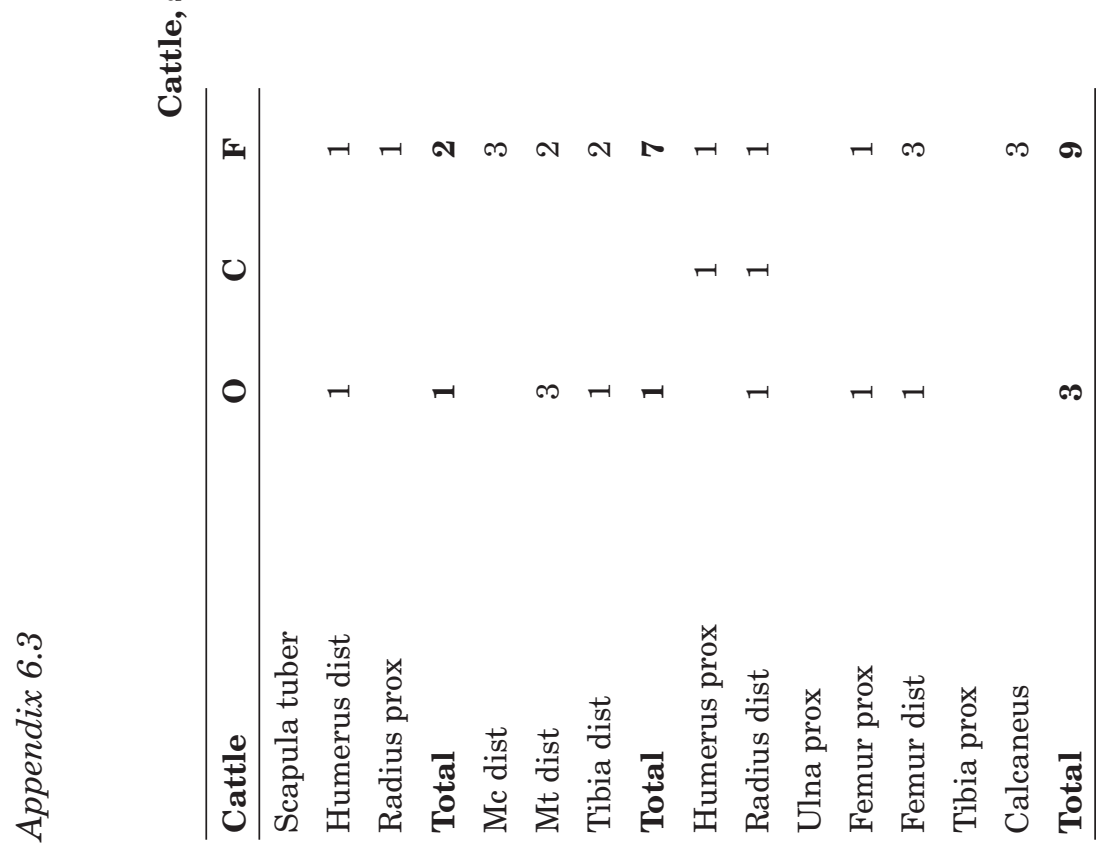




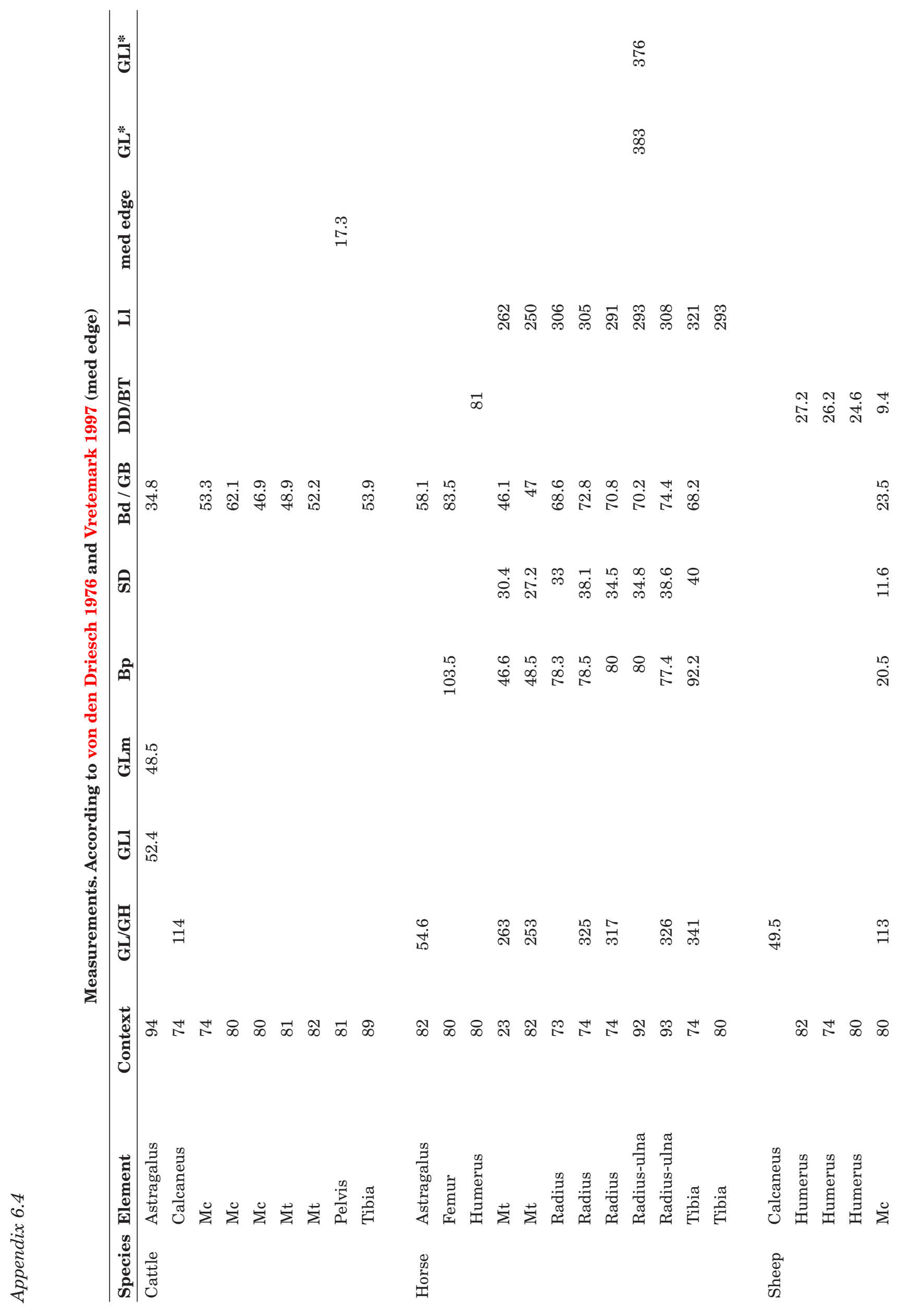




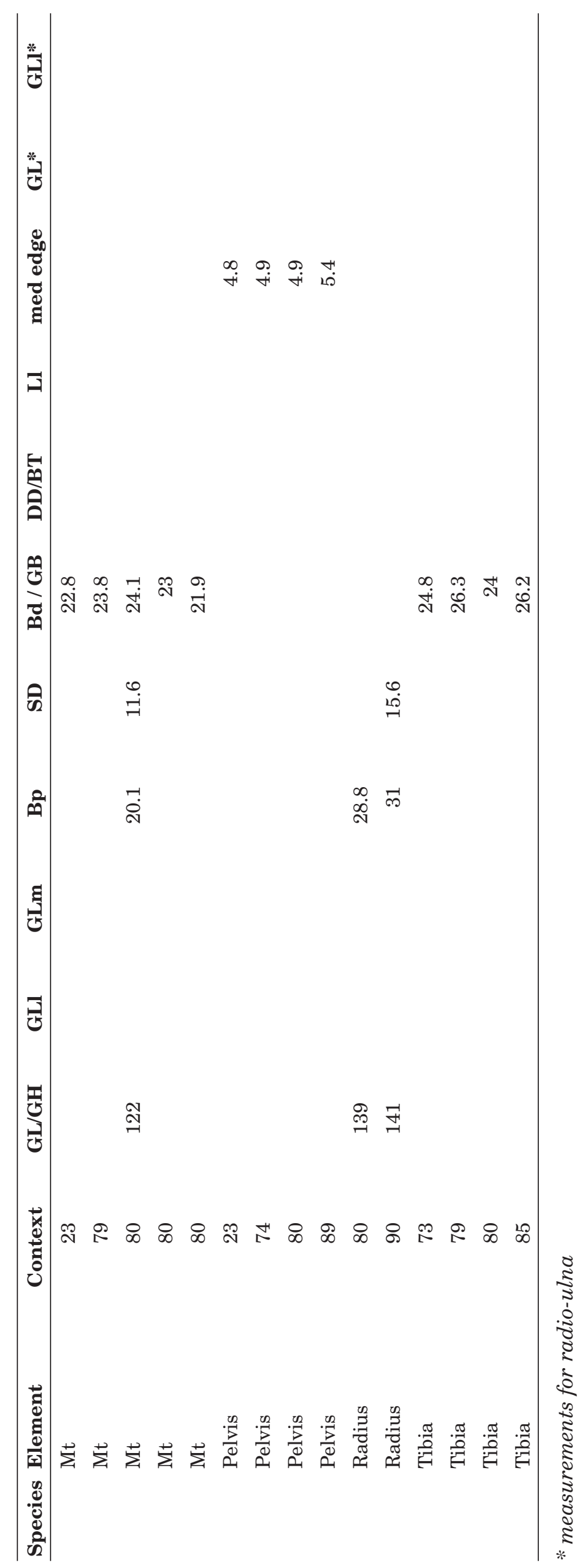




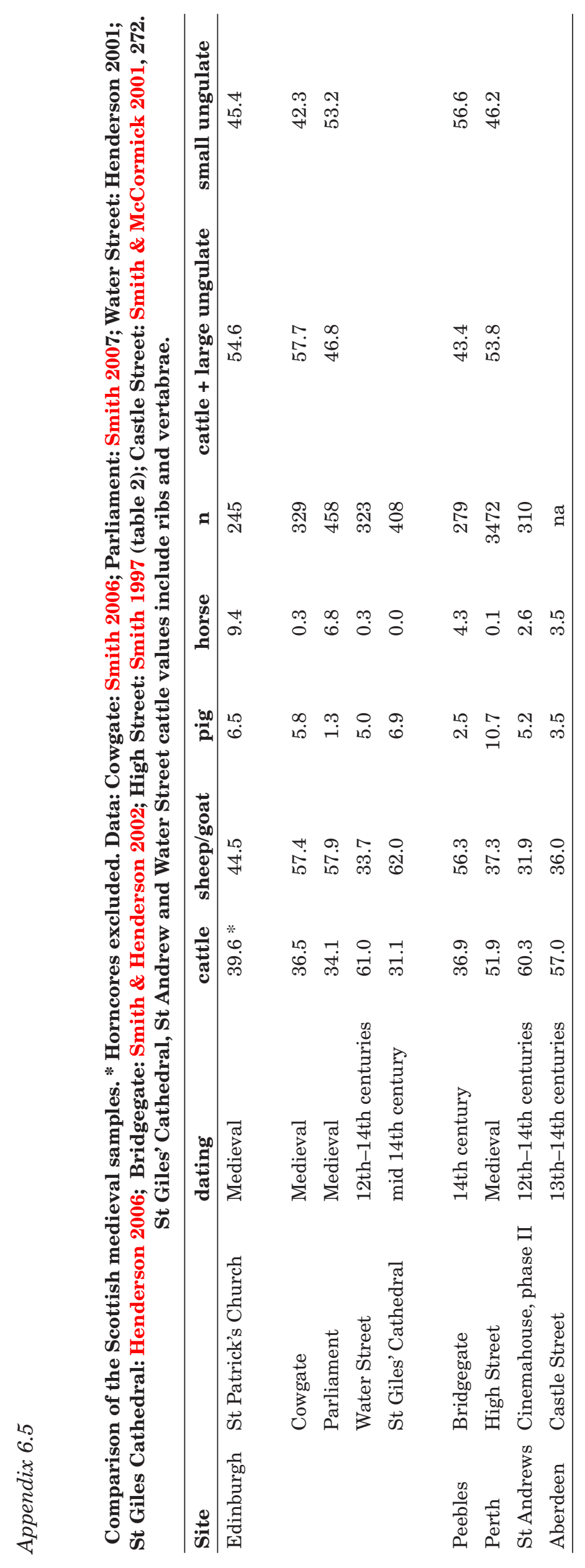




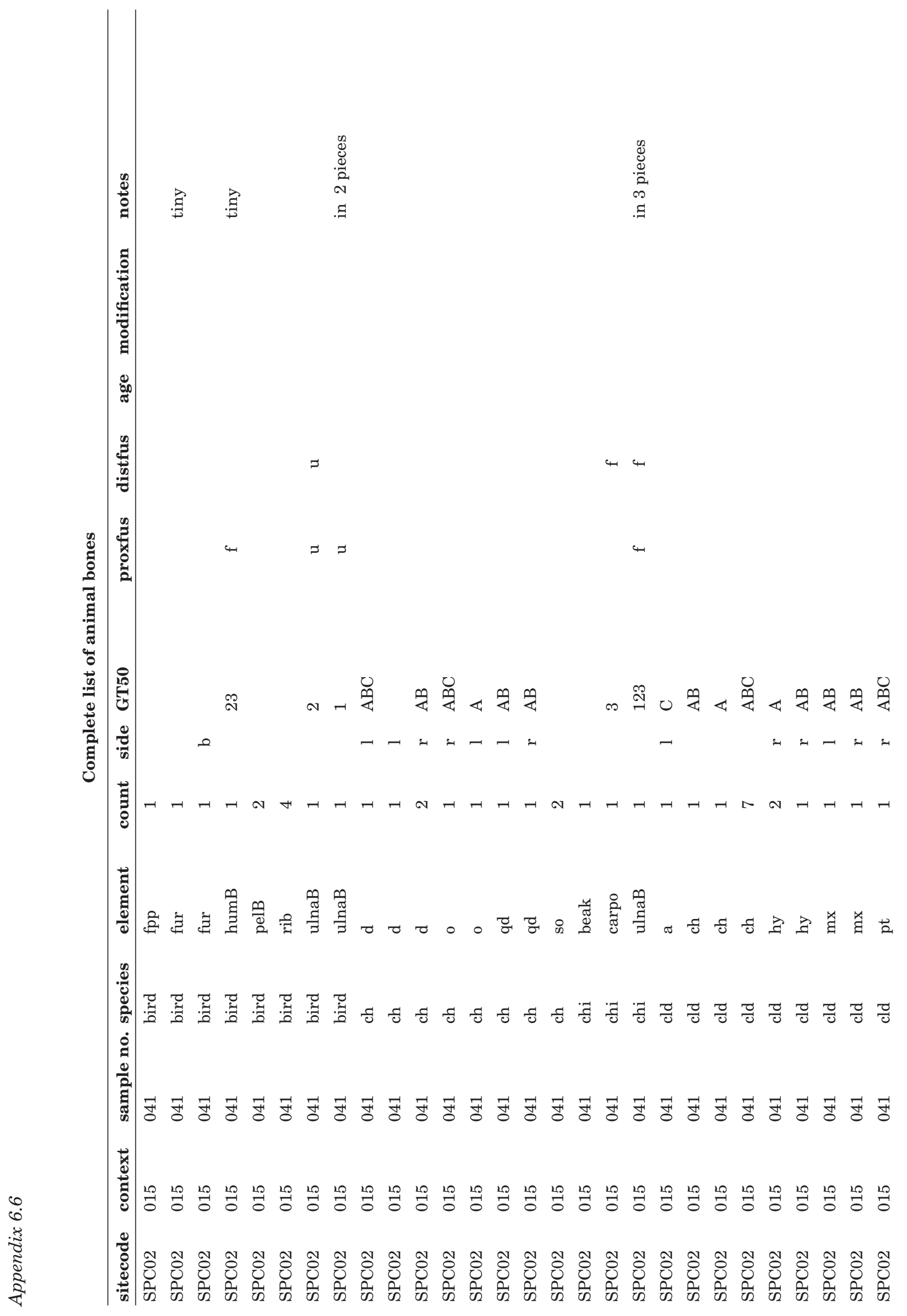




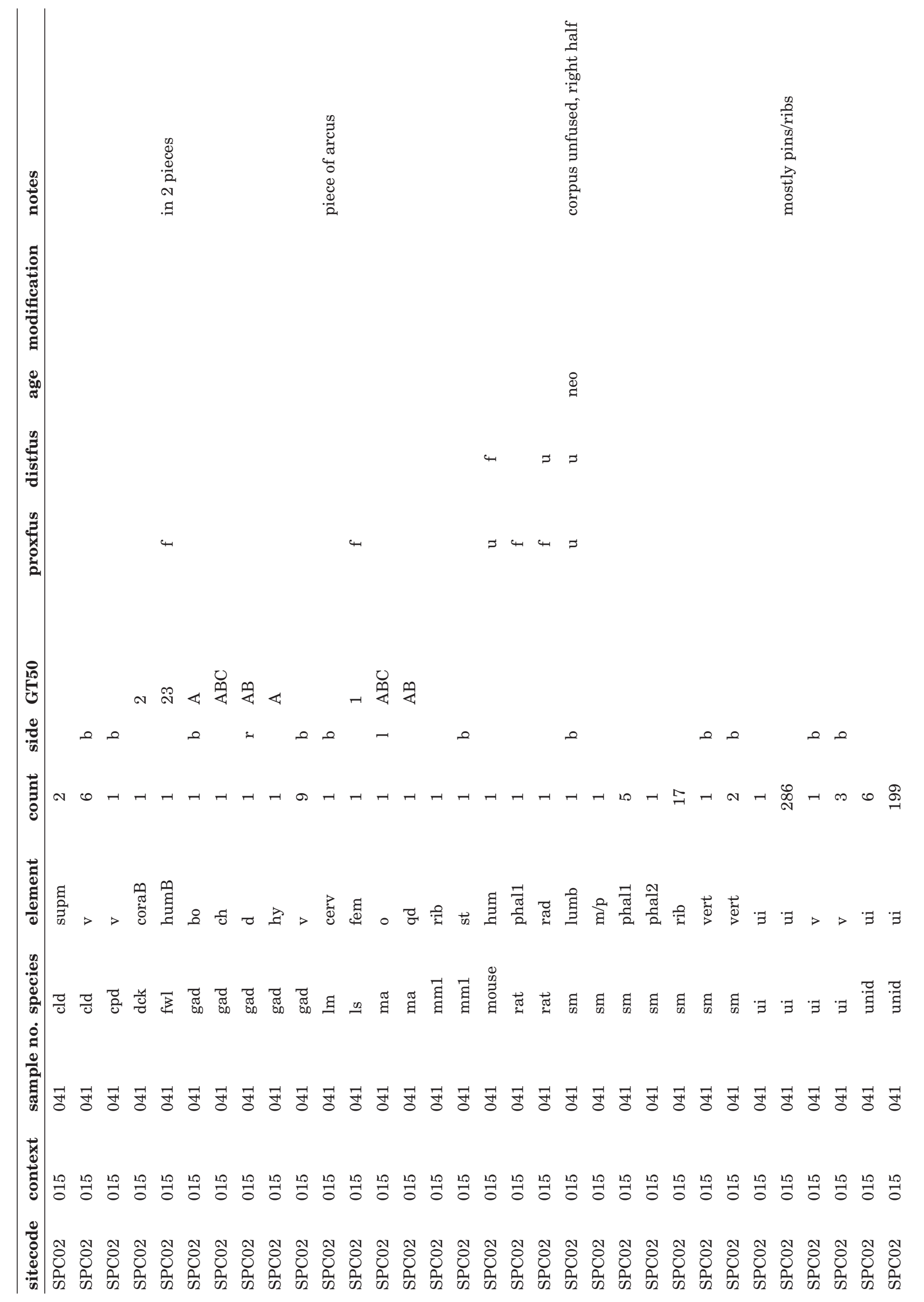

86 


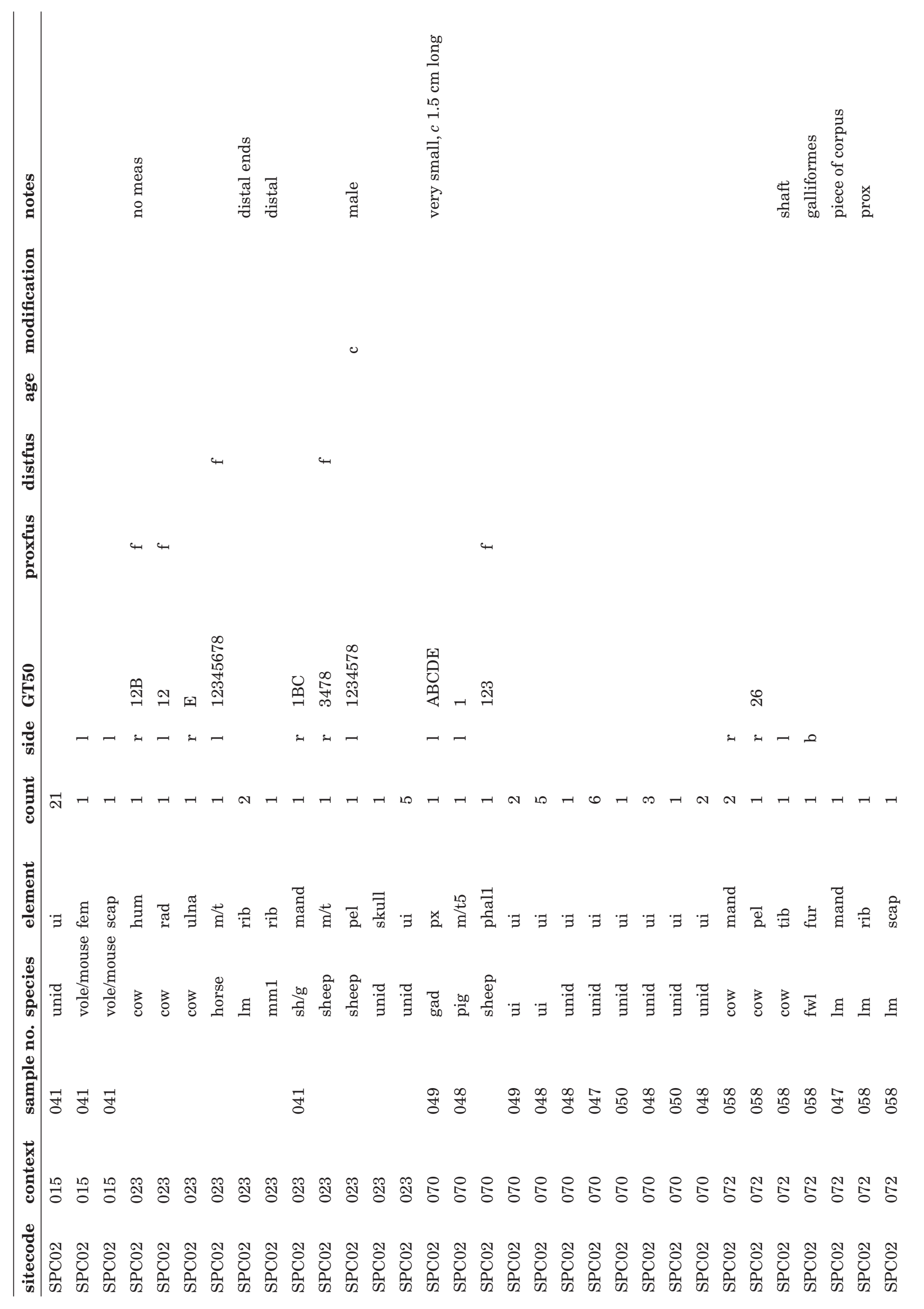









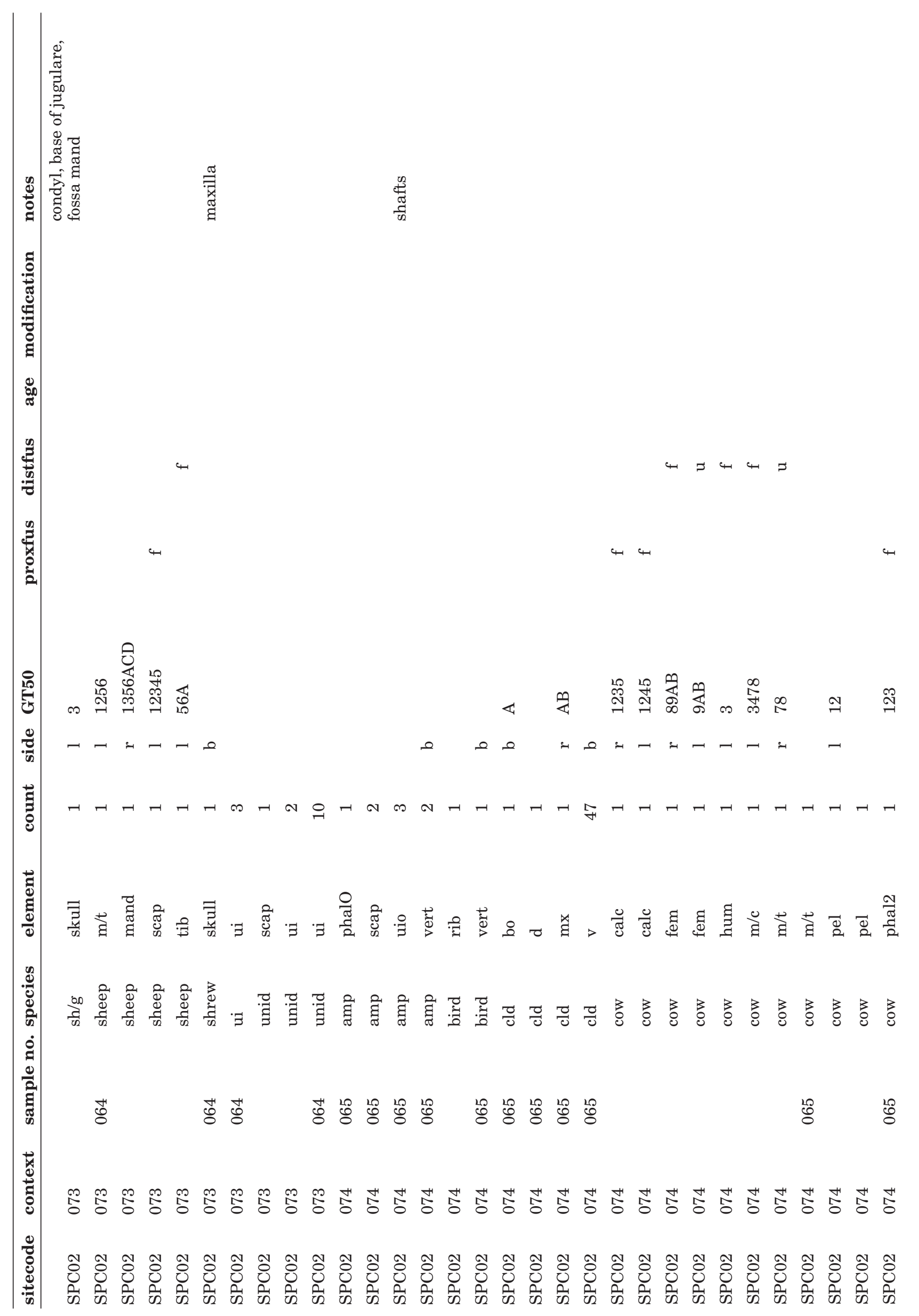




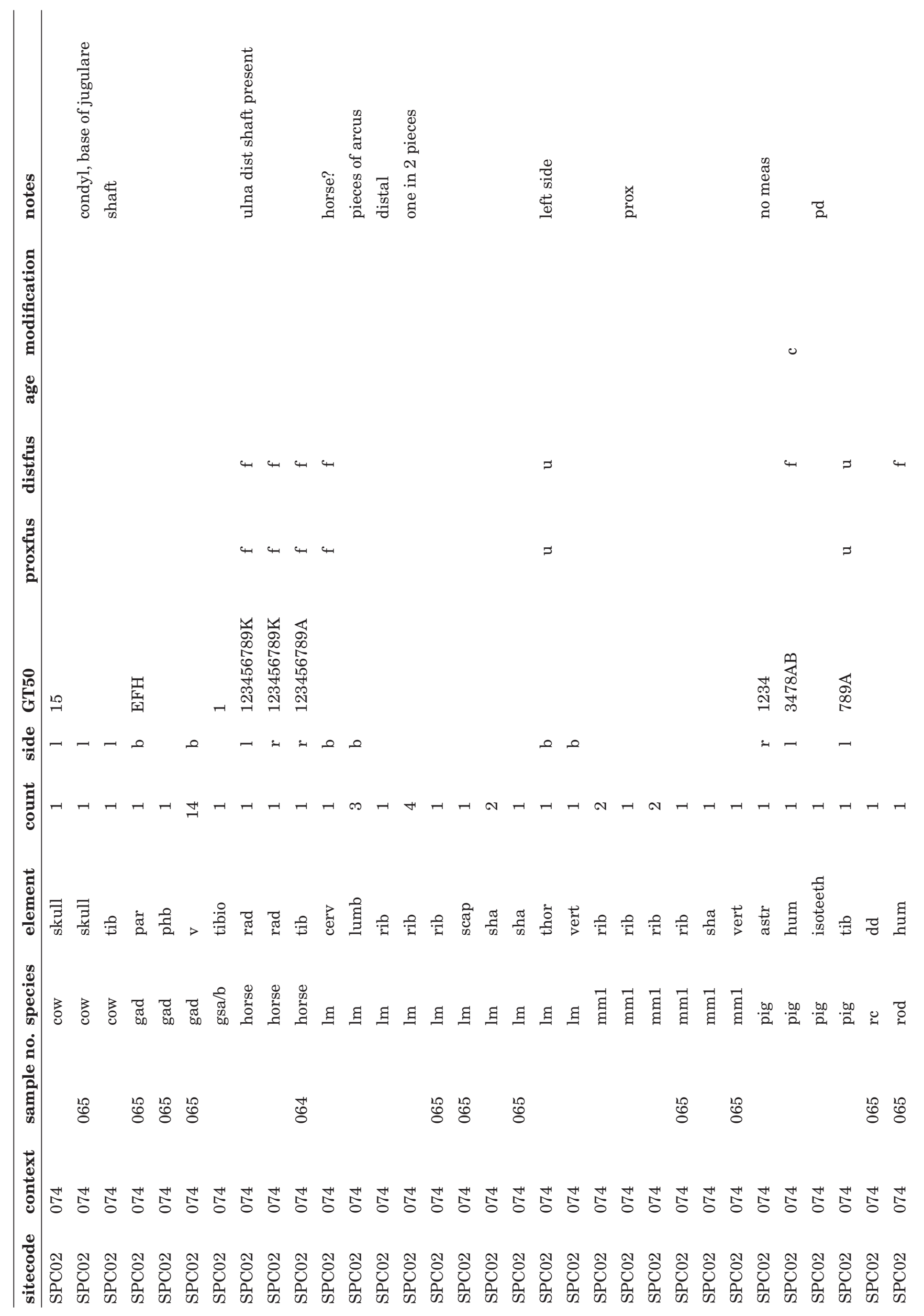




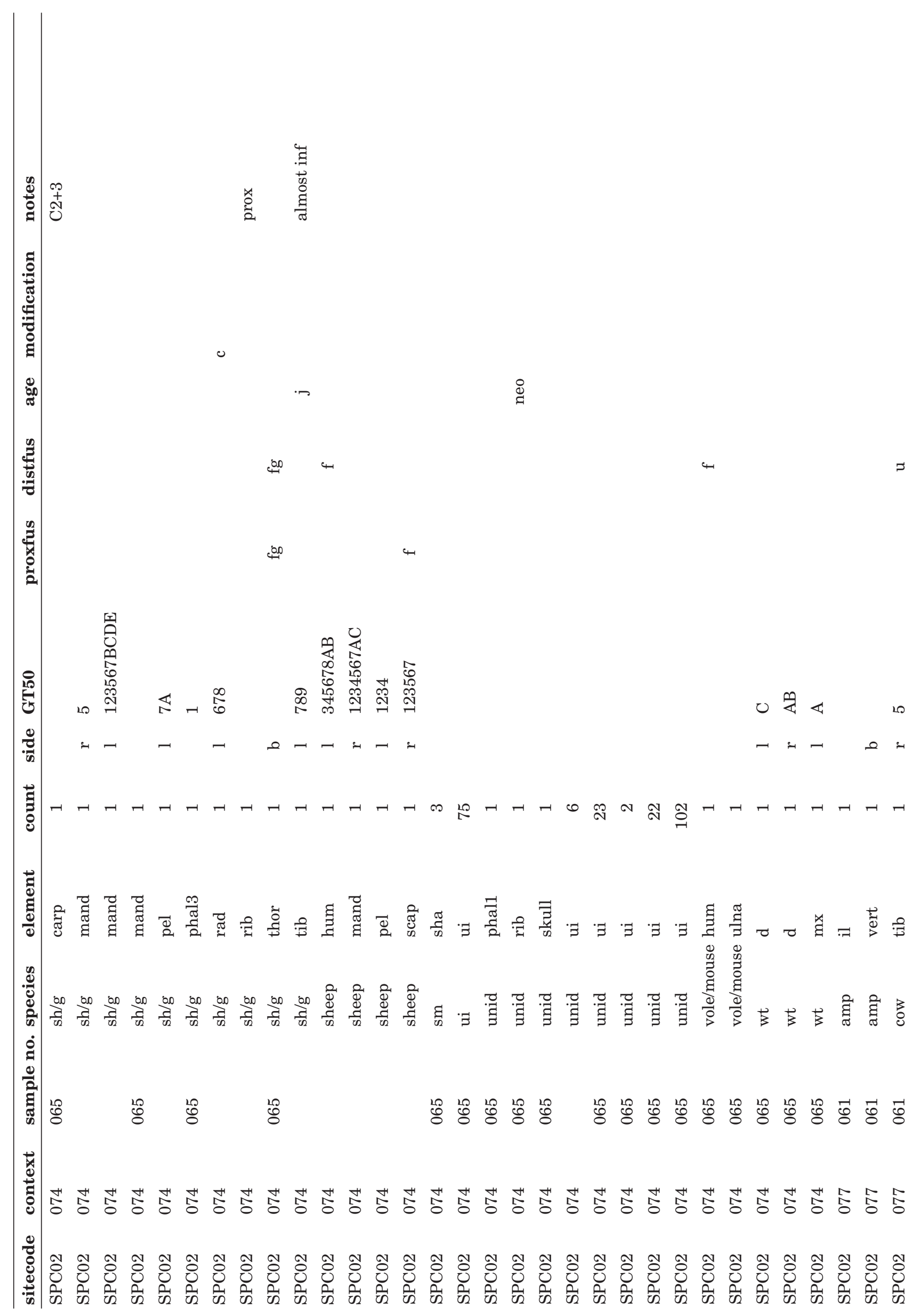




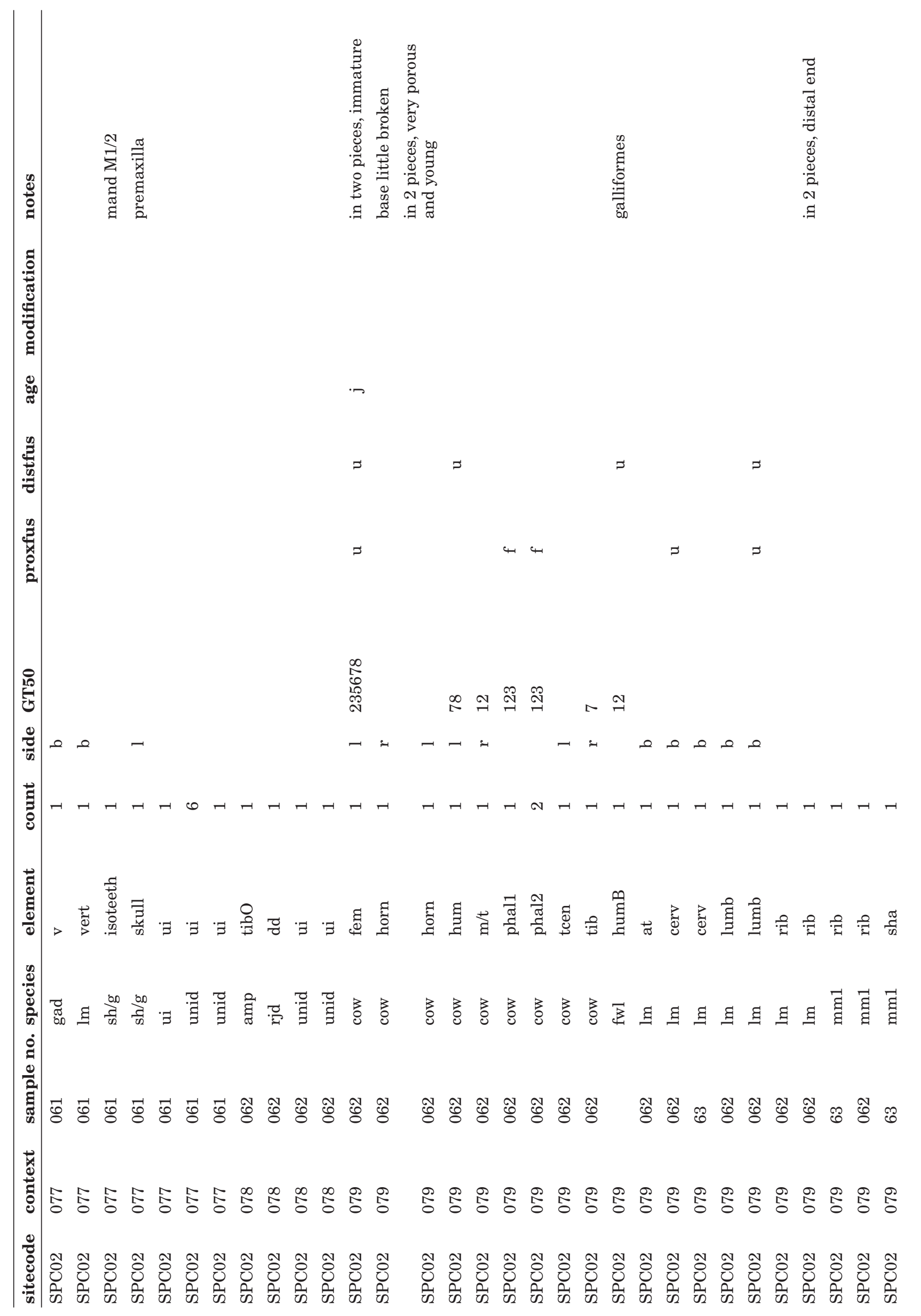




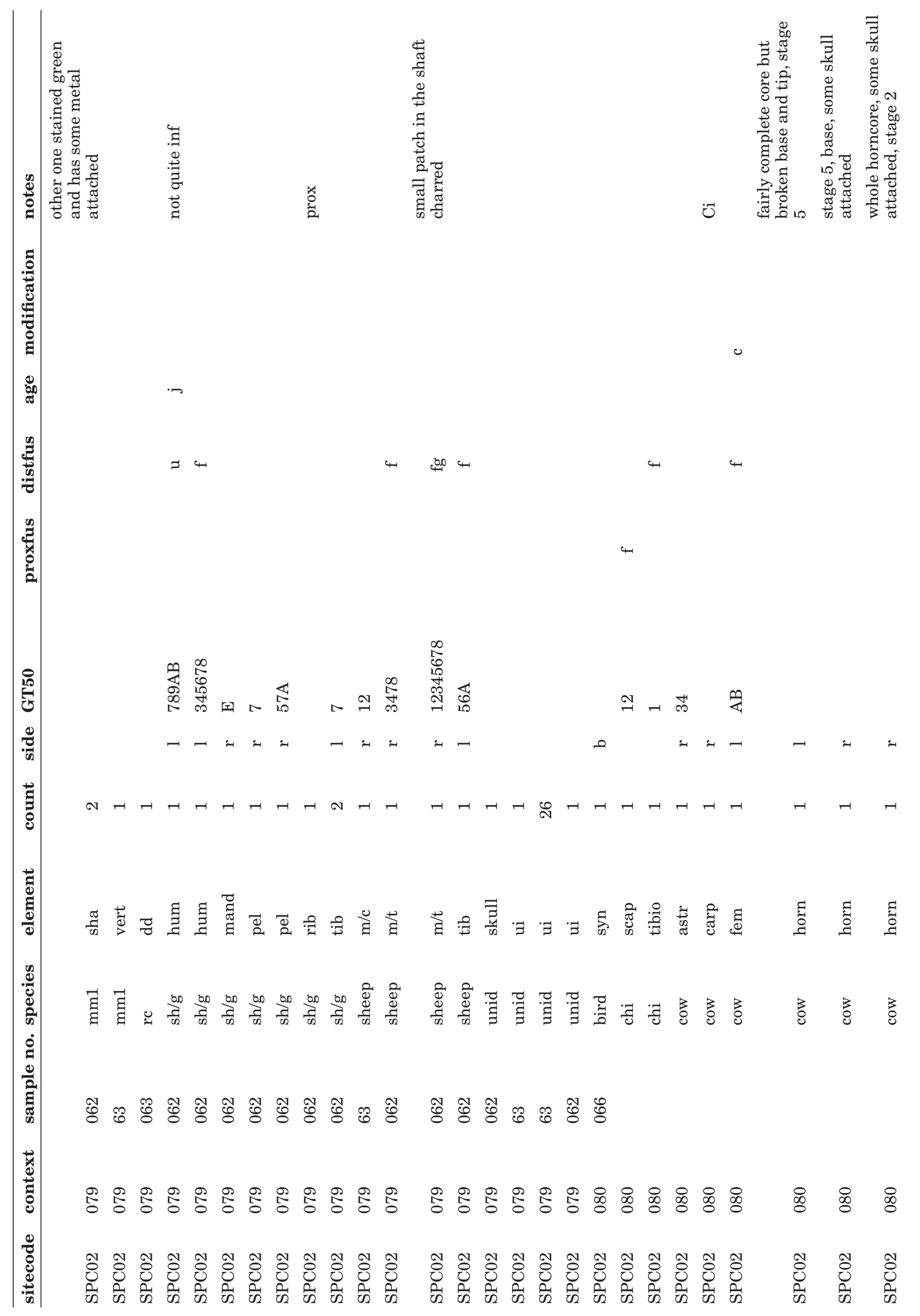




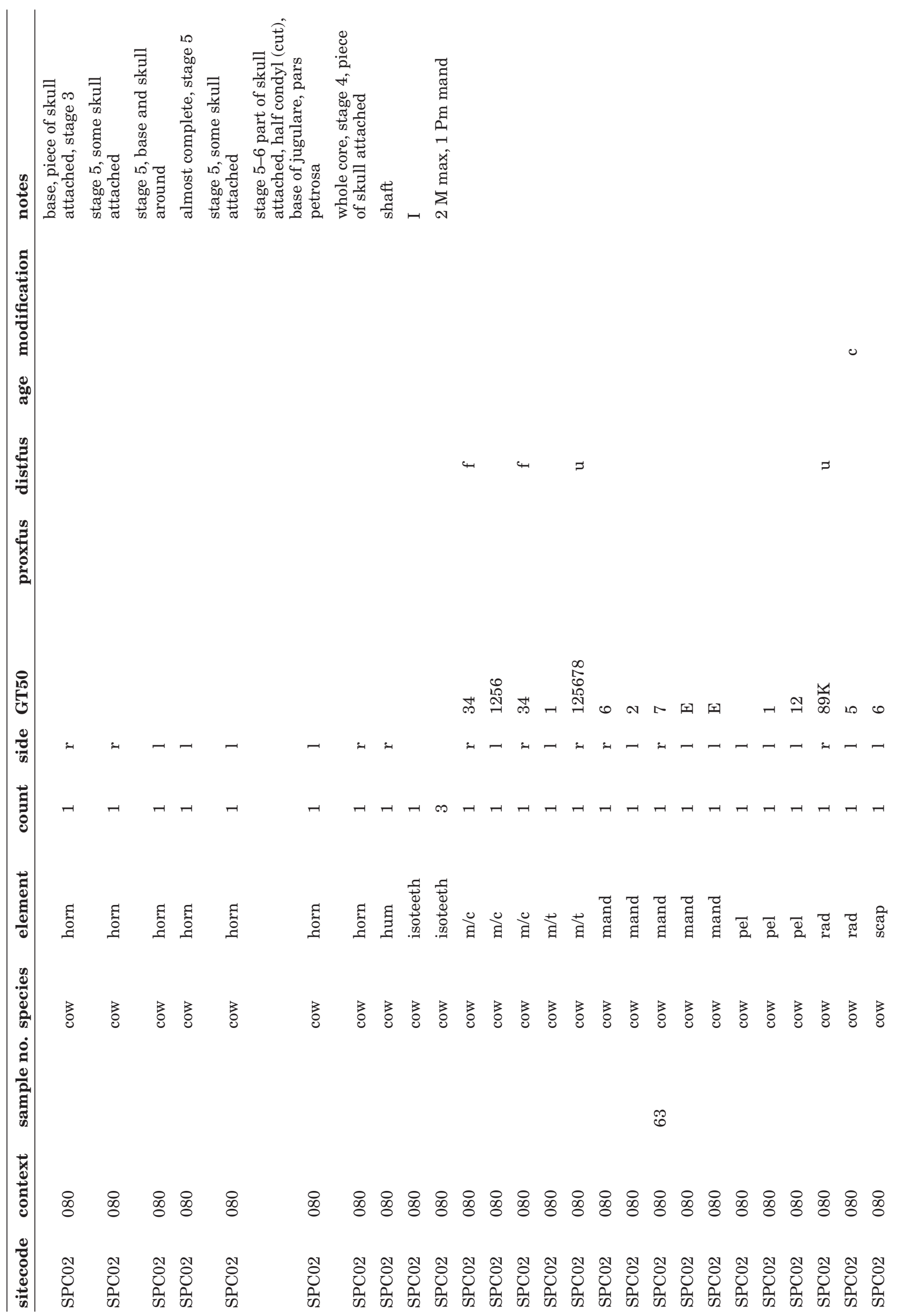




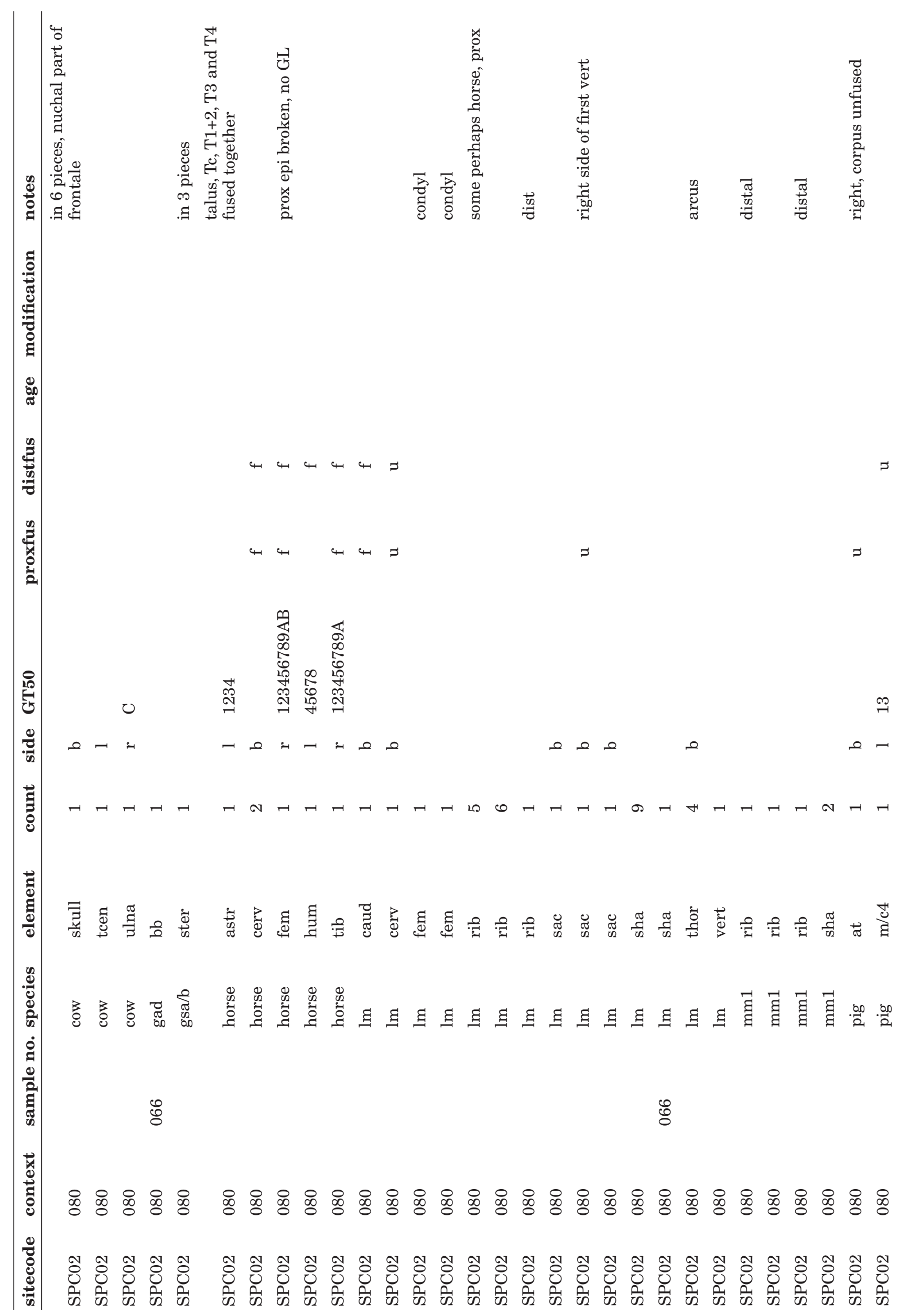




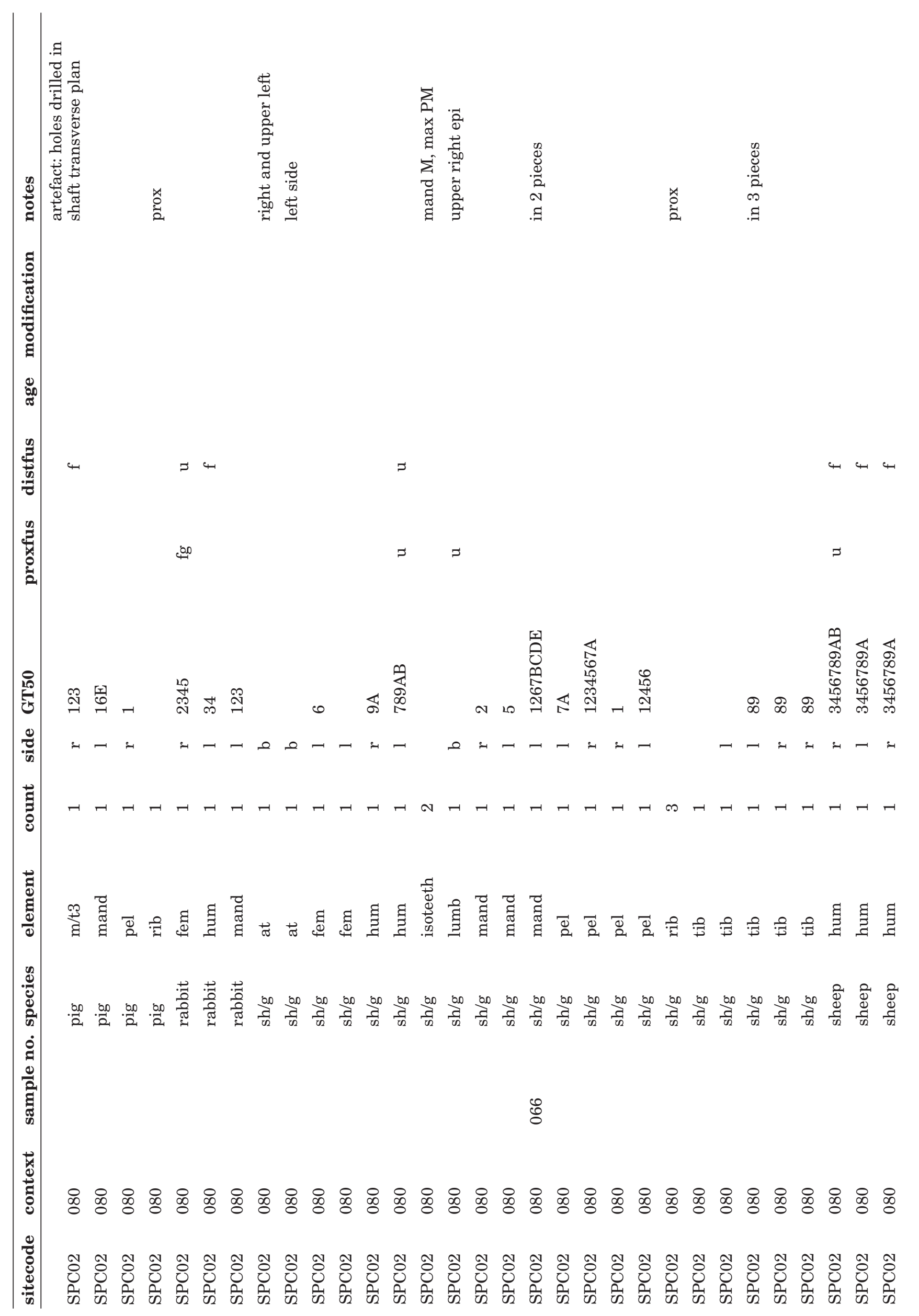




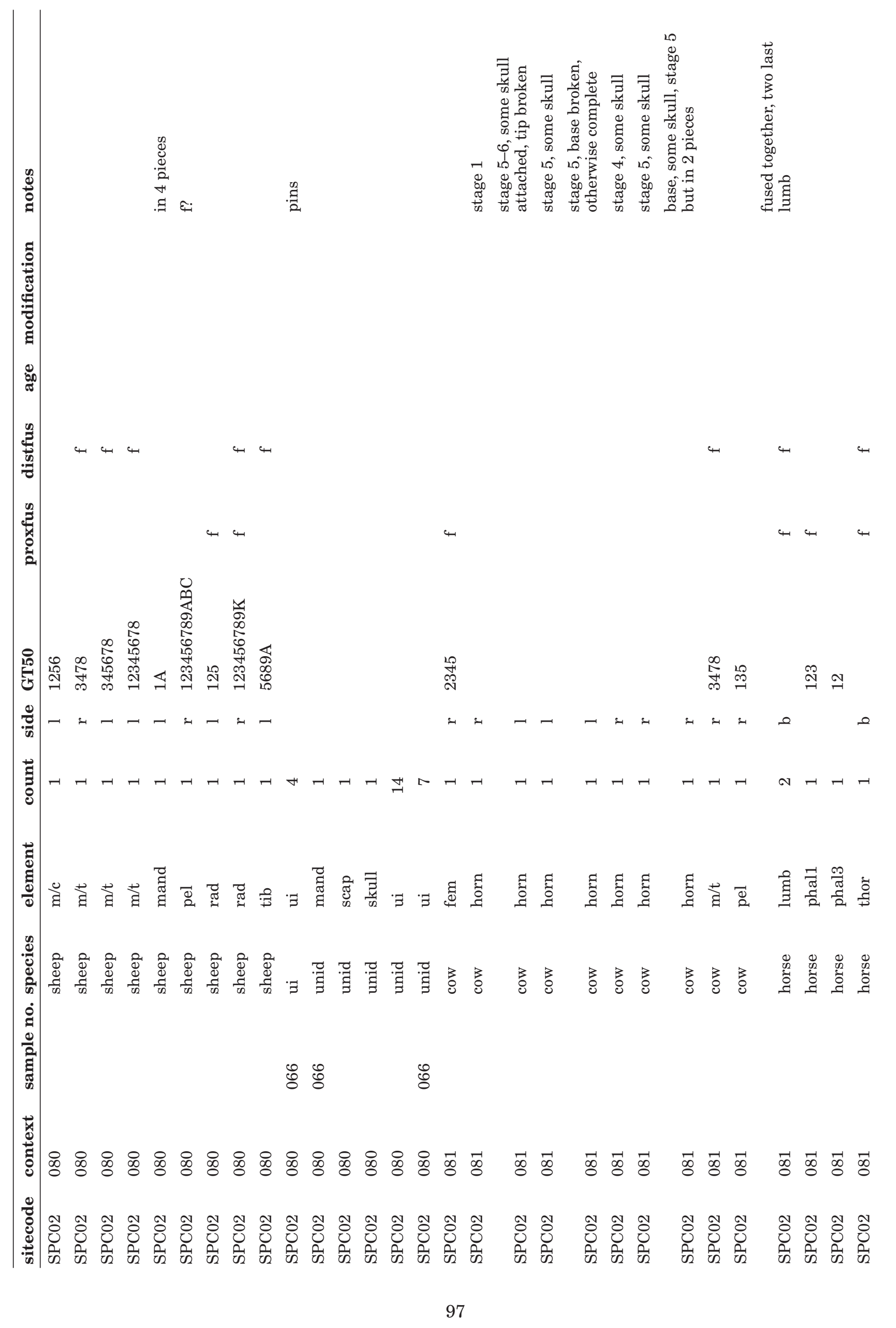




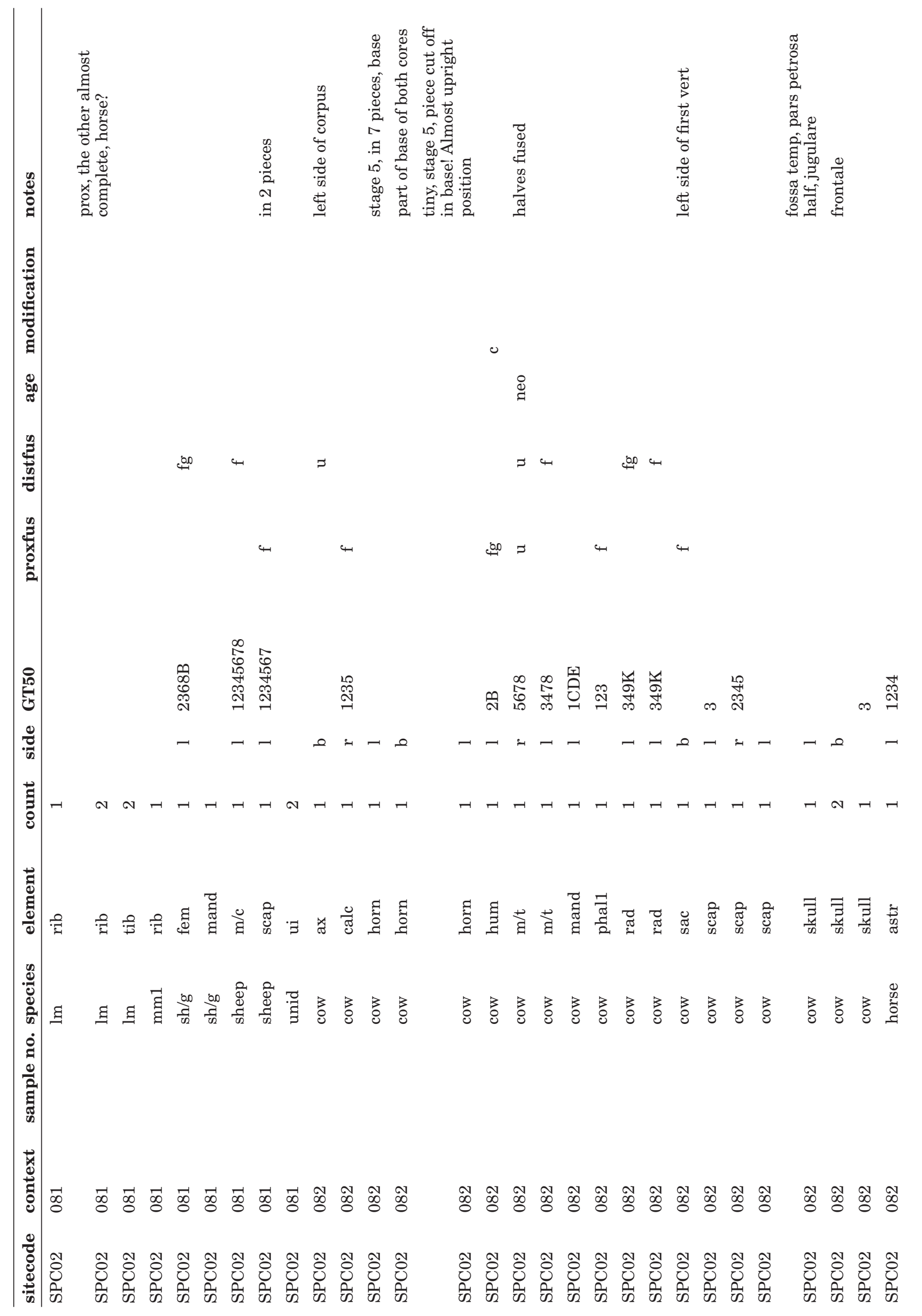




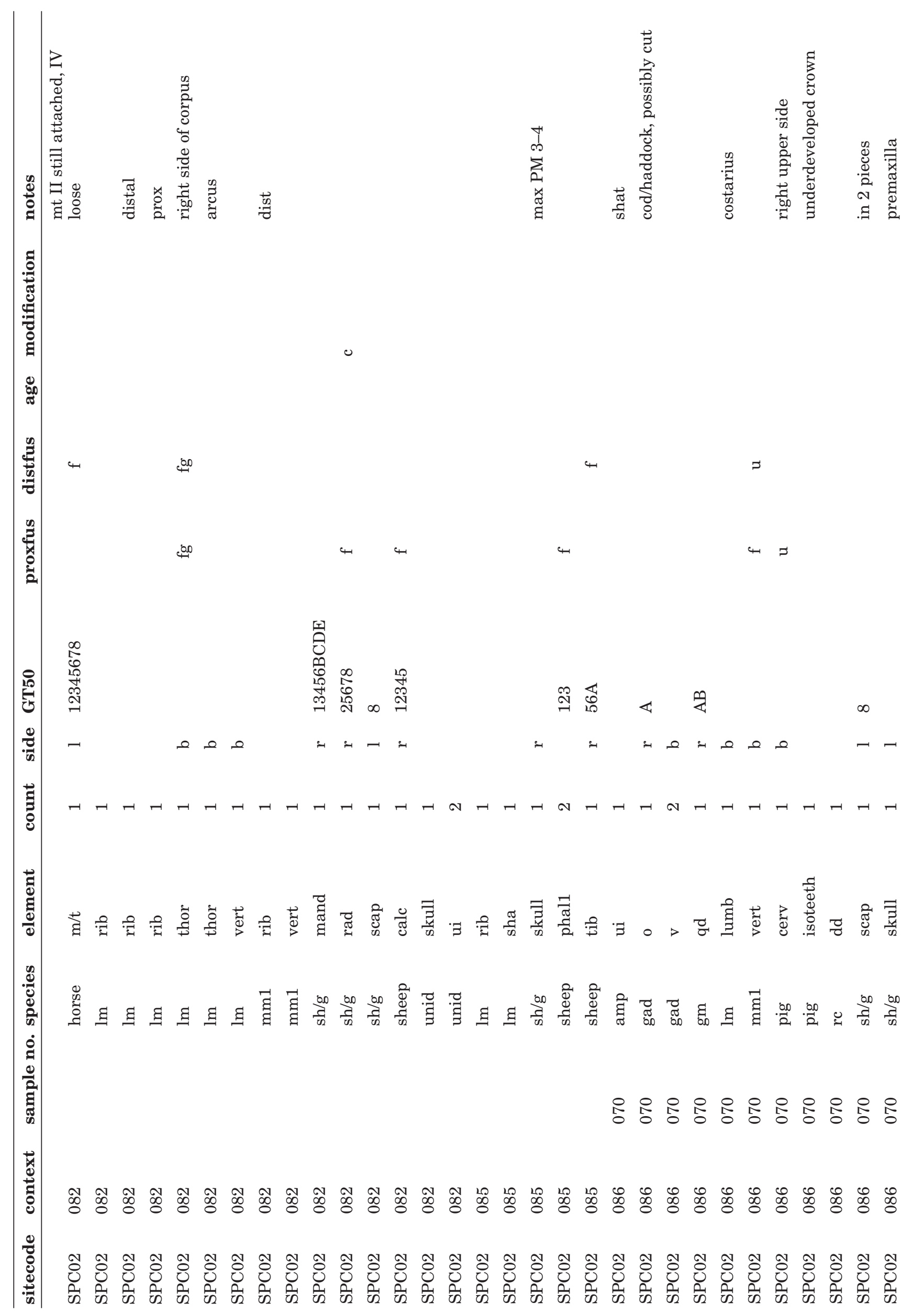




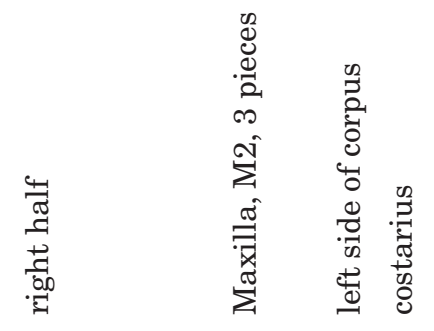

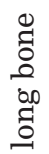

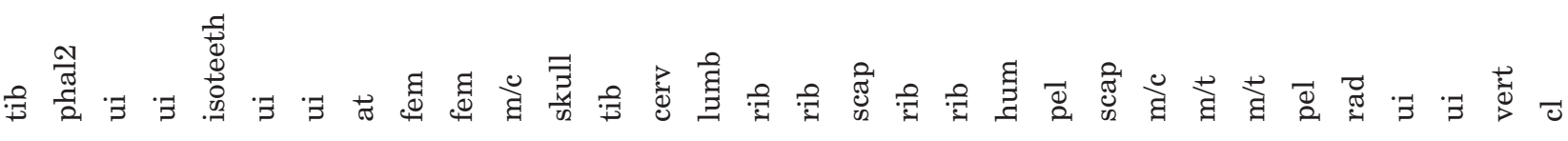

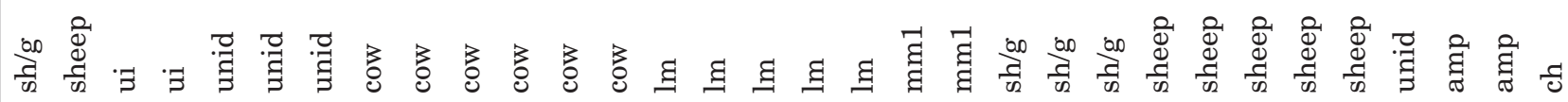

옹옹옹옹옹옹옹

: 


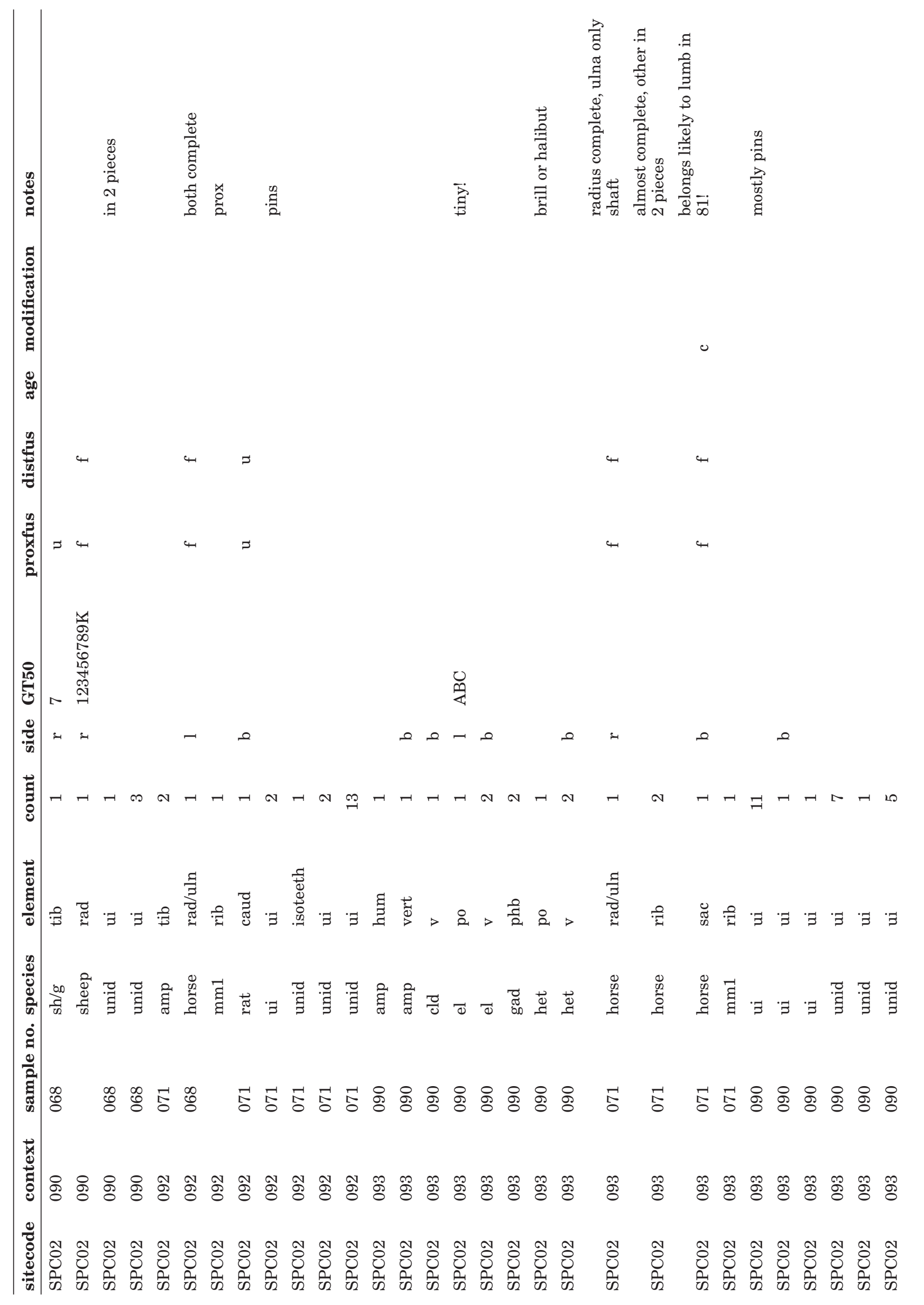




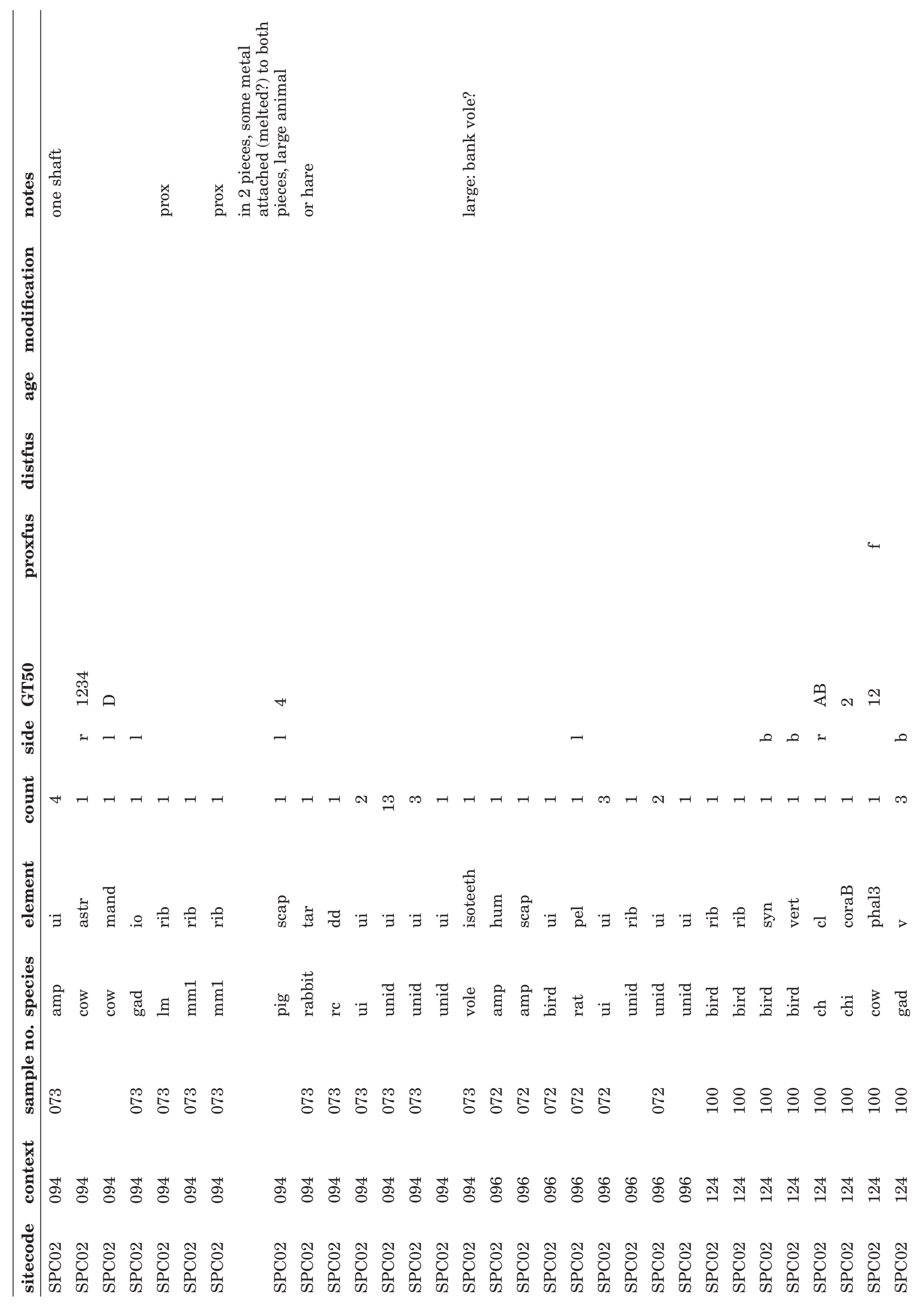




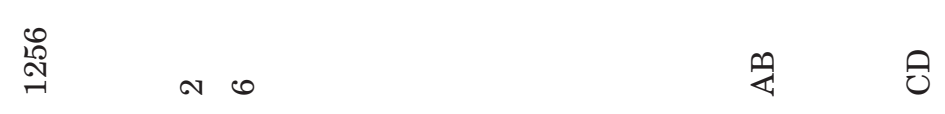

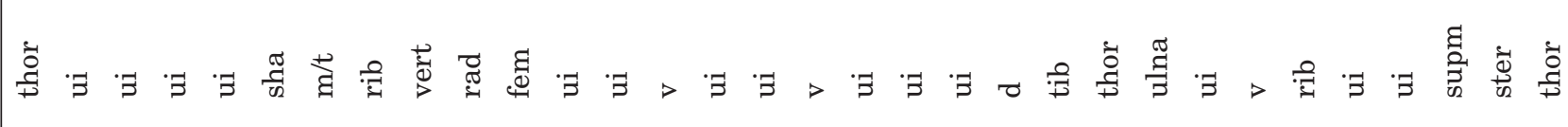

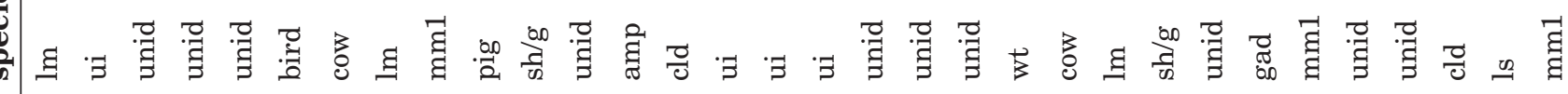

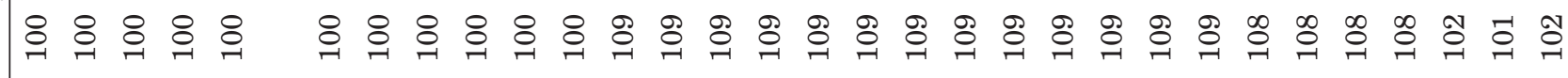

:

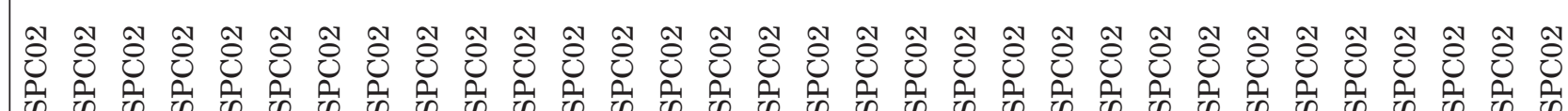




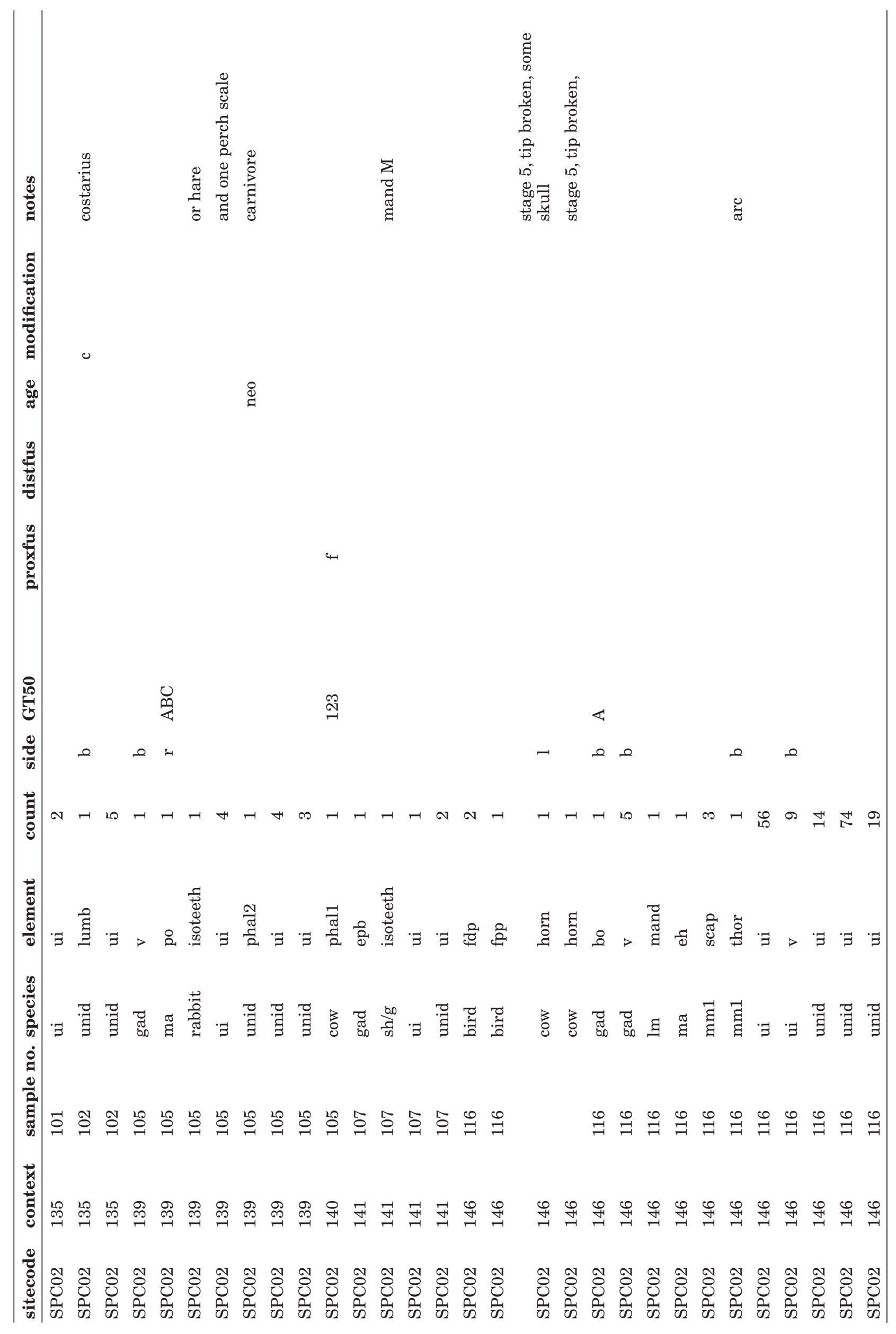




\title{
Appendix 3-Soil thin sections
}

\author{
Stephen Lancaster
}

Headland Archaeology Ltd, 13 Jane Street, Edinburgh EH6 5HE 



\section{APPENDIX 3: CONTENTS}

LIST OF TABLES $\ldots \ldots \ldots \ldots \ldots \ldots \ldots$

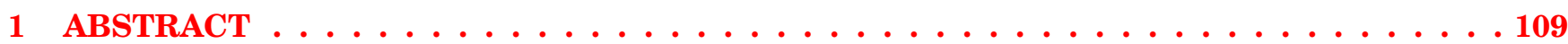

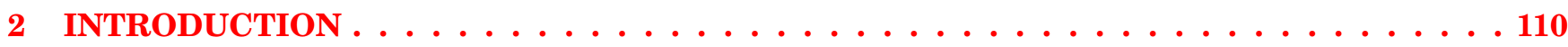

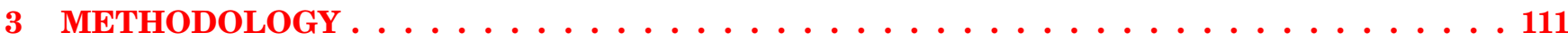

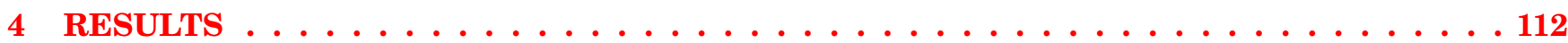

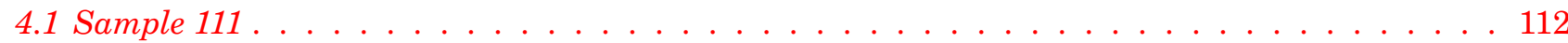

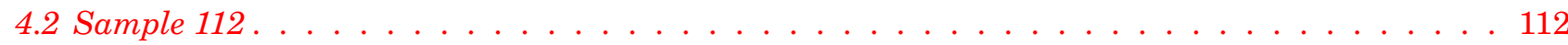

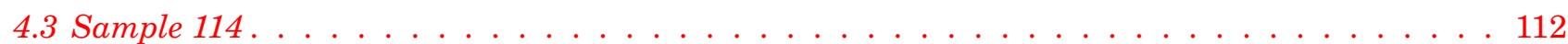

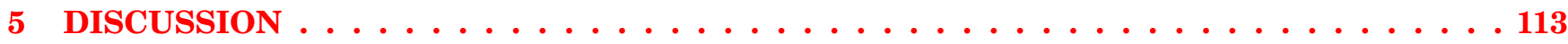

5.1 Depositional sequence . . . . . . . . . . . . . . . . . . . . . . . . 113

5.2 Archaeological implications . . . . . . . . . . . . . . . . . . . . . . . . . . . 113 


\section{LIST OF TABLES}

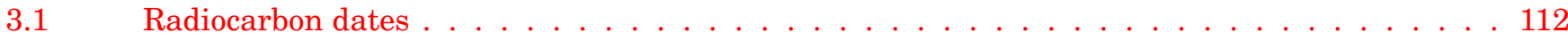

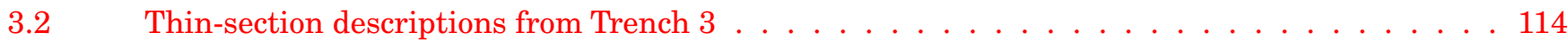




\section{ABSTRACT}

Soil thin-section samples were taken from Trench 3 at St Patrick's Church, Cowgate. The samples were analysed in order to investigate the processes of formation of the lower deposits on the site. The lower deposits have accumulated by slope wash, with one demonstrable episode of flash flooding. The deposition of the lower deposits probably represents the impact of the extension of settlement upslope in the Old Town. 


\section{INTRODUCTION}

The objectives of the excavation included furthering our understanding of the development of the Cowgate during the medieval period, specifically through investigating the deposit formation processes at the site. Of the excavated trenches, it was determined that samples from Trench 3 offered the greatest opportunity for undertaking this investigation. 


\section{METHODOLOGY}

The samples for thin-section analysis were taken in Kubiena tins from the side of Trench 3. Thin sections were prepared from three soil blocks. Resin impregnation and thin-section preparation were undertaken by the Department of Geography, Royal Holloway University of London, and followed standard procedures (Murphy 1986). The thin sections were recorded under a variety of lighting techniques using the descriptive scheme and terminology recommended by Bullock et al (1985), as supplemented and modified by Courty et al (1989). 


\section{RESULTS}

Descriptions of the thin sections are given in Table 3.2. Particularly salient points are noted below.

\subsection{Sample 111}

Sample 111 was taken from Context [070]. The sample comprises two zones. Zone 1, the upper zone, is predominantly composed of fine material, with thin laminae of fine sand, 500-2000 $\mu \mathrm{m}$ thick distributed across most of the depth of the zone. Fragments of plant tissue, with a thin 'filament' shape are found throughout the fine fraction, with an orientation that matches that of the sand laminae.

Zone 2 has a similar composition to Zone 1, but has no sand laminae. The plant tissue fragments are shorter, and show only partial orientation. Ferruginous impregnative pedofeatures appear to 'shadow' the boundary between the zones.

\section{$4.2 \quad$ Sample 112}

This sample has a similar composition to that of sample 111 and was also taken from Context [070]. Sample 112 has fine sand laminae, although these decline in frequency and then cease by the base of the sample. The laminae exhibit upward grading from sand to silt. The organic component is partially orientated with respect to the sand laminae. A group of fragments of calcite-containing mineral and organic particles was noted. These are interpreted as fragments of mortar.

\section{$4.3 \quad$ Sample 114}

Sample 114 comprises two zones. The sample was taken from a deposit identified in the field as a single context [142]. Zone 1 is composed of a chaotic mass of coarse particles and fragments of soils and sediments. The coarse mineral fraction includes rock fragments not observed in the overlying samples. The organic components mostly occur in highly humified and compressed aggregates. The red-brown organo-ferruginous impregnative pedofeatures only occur in a few aggregates of fine material, in contrast to the orange ferruginous impregnative pedofeatures, which occur more widely across the zone. Soil/sediment fragments are composed of areas of organic-rich clay, which exhibits laminar extinction patterns, and of concentrations of coarse sand with organo-mineral fine material. Fragments of mortar were recovered from this context during wet sieving for small finds and environmental remains.

Zone 2 is composed of fine organic-rich material similar to that of the other samples, but has a void space comprising channels and chambers and a much more homogenous fabric than the other samples. The plant fragments do exhibit partial orientation, but this disappears in areas of higher porosity. There are occasional areas of vivianite: these are mostly associated with bone fragments.

An AMS radiocarbon date from a seed extracted from Context [142] yielded a date of AD 1020-1210 (Table 3.1).

Table 3.1 Radiocarbon dates

\begin{tabular}{lllll}
\hline $\begin{array}{l}\text { Lab } \\
\text { code }\end{array}$ & $\begin{array}{l}\text { Sample } \\
\text { material }\end{array}$ & $\begin{array}{l}\text { Lab.Age BP } \\
\mathbf{\delta C 1 3}\end{array}$ & $\begin{array}{l}\text { Conventional } \\
\text { Radiocarbon Age }\end{array}$ & Calibrated dates 2 $\boldsymbol{1}$ \\
\hline Beta-241080 & $\begin{array}{l}\text { Burnt seed from } \\
\text { context [142], sample } \\
110\end{array}$ & N/A* & $920 \pm 40$ BP & AD 1020-1210 \\
& & & & \\
\hline
\end{tabular}

* The original sample was too small for a 13C/12C ratio measurement. However, a ratio including both natural and laboratory effects was measured during the $14 \mathrm{C}$ detection to derive a Conventional Radiocarbon Age, suitable for applicable calendar calibration. 


\section{DISCUSSION}

\subsection{Depositional sequence}

Field observations of the base of the sequence noted the presence of till, which would be the expected sub-soil in this area of Edinburgh. No buried soil deriving from the till was noted in the field. Overlying the till is Context [142]. On the basis of the thin-section analysis this context can be divided into two distinct deposits. The lower deposit is represented by Zone 2 of sample 114. This deposit is characterised by the fine, organic-rich nature of the sediment. The partial survival of sedimentary structure, ie the orientation of plant fragments, and the limited nature of the biological reworking, suggests that this deposit accumulated relatively rapidly in low-energy conditions. The survival of identifiable fragments of organic material and the formation of vivianite crystals indicate accumulation in damp conditions. The position of the deposit in the landscape suggests that slope wash was the most likely mechanism by which the moisture developed. The fine and relatively well-sorted texture of the deposit demonstrates that the deposit is not directly derived from the local till, which would be unsorted, and contains a much wider range of fraction sizes. Given the apparent absence of a buried soil derived from the till, and the medieval date of Context [142], it may be speculated that this area of the Cowgate was subject to erosional processes that periodically removed earlier soils and sediments. This interpretation is lent weight by the nature of Zone 1 of sample 114 and its relation with Zone 2.

The boundary between Zone 1 and Zone 2 is abrupt but highly irregular in shape, indicating an erosive contact. Zone 1 represents the upper deposit of sample 114. The deposit is characterised by the chaotic mass of unsorted sand and rock fragments, with fragments of soil and sediment, some resembling the fabric of Zone 2, suggesting that the deposit was formed in high-energy conditions, an interpretation corroborated by the erosive contact with the underlying deposit. This indicates that the process of deposition of the upper sandy layer (Zone 1) has caused the scouring and partial truncation of the lower, organic-rich, silty layer (Zone 2). That there is a single layer of this kind in the overall profile suggests an unusual event, which may have been rapid and local, such as a flash flood. Such a process may also explain the absence of either substantial sediment deposits or a mature buried soil of prehistoric date at the base of the sequence, as alluded to above. There are fine textural infillings of some of the voids within the deposit, indicating the disturbance and deposition of fine material: given the general lack of fine material in the deposit it is probable that these infillings represent the effect of the renewed deposition of fine material by low energy processes. There are traces of biological activity in the form and distribution of voids in the deposit, and the presence of earthworm excrement. This activity was insufficient to disrupt the sedimentary structure of the deposit, or the fine-textured infillings, indicating such activity was relatively shortlived.

Overlying this deposit was Context [070]. This context is predominantly of fine, organically rich sediment. It contains sedimentary structures, notably graded laminations. The survival of sedimentary structures indicates accumulation sufficiently rapid to prevent the reworking of the deposit by biological activity. The graded laminations from fine sand to organo-mineral fine material indicate pulses of deposition, each pulse diminishing in energy as it occurs. This pattern is characteristic of deposition by slope wash. No reliably datable material has been recovered from this context. From the overlying deposit (Context [140]) pottery datable to the 1214 th centuries has been recovered. This gives the relatively short period from under 100 years to 300 years for the accumulation of Context [070].

\subsection{Archaeological implications}

The first implication of the medieval date for the lower part of Context [142] is that there is no survival of prehistoric material in the vicinity of the site, probably as a result of scouring by flood events such as created the upper part of Context [142]. It should be noted that this effect may be highly localised and should only be regarded as affecting the lowest-lying parts of the Cowgate.

The deposition of contexts [142] and [070] is the result of natural processes. During the period of deposition, this area of Edinburgh was not an area of intensive human activity. This is not to argue an absence of human impact on the area. The initiation of sediment accumulation implies changes in the run-off regime and/or the supply of sediment available for deposition. Clearance or disruption of local soil profiles upslope of the site would explain this, the most likely cause being the extension of settlement towards the area in the medieval period. The presence in these contexts of fragments of bone, mortar pottery and a piece of prill corroborates the likely anthropogenic cause. The rapid accumulation of Context [070] and the cessation of deposition indicate rapid changes in the sediment supply. The deposition probably reflects the initial disturbance occasioned by trampling and disruption of soil profiles upslope of the site during the extension 


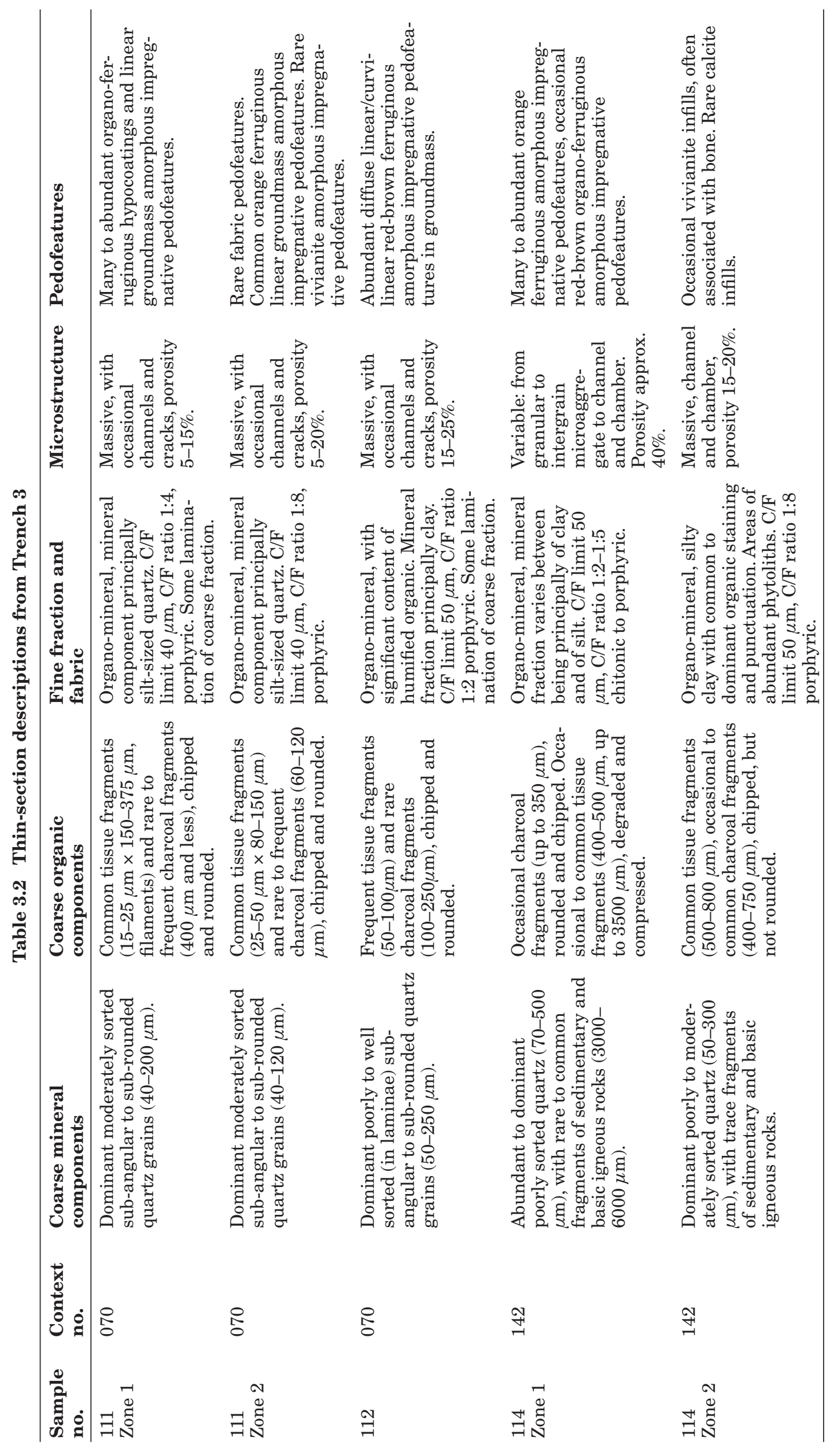


of the Old Town, without the laying down of hard surfaces or the efficient control of wastewater. This was followed by the paving of the Old Town, which would have protected the remaining soil profiles from continued disruption, massively reducing the sediment supply available for deposition on the Cowgate, thus ending the deposition of Context [070]. 



\section{Appendix 4 - Plant macrofossils}

Scott Timpany \& Sarah-Jane Haston

Headland Archaeology Ltd, 13 Jane Street, Edinburgh EH6 5HE 



\section{APPENDIX 4: CONTENTS}

LIST OF ILLUSTRATIONS $\ldots \ldots \ldots \ldots \ldots \ldots \ldots$

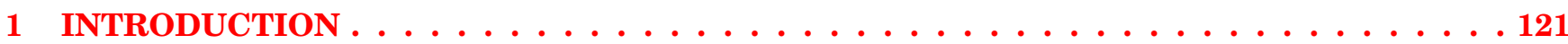

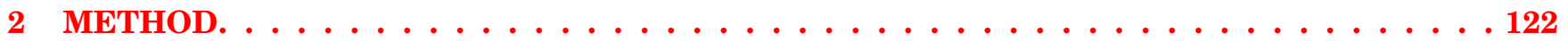

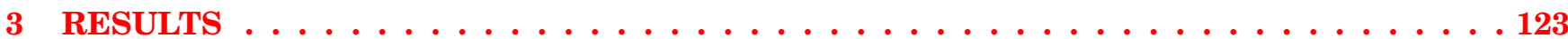

3.1 Introduction . . . . . . . . . . . . . . . . . . . . . . . . . . . 123

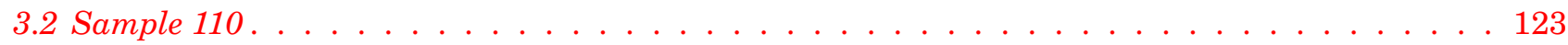

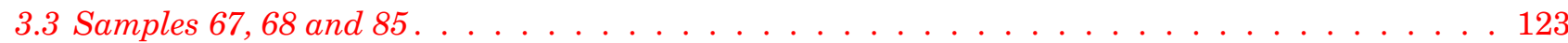

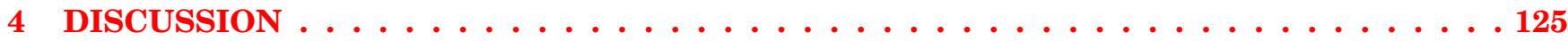

4.1 Primary occupation layer (Context [142]) _ . . . . . . . . . . . . . . . . . . . 125

4.2 Medieval ditch layers (Contexts $[089 \&$ 090]) . . . . . . . . . . . . . . . . . . . . . 125 


\section{LIST OF ILLUSTRATIONS}

$4.1 \quad$ Plant macrofossil diagram Context [142] . . . . . . . . . . . . . . . . . . . . . . . . 123

$4.2 \quad$ Plant macrofossil diagram Context [090] . . . . . . . . . . . . . . . . . . . . . . . 124 


\section{INTRODUCTION}

Previous palaeoenvironmental work undertaken as part of the assessment of material from St Patrick's identified the potential for further palaeoecological work from these deposits (Timpany 2007). For this analysis phase the main focus of the investigation was the primary occupation layer [142] dating to $\mathrm{AD} 1020-1210$ and the basal layers of the medieval ditch [090 \& 089]. These deposits were found to contain well-preserved organic material and thus a multi-disciplinary study including pollen (see Mighall Appendix 5), beetles (see Reilly Appendix 6) and plant macrofossils was undertaken. The results of the plant macrofossil analyses are presented here. 
Four ten litre bulk samples were chosen for analysis; three from the primary fills of the medieval ditch (sample 67 from Context [089]; samples 68 and 85, from Context [090]) and one from the primary occupation layer (sample 110, Context [142]). All samples were subject to flotation through a Sirafstyle flotation tank and the floating debris (flot) collected in a $250 \mu \mathrm{m}$ sieve.

All plant macrofossil samples were analysed using a stereomicroscope at magnifications of $\times 10$ and up to $\times 100$ where necessary to aid identification. Identifications were confirmed using modern reference material and seed atlases including Cappers et al (2006). Results from the analyses have been plotted as plant macrofossil diagrams using the TILIA and TGView version 2.0.2 programmes (Grimm 2004). Diagrams follow the taxonomic order of Stace (1997). 


\section{RESULTS}

\subsection{Introduction}

Preservation of material was found to be good in all samples, with waterlogging of sediments being the main mechanism for preservation of material. Cereal grain recovered from the samples was preserved through charring and is thus likely to indicate anthropogenic (ie domestic/commercial activities) mechanisms for preservation rather than natural (ie waterlogging) mechanisms. The results of the analyses are presented in illus 4.1 and 4.2.

\section{$3.2 \quad$ Sample 110}

Sample 110 from the primary occupation layer was found to contain relatively sparse numbers of plant macrofossils (see illus 4.1). The largest numbers of fruits from within this sample were of Ranunculus sceleratus (celery-leaved buttercup), Polygonum aviculare (knotgrass) and Persicaria lapithifolia (pale persicaria). Smaller numbers of seeds and fruits were recovered from species including Urtica urens (small nettle), Chenopodium album (fat-hen), Stellaria media (common chickweed) and Juncus effusus (soft rush).

\subsection{Samples 67, 68 and 85}

Sample 68 is from the basal layer of the primary fill of the ditch [090] and sample 85 from just above this layer but both lie within this context [090]. Sample 67 is taken from the layer overlying the primary fill, context [089]. Sample 85 was found to contain the most abundant numbers of plant macrofossils, with sample 67 also having a rich assemblage (see illus 4.2). The assemblage from sample 68 was fairly sparse in comparison to the other two samples. The assemblages from the ditch deposit contained a number of species with particularly high numbers of seeds and fruits of Ranunculus sceleratus, Stellaria media, Urtica dioica (common nettle) and Conium maculatum (hemlock). Small numbers of charred cereal grain of Avena sp. (oat) and Hordeum vulgare (hulled barley) were also recovered within these assemblages.

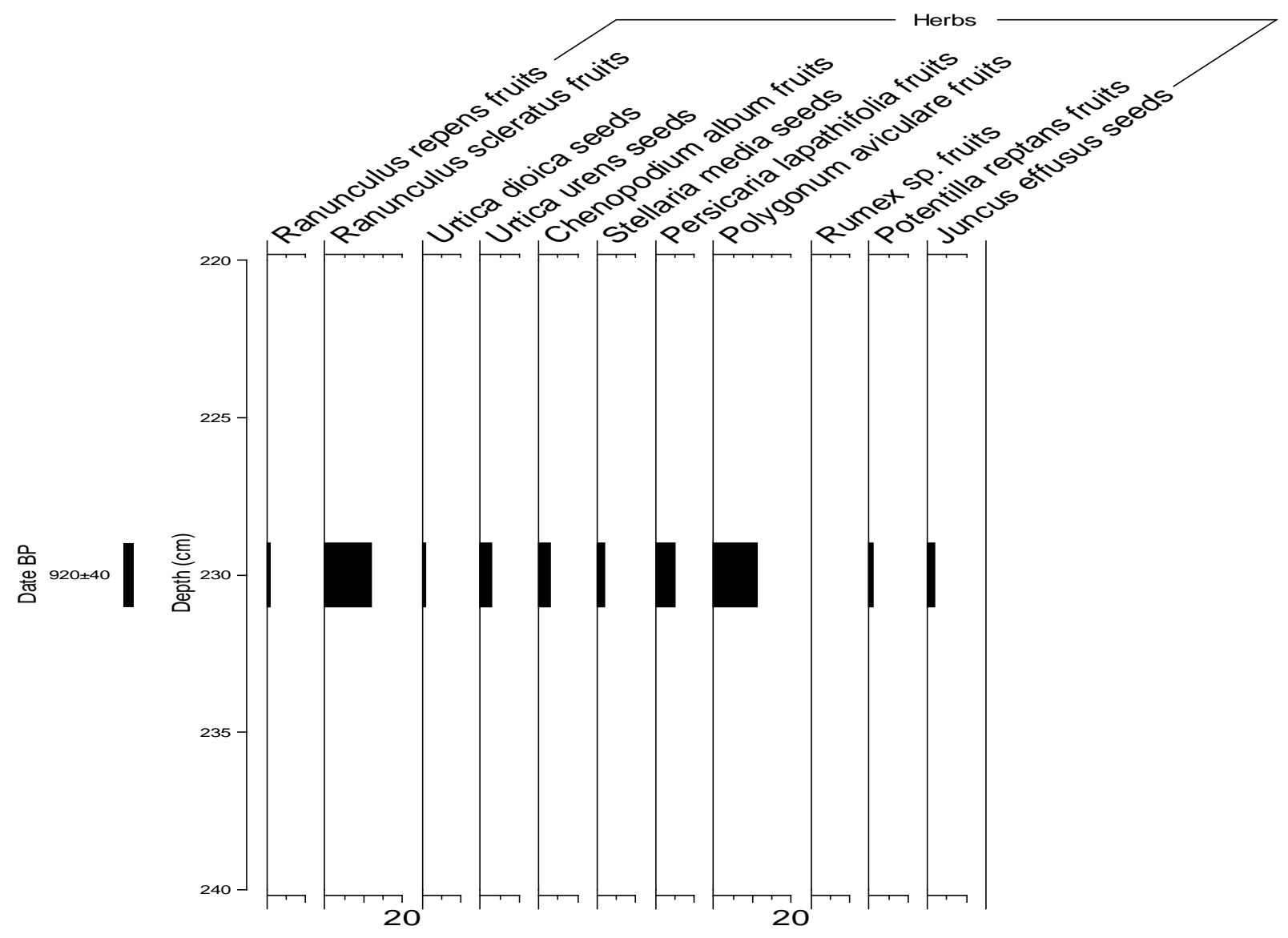

Illus 4.1 Plant macrofossil diagram Context [142] 


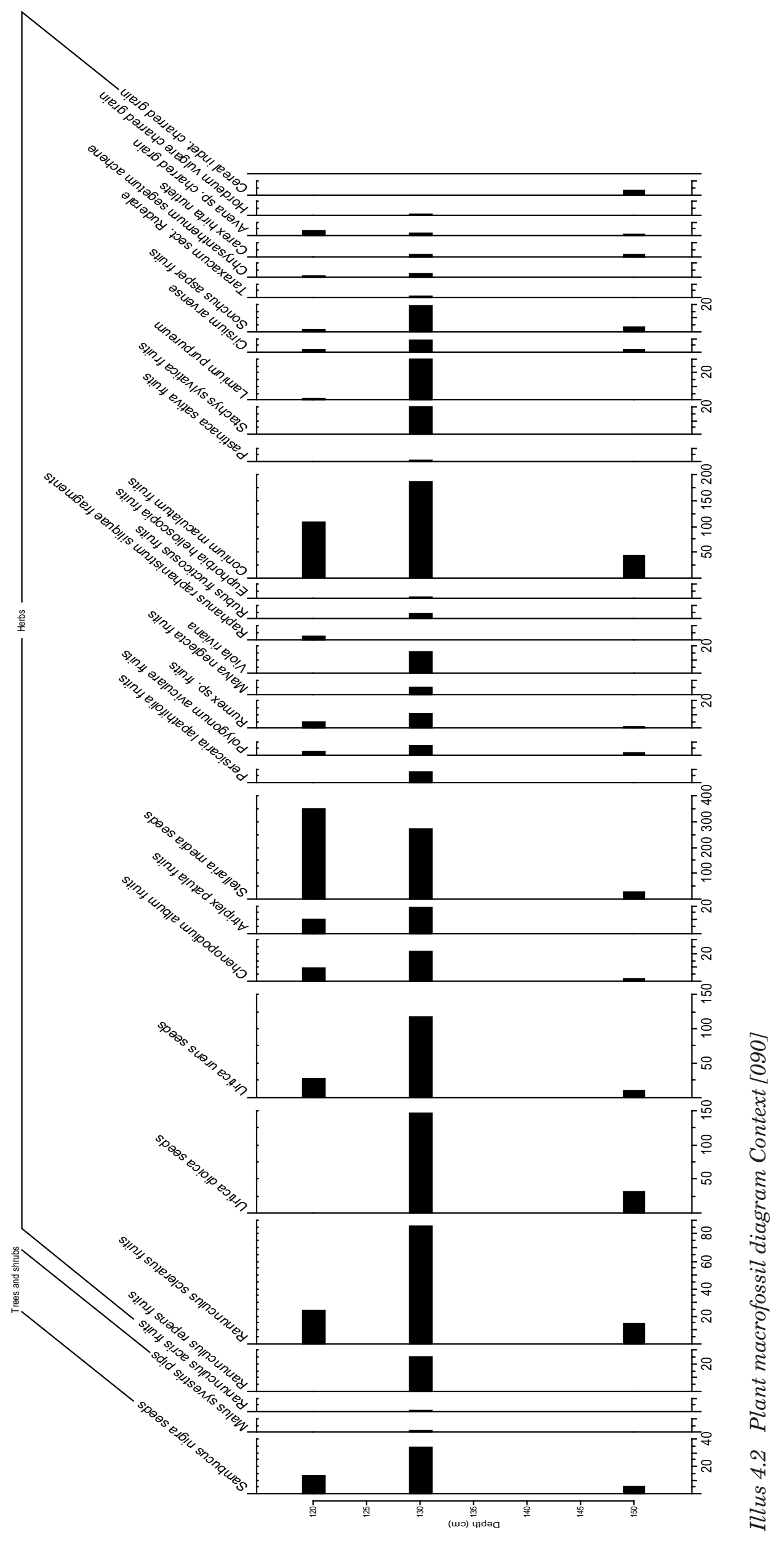




\section{DISCUSSION}

\subsection{Primary occupation layer (context [142])}

The assemblage from this layer is dominated by taxa indicative of open waste ground and cultivated ground, including taxa such as Polygonum aviculare, Persicaria lapithifolia, Stellaria media and Urtica urens (Clapham et al 1962). However, the absence of taxa purely associated with cultivated ground suggests the assemblage is more likely to represent waste ground. There is some evidence of periodic pooling of water on the surface of this layer through the presence of Ranunculus sceleratus and Juncus effusus (Clapham et al 1962). The plant macrofossil assemblage thus indicates the local environment during this period was a waste ground area that was subject to periodic pooling of water.

\subsection{Medieval ditch layers (contexts [089 \& 090])}

The assemblages from the medieval ditch contexts are representative principally of those plants that grew in or around the ditch following its construction. The basal layer of the ditch contains a relatively species-poor assemblage in comparison to the overlying layers (see illus 4.2). Taxa from within this layer are representative of plants growing in ephemeral pools of standing water, likely when the ditch was inundated, which suggests drainage of the ditch was poor. Such species include Conium maculatum and Ranunculus sceleratus. There is some evidence of Sambucus nigra (elder) in the vicinity of the ditch, with seeds present within the assemblage suggesting the area around the ditch was not completely devoid of trees. The presence of a small number of charred grains of Avena sp. and Cerealia indeterminate, are likely to have washed into the ditch and represent domestic/commercial activities taking place in the town (eg baking). The remainder of the assemblage of this layer constitutes species suggestive of waste and cultivated ground, including Stellaria media, Sonchus asper (prickly sow-thistle) and Urtica dioica.
The upper levels of the ditch contain a wider variety of species in greater abundance than the basal layer (see illus 4.2). However, despite this increase the assemblage still shows the same surrounding environment: a mixture of waste and cultivated ground. There is an increase in the representation of cultivated ground species within the upper layers with the appearance of species such as Euphorbia helioscopia (sun spurge) and Viola riviana (common dog-violet), suggesting that some cultivation was taking place near to the ditch. A number of taxa associated with damp meadows are present, including Cirsium arvense (creeping thistle) and Carex hirta (hairy sedge), which indicate that the drainage of these fields may have been poor and that these species may have grown amongst the cereals. The presence of charred Avena sp. and Hordeum vulgare grains in these levels shows that agrarian activities were taking place, although it is unknown whether these grains represent local crop usage or importing of crops from elsewhere. The charred grains are again believed to represent domestic/commercial activities in the town.

Of particular note within these samples, particularly that of sample 85 , is the major increase in species associated with pooling of water, suggesting that the ditch was largely inundated during these periods. The rise in seed numbers of Ranunculus sceleratus and Urtica dioica in this sample may also indicate an increase in the amount of faecal matter being washed into the ditch from humans and animals. Both of these taxa are associated with habitats of extremely nitrogen-rich, periodically wetted and disturbed ground, such as the manured surrounds of streams where cattle water (Rodwell 2000). Rodwell (2000) notes that $R$. sceleratus is one of the few plants that will readily grow on the sludge beds of sewage farms. Thus the high amount of $R$. sceleratus fruits not only provides an ecological picture of the site but also an impression of the conditions on the Cowgate during this period. 



\title{
Appendix 5 - Pollen
}

\author{
T M Mighall
}

Department of Geography and Environment, School of Geosciences, University of Aberdeen, Elphinstone Road, Aberdeen, AB24 3UF 



\section{APPENDIX 5: CONTENTS}

LIST OF ILLUSTRATIONS $\ldots \ldots \ldots \ldots \ldots \ldots \ldots$

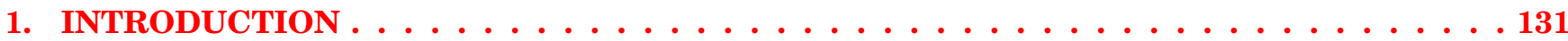

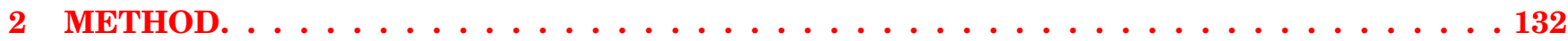

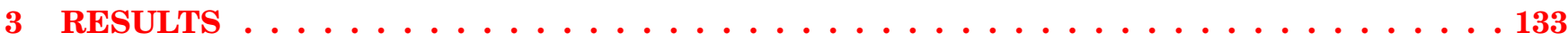

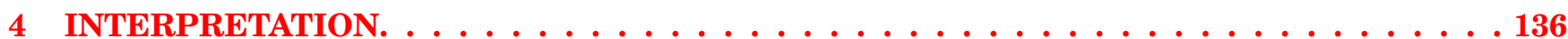




\section{LIST OF ILLUSTRATIONS}

$5.1 \mathrm{a}$

Pollen diagram: trees

134

$5.1 \mathrm{~b}$

Pollen diagram: herbs

135 


\section{INTRODUCTION}

Twenty-four samples from contexts [098] and [090] from a ditch thought to represent an early medieval town boundary were sent to the palaeoecology labor- atory, Department of Geography \& Environment, University of Aberdeen for pollen analysis. 
Pollen and non-pollen palynomorph (NPP) data are presented in this report from contexts [098] and [090]. Samples were prepared for pollen and non-pollen palynomorphs (NPPs) following Barber (1976) at selected intervals down the core, with samples at $2 \mathrm{~cm}$ intervals at selected levels: from $176 \mathrm{~cm}$ to $190 \mathrm{~cm}$ from Context [098] and between 241 and $267 \mathrm{~cm}$ from Context [090]. In order to remove mineral matter, the organic component of each sample was separated using a density flotation method (Nakagawa et al 1998). A sum of 300 total land pollen (TLP) was employed in those samples with relatively abundant pollen content, excluding spores and aquatic taxa. At certain depths the pollen content was sparse, so a minimum count of 100 was employed. All data are expressed as a percentage of total land pollen, although spores and aquatics were excluded from the TLP sum, while NPPs are expressed as a percentage of TLP plus total NPPs. Identification, including cereal-type pollen, was aided by reference to the keys in Fægri et al (1989) and Moore et al (1991). Because the separation of Myrica gale from Corylus avellana-type pollen is difficult, these grains are classed as Corylus avellana-type (Edwards 1981). Plant nomenclature follows Stace (1997) but takes into account the suggestions recommended by Bennett et al (1994). Summary curves for trees, shrubs (constituting arboreal pollen, AP) dwarf shrubs and herbs (non-arboreal pollen, NAP) are shown. NPPs were recorded during routine pollen counting and classified using illustrations and descriptions in van Geel $(1978 ; 1986 ; 2001)$ and van Geel et al $(1981$; 1983; 2003). The NPP data are expressed as a percentage of total land pollen and NPPs. Rare types are shown as a cross, where one cross denotes one grain or palynomorph. 


\section{RESULTS}

A pollen diagram for eight samples from Context [090] is shown in illus 5.1a and 5.1b. Pollen abundance and preservation varied considerably between the contexts and samples. Pollen abundance was poor in the samples from Context [098] but improved in samples from Context [090], therefore the latter samples were targeted for counting. In most of the samples a sizeable proportion of the pollen was degraded, broken or in the case of larger pollen grains, such as cereals, crushed. Differential preser- vation and possible secondary reworking, therefore, cannot be ruled out (cf Havinga 1985). Counting was restricted to those samples with good pollen content, while the remaining samples were scanned and the pollen taxa identified were recorded. No quantitative method has been used to assess microscopic charcoal, but all the slides contain it and therefore the use of fire, deliberate or accidental, is recorded in the sedimentary sequence. 


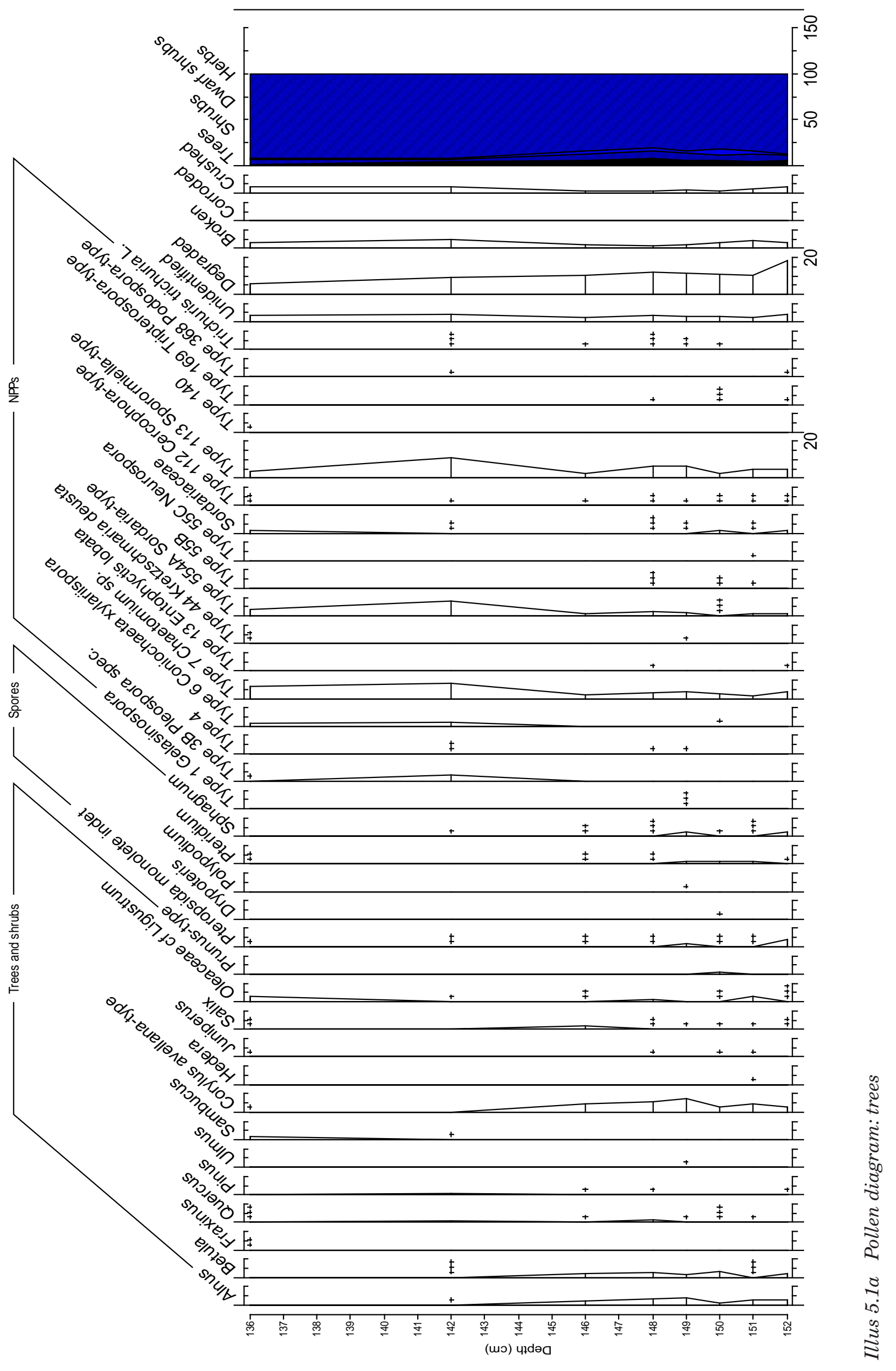




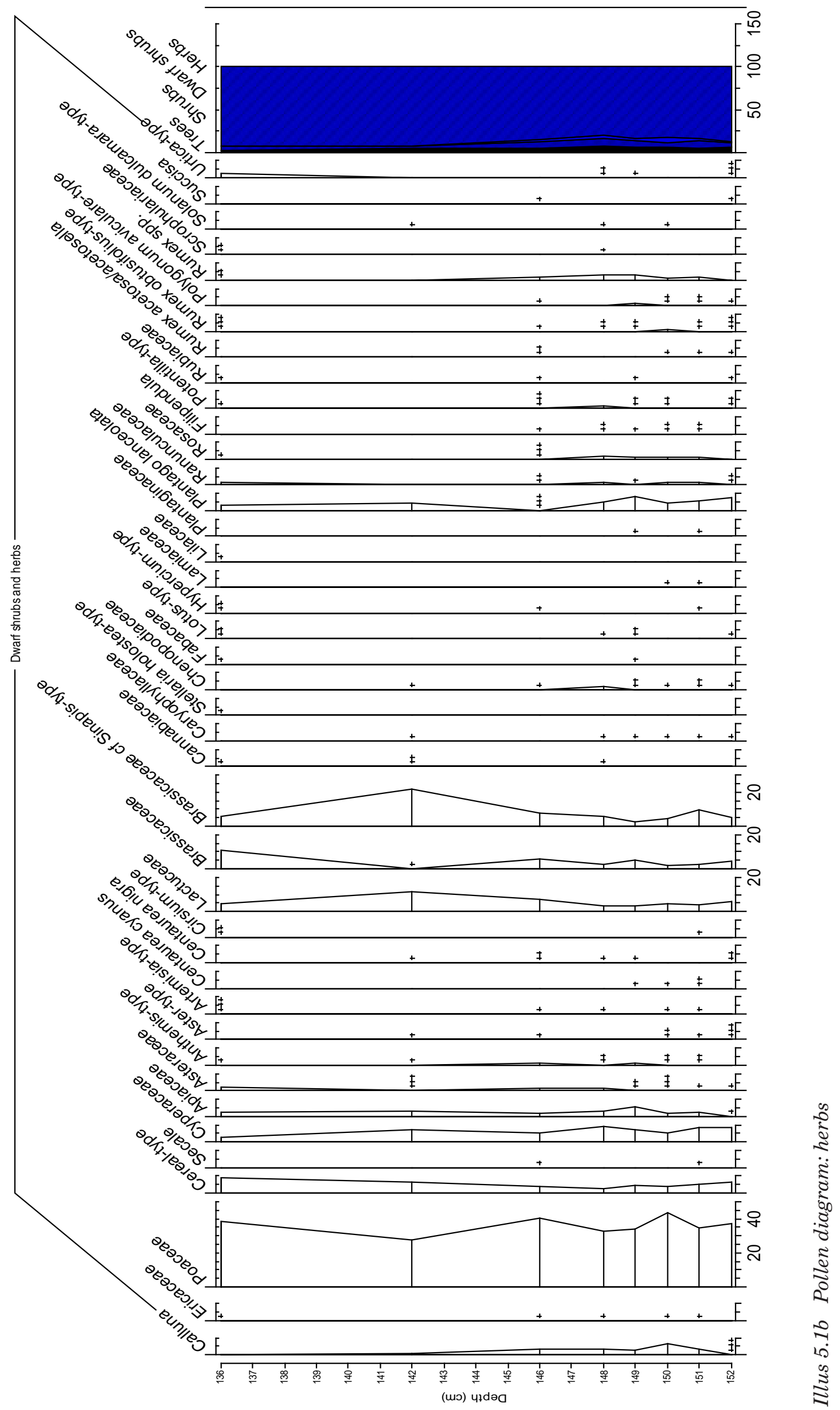




\section{INTERPRETATION}

The pollen record preserved in the ditch suggests that the landscape was open and dominated by grasslands. Evidence for woodland is limited, as the total tree and shrub percentages remain below $15 \%$. Possible scattered individual trees or small patches of woodland containing alder (Alnus), birch (Betula) and hazel (Corylus avellana) existed with minor occurrences of oak (Quercus), elm (Ulmus), pine (Pinus) and willow (Salix). It is likely alder and willow grew in wet woodland. The number of trees in the landscape diminishes even further from $263 \mathrm{~cm}$ as the total arboreal pollen percentage gradually decreases up to $251 \mathrm{~cm}$. It is possible that woodland was removed deliberately for either domestic or industrial purposes.

The deposits are relatively rich in cereal-type pollen, including rye (Secale cereale). While some of these grains might be wild grasses, it is likely that a high proportion reflect agricultural activity close to the ditch, because cereal grains are relatively large in size and therefore they are poorly dispersed by natural agencies (Heim 1962; Behre 1981). Further measurement of these grains will enable us to classify these grains more accurately. Heim (1962), based on observations of modern cereal pollen, suggests that cereal pollen percentages only rise above $4-5 \%$ when crops are grown in the immediate vicinity of the site. The cereal-type pollen percentages at St Patrick's Church reach up to 10\% TLP in the uppermost samples in the pollen diagram and only fall below $5 \%$ TLP at $263 \mathrm{~cm}$. Other agricultural indicators of both arable and pasture are well represented. This includes ribwort plantain (Plantago lanceolata), cornflower (Centaurea cyanus), Goosefoot family (Chenopodiaceae), mugworts (Artemisia-type) and thistles (Cirsium-type) (MacGuire 1983). The broadleaved dock (Rumex obtusifolius) and other docks and sorrels (Rumex acetosa / acetosella) are common by rivers and on waste and cultivated ground (Stace 1997). Pollen from the cabbage family (Brassicaceae) is also well represented, including possible members of the Mustards (Sinapis) which grow on waste and arable land.

A grazing-based economy is also supported by the presence of dung indicators, Cerophora-type, Sporormiella-type and Podospora-type in the non-pollen palynomorph record (van Geel et al 2003; van Geel 2001. The occurrence of tormentils (Potentilla-type) and Devil's-bit scabious (Succisa) along with pollen grains from the Carrot family (Apiaceae), buttercup family (Ranunculaceae), nettles (Urtica) and the occasional meadowsweet (Filipendula) suggests that some of the pasture was relatively wet. Further evidence for dung and/or dead wood is the presence of Chaetomium (Type 7) and Coniochaeta xylariispora (Type 6) (Innes and Blackford 2003). Evidence of burning is also indicated by the presence of Gelasinopsora (Type 1) and Neurospora (Type 55C), which is consistent with the regular presence of microscopic charcoal in all of the samples analysed from Context [090].

The ditch may have also been used to discard human waste. Parasitic eggs of Trichuris trichuria L. were recorded from most of the samples from Context [090]. Trichuris trichuria L., the whipworm, is the most common human intestinal parasite. Because the adult nematode worm inhabits the large intestine of its host, the eggs are passed in the host faeces (Dark 2004). The earliest known occurrence of whipworm occurred in late Mesolithic deposits from south Wales (ibid) but archaeological evidence for the presence of the whipworm includes other urban sites such as late Saxon London (de Rouffignac 1991), Viking Age and medieval York, and medieval Winchester (eg Jones 1985; Pike \& Biddle 1966). The eggs found at St Patrick's are similar in size and shape to those described by Dark (2004) and therefore are most likely to come from humans rather than Trichuris eggs that are associated with animals such as pigs, sheep and cattle. Trichuris eggs were also found by rapid scanning of the slide at $130 \mathrm{~cm}$, along with cereal-type pollen, suggesting that such agricultural activity continued throughout Context [090].

The samples from Context [098] contained little pollen. A rapid scan of these slides recorded high amounts of elder (Sambucus) and Apiaceae pollen with the occasional pollen grain indicative of agricultural activity (eg Centauera cyanus at $180 \mathrm{~cm}$ ) in the uppermost samples from 188 to $176 \mathrm{~cm}$. At $190 \mathrm{~cm}$ grasses (Poaceae), Brassicaceae, Apiaceae and Asteraceae were all recorded. 


\title{
Appendix 6 - Insect remains
}

\author{
Eileen Reilly
}

Botany Department, Trinity College Dublin, College Green, Dublin 2 

APPENDIX 6: CONTENTS

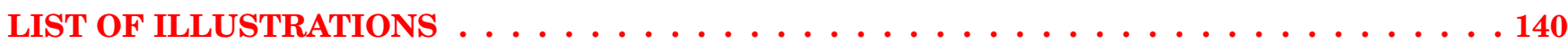

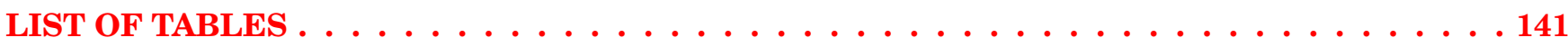

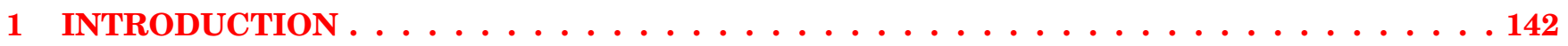

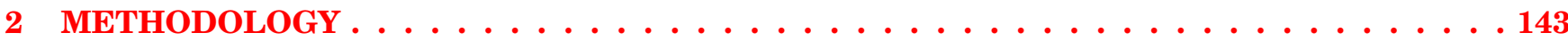

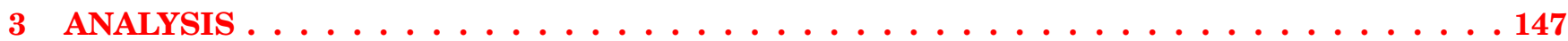

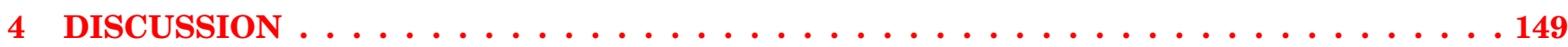


6.1 Graph of habitat groups indicated for all insects identified - raw counts and percentage presence of each habitat group (source: created by BUGSCEP) . . . . . . . . . . 144

6.2 Summary data - total number of species, individuals and sum abundance per sample for insect remains identified (source: created by BugsCEP). . . . . . . . . . . . 146

6.3 NMS ordination showing 1-axis solution for samples examined from insert remains . . . . . . 149

$6.4 \quad$ NMS ordination showing 1 -axis solution for species distribution . . . . . . . . . . . 150 


\section{LIST OF TABLES}

$6.1 \quad$ Species list for insects (source: nomenclature follows Lucht 1987) . . . . . . . . . . . . . . 152 


\section{INTRODUCTION}

Six samples were selected for insect analysis. Insect analysis is just one strand of a multidisciplinary approach being taken to understand the local environment of the area, which also includes pollen, bone, mollusca, wood and plant-macrofossil analyses.
Samples for insect analysis were selected from the pre-ditch ground surface, possible old stream channel and fills from two phases of the medieval ditch (see Section 3 below for full description). 


\section{METHODOLOGY}

Samples were 10 litres in volume. Sub-samples of 4-5 litres were analysed. The remaining material was retained for potential future use.

All samples were subject to the paraffin flotation method of extracting insect remains from archaeological deposits, devised first by Coope and Osborne (1968) and later modified by Kenward (1980), with further refinements by Kenward et al (1986). The samples were disaggregated using water and washed over a $300 \mu \mathrm{m}$ sieve. The retent in the sieve was then treated with paraffin and cold water added. The paraffin concentrates the insects by adhering to the waxy cuticle of the insect exoskeleton. The flot was then poured through a $300 \mu \mathrm{m}$ sieve, washed with detergent in hot water to remove the excess paraffin and stored in 70\% ethanol. Processing took place at the flotation facility of Margaret Gowen and Company Ltd, Merrion Square, Dublin 2.

Flots varied in size between 100 and $200 \mathrm{ml}$. All were fully sorted and insect sclerites extracted onto wet filter paper. Identifications were carried out using published keys and the writer's own reference material. Table 6.1 details the full species list. Species marked with '?' indicate identifications that require further checking. The species list was then entered into Bugstats, part of BugsCEP, the Coleopteran Ecology Package devised by Philip and Paul Buckland (Buckland \& Buckland 2006). This allowed for analysis of the insect data by producing a multi-sample environmental summary diagram using coded habitat data. This diagram should aid identification of environmental changes through time, in the case of stratified sequences, or spatial analysis in the case of dispersed archaeological samples. The package uses 22 EcoCodes derived from the work of various authors (Kenward 2001; Ponel 1995; Robinson 2001) and the ecological codes assigned by Koch (1989-92). Each taxon (or individual) may be assigned to more than one habitat but will only be assigned to one 'indicator' class, where appropriate. Illus 6.1 shows two EcoGraphs, one displaying the raw counts per habitat group and the other the percentage presence of each habitat as a proportion of the total number of taxa ('environmental representations') in that sample. Illus 6.2 shows the summary statistics for the data. The analysis and discussion (Sections 3 and 4) are based on the results of these graphs.

The index of diversity for the assemblages was also calculated (see Section 4 below). Fisher's alpha is a mathematical model used to measure diversity in ecological communities (Fisher et al 1943).

In addition, NMS (non-metric multi-dimensional scaling) ordination of the data was carried out, using PC-Ord 5.0 (McCune \& Grace 2002). Ordination is used to summarise complex relationships, extracting one or a number of dominant patterns from an infinite number of possible patterns ( $\mathrm{ibid}$ ). It is used here to examine underlying variance/similarities in the insect assemblages between deposit types (illus $6.3 \&$ 6.4). NMS is well suited to data that are nonnormal or on arbitrary, discontinuous, or otherwise questionable scales, particularly data sets that have upwards of $70 \%$ zeroes. 


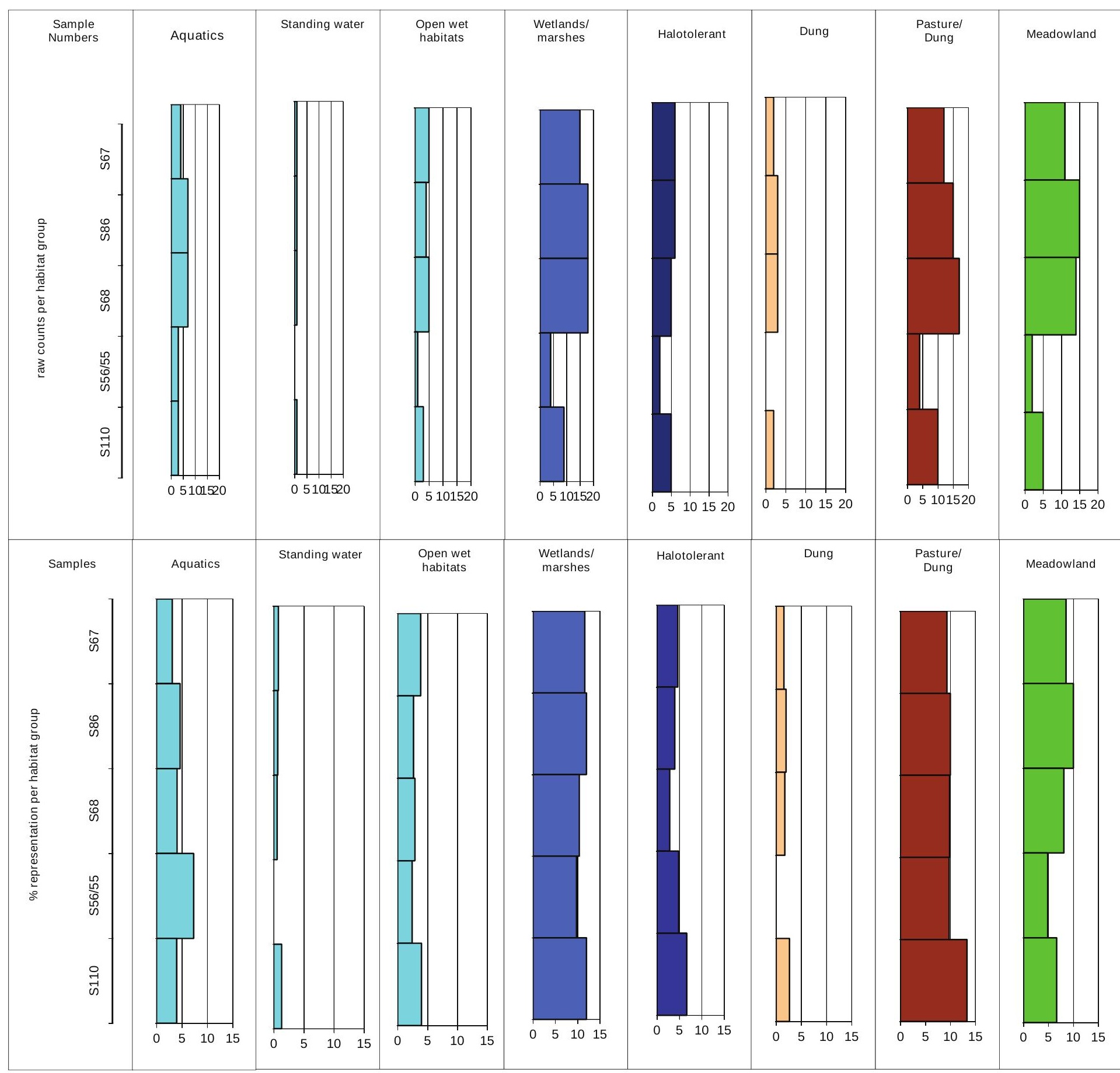

Illus 6.1 Graph of habitat groups indicated for all insects identified-raw counts and percentage presence of each 


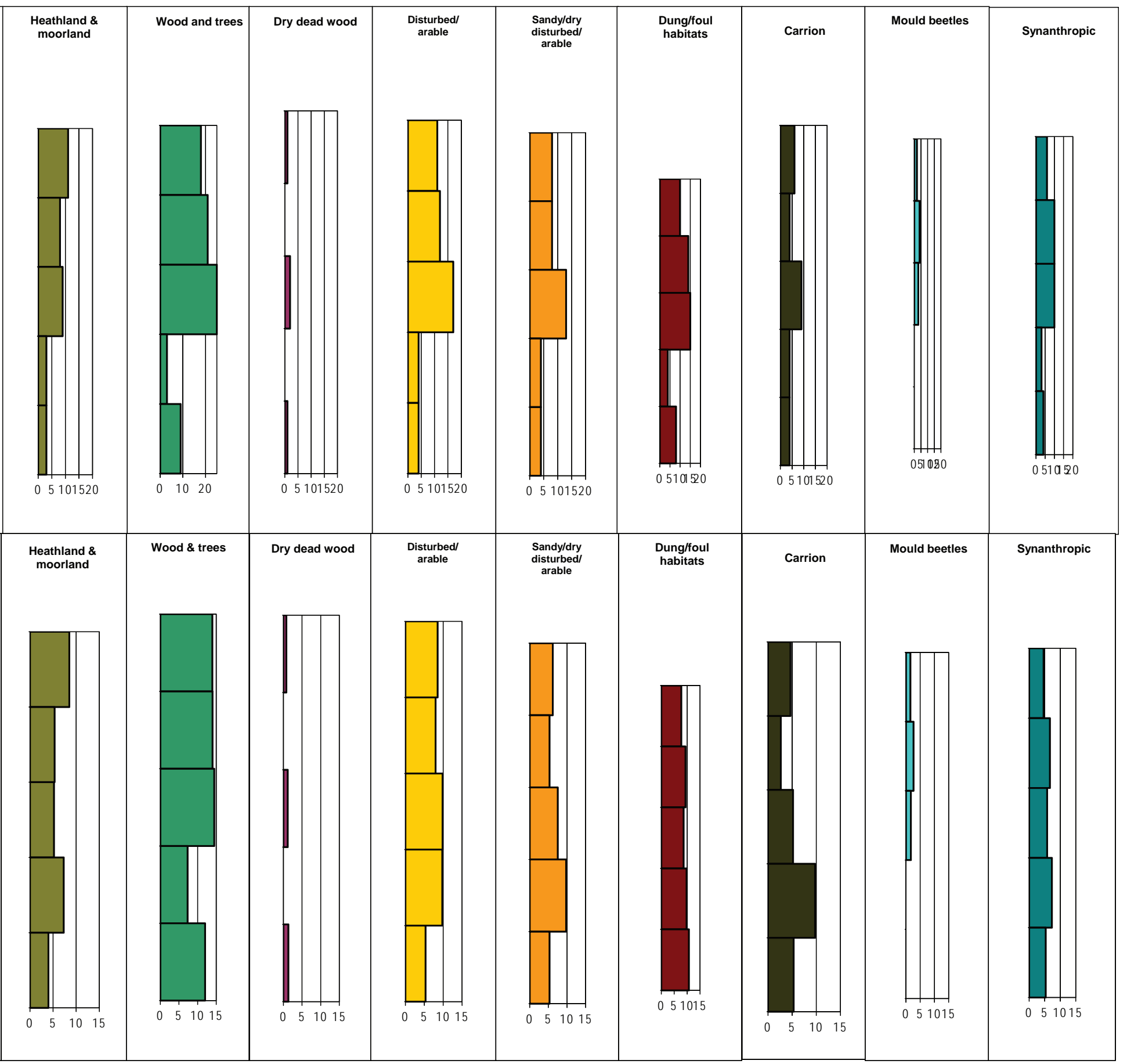

habitat group (source: created by BUGSCEP) 


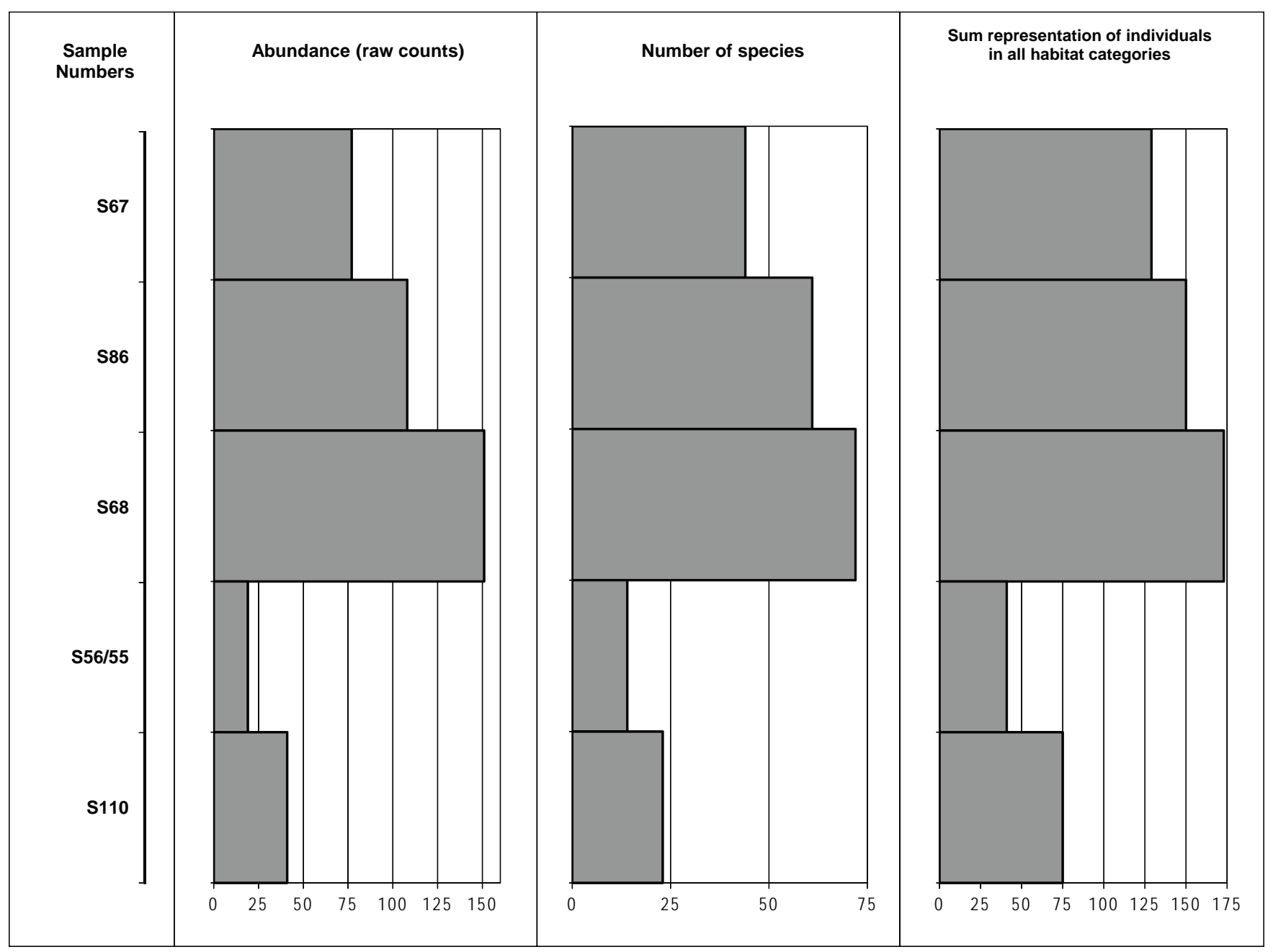

Illus 6.2 Summary data-total number of species, individuals and sum abundance per sample for insect remains identified (source: created by BugsCEP) 
Samples are analysed in chronological order.

\subsection{Context [142], sample 110}

Context 142 is described as a blackish-brown peaty deposit, gritty and organic. The clay and charcoal content was high. Animal bone and shellfish were visible during processing.

This produced an interesting, albeit small, assemblage (MNI $=41$, illus $6.1 \& 6.2$, Table 6.1). Many of the sclerites were fragmented and identification past genus level was not always possible. This resulted in a mixed signature within the assemblage, with many species assigned to multiple habitats. However, generally, foul habitats/dung/pasture indicators were very common, as well as wetland/ marsh indicators. The most commonly encountered beetles were Helophorus spp., generalist water beetles found in a wide variety of aquatic environments, and Aphodius luridus, a dung beetle found in sheep, horse and cow dung in both open and shaded (wooded) locations (Jessop 1986). A small number of arable/disturbed ground species also occurred including Harpalus affinis, a generally xerophilus ground beetle found in weedy, agricultural ground and dry grassland (Lindroth 1985; Luff 1998) and Ceutorhynchus erysimi, which occurs on Shepherd's Purse (Capsella bursa-pastoris) (Bullock 1993). There were no indicators of moving water or specific indicators of wetland plant communities (except one undiagnostic fragment of Plateumaris spp.), which might have been expected in an in-filled streamchannel. Overall, the assemblage represented damp, foul ground conditions with occasional representations from nearby agricultural (both pasture and arable) land.

\subsection{Context [070], samples 55/56}

Context [070] is described as mid-grey silty clay, with lots of pebbles and small stones. It was highly inorganic with few insect remains observed during processing. Lots of small charcoal fragments and a small plant-macrofossil component were also observed.

Two samples were submitted for insect analysis from this deposit. Unfortunately, sample 55 produced only three identifiable fragments, while sample 56 was similarly poor at just sixteen identifiable insects. This was due primarily to the inorganic nature of the deposit. For the purposes of illus 6.1-6.4, these samples are combined. The assemblage indicated mixed origins, with a small number of water beetles
(Limnebius sp., Helophorus sp.) and one possible indicator of flowing water, Oulimnius sp., present. The latter beetle is generally found under stones or on moss in fast-flowing, shallow streambeds (Koch 1989-92) and is one of the few species present that suggests the presence of a stream in the locality. A number of species present suggest that, once again, dung/foul-indicating habitats prevailed. The carrion feeder Necrophorus humator was identified, as well as Aphodius spp., Anotylus tetracarinatus and A. complanatus. These beetles probably represent the beginnings of accumulated rubbish associated with the growth of the medieval town. In addition, the disturbed waste ground and/or arable signature present in context [142] is also visible in this assemblage through species such as Otiorhynchus sulcatus, Chrysolina sp. and Phyllotreta sp. (Table 6.1). O. sulcatus (the 'vine' weevil) is generally closely associated with humans (Morris 1997). Along with other beetles identified in this assemblage, such as Ptinus fur, it suggests the beginnings of a synanthropic (ecologically associated with humans) element in the local insect fauna (also vaguely suggested in context [142]), prior to the digging of the town ditch.

\subsection{Context [090], samples 86/68}

Context [090] is described as blackish-brown silty clay with wood, marine molluscs, land/freshwater molluscs, plant macrofossils and animal bone present. A small silt and charcoal component was visible during processing. This is the primary fill of the original medieval ditch cut.

Two samples from context [090] were analysed for insect remains, sample 86 and sample 68 (see illus 6.1, 6.2 and table 6.1). Both produced large species-rich assemblages. The most frequently occurring species were Helophorus spp., Megasternum obscurum, Ceutorhynchus contractus, Ophonus rufibarbis, Philonthus spp. and Phratora vugatissima. This mix of species is indicated in the habitats represented in illus 6.1, with general aquatics, wetland/marsh, pasture/dung and disturbed/arable (combined) dominant. Also well represented is wood/ trees, for example, $P$. vulgatissima generally occurs on willow and poplar (Bullock 1993).

There are also a number of ground beetles within the assemblages that can be indicative of carr woodland, such as Leistus spinibarbis, Trechus rubens and Pterostichus madidus. However, many of these species are equally likely to occur in humusrich soils in pasture/cultivated land (Lindroth 1974) and the wet ditch fill may have provided an ideal habitat. Other beetles and one fly species recorded 
in the assemblages suggest that wood/leaf litter may have formed part of the fill, possibly fuel or fodder waste. Species such as Phyllobius oblongus, P. pyri, Cryptocephalus sp. and Dorytomus sp. occur on the leaves of a variety of tree and shrub species. The puparia of Minettia ?lupulina, a leaf miner in alder and fruit tree species (Smith 1989), were recorded in moderate numbers from sample 68 .

In addition, Rhizophagus sp., which occurs under bark, and some unidentifiable fragments of Anobids ('woodworm' beetles) were present but in very small numbers. This is somewhat surprising for the fill of a medieval ditch, where species associated with wooden buildings might expect to become incorporated into ditch fills. The 'synanthropic' element of the fauna is generally very small (no more than $8 \%$ of the overall assemblage in each sample). Typical species of this habitat group, such as Cryptophagus dentatus, Ptinus fur, Tipnus unicolor, Mycetaea hirta, Atomaria spp. are present but in small numbers. These species are common in medieval house floor layers and pit fills of this period (Hall \& Kenward 1995; Reilly 2003). Along with the lack of structural wood pests, it suggests that waste from houses was not the primary material making up the ditch fill.

An interesting dry/disturbed/arable ground fauna is present in the assemblages. Species indicative of weeds include Sitona sp., Rhinoncus sp., Chaetocnema concinna and Chrysolina fastuosa. The digging of the ditch would have caused significant ground disturbance that probably eventually resulted in a diverse weed-plant community growing locally, on which many of these beetles are to be found. Two curious finds, Batophia rubi and Byturus tomentosus, occur on raspberry and blackberry and may indicate the presence of brambles growing in close proximity to the ditch. However, it is the ground beetle (Carabidae) fauna indicative of disturbed ground that is particularly interesting and diverse. Species such as Ophonus rufibarbis, Harpalus affinis, Pterostichus madidus, Anchomenus dorsalis, Amara familiaris and A. equestis all point to mixed local ground conditions from dry, disturbed, sandy ground to cultivated ground/garden soils. The ditch probably acted as a large pit-fall trap, resulting in diverse ground beetle fauna becoming incorporated into this fill. Undoubtedly, many of these species were attracted to the disturbed ground surface generated by the digging of the ditch but may reflect the landscape surrounding the town at this time also.

The fauna associated with material thrown into the ditch generally indicates foul origins. In particular, the dipterous (fly) fauna, along with elements of the beetle fauna, such as carrion and dung feeders, suggests that fermenting food waste, animal dung/ manure and remains of carcasses ended up in the ditch.

\subsection{Context [089], sample 67}

Context [089] is described as blackish-brown silty clay, with visible wood, animal bone, plant macrofossils, land/freshwater molluscs and frequent stones. Pottery fragments were also recovered. This deposit overlay [090].

While not as numerically rich as either sample 86 or sample 68 , sample 67 proved to be just as species-rich. It contains a similar habitat range as the earlier fill, but with a proportionally smaller synanthropic element. Dung/pasture and foul (including carrion) habitats are again wellrepresented, with a number of species of Aphodius present, as well as common 'cess-pit' species like Oxytelus sculptus, Megasternum obscurum and Xylodromus concinnus. In addition, puparia of flies such as Sepsis spp., Drosophila spp. and Musca domestica clearly indicate the presence of dung, including human excrement/urine, fermenting vegetables/fruit and general decaying animal and plant matter (Smith 1989).

The disturbed ground/arable indicators are again well-represented in this deposit. Ophonus rufibarbis, Pterostichus madidus, Phyllotreta undulata, Sitona sp. and Ceutorhynchus sp. all suggest locally open/disturbed ground with associated weeds. In addition, there is a proportionally larger representation of species associated with heath/moorland. These include the ground beetle Amara lunicollis, which only occurs in this deposit and is generally indicative of heath (Lindroth 1986). Dumped peat or turf used for roofing or fuel may possibly be the source for such beetles in the ditch fill.

The woodland/dead wood element of the fauna is proportionally similar to [090], with a similar range of species present. 


\section{DISCUSSION}

\subsection{Diversity and ordination}

Three of the six samples examined, the ditch fills, produced rich, diverse insect faunas. The wet nature of ditches, the associated ground disturbance, the fact that ditches were regularly used for dumping and the 'pit-fall trapping effect' of open-cut features means that ditch fills tend to be species-rich. The index of diversity (Fisher's alpha) for the ditch fills was between 44-60, which is extremely high (Kenward 1978). 12th-13th century midden deposits at Gallowgate Middle School, Aberdeen produced similar high diversity indices (Hall et al 2004). The least species-diverse deposit was context [142] (sample 110) with an alpha value of only 23 .

The ordination of the samples produced an interesting pattern with the three ditch fills clustering together (illus 6.3). The species diagram (illus 6.4) suggests that the clustering is not due solely to numerical or species richness but species diversity and relatedness between the deposits. The three ditch fills contain a similar range of species, and there is more overlap between these three assemblages and the assemblage present in Context [142] than in Context [070].

Very few contemporary sites in Edinburgh, or Scotland as a whole, have been analysed for insect remains. A number of medieval-dated sites in Aberdeen (Hall et al 2004; Kenward \& Hall 2001) will be referred to below but otherwise comparisons are mainly with Iron Age to medieval-dated sites with prominent cut features in other parts of Britain and in Ireland.

\subsection{Local and wider environment}

\subsubsection{Dry/disturbed/arable ground and dung/pasture}

There is some overlap between these groups and those of 'meadowland' and 'heathland/moorland'. Numerically, species belonging to these groups make

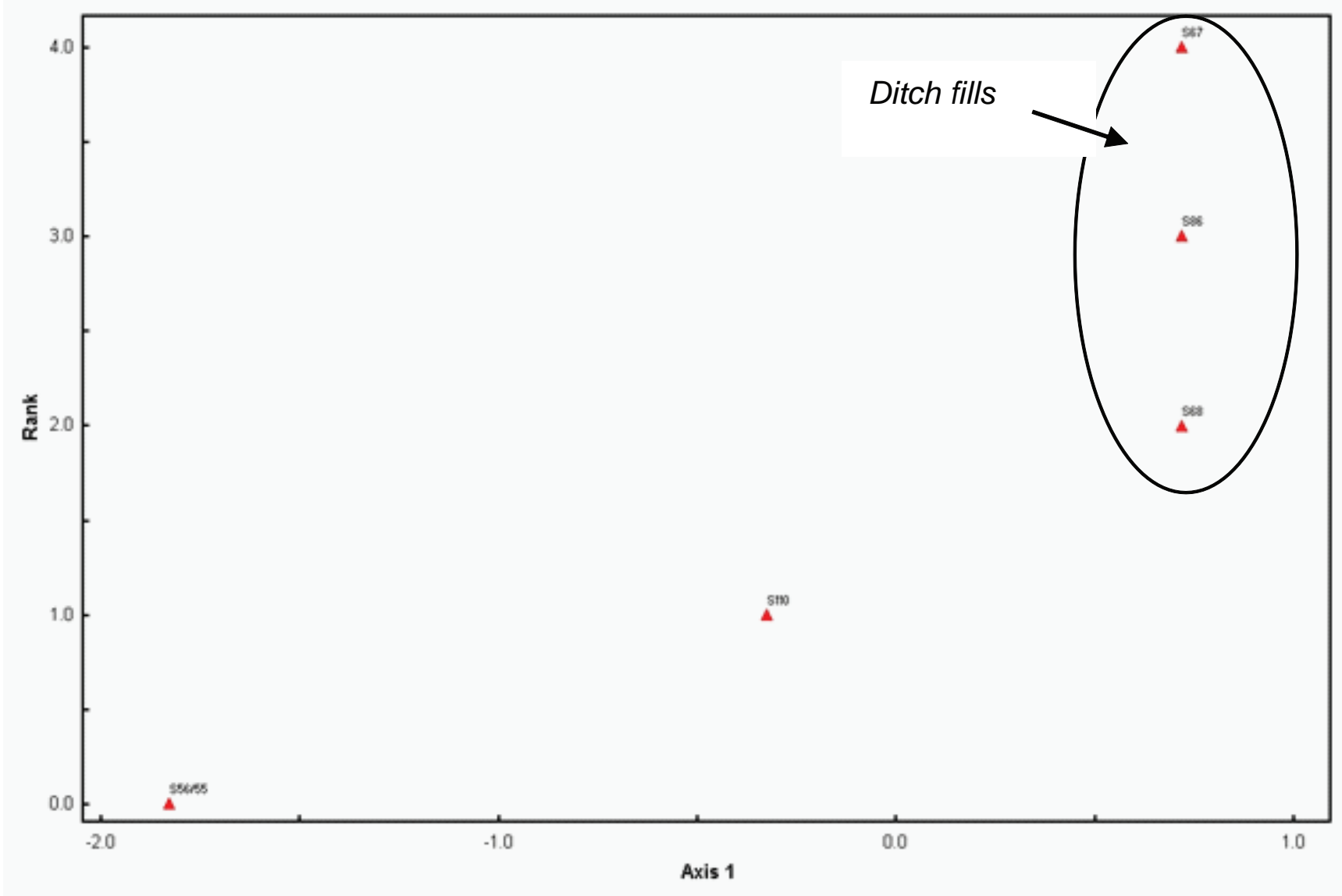

Illus 6.3 NMS ordination (1-axis solution) for samples examined from insect remains, St Patrick's Church, Cowgate, Edinburgh 


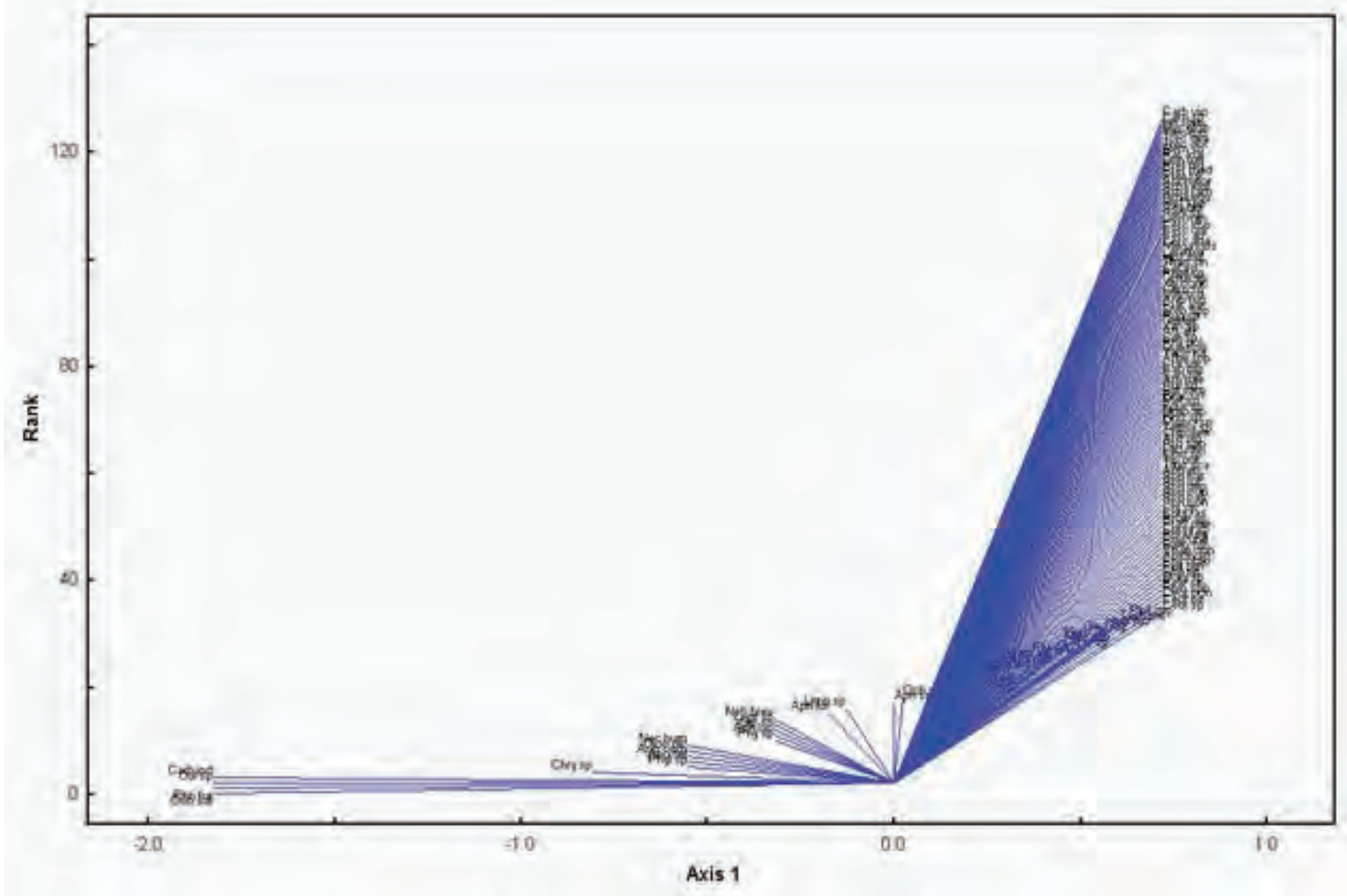

Illus 6.4 NMS ordination (1-axis solution) for species distribution in samples from St Patrick's Church, Cowgate, Edinburgh

up the largest part of the ditch-fill assemblages and form a large proportion of the Context [142] assemblage. It is not unusual for enclosing ditches of settlement sites to contain a large 'outdoor' element in the assemblage. Ditches by their nature are an interface between the settlement space and the surrounding landscape. Therefore, both allochthonous and autochthonous insects will generally be represented. Sources of the disturbed ground/arable and dung/pasture species, however, can be mixed with insects being introduced directly (ie by pitfalltrapping effect) or indirectly in fodder residues and manure (Hall \& Kenward 1998).

Similar faunas, rich in ground beetles, weed/ meadow plant feeders and dung beetles are present in the ditches of Iron Age sites like Mingies Ditch, Oxford (Robinson 1993), Fisherwick, Staffordshire (Osborne 1979), and Roman-age sites like Alchester (Robinson 1975) and Drayton (Robinson 2003). Equally, many Roman well sites produce similar mixed signatures and have a similar pitfalltrapping effect, particularly for many xerophilous ground-dwelling beetles (ie species that would not usually be found in wet ditches). Roman wells such as Appleford, Oxford (Robinson 1981), Rudston, Yorkshire (Buckland 1980), Dragonby, Lincolnshire (Buckland 1996), Dalton Parlours, Yorkshire (Sudell 1990) and Wheatpieces, Tewkesbury (Tetlow 2006a) have many species in common with the ditch-fill assemblages at the Cowgate, including Harpalus affinis, Amara familiaris, A. lunicollis and dung beetles like Aphodius luridus. In addition, common ruderal plant feeders like Ceutorhynchus concinna, Rhononcus spp. and Ceutorhynchus contractus, $C$. ersymi and C. hirtulus were recovered from Iron Age, Roman and medieval ditch, pit and well fills at Sutton Common (Roper \& Whitehouse 1997) Bancroft, Buckinghamshire (Pearson \& Robinson 1995), Chichester (Girling 1989), Piddington (Simpson 2001) and Aberdeen (Kenward \& Hall 2001). Curiously, the most common ground beetle indicative of disturbed/dry ground encountered in the ditch fills, Ophonus rufibarbis, does not appear to have been recorded before from a British prehistoric or medieval site. It is generally confined to coastal locations in Britain and Ireland today (Luff 1998).

\subsubsection{Foul habitats and the 'human factor'}

Analysis of all deposits suggested the presence of 'foul' conditions at all times in the past but this was particularly clear from the ditch fills. This is unsurprising as ditches regularly fulfilled the role of unofficial rubbish dump for medieval town 
residents. Even after the ditch went out of use, the excavation revealed a large midden of material had built up in this part of the old town of Edinburgh, on top of which later post-medieval structures were built (Jones 2007).

The pre-ditch 'foul' element of the old stream channel was made up primarily of indicators of wet decaying vegetation, which probably represented in situ decay rather than dumped material. The synanthropic element of the fauna was very small, again suggesting autochthonous sources for the foul indicating beetles. However, the puparia of the fly genus Scathophaga sp. were frequently encountered in this sample and suggest the presence of dung, human excrement and carrion (Smith 1989). It is possible that animals grazed this area prior to the digging of the town ditch, which would account for the puparia and the presence of Aphodius luridus (Section 3).

The foul element in the ditch fills is likely to come from two main sources - the ground conditions prevailing within the ditch itself and dumped or slowly accumulating debris. Ditch fills from sites like the Bronze Age-dated enclosure at Chancellorsland, Co. Tipperary (Reilly 2008b), Iron Age-dated Haughey's Fort, Co. Armagh (Anderson 1989) and Mingies Ditch, Oxford (Robinson 1993) and Roman period Alchester (Robinson 1975) generally have this feature in common. Ditches regularly cut the water table and permanently hold water at the base so that both slow accumulating autochthonous plant matter and dumped organic material are well preserved. Surprisingly, the synanthropic element of the ditch fills is very small. 'House fauna' often makes up a significant proportion of deposits in cut features, like pits and wells, in Roman and medieval sites due to their location within the settlement (Girling 1989; Kenward and Hall 1995; Reilly 2003). However, analysis of fills from Roman wells in Wheatpieces, Tewkesbury (Tetlow 2006a) and Piddington, Northhamptonshire (Simpson 2001) produced quite restricted synanthropic faunas. Tetlow (2006a) suggests that the well at Wheatpieces, in common with pit and ditch features examined at Heathrow Airport (Tetlow 2006b), may not have been used for deliberate dumping and were set in a largely pastoral landscape.

While the Cowgate has a similar range of pasture/ disturbed ground indicators in the ditch fills to that of Wheatpieces, it is clear from archaeological evidence that the ditch location was the site of deliberate dumping. However, the quantity and range of dung beetles, meadow plant indicators, carrion feeders, and fly species indicative of dung and carcasses suggests that the dumped material was waste from agricultural and/or butchering activity, rather than domestic activity. Of course, the line between these types of activity may have been somewhat blurred in a medieval town. Similar assemblages indicative of very foul conditions were noted from midden and floor deposits in the heart of the medieval town of
Novgorod at the site of a possible leather workshop (Reilly 2008a).

\subsubsection{Further afield? Haleotolerant and heath/ moorland indicators}

Two other interesting elements of the fauna are species indicative of coastal/salt marsh environments and heath/moorland (see Section 3). Given the coastal location of Edinburgh, some halaeotolerant beetles are to be expected in the deposits. In particular, marine shell was recorded in Context [090] (primary ditch fill) and the presence of seaweed is suggested by the finding of Cafius sp. in sample 86. Seaweed may also have been brought into the town for use as either animal fodder or manure. Salt-tolerant species were also noted in a number of Dublin sites by the author and others (Reilly 2003; Whitehouse 2007).

As discussed in Section 3, the presence of the ground beetle Amara lunicollis and a small group of other beetles is suggestive of heath or moorland. Their presence in the ditch fills may be due to the use of turf in floors, roofs or for fuel within the town. However, the range of species is more limited than that identified from midden deposits in Galloway Middle School, Aberdeen (Hall et al 2004) or from 17th-century pit/latrine fills in Newmarket, Dublin (Whitehouse 2007). In both these cases, the presence of peat appeared to be indicated by the range of water beetles, plant feeders and ground beetles present as well as the plant macrofossil evidence. The evidence is somewhat more tentative in the Cowgate due to the fact that many beetle species are not identified beyond genus. Bugstats assigns such genera to multiple-habitat categories to reflect the full range of habitats they may potentially represent. This can lead to an over-representation of some habitat categories in the final graph (illus 6.1).

\subsection{Conclusions}

The four contexts examined for insects cover the period prior to the digging of the town ditch and the primary and secondary phase of ditch use. The insects reflect the change in environment from wet in-filled stream channel, with its limited fauna largely indicative of the decaying accumulating vegetation and surrounding pasture/arable landscape, to inorganic water-deposited clay layer, to the rich diverse communities of the ditch fills, reflecting both the surrounding landscape and the dumped waste of the urban environment. The poor synanthropic element in the assemblages suggests household waste was not the primary source of the ditch fills. Rather, the assemblages are reflective of fouler material, such as butchery waste, animal dung and rotting vegetables/fruit, suggesting market/industrial rather than domestic sources. 


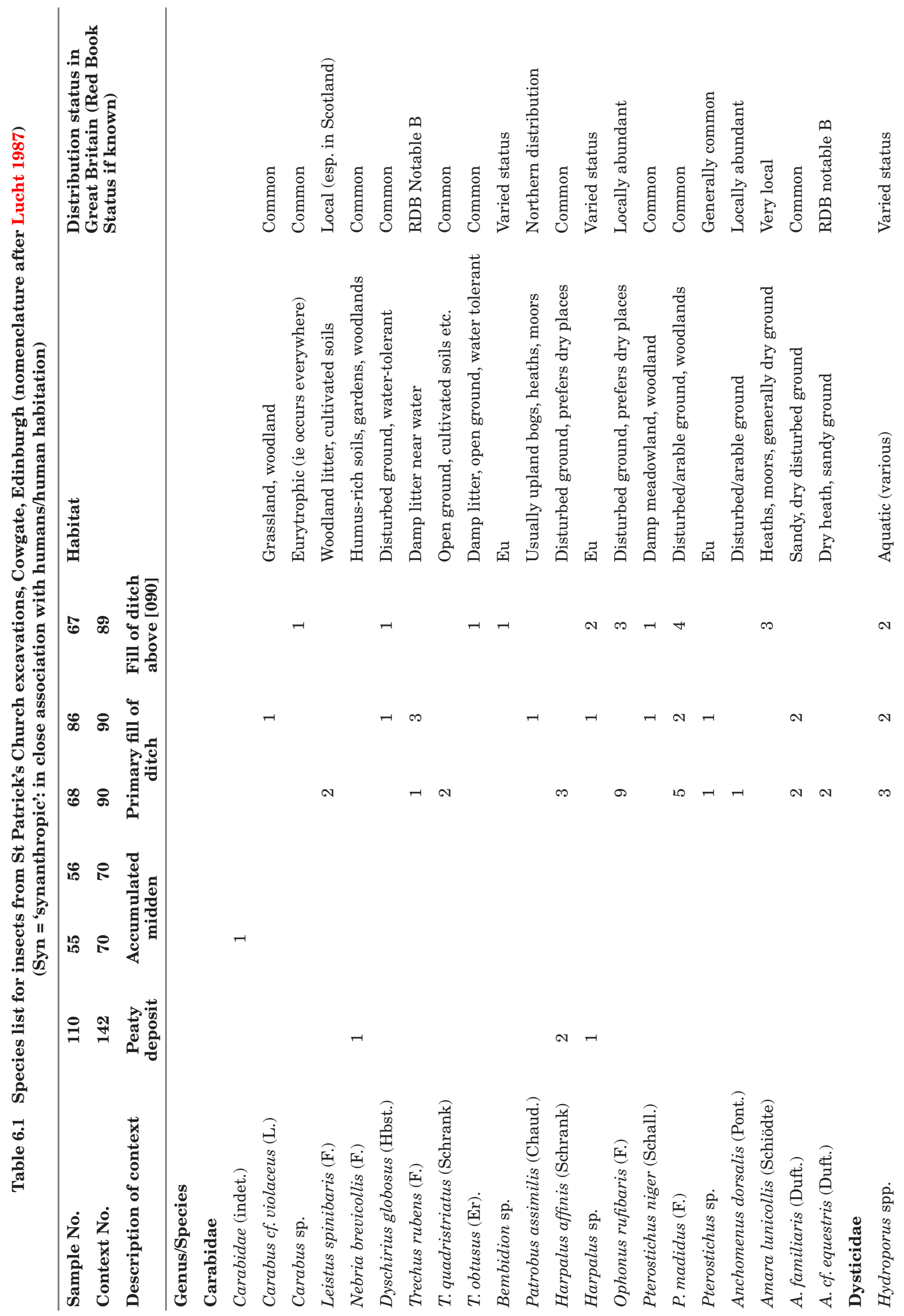




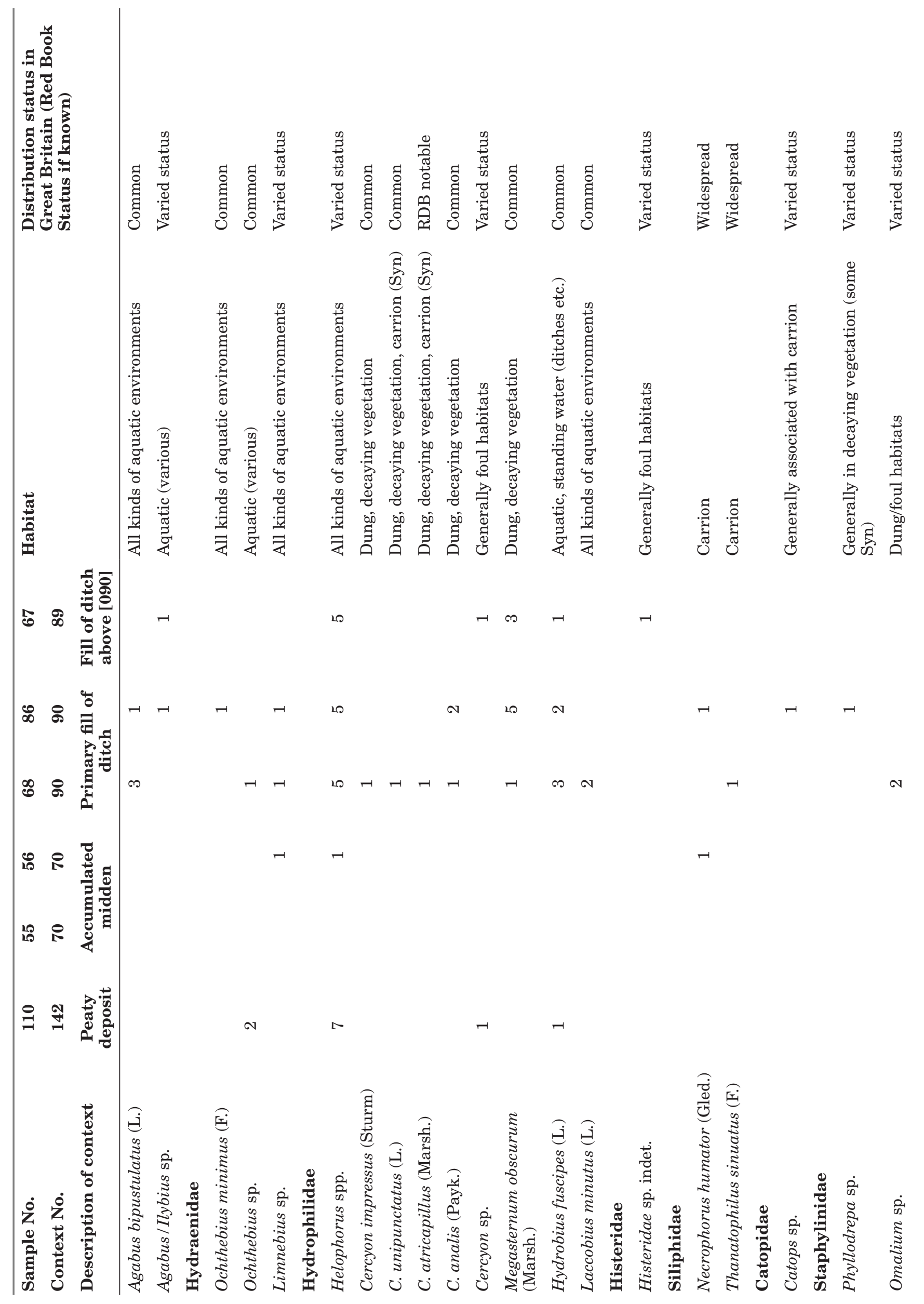




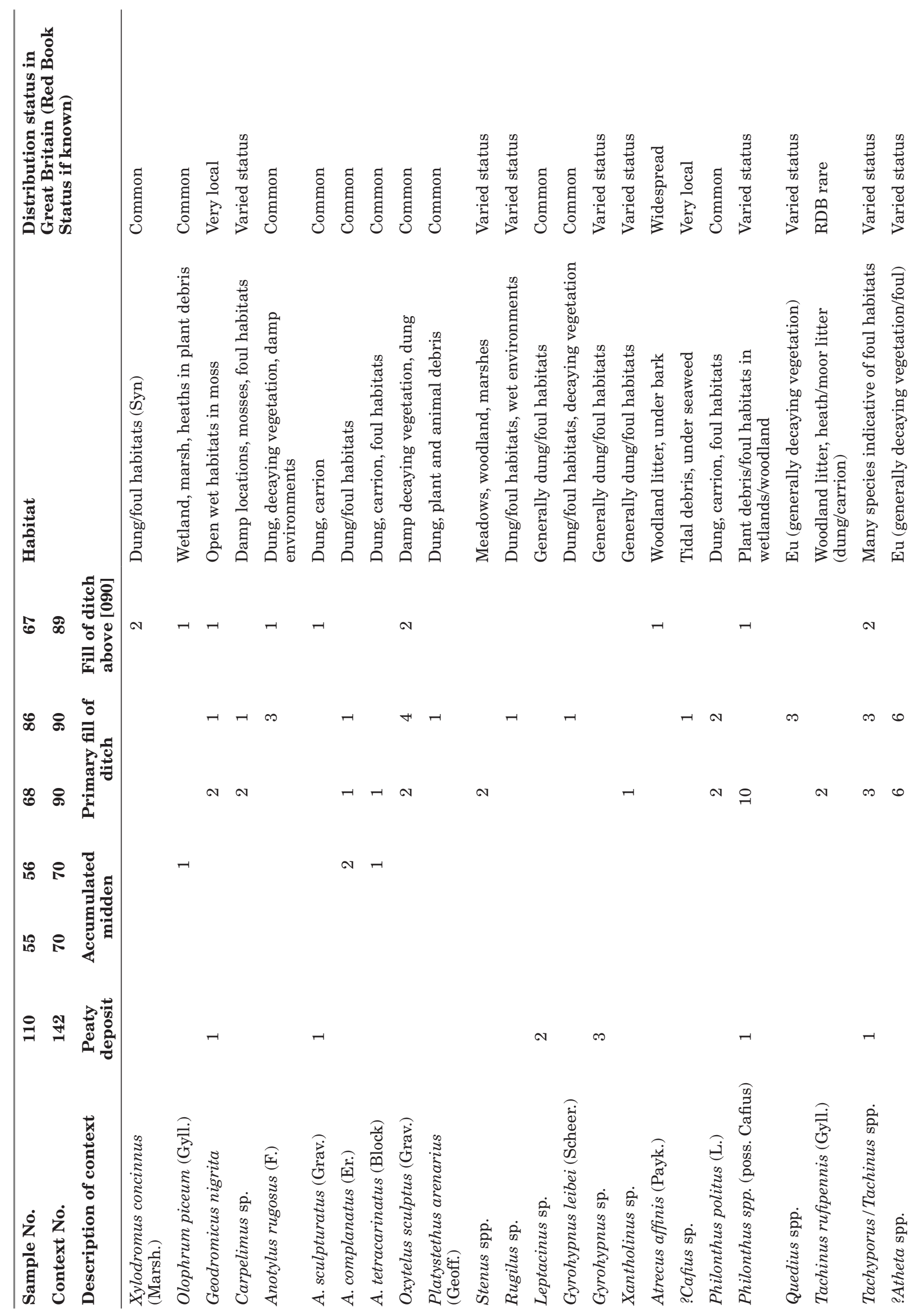




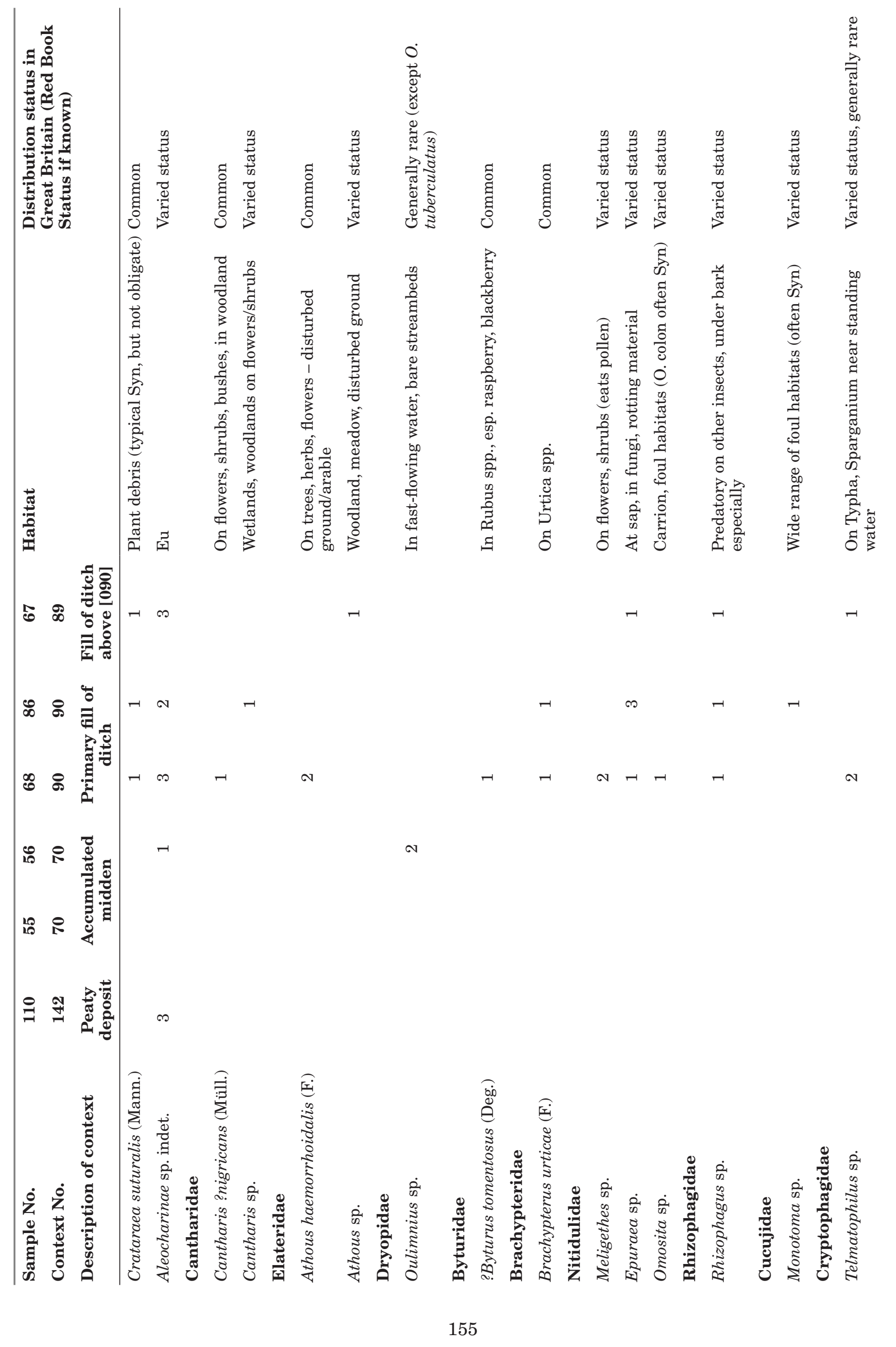




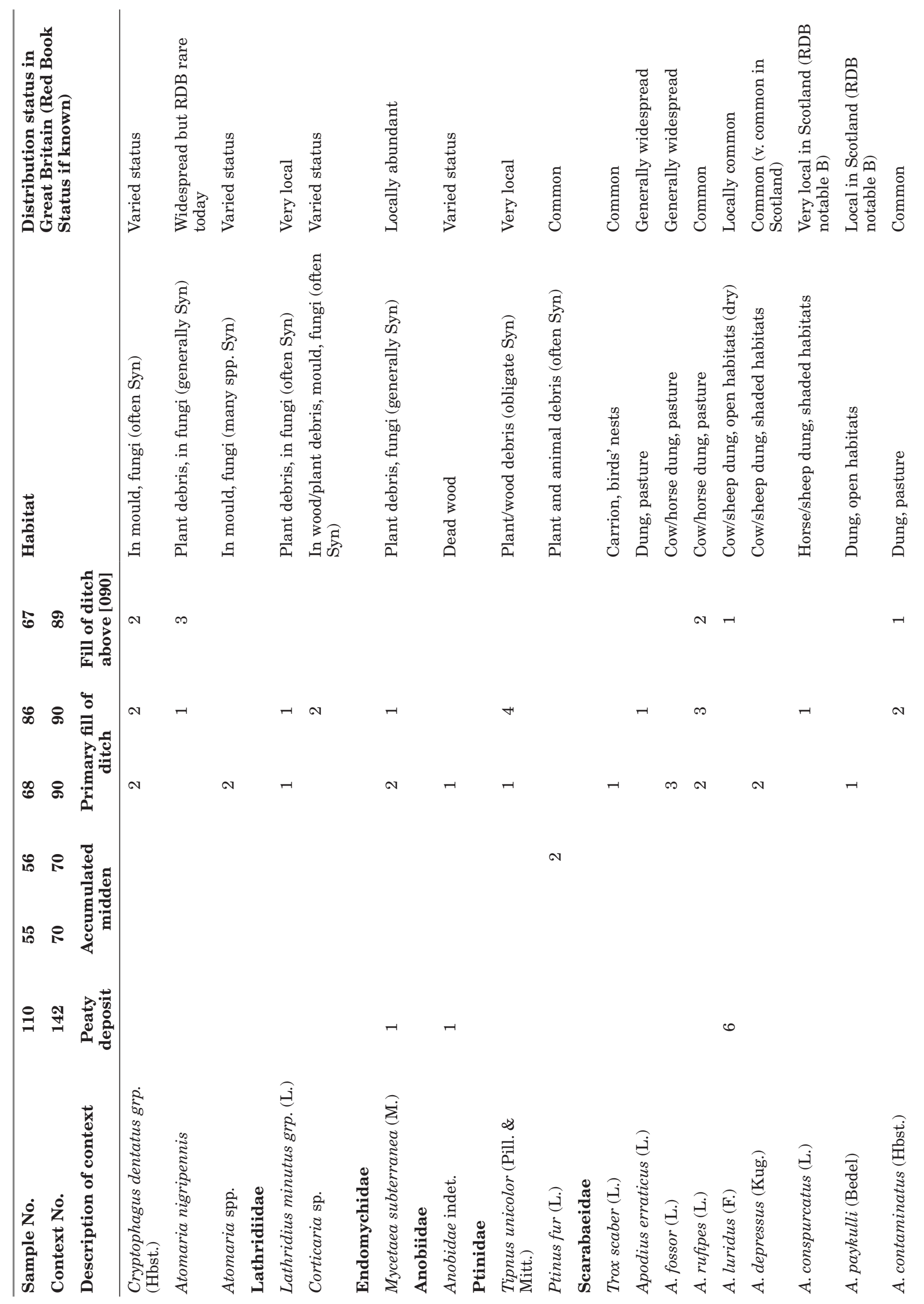




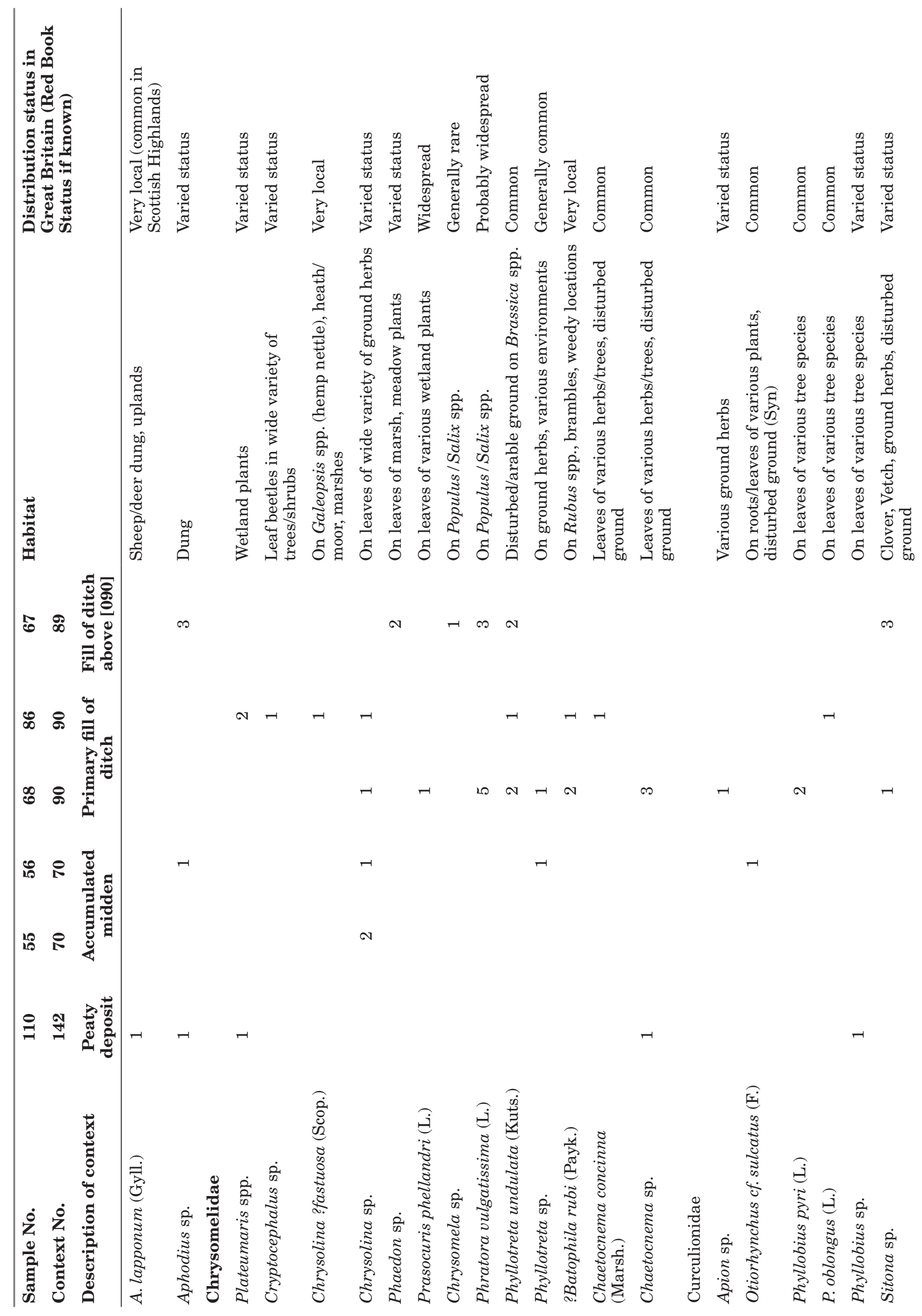




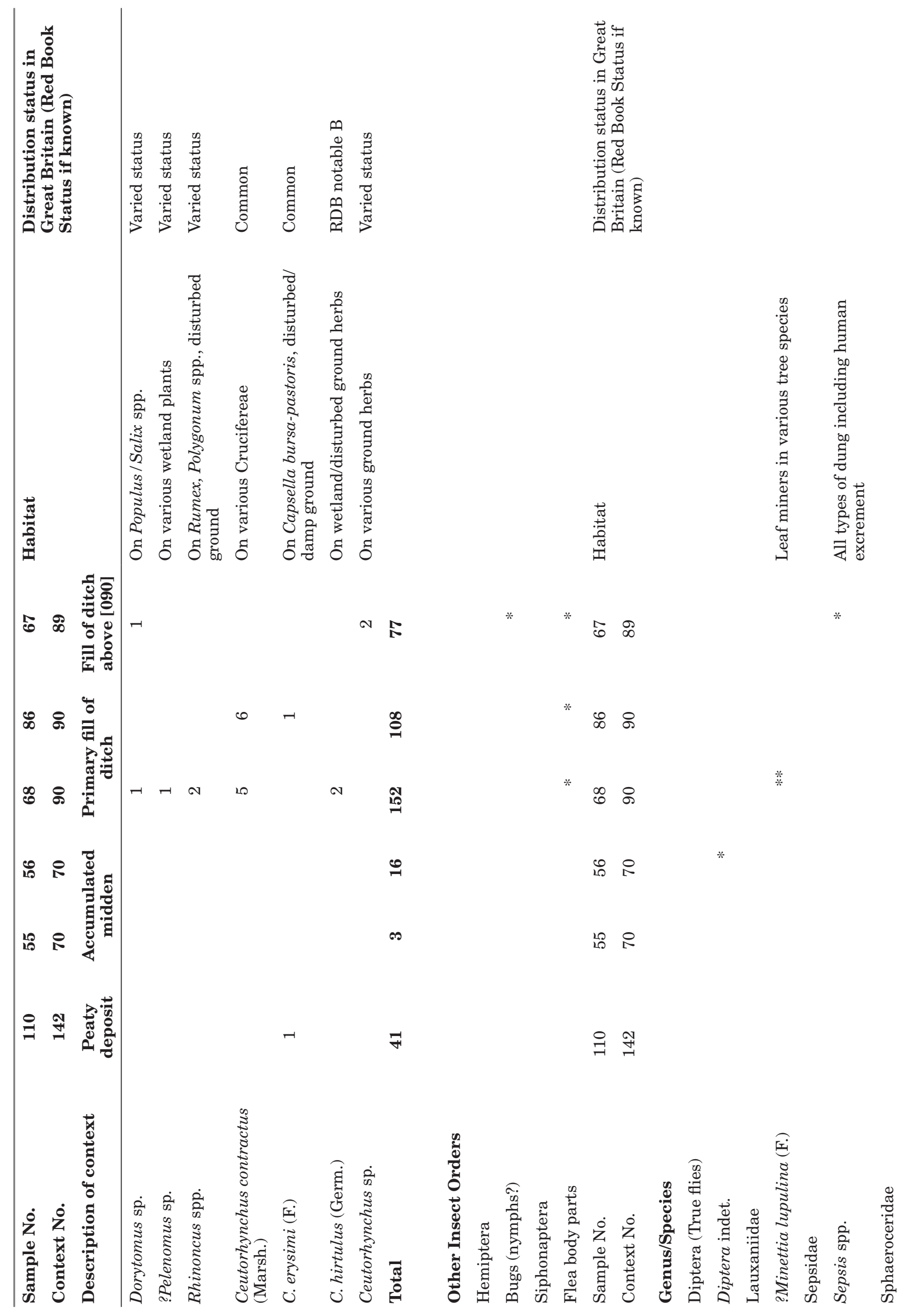




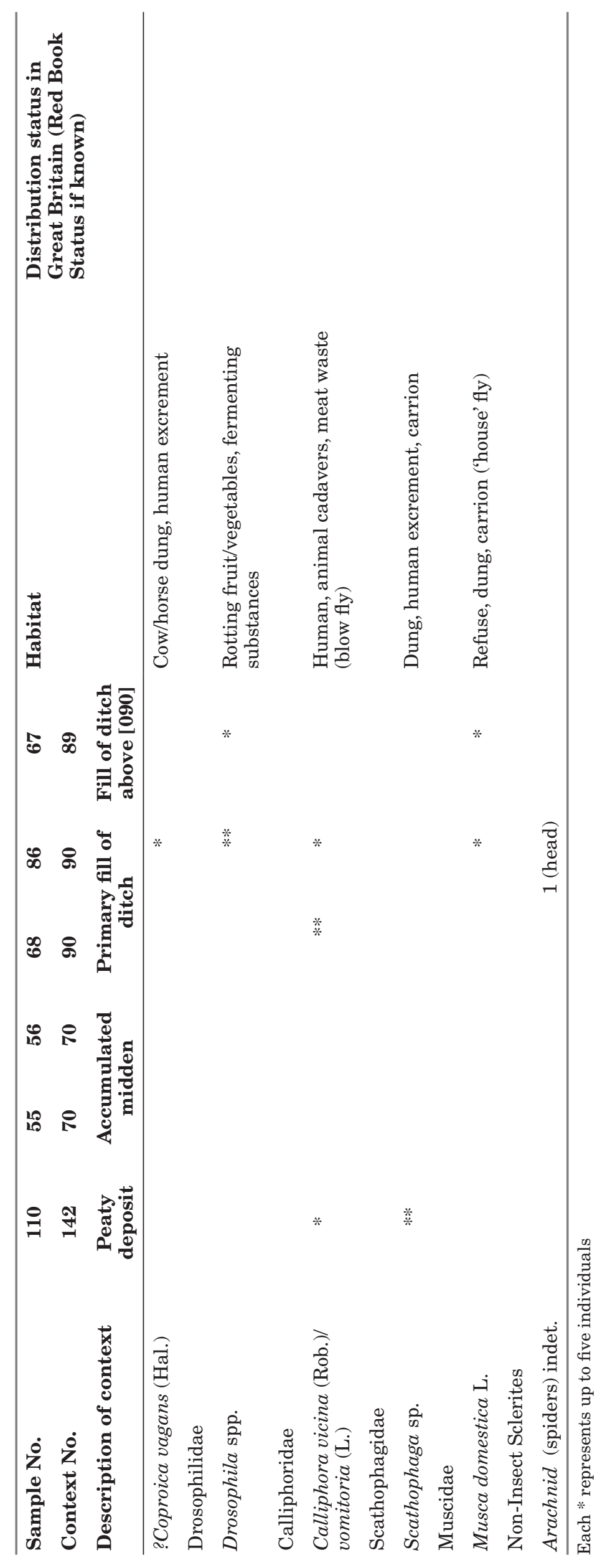

